ARINE PELLEGRINO

Avaliação genética de gatos da raça Persa: mapeamento da mutação relacionada à cardiomiopatia hipertrófica de origem familial

São Paulo

2014 


\section{Avaliação genética de gatos da raça Persa: mapeamento da mutação relacionada à cardiomiopatia hipertrófica de origem familial}

Tese apresentada ao Programa de Pós-Graduação em Clínica Veterinária da Faculdade de Medicina Veterinária e Zootecnia da Universidade de São Paulo para obtenção de título de Doutor em Ciências

Departamento:

Clínica Médica

Área de concentração:

Clínica Veterinária

Orientador:

Prof $^{a}$. Dr ${ }^{a}$. Maria Helena Matiko Akao Larsson

São Paulo 
Autorizo a reprodução parcial ou total desta obra, para fins acadêmicos, desde que citada a fonte.

\section{DADOS INTERNACIONAIS DE CATALOGAÇÃO-NA-PUBLICAÇÃO}

(Biblioteca Virginie Buff D’Ápice da Faculdade de Medicina Veterinária e Zootecnia da Universidade de São Paulo)

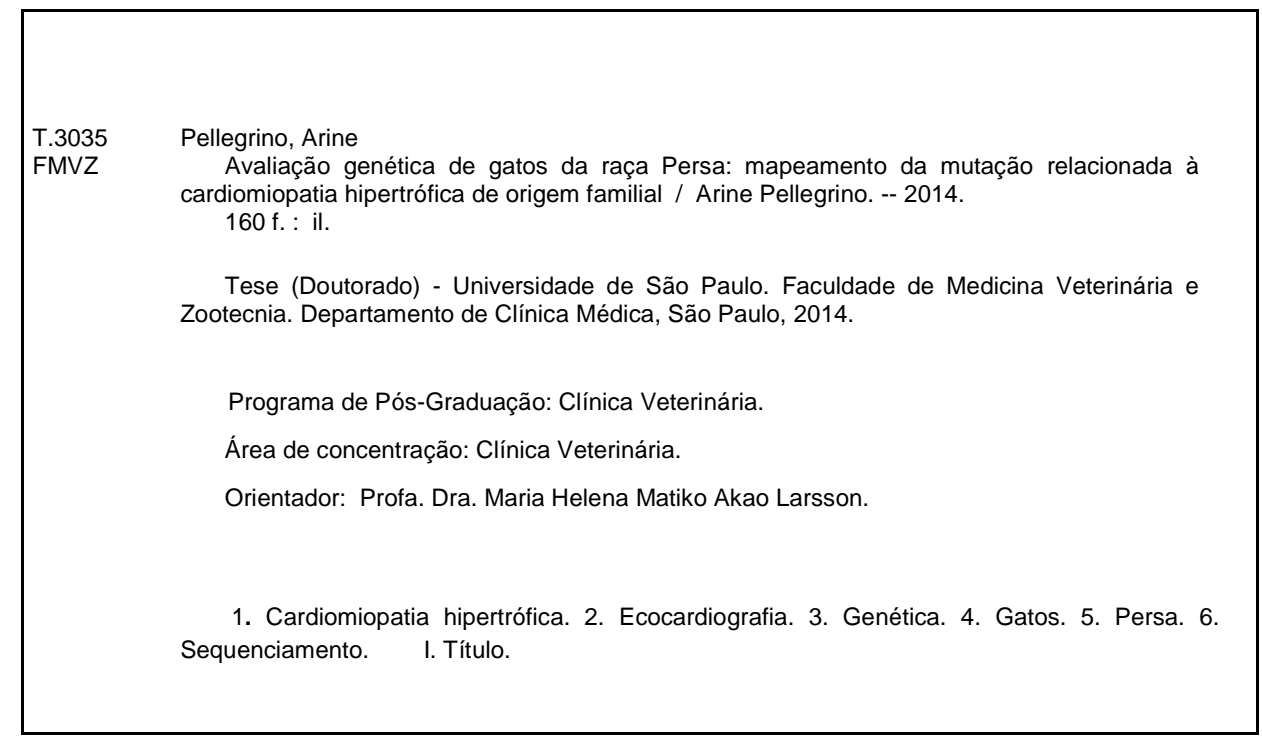




\section{FACULDADE DE MEDICINA VETERINÁRIA E ZOOTECNIA}

\section{Comissão de Ética no uso de animais}

Of. CEUAVET no 11/FMVZ/2012

Ifrs

São Paulo, 13 de fevereiro de 2012.

À senhora

Profa. Dra. Maria Helena Matiko Akao Larsson

Assunto: Projeto no 2533/2012, intitulado "Avaliaçãó genética de gatos da raça Persa mapeamento da mutação relacionada à cardiomiopatia hipertrófica de origem familial".

Senhora Professora,

A Comissão de Ética no uso de Animais desta Faculdade analisou o protocolo acima mencionado e solicita a Vossa Senhoria encaminhar o modelo do Termo de Consentimento Livre e Esclarecido (TCLE) que será apresentàdo aos gatis comerciais, criatórios e/ou proprietários que participarão do estudo. Lembramos, ainda, que os termos assinados devem ser mantidos sob a responsabilidade dos pesquisadores, ficando à disposição da CEUA para futuras consultas.

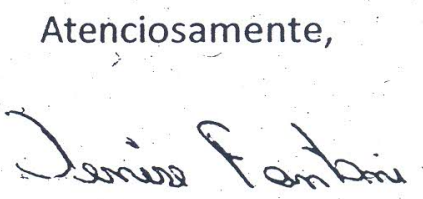

Denise Tabacchi Fantoni

Presidente 
À llustríssima Senhora

Professora Doutora Maria Helena Matiko Akao Larsson

\author{
DECLARAÇÃO
}

Declaramós que o projeto "Avaliação genética de gatos da raça Persa - mapeamento da mutação relacionada à cardiomiopatia hipertrófica de origem familial" desenvolvido pela Pós-Graduanda Arine Pellegrino e sob a sua responsabilidade, previamente aprovado pela Comissão de Ética no Uso de Animais dessa Faculdade, foi analisado e atende às normas da Comissão de Ética deste Hospital, que acompanhará administrativamente sua execução. Substituição do responsável, inserção de novos colaboradores e mudanças na metodologia proposta deverão ser imediatamente comunicadas a esta Comissão, bem como, as datas de suspensão ou término do projeto.

São Paulo, 02 de julho de 2012

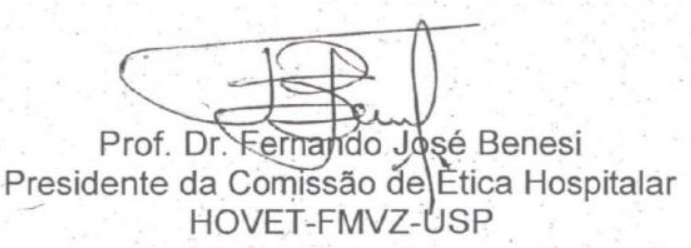

Av. Prof, Dr, Orlando Marques de Paiva, 87

Fone: $+55113091-1291 / 3091-1240$

Cidade Universitária "Armando de Salles Oliveira"

Fax: +55 11 3091--1291

São Paulo/SP - Brasil

E-mail: hovet@edu.usp.br

05508-270

http://www.fmvz.usp.br 


\section{FOLHA DE AVALIAÇÃO}

Nome: PELLEGRINO, Arine

Título: Avaliação genética de gatos da raça Persa: mapeamento da mutação relacionada à cardiomiopatia hipertrófica de origem familial

Tese apresentada ao Programa de Pós-Graduação em Clínica Veterinária da Faculdade de Medicina Veterinária e Zootecnia da Universidade de São Paulo para obtenção de título de Doutor em Ciências

Data:

\section{Banca Examinadora}

Prof. Dr.

Instituição: Julgamento:

Prof. Dr.

Instituição:

Julgamento:

Prof. Dr.

Instituição:

Julgamento:

Prof. Dr.

Instituição:

Julgamento:

Prof. Dr.

Instituição:

Julgamento: 


\section{DEDICATÓRIA}

Ao Alexandre G. T. Daniel...pela cumplicidade, companheirismo, amor, força, paciência, motivação...por tudo que me ensina e por tudo que vivemos juntos...pela nossa paz...pelas pequenas coisas...pelo mais importante... 


\section{AGRADECIMENTOS}

À minha mãe científica, amiga e orientadora, professora Maria Helena Matiko Akao Larsson, por confiar e acreditar em mim desde aluna...por me motivar sempre quando foi preciso...por todo carinho, amor, confiança e amizade...pelos ensinamentos e conselhos pessoais e profissionais. Obrigada por me abrir portas e janelas...por me inserir no mundo da cardiologia que me faz tão realizada.

Ao professor Bruno Cogliati, pela ajuda desde o início do projeto...por compartilhar experiências e por ajudar em toda avaliação genética...pela companhia desde as fases iniciais do nosso estudo...por acreditar na ciência e em bons resultados.

À professora Alice Maria M.P.D. Libera...pela paz e alegria que transmite...por me ajudar, mesmo sem saber, nos momentos em que mais precisei de motivação...você é especial.

Ao meu amigo e irmãozinho Fernando Caratti, por ser tão especial...por estar sempre perto...pela paz e alegria de uma amizade verdadeira...pela proteção, companheirismo...pela sensação de estar sempre bem e em sintonia...obrigada pela companhia, risadas e gordices!

À Liz Marques, pela amizade, conselhos, risadas...por me acompanhar nas nossas inúmeras profissões...por estar sempre por perto e disposta a ajudar...pela nossa ligação...pelo quarteto!

Aos meus pais, José Domingos Pellegrino e Inês Tezoni Pellegrino, pelo amor, carinho, preocupação, criação...pelos conceitos de certo e errado...pelo amor que recebi em minha infância. Obrigada, pai, pelo exemplo de honestidade e de coração puro que é...é muito bom saber que posso contar com você sempre.

Ao meu irmão, Luís Fernando Pellegrino, pelas risadas e aventuras desde criança...por me ensinar que a vida deve ser levada mais leve...por estar sempre comigo nas nossas bagunças...por me fazer rir sempre!

Às amigas Débora Santos Barone e Juliana Messias, pela companhia diária...por tornar o trabalho mais divertido...pela amizade, aventuras, risadas, conselhos, risos e choros...obrigada por estarem sempre por perto!

Aos amigos Audrey Rosatti de Souza, Camila Lins, Carolina Pereira, Diana Sogaiar Elias, Douglas A. Daniel, Eliana Caratti, Fabiana Cassiano, Khadine K. 
Kanayama, Marcelo Demarchi, Marco Antônio Leon Roman, Miralva Nascimento Rocha, Roberta Coradin que sempre me apoiaram nos momentos de dificuldades e compartilharam alegrias e experiências... Obrigada pela amizade.

Aos amigos e companheiros da cardiologia André Gimenez, Caroline Infantozzi, Cristina T. Amaral, Elaine C. Soares, Fernanda L. Yamaki, Guilherme Pereira, Guilherme T. Goldfeder, Jaqueline R. de Castro, Kátia M. Tárraga, Lilian C. Petrus, Luciano Pereira, Matheus Mantovani, Moacir L. Neto, Patrícia C. Chamas, Paula H. Itikawa, Priscylla R. Rosa, Ronaldo Jun Yamato, Thalita Vieira, Valéria M. C. Oliveira por compartilharem, sempre com amizade e carinho, momentos de dúvidas e de desabafos. Pelo aprendizado, apoio e consideração.

Aos professores Denise S. Schwartz, Denise T. Fantoni, Maria Cláudia A. Sucupira e Fernando José Benesi, pela amizade, confiança, motivação e consideração a mim dispensados.

Aos amigos e pós-graduandos da FMVZ, pela alegria do convívio durante a pós-graduação. Aos companheiros do Projeto dos Persas, Alexandre G. T. Daniel, Bruno Cogliati, Cayo Y. Nitta, Gabriel G. De Lucca, Juliana M. Guerra, Mariana F. Freitas, Natália C. Cardoso e Rebecca Pessoa.

A todos os criadores de gatos da raça Persa que participaram do presente projeto, sempre dispostos a ajudar e bastante solícitos. Aos amigos que colaboraram com seus gatos de estimação e me ajudaram a completar os grupos: Carolina Pereira, Débora S. Barone, Karen Zardo, Michelle Tibério, Paula Hatherly. E a todos os Persas que participaram do projeto...obrigada pelo aprendizado, paciência e sinceridade incondicional.

Aos funcionários do HOVET-USP, da Biblioteca da FMVZ-USP e da Secretaria da Pós-graduação, sempre dispostos a auxiliar na execução do presente trabalho.

À FAPESP pelo auxílio pesquisa concedido.

Aos amigos da Gattos- Clínica Especializada em Medicina Felina e do Hospital Veterinário Santa Inês, pela compreensão e auxílio nos momentos de correria e pela paciência durante a fase de conclusão deste trabalho.

A todos os não citados que contribuíram para minha formação e auxiliaram nas diversas etapas de minha vida. Muito obrigada por compartilhar momentos e sabedoria. 
PELLEGRINO, A. Avaliação genética de gatos da raça Persa: mapeamento da mutação relacionada à cardiomiopatia hipertrófica de origem familial. [Genetic evaluation of Persian cats: screening of hypertrophic cardiomyopathy mutation]. 2014. 160 f. Tese (Doutorado em Ciências) - Faculdade de Medicina Veterinária e Zootecnia, Universidade de São Paulo, São Paulo, 2014.

A cardiomiopatia hipertrófica $(\mathrm{CMH})$ é a principal cardiopatia dos felinos, caracterizada por hipertrofia ventricular esquerda, sem dilatação. A prevalência em humanos é de um a cada 500 indivíduos e, em pelo menos $60 \%$ dos casos, a doença é de origem familial. Há mais de 1400 mutações em mais de 11 genes que codificam proteínas do sarcômero relacionadas à $\mathrm{CMH}$. Em algumas famílias de gatos, a CMH é transmitida de forma autossômica dominante sendo muito similar à humana. No Maine Coon, redução na miomesina e mutação no gene que codifica a proteína C miosina ligante (MYBPC3) são alterações encontradas nos acometidos pela $\mathrm{CMH}$. No Ragdoll, a $\mathrm{CMH}$ está relacionada com mutação no mesmo gene, porém em um códon diferente e altamente conservado na espécie. Em outras raças como Persa, British Shorthair, Norwegian Forest também há evidências da $\mathrm{CMH}$ familial, porém não há comprovação do tipo de herança envolvida. No presente estudo, uma população de 100 gatos da raça Persa foi avaliada por meio de exames ecocardiográfico, eletrocardiográfico, laboratoriais, mesuração da pressão arterial e pesquisa da mutação relacionada à doença renal policística (PKD), prevalente em gatis de Persas. Os animais foram classificados quanto à presença ou não da $\mathrm{CMH}$ e, após seleção dos grupos experimentais (20 gatos sem $\mathrm{CMH}$ e 22 gatos com $\mathrm{CMH}$ ), amostras de sangue foram submetidas à extração do DNA, genotipagem pela técnica de PCR e sequenciamento dos genes da alfa-actina cardíaca (exon 5 do gene ACTC1) e da proteína C miosina ligante (exon 27 do gene MYBPC3), com posterior correlação das mutações com a presença da afecção. À avaliação da população total, a $\mathrm{CMH}$ foi mais prevalente em gatos machos e de maior faixa etária; ocorreu em 22 animais; e a forma assimétrica com hipertrofia miocárdica em região septal basal foi a mais comum na raça. A presença de mutação relacionda à PKD foi mais comum nos gatos com hipertrofia ventricular, apesar dos mesmos apresentarem pressão arterial e função renal normais. Foi identificado um 
polimorfismo de nucleotídeo único (SNP) na posição 890 do exon 5 do gene ACTC1 e três SNP no intron 5-6 do mesmo gene. Nenhum polimorfismo, adição ou deleção foi observado em outras regiões do gene ACTC1 ou no gene MYBPC3. Apesar dos SNP observados no estudo, os mesmos não se enquadram nos critérios de mutação causal da $\mathrm{CMH}$ porque não provocam mudança em aminoácidos e não ocorreram exclusivamente em animais com $\mathrm{CMH}$. Desta forma, a mutação causal da $\mathrm{CMH}$ em gatos da raça Persa não foi elucidada e mutações nestes dois exons de genes cardíacos não parecem ser a causa da cardiomiopatia na referida raça. Avaliações de genes cardíacos adicionais são necessárias para a identificação da causa molecular desta cardiopatia no Persa. Em relação aos resultados encontrados nos gatos PKD positivos, há necessidade de mais estudos para avaliar a relação causal (PKD e hipertrofia) ou associação genética entre ambas. Faz-se necessária a avaliação cardiológica de gatos PKD positivos, bem como é necessário incluir a PDK como diagnóstico diferencial da $\mathrm{CMH}$ no Persa.

Palavras-chave: Cardiomiopatia hipertrófica. Ecocardiografia. Genética. Gatos. Persa. Sequenciamento. 


\begin{abstract}
PELLEGRINO, A. Genetic evaluation of Persian cats: screening of hypertrophic cardiomyopathy mutation. [Avaliação genética de gatos da raça Persa: mapeamento da mutação relacionada à cardiomiopatia hipertrófica de origem familial]. 2014. 160 f. Tese (Doutorado em Ciências) - Faculdade de Medicina Veterinária e Zootecnia, Universidade de São Paulo, São Paulo, 2014.
\end{abstract}

Hypertrophic cardiomyopathy (HCM) is the most important feline heart disease and it is characterized by ventricular hypertrophy in absence of dilated left ventricle. In humans, the prevalence is 1 to 500 individuals and the familial HCM occurs in at least $60 \%$ of cases. There are more than 1400 mutations in more than 11 sarcomeres genes related to HCM. In some families of cats, HCM is an autosomal dominant genetic disease very similar to the human HCM. Reduction in miomesine and a mutation in myosin binding protein $\mathrm{C}$ gene (MYBPC3) are observed in Maine Coon cats with HCM. In Ragdoll cats, HCM is associated with a mutation in the same gene, but in a different codon highly conserved in feline species. In other breeds such as Persian, British Shorthair and Norwegian Forest there is also evidence of familial HCM, but the type of genetic inheritance is unknown. In this study, a population of 100 Persian cats was assessed by: echocardiography, electrocardiography, laboratorial tests, blood pressure determination and genetic test for the presence of the polycystic kidney disease (PKD) mutation, common in Persians. The animals were classified according to the presence or not of HCM. Blood samples from experimental groups (20 cats without HCM and 22 cats with $\mathrm{HCM}$ ) were subjected to DNA extraction, genotyping by PCR and sequencing of cardiac alpha-actin gene (exon 5 of ACTC1) and myosin binding protein $\mathrm{C}$ gene (exon 27 of MYBPC3) with subsequent correlation with the presence of mutations and HCM. In the evaluated population, HCM was more prevalent in older and male cats; it occurred in 22 animals; and the asymmetric hypertrophy at basal region of septum was the most common. The PKD mutation was more common in cats with left ventricular hypertrophy, despite they presenting normal blood pressure and renal function. One single nucleotide polymorphism (SNP) at position 890 of exon 5 of the gene ACTC1 and three SNP in intron 5-6 of the same gene were identified. No polymorphism, addition or deletion was observed in other regions of the gene ACTC1 
or MYBPC3 gene. Despite the SNP observed in the study, they do not fit the criteria of HCM causal mutation because they do not cause changes in amino acids and do not occurred exclusively in animals with HCM. Thus, a causal mutation of HCM in Persians cat has not been elucidated and mutations in these two exons of cardiac genes do not seem to be the cause of HCM in this breed. Additional screening of cardiac genes is necessary to identify the molecular cause of this feline disease in Persian cats. Regarding the results founded in PKD positive cats, it is important for further studies to evaluate the genetic association or causal relationship (PKD and hypertrophy). The cardiologic evaluation of PKD positive cats is necessary, and the PDK must be included as a differential diagnosis of HCM in Persian.

Keywords: Hypertrophic cardiomyopathy. Echocardiography. Genetic. Cats. Persian. Sequence. 


\section{LISTA DE ILUSTRAÇÕES}

Figura 1- Sequenciamento do DNA identificando uma simples mudança no par de base (G para $\mathrm{C}$ ) no códon 31 do gene MYBPC3 em gato Maine Coon com $\mathrm{CMH}$ (affected); a mesma mudança não é observada nos gatos sem CMH (unaffected). Fonte: MEURS et al., 2005.

Figura 2- Genes que codificam proteínas do sarcômero e que estão relacionados às mutações envolvidas na $\mathrm{CMH}$ familial humana. Fonte: MARON; MARON, 2013.

Figura 3- Modo M- Corte transversal à altura dos músculos papilares, demonstrando hipertrofia miocárdica concêntrica simétrica de grau importante.

Figura 4- Modo bidimensional- Corte longitudinal de via de saída do ventrículo esquerdo (em janela paraesternal direita) demonstrando hipertrofia miocárdica septal assimétrica (em região septal basal)...

Figura 5- Doppler pulsado do fluxo transmitral demonstrando padrão de disfunção diastólica, caracterizado por alteração no relaxamento ventricular (relação E/A inferior a um.

Figura 6- Doppler pulsado demonstrando tempo de relaxamento isovolumétrico aumentado, comumente observado na disfunção diastólica.

Figura 7- Avaliação da função diastólica por meio de Doppler pulsado do fluxo transmitral, fluxo venoso pulmonar e Doppler tecidual pulsado. Formas para diferenciação entre padrão de alteração de relaxamento do ventrículo esquerdo, padrão pseudonormal e padrão restritivo de disfunção diastólica.

Figura 8- Doppler colorido demonstrando insuficiência valvar mitral e obstrução de via de saída do ventrículo esquerdo.

Figura 9- Ecocardiograma em modo bidimensional- Corte transversal à altura dos grandes vasos (janela paraesternal direita- eixo curto), demonstrando aumento atrial esquerdo de grau importante.

Figura 10- Eletroforese em gel de agarose $2 \%$ dos produtos de PCR purificados do exon 5 do gene ACTC1 felino 
Figura 11- Sequência do RNA mensageiro do gene ACTC1 felino depositada no GenBank.

Figura 12- Eletroferograma do sequenciamento do exon 5 do gene ACTC1 felino demonstrando uma alteração em heterozigose na posição 890 do RNA mensageiro.

Figura 13- Sequência obtida pelo programa ORF Finder considerando o polimorfismo de nucleotídeo único (troca de $\mathrm{C}$ por $\mathrm{A}$ ) na posição 890 do exon 5 do gene ACTC1 felino.

Figura 14- Eletroferograma do sequenciamento do intron 5-6 do gene ACTC1 felino, demonstrando presença de polimorfismo de nucleotídeo único (SNP-1).

Figura 15- Eletroferograma do sequenciamento do intron 5-6 do gene ACTC1 felino, demonstrando presença de polimorfismo de nucleotídeo único (SNP-2)

Figura 16- Eletroferograma do sequenciamento do intron 5-6 do gene ACTC1 felino, demonstrando presença de polimorfismo de nucleotídeo único (SNP-3), com alteração em heterozigose.

Gráfico 1- Distribuição etária (em meses) dos gatos da raça Persa nos diferentes grupos experimentais - São Paulo - 2014

Gráfico 2- Proporção de animais castrados e inteiros nos gatos da raça Persa nos diferentes grupos experimentais - São Paulo - 2014

Gráfico 3- Distribuição sexual dos gatos da raça Persa nos diferentes grupos experimentais - São Paulo - 2014

Gráfico 4- Largura da onda $P$ (em segundos; na derivação DII) do eletrocardiograma em gatos da raça Persa nos diferentes grupos experimentais - São Paulo - 2014

Gráfico 5- Amplitude da onda $P$ (na derivação DII) e da onda $R$ (em derivação DII e em precordial CV6LL) no eletrocardiograma de gatos da raça Persa nos diferentes grupos experimentais - São Paulo-2014 
Gráfico 6- Espessuras diastólicas do septo interventricular e da parede livre do ventrículo esquerdo ao ecocardiograma de gatos da raça Persa nos diferentes grupos experimentais - São Paulo - 2014

Gráfico 7- Diâmetro do átrio esquerdo ao ecocardiograma de gatos da raça Persa nos diferentes grupos experimentais - São Paulo - 2014.......

Gráfico 8- Gradiente de pressão $(\mathrm{mmHg})$ do fluxo aórtico ao ecocardiograma de gatos da raça Persa nos diferentes grupos experimentais - São Paulo - 2014

Gráfico 9- Teste genético da doença renal policística (PKD1) em gatos da raça Persa nos diferentes grupos experimentais - São Paulo 2014.

Quadro 1- Primers da reação de PCR dos genes felinos ACTC1 (exon 5) e MYBPC3 (exon 27) - São Paulo - 2014.

Quadro 2- Gatos da raça Persa positivos para a mutação relacionada à doença renal policística autossômica dominante (PKD1) - São Paulo - 2014 


\section{LISTA DE TABELAS}

Tabela 1- Distribuição dos animais (fenotipicamente normais e acometidos pela $\mathrm{CMH}$ ), segundo peso corpóreo, idade e sexo - São Paulo 2014

Tabela 2- Parâmetros eletrocardiográficos nos diferentes grupos avaliados São Paulo - 2014

Tabela 3- Média e desvio padrão de parâmetros eletrocardiográficos de gatos da raça Persa - São Paulo - 2014

Tabela 4- Média e desvio padrão de parâmetros de ecocardiografia convencional de gatos da raça Persa - São Paulo - 2014.

Tabela 5- Frequência alélica relacionada ao SNP na posição 890 do RNA mensageiro do exon 5 do gene ACTC1 felino - São Paulo - 2014...

Tabela 6- Frequência genotípica relacionada ao SNP na posição 890 do RNA mensageiro do exon 5 do gene ACTC1 felino - São Paulo 2014.

Tabela 7- Frequência alélica relacionada ao SNP-1 no intron 5-6 do gene ACTC1 felino - São Paulo - 2014.

Tabela 8- Frequência genotípica relacionada ao SNP-1 no intron 5-6 do gene ACTC1 felino - São Paulo - 2014.

Tabela 9- Frequência alélica relacionada ao SNP-2 no intron 5-6 do gene ACTC1 felino - São Paulo - 2014.

Tabela 10- Frequência genotípica relacionada ao SNP-2 no intron 5-6 do gene ACTC1 felino - São Paulo - 2014.

Tabela 11- Frequência alélica relacionada ao SNP-3 no intron 5-6 do gene ACTC1 felino - São Paulo - 2014.

Tabela 12- Frequência genotípica relacionada ao SNP-3 no intron 5-6 do gene ACTC1 felino - São Paulo - 2014. 
Tabela 13- Distribuição dos animais segundo peso corpóreo, idade e sexo (n=82) - São Paulo - 2014......

Tabela 14- Média e desvio padrão de parâmetros ecocardiográficos em gatos

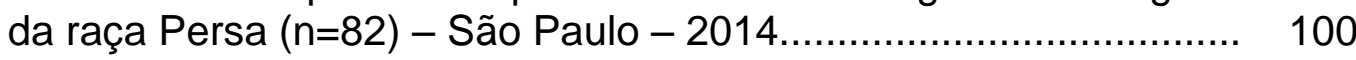

Tabela 15- Média e desvio padrão de parâmetros eletrocardiográficos em gatos da raça Persa $(n=82)$ - São Paulo - 2014............................. 


\section{LISTA DE APÊNDICES}

Apêndice A- Parâmetros eletrocardiográficos de gatos da raça Persa - São Paulo - 2014

Apêndice B- Parâmetros eletrocardiográficos de gatos da raça Persa em derivações precordiais - São Paulo - 2014.

Apêndice C- Pressão arterial sistólica de gatos da raça Persa - São Paulo 2014.

Apêndice D- Parâmetros ecocardiográficos de gatos da raça Persa - São Paulo - 2014

Apêndice E- Parâmetros ecocardiográficos (Doppler pulsado, contínuo e colorido) de gatos da raça Persa- São Paulo - 2014 
1 INTRODUÇÃO

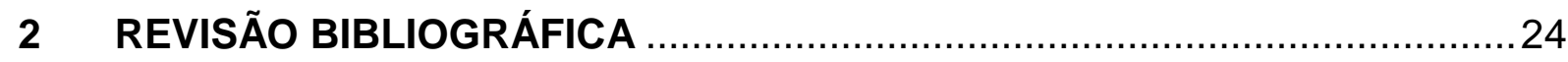

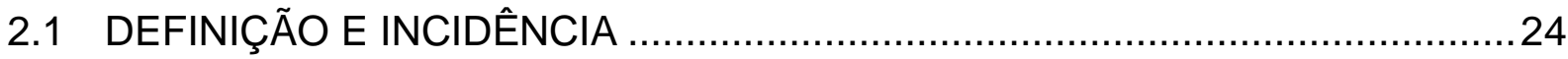

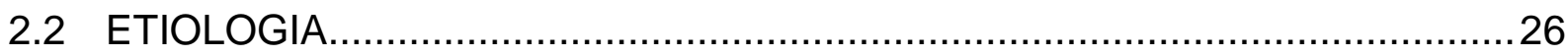

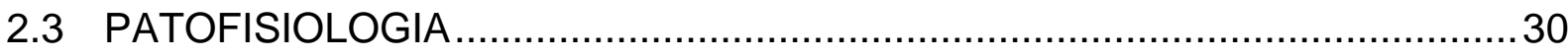

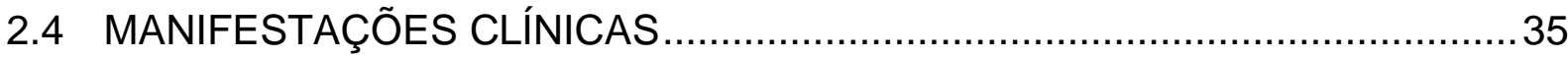

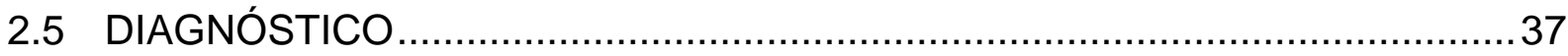

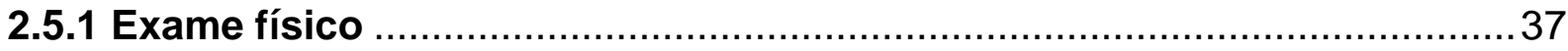

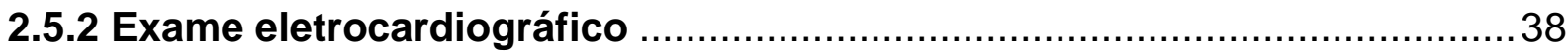

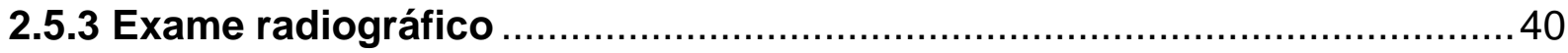

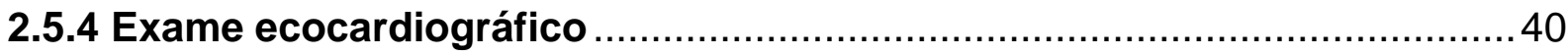

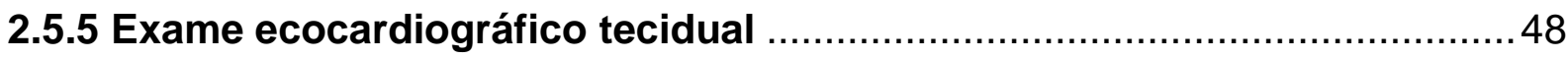

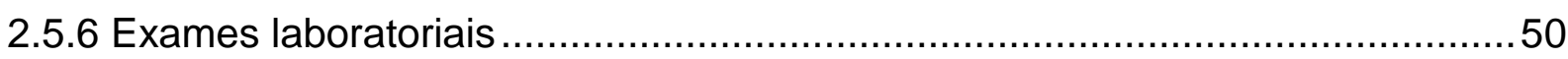

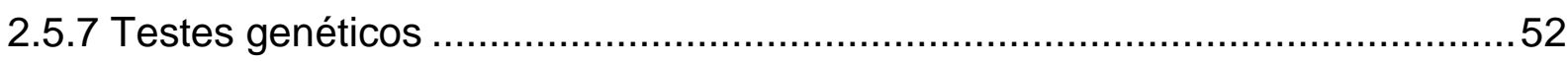

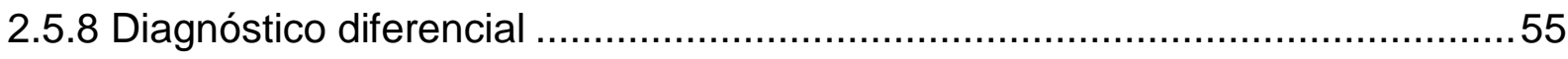

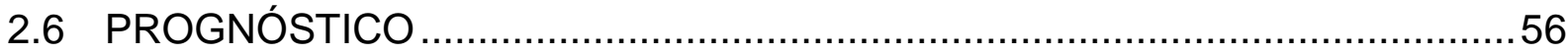

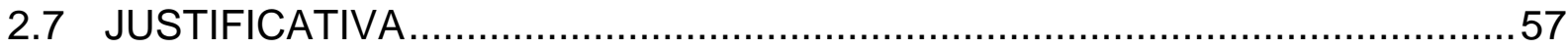

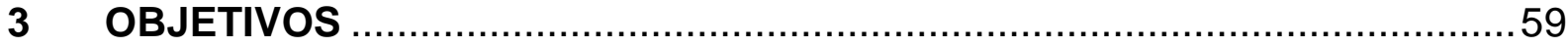

4 HIPÓTESE

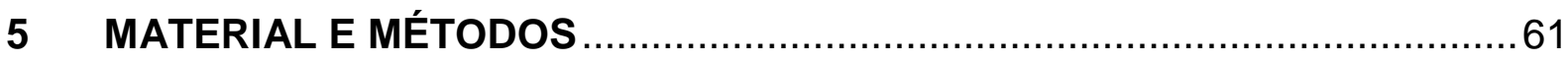

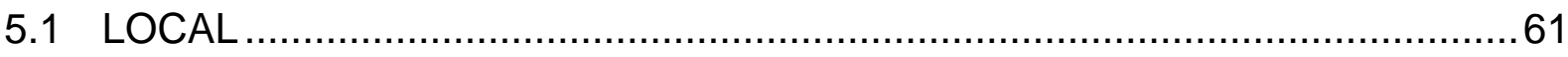

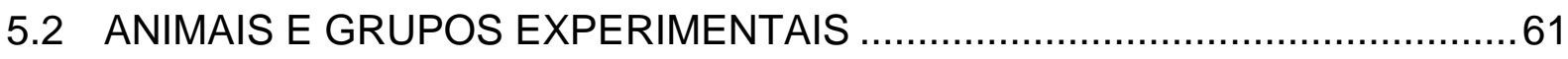

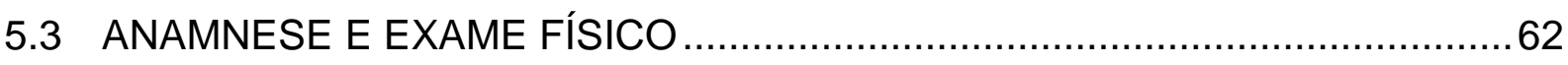

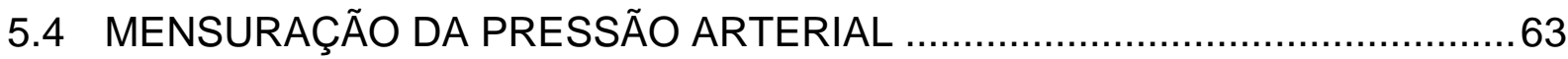




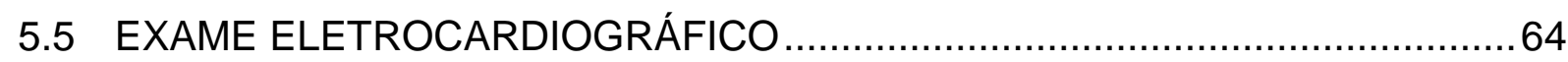

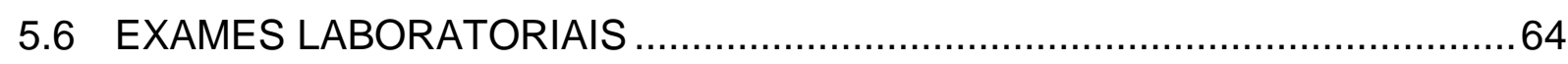

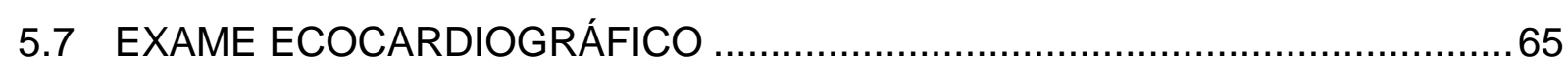

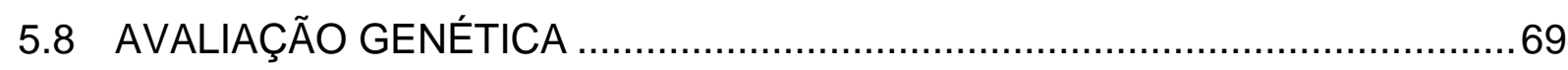

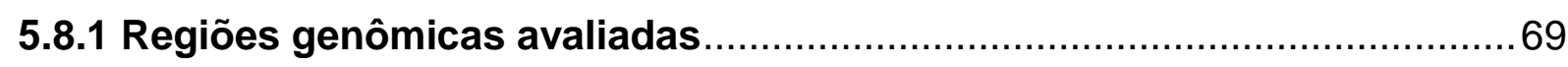

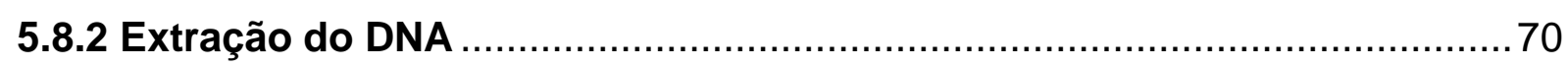

5.8.3 Genotipagem e reação de polimerase em cadeia (PCR) …......................70

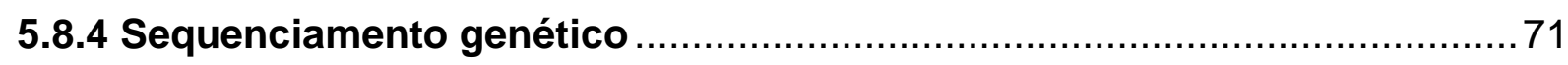

5.8.5 Interpretação dos resultados genéticos.............................................. 72

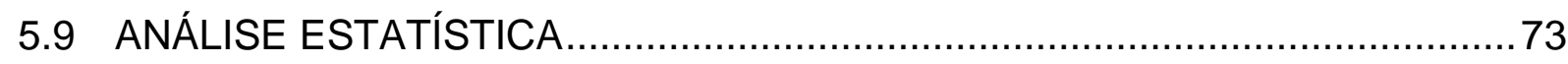

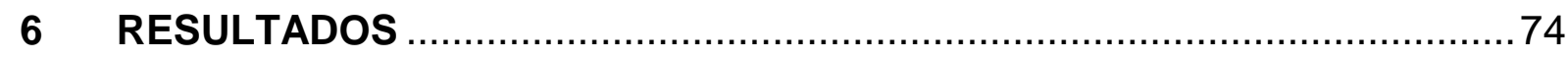

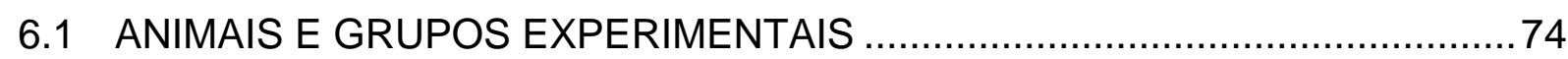

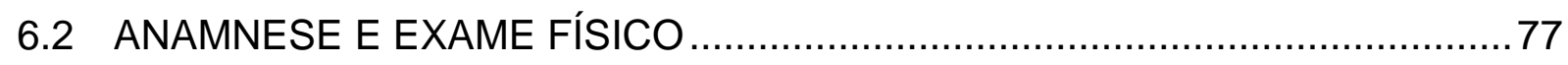

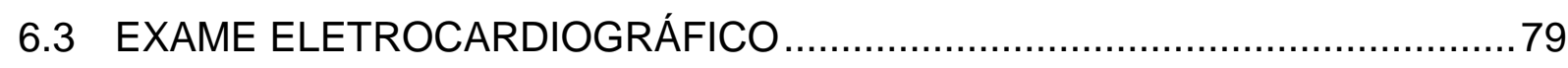

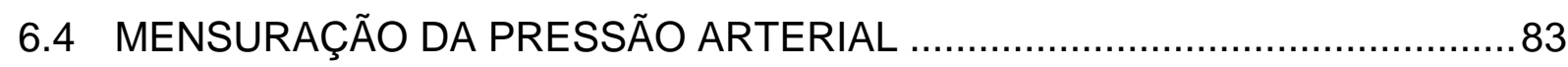

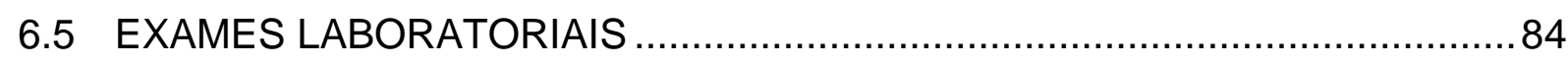

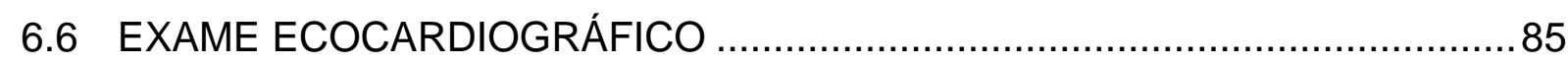

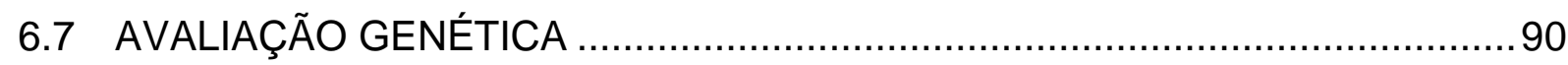

6.7.1 Análise do sequenciamento de DNA do exon 5 do gene ACTC1 …..........90

6.7.2 Análise do sequenciamento de DNA do exon 27 do gene MYBPC3 ..........97

6.8 ESTUDO POPULACIONAL DOS GATOS DA RAÇA PERSA $(\mathrm{N}=100) \ldots \ldots \ldots . . . .98$

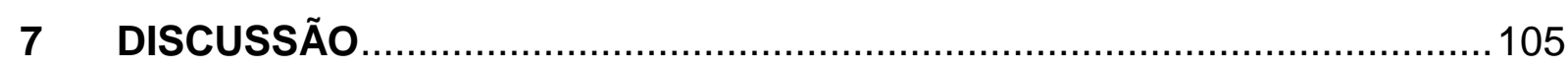

7.1 ESTUDO DA POPULAÇÃO DE GATOS DA RAÇA PERSA …......................105

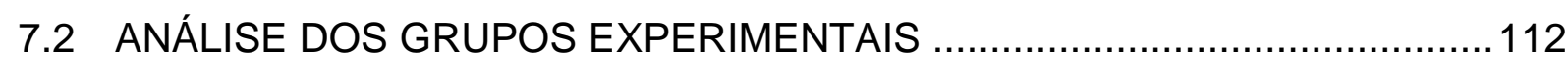

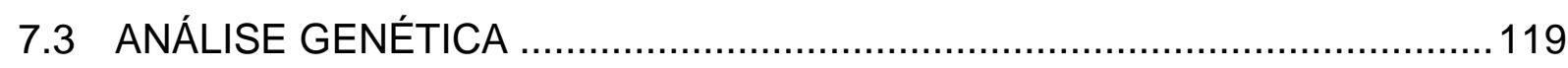

7.4 DOENÇA RENAL POLICÍSTICA E HIPERTROFIA VENTRICULAR ..............123

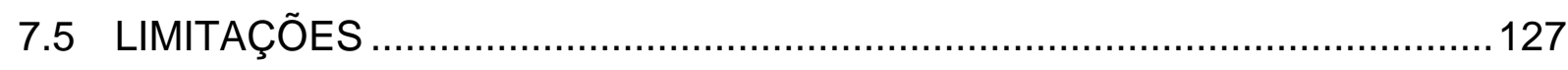


8 CONCLUSÃO.

129

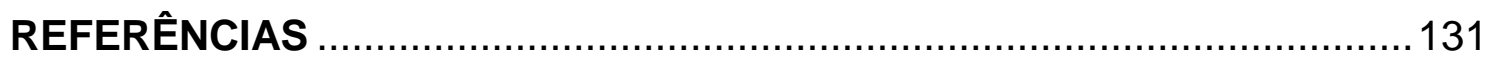

APÊNDICES 


\section{INTRODUÇÃO}

A Organização Mundial da Saúde (WHO - World Heatlh Organization), em 1980, definiu as cardiomiopatias como doenças do músculo cardíaco de causa desconhecida cuja principal característica é a cardiomegalia e a insuficiência cardíaca congestiva (ICC). Em 1995, a definição das cardiomiopatias foi atualizada e definida como afecções do miocárdio associadas a alguma disfunção cardíaca (sistólica ou diastólica) (RICHARDSON; MCKENNA; BRISTOW, 1996). Em gatos domésticos, mais de $95 \%$ das doenças cardíacas relatadas são causadas por cardiomiopatias (FOX; LIU; MARON, 1995; FOX, 1999). Referem-se a um conjunto de doenças cuja característica principal é o enfraquecimento estrutural e funcional dos músculos cardíacos, sendo responsável por grande parte da morbidade e mortalidade em felinos domésticos (FOX, 1999; WARE, 2007).

Existem diferentes classificações das cardiomiopatias atualmente. Categorizadas quanto à etiologia, podem ser diferenciadas em primárias idiopáticas, quando são afecções inerentes ao miocárdio; ou secundárias, quando atribuíveis a outras doenças cardíacas, metabólicas ou vasculares (FOX, 1999; SISAKIAN et al., 2014). Já quanto à função cardíaca, as cardiomiopatias podem ser divididas naquelas que causam disfunção sistólica, disfunção diastólica ou ambas (FUENTES, 2006; MARON et al., 2006; SISAKIAN et al., 2014).

A WHO categoriza, comumente, as cardiomiopatias quanto a sua morfologia, dividindo-as em hipertrófica $(\mathrm{CMH})$, restritiva $(\mathrm{CMR})$, dilatada (CMD), cardiomiopatia arritmogênica do ventrículo direito (CMAVD) e, mais recentemente, cardiomiopatia não classificada (RICHARDSON; MCKENNA; BRISTOW, 1996; FERASIN, 2009a; SISAKIAN et al., 2014). Entretanto, esta classificação tem sido alvo de críticas nos últimos anos: alguns autores apontam confusão na hora de diferenciar as doenças, pois foram relatadas ocorrências de casos específicos se situarem em duas categorias simultaneamente (MARON et al., 2006; SISAKIAN et al., 2014).

Alguns casos de remodelamento cardíaco foram constatados em algumas cardiomiopatias, como explicado por Maron et al. (2006), em que algumas características miocárdicas da $\mathrm{CMH}$ evoluíram para outra forma de cardiomiopatia durante seu curso clínico natural. Dentre os exemplos observados, pode-se citar a evolução de cardiomiopatia hipertrófica para cardiomiopatia dilatada ou para 
cardiomiopatia restritiva (MARON et al., 2006; SISAKIAN et al., 2014).

A cardiomiopatia hipertrófica $(\mathrm{CMH})$ é a afecção miocárdica mais comum em gatos domésticos (FOX; LIU; MARON, 1995; FOX, 1999; BONAGURA, 2010) e, segundo Kittleson et al. (1999) e Ferasin et al. (2003), atinge quase dois terços de todos os casos de doenças cardíacas observadas na espécie. Tem sido foco de estudos por mais de 40 anos e foi identificada principalmente em gatos e humanos, apesar de acometer diversas outras espécies, incluindo cães (TEARE, 1958; MARON et al., 1995; FERNANDEZ, 1998). É uma doença primária do músculo cardíaco, geneticamente transmitida e com amplo espectro clínico e morfológico. Seu reconhecimento é ainda muito recente, acumulando diversas pesquisas, desde sua primeira descrição, em oito jovens humanos em 1958, dos quais sete apresentaram morte súbita (TEARE, 1958; GOODWIN et al., 1960; WIGLE et al., 1985; MARON et al., 1995). Posteriormente, a CMH humana foi caracterizada clinicamente e descrita, sistematicamente, por Goodwin et al. (1960) e Braunwald et al. (1964).

A $\mathrm{CMH}$ é uma doença miocárdica geneticamente e fenotipicamente heterogênea (HÄGGSTRÖM, 2003; BATY, 2004; GARCIA-PAVIA et al., 2011; GRANSTRÖM et al., 2011), caracterizada por aumento na massa ventricular esquerda tanto pelo aumento na espessura da parede (na ausência de sobrecarga de pressão e estímulo metabólico), quanto pelo desarranjo histológico de miócitos e miofibrilas (CONNOLLY et al., 2003; WESS; SARKAR; HARTMANN, 2010).

Estima-se que a prevalência da $\mathrm{CMH}$ em humanos seja de um a cada 500 indivíduos e, em pelo menos $60 \%$ dos casos, a doença é de origem familial (FERNANDEZ, 1998; GRAZIANO; ACQUATELLA, 2007; MARON et al., 2014). Em gatos, a prevalência de hipertrofia esquerda atribuída à $\mathrm{CMH}$, observada em avaliações ecocardiográficas de felinos, encontra-se entre 14,5\% e 34\% (embora a hidratação, valores de tiroxina séricos e pressão arterial sistêmica não tenham sido mensurados em todos os animais) (PAIGE et al., 2009; WAGNER et al., 2010; CÔTÉ et al., 2011).

Ao longo dos anos, diversas explicações com base genética foram defendidas como causa da hipertrofia ventricular na $\mathrm{CMH}$. Alguns autores sugerem um defeito congênito presente na formação das estruturas responsáveis pela contração dos miócitos cardíacos. Desta forma, a atividade reduzida das células anormais causaria uma sobrecarga às normais, acarretando a hipertrofia característica da doença. 
Outros autores consideram que a hipertrofia ocorre por alterações nos sarcômeros, relatando a possibilidade da utilização de biopsia no miocárdio para se diagnosticar precocemente a doença (KITTLESON et al., 1999; HÄGGSTRÖM, 2003; KEREN; SYRRIS; MCKENNA, 2008; KIMURA, 2008).

Apesar dos diversos estudos fundamentados em $\mathrm{CMH}$, ainda não se sabe sua etiologia nas diferentes raças de gatos domésticos (KITTLESON et al., 1999; MEURS et al., 2009; BONAGURA, 2010). Recentemente, uma mutação para cardiomiopatia hipertrófica foi identificada no gene sarcomérico da proteína $C$ miosina ligante (MYBPC3) em raças Maine Coon (MEURS et al., 2005) e Ragdoll (MEURS et al., 2007). Esta mutação foi encontrada em diferentes regiões do mesmo gene nas duas raças: em Maine Coon, foi identificada entre os domínios C0 e C1 do gene e, em Ragdoll, no domínio 6 (MEURS et al., 2007).

Estudos realizados em gatos Maine Coon foram importantes por atribuírem à $\mathrm{CMH}$ um padrão genético com herança do tipo autossômico dominante (KITTLESON, 2009a; MEURS et al., 2007) e, segundo Baty (2004), uma herança similar pode também estar presente em outras raças.

Segundo Nelson e Couto (2005) e Fuentes (2006), além de mutações em genes que codificam proteínas miocárdicas contráteis reguladoras, existem outras causas que podem contribuir no desenvolvimento desta doença, como alterações nos mecanismos de transporte de cálcio no miocárdio e aumento da sensibilidade miocárdica às catecolaminas.

Entretanto, apesar dos avanços nos trabalhos relacionados à $\mathrm{CMH}$ e do conhecimento de um envolvimento genético na maior parte dos casos, ainda não se conhece o mecanismo exato que explique o desenvolvimento da hipertrofia no músculo cardíaco e faltam, ainda, estudos nas diferentes raças de gatos (MEURS et al., 2005; ABBOTT, 2010). 


\section{REVISÃO BIBLIOGRÁFICA}

\subsection{DEFINIÇÃO E INCIDÊNCIA}

A cardiomiopatia hipertrófica $(\mathrm{CMH})$ é a principal cardiopatia dos felinos, sendo caracterizada por hipertrofia miocárdica esquerda primária, sem dilatação ventricular (FOX et al., 1999; CHETBOUL et al., 2006a; MCDONALD et al., 2007). Esta enfermidade é a principal cardiopatia causadora de morbidade e letalidade em felinos (KOFFAS et al., 2003; MEURS et al., 2005; FUENTES, 2006), que intriga os cardiologistas há décadas (SAMPEDRANO et al., 2006) e está associada ao desenvolvimento de insuficiência cardíaca, tromboembolismo arterial sistêmico e morte súbita (KITTLESON et al., 1999; BONAGURA, 2010). É uma doença miocárdica geneticamente e fenotipicamente heterogênea (HÄGGSTRÖM, 2003; BATY, 2004) caracterizada por aumento na massa ventricular esquerda tanto pelo aumento na espessura da parede (na ausência de sobrecarga de pressão e estímulo metabólico) quanto pelo desarranjo histológico de miócitos e miofibrilas (CONNOLLY et al., 2003; WESS; SARKAR; HARTMANN, 2010).

Em humanos, a prevalência da $\mathrm{CMH}$ é de aproximadamente $0,2 \%$ e, em mais de $50 \%$ dos casos, a doença apresenta caráter hereditário e familial (FERNANDEZ, 1998; GRAZIANO; ACQUATELLA, 2007; CAPEK et al., 2011). Em gatos, a prevalência descrita na literatura varia de 8,5\% (GRANSTRÖM et al., 2011) a 41,5\% (PAIGE et al., 2009; MARY et al., 2010), com diferenças de acordo com a época do estudo e com o padrão racial avaliado.

De acordo com Ferasin (2009b), o número de gatos diagnosticados com doenças cardíacas tem aumentado nos últimos anos, fato principalmente decorrente da melhora significativa da tecnologia e de exames como a ecocardiografia e radiografia, além do aumento da popularidade do gato como animal doméstico.

Uma evidência desse aumento pode ser observada por meio da comparação de trabalhos realizados em épocas diferentes. Dados oriundos de um estudo feito a partir da necropsia de 4.933 gatos domésticos, entre 1962 e 1976, Fox et al. (1999) evidenciaram uma incidência de $\mathrm{CMH}$ em 5,2\% dos casos. Já Riense et al. (2008) efetuaram um estudo no qual foram examinados 408 gatos de 22 raças. Foi possível 
identificar 287 indivíduos com doenças cardiovasculares e, dentre estas, a cardiomiopatia hipertrófica estava presente em $67 \%$ dos casos, caracterizando-se como o diagnóstico mais comum.

$\mathrm{A} \mathrm{CMH}$ é relatada mais frequentemente em gatos machos de meia idade, mas também pode acometer fêmeas, jovens ou idosos (CHETBOUL et al., 2006a; FUENTES, 2006; PAYNE et al., 2010). Segundo Ferasin et al. (2003), a idade média de gatos diagnosticados com $\mathrm{CMH}$, em geral, é de cinco anos e meio, podendo estender-se desde os quatro meses até os 17 anos. De acordo com Trehiou-Sechi et al. (2012), em Persas, a CMH é mais comumente diagnosticada em animais mais velhos, com média de idade no diagnóstico de 11 anos, padrão diferente do encontrado em outras raças como Maine Coon e Ragdoll (onde a afecção é mais precoce). Segundo Chetboul et al. (2006a) e Meurs et al. (2007), gatos da raça Maine Coon geneticamente predispostos à $\mathrm{CMH}$ geralmente desenvolvem a enfermidade apresentando manifestações de insuficiência cardíaca congestiva ou morte súbita entre um e meio a três anos de idade. Já os gatos da raça Ragdoll podem apresentar uma forma agressiva da $\mathrm{CMH}$, sendo que alguns animais morrem antes do primeiro ano de vida (KITTLESON, 2009a; BORGEAT et al, 2014). Segundo Chetboul et al. (2012), no Sphynx, a prevalência da CMH aumenta significativamente de acordo com a faixa etária, acometendo aproximadamente 20,2\% da população estudada.

Segundo Ferasin et al. (2003) e Payne et al. (2010), machos apresentam maior predisposição à doença. Porém, alguns estudos não referem diferenças na ocorrência da afecção entre machos e fêmeas (MCDONALD et al., 2007; WARE, 2007). Abbott (2010) e Payne et al. (2010) sugerem índice maior de $75 \%$ em machos; outros autores apontam a manifestação mais precoce da doença e de uma forma mais grave também nos machos (MCDONALD et al., 2007; WARE, 2007; GRANSTRÖM et al., 2011).

$\mathrm{A} \mathrm{CMH}$, apesar de afetar principalmente raças puras, tem sido cada vez mais observada em gatos de raças indeterminadas (RIENSE et al., 2008). Raças conhecidas por terem maior predisposição incluem Ragdoll, Cornish Rex, Maine Coon e Persa, esta última tendo maior incidência dentre as quatro referidas (3-15\% dos gatos com CMH são Persas), talvez por ser uma raça bastante comum (RUSH et al., 2002; MEURS et al., 2007). Côté et al. (2011) incluem a esta lista as raças Siamesa, Abissínia e Birmanesa, apesar de apresentarem casos mais raramente. Há 
relatos de $\mathrm{CMH}$ geneticamente determinada no Sphynx, British Shorthair, Norwegian Forest, Turkish Van, American Shorthair e Scottish Fold (KITTLESON, 2009a; GRANSTRÖM et al., 2011; CHETBOUL et al., 2012; SILVERMAN; STERN; MEURS, 2012). No entanto, o gato doméstico de pelo curto (sem definição racial) é o felino mais acometido dentre os espécimes felinos (FOX; LIU; MARON, 1995; CÔTÉ et al., 2011).

\subsection{ETIOLOGIA}

Apesar da causa da $\mathrm{CMH}$ ainda não ser totalmente conhecida, sabe-se que há envolvimento genético em muitos casos (MEURS et al., 2005; KOFFAS et al., 2008). A doença é bastante prevalente em determinadas linhagens sanguíneas de raças variadas (KITTLESON, 2009a; ETTINGER; FELDMAN, 2005; MEURS et al., 2009). Em humanos, a primeira ocorrência natural da $\mathrm{CMH}$ familial foi relatada em 1958 (TEARE, 1958; MARIAN; ROBERTS, 1995). A maioria dos casos de cardiomiopatia hipertrófica humana apresenta componente familial; e várias anormalidades de genes específicos para proteínas miocárdicas já foram identificadas em diferentes gerações (MARIAN; ROBERTS, 1995; HO et al., 2009).

Atualmente, há mais de 1400 mutações em 11 genes que codificam proteínas do sarcômero relacionadas à cardiomiopatia em humanos (MCTAGGART, 2002; HÄGGSTRÖM, 2003; WESS et al., 2010; MARON; MARON, 2013), incluindo alterações em cadeia pesada de alfa e beta miosina, proteína C miosina ligante, troponinas T, I e C, alfa tropomiosina, actina, entre outras (MARIAN et al., 1995; MEURS et al., 2007; SAMPEDRANO et al., 2009; GARCIA-PAVIA et al., 2011).

Em humanos, a forma de transmissão mais comum da $\mathrm{CMH}$ é a autossômica dominante, com penetrância variável (INGLES et al., 2001; HO et al., 2011; DE et al., 2011). Poucos casos estão relacionados às mutações do genoma mitocondrial. Cerca de dois terços dos indivíduos apresentam histórico familiar e o restante apresenta mutações esporádicas, sendo que a penetrância é alta nos que expressam a enfermidade desde a juventude (MARON; MARON, 2013; SISAKIAN, 2014). 
Em algumas famílias de gatos, como os felinos da raça Maine Coon, a $\mathrm{CMH}$ é uma enfermidade de herança autossômica dominante (MEURS et al., 2005; GUNDLER; TIDHOLM; HÄGGSTRÖM, 2008), sendo de morfologia bastante similar à CMH em humanos (FUENTES, 2006; MEURS et al., 2009; WESS et al., 2010). Portanto, a $\mathrm{CMH}$ felina pode ser considerada como modelo da doença humana (TILLEY et al., 1977; KITTLESON et al., 1999; HÄGGSTRÖM, 2003; CHETBOUL et al., 2006b).

A fisiopatologia da $\mathrm{CMH}$ relacionada às mutações em genes que codificam proteínas do sarcômero ainda é pouco conhecida e controversa (KITTLESON, 2009a; HO, 2011). Uma das teorias afirma que a proteína anormal produzida pelo gene mutado resulta em sarcômeros com função e contratilidade reduzidas, o que faz com que os sarcômeros funcionais tenham que trabalhar para suportar uma carga maior (KITTLESON, 2011; LONGERI et al., 2013; MARSIGLIA, 2013). O miocárdio sofre remodelamento e compensa substituindo os sarcômeros alterados por sarcômeros adicionais, o que resulta em hipertrofia miocárdica e desarranjo de miócitos e miofibrilas (KITTLESON, 2009a; HO, 2011; LONGERI et al., 2013; MARSIGLIA, 2013). Apesar do grande número de genes já descritos em humanos com $\mathrm{CMH}$, os mecanismos moleculares que levam à manifestação fenotípica ainda não foram elucidados (MARSIGLIA, 2013).

A primeira família de gatos da raça Maine Coon com $\mathrm{CMH}$ familial foi identificada em 1992 e relatada em 1999 (KITTLESON et al. 1999; KITTLESON, 2009a). Em 2005, a primeira mutação genética relacionada à $\mathrm{CMH}$ dos gatos da raça Maine Coon foi identificada (MEURS et al., 2005). Nestes gatos com $\mathrm{CMH}$, foi demonstrada a redução na miomesina (proteína do sarcômero) e mutação no gene que codifica a proteína C miosina ligante (MYBPC3-A31P) (FRIES; HEANEY; MEURS, 2008; KOFFAS et al., 2008; KITTLESON; MEURS; MUNRO, 2010; MARY et al., 2010). O sequenciamento do DNA revelou uma simples troca no par de bases (G por $\mathrm{C}$ ) no códon 31 (exon 3) nos gatos afetados (MEURS et al., 2009; WESS et al., 2010; GODIKSEN et al., 2011; LONGERI et al., 2013) (Figura 1). Esta mutação resulta em troca do aminoácido alanina por prolina na estrutura proteica e esta alteração acarreta em modificação estrutural e funcional da proteína (MEURS et al., 2007; FRIES; HEANEY; MEURS, 2008; KITTLESON; MEURS; MUNRO, 2010). A penetrância incompleta é comum neste tipo de mutação, tornando o diagnóstico ecocardiográfico mais difícil em indivíduos heterozigotos (MCDONALD et al., 2007; 
SAMPEDRANO et al., 2009; GODIKSEN et al., 2011). Segundo Meurs et al. (2005), Chetboul et al. (2006b) e Kittleson (2009a), gatos da raça Maine Coon com CMH mimetizam os aspectos hereditários, a expressão fenotípica, a história natural e as características fisiopatológicas observadas na $\mathrm{CMH}$ humana de origem familial.

Figura 1 - Eletroferograma do sequenciamento do DNA do códon 31 do gene MYBPC3 em gato Maine Coon com $\mathrm{CMH}$

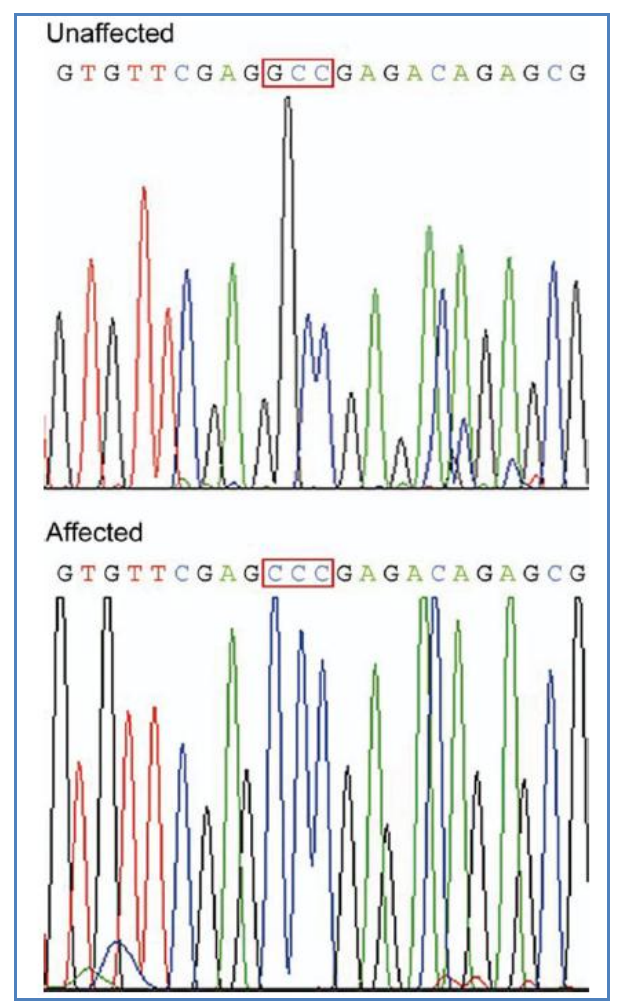

Legenda: Sequenciamento do DNA identificando uma simples mudança no par de base (G para $C$ ) no códon 31 do gene MYBPC3 em gato Maine Coon com CMH (affected); a mesma mudança não é observada nos gatos sem $\mathrm{CMH}$ (unaffected).

Fonte: (MEURS et al., 2005).

Em gatos da raça Ragdoll, a $\mathrm{CMH}$ está relacionada com mutação no mesmo gene da proteína C miosina ligante (MYBPC3), porém num códon diferente e altamente conservado na espécie (C820T) (MEURS et al., 2007; KITTLESON, 2009a; GRANSTRÖM et al., 2011; BORGEAT et al, 2014). O sequenciamento do DNA revelou uma simples troca no par de bases ( $C$ por $\mathrm{T}$ ) no códon 820 nos gatos acometidos, resultando em troca do aminoácido arginina por triptofano, acarretando em modificação estrutural da proteína codificada (MEURS et al., 2007; VERA et al., 2010; LONGERI et al., 2013). A prevalência da mutação na população de gatos da raça Ragdoll varia de $17 \%$ a 30,1\% (BORGEAT et al., 2014). Os gatos acometidos 
podem apresentar $\mathrm{CMH}$ de forma agressiva e alguns animais morrem antes do primeiro ano de vida; acredita-se que estes quadros agressivos possam estar relacionados ao maior número de animais homozigotos e de endogamia nesta raça (KITTLESON, 2009a; LONGERI et al., 2013; BORGEAT et al, 2014).

Em algumas famílias de gatos da raça American Shorthair, há relatos de movimento anterior sistólico da valva mitral (MAS) antes mesmo do desenvolvimento de hipertrofia ventricular, provavelmente decorrente de mutação de herança autossômica dominante relacionada à CMH (MEURS et al., 1997). Em outras raças como Persa, British Shorthair, Norwegian Forest, Turkish Van e Scottish Fold também há evidências da $\mathrm{CMH}$ geneticamente determinada, porém não há estudos comprovando o tipo de herança genética envolvida (KITTLESON, 2009a; GRANSTRÖM et al., 2011; LONGERI et al., 2013). Alguns trabalhos sugerem evidências de CMH familial em gatos Persas (TILLEY et al., 1977; MARTIN et al., 1994) e em American Shorthair. Segundo Chetboul et al. (2012) e Silverman, Stern e Meurs (2012), a análise do pedigree de gatos da raça Sphynx sugere a presença de $\mathrm{CMH}$ de herança autossômica dominante, mas ainda não se conhece qual a mutação envolvida.

Devido ao alto número de cruzamentos entre animais de diferentes raças e devido à alta prevalência da $\mathrm{CMH}$ na população felina, o conhecimento das mutações envolvidas com a cardiopatia se faz necessário para o estabelecimento de programas de cruzamentos em gatis (KITTLESON, 2011).

De acordo com Meurs et al. (2009) e Maron e Maron (2013), os principais genes que codificam proteínas do sarcômero e que estão relacionados às mutações envolvidas na $\mathrm{CMH}$ familial humana são: gene da cadeia pesada da beta-miosina (MYH7), gene da proteína C miosina ligante (MYBPC3), gene da troponina cardíaca T (TNNT2), gene da troponina I (TNNI3), gene da alfa-tropomiosina (TPM1), gene regulador da cadeia leve de miosina (MYL2), gene essencial da cadeia leve de miosina (MYL3) e gene da alfa-actina cardíaca (ACTC1), sendo que este grau de heterogeneidade genética também é observado em famílias de gatos (Figura 2).

Aproximadamente $70 \%$ das mutações relacionadas à $\mathrm{CMH}$ humana familial estão localizadas nos genes da cadeia pesada da beta-miosina (MYH7) e da proteína C miosina ligante (MYBPC3) (MARON; MARON, 2013; MARSIGLIA, 2013).

Além de mutações em genes que codificam proteínas miocárdicas contráteis reguladoras, outras causas atribuídas à afecção incluem: maior sensibilidade 
miocárdica às catecolaminas, maior produção de catecolaminas, resposta anormal de hipertrofia frente à isquemia, à fibrose ou a fatores tróficos, anormalidade colágena primária, influência relacionada à taxa de crescimento e fatores nutricionais, além de anormalidades no processo de utilização do cálcio no miocárdio (NELSON; COUTO, 2005; FUENTES, 2006; FREEMAN et al., 2012). Hipertrofia miocárdica, mas pouco associada à insuficiência cardíaca congestiva, também pode ocorrer em casos de distrofia muscular felina, caracterizada por deficiência de distrofina de caráter recessivo e ligada ao cromossomo $\mathrm{X}$, semelhante à distrofia muscular de Duchenne em humanos (ETTINGER; FELDMAN, 2005; WARE, 2007).

Figura 2 - Genes que codificam proteínas do sarcômero e que estão relacionados às mutações envolvidas na $\mathrm{CMH}$ familial humana

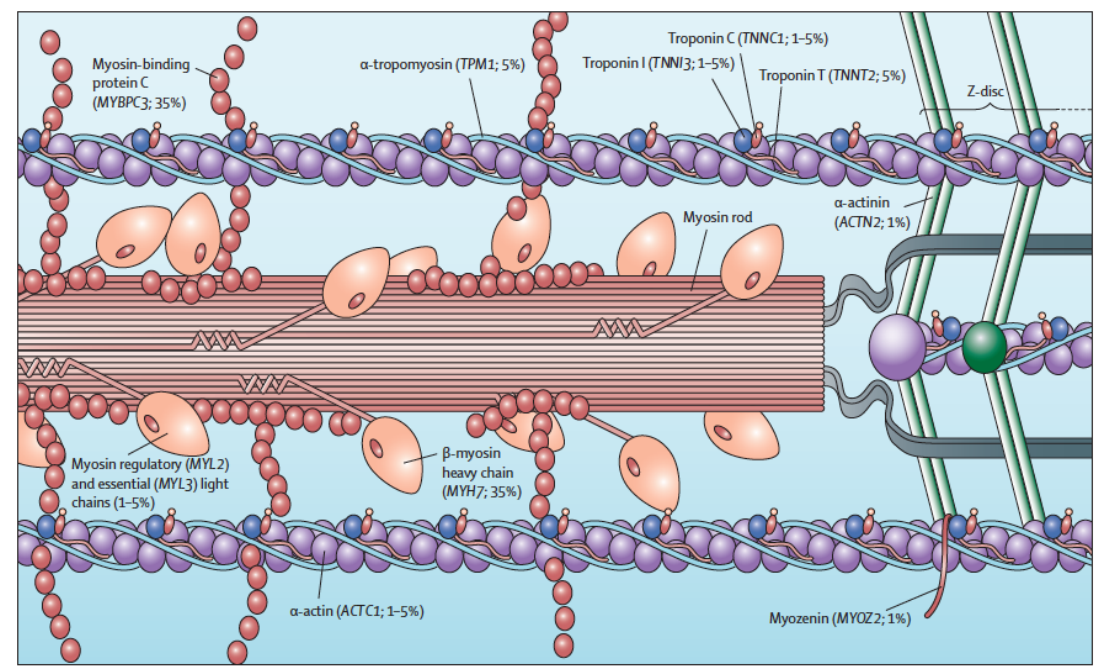

Legenda: A prevalência da mutação associada à $\mathrm{CMH}$ humana em cada gene está descrita entre parênteses.

Fonte: $\quad$ (MARON; MARON, 2013).

\subsection{PATOFISIOLOGIA}

O espessamento miocárdico que ocorre na $\mathrm{CMH}$ leva ao aumento na rigidez ventricular e ao desenvolvimento de alterações no relaxamento (KITTLESON; KIENLE, 1998). Há alteração no enchimento ventricular esquerdo, e pressões diastólicas aumentadas são necessárias devido à rigidez e à menor distensibilidade ventricular (CONNOLLY et al., 2003; GUNDLER; TIDHOLM; HÄGGSTRÖM, 2008). 
Além disso, o relaxamento miocárdico pode tornar-se mais prolongado e incompleto, principalmente se houver isquemia miocárdica (FOX et al., 1999). Acredita-se que a disfunção diastólica seja a principal anormalidade observada na $\mathrm{CMH}$ (KOFFAS et al., 2006; KATO et al., 2007; KOFFAS et al., 2008).

A fibrose e a estrutura celular miocárdica desorganizada também podem contribuir com o desenvolvimento de rigidez anormal do ventrículo (CONNOLLY et al., 2003; MCDONALD; KITTLESON; KASS, 2008). O ventrículo esquerdo, cada vez mais rígido, requer pressões de enchimento progressivamente maiores e, consequentemente, as pressões diastólicas no átrio e no ventrículo esquerdo aumentam (SEVERINO et al., 2000; WARE, 2007). O relaxamento ventricular inicial (processo ativo) fica mais lento ou incompleto, aumentando o tempo de relaxamento isovolumétrico (TRIV), o que diminui o preenchimento ventricular inicial e aumenta a importância da contração atrial para o preenchimento do ventrículo (ETTINGER; FELDMAN, 2005; NELSON; COUTO, 2005).

O átrio aumenta de tamanho, às vezes de forma acentuada, mas o volume ventricular esquerdo permanece normal ou diminuído (ABBOTT; MCLEAN, 2006; FERASIN, 2009a). A diminuição do volume ventricular resulta em menor volume ejetado e pode incitar a ativação do sistema renina-angiotensina-aldosterona (SRAA) e do sistema nervoso simpático (SISSON, 2004; MCDONALD et al., 2006a).

A $\mathrm{CMH}$ é caracterizada por alta variabilidade fenotípica e a hipertrofia do miocárdio pode acometer porções diferentes do septo interventricular e/ou da parede ventricular. Segundo Fox, Liu e Maron (1995), pelo menos quatro diferentes padrões de hipertrofia miocárdica podem ser observados na doença: (1) hipertrofia simétrica difusa, afetando o septo interventricular e a parede livre do ventrículo esquerdo; (2) hipertrofia assimétrica difusa, atingindo preferencialmente o septo interventricular (ou, em menor parte, a parede ventricular); (3) hipertrofia segmentada confinada apenas à porção de parede ventricular; e (4) hipertrofia segmentada afetando fragmentos não adjacentes do septo interventricular e da parede do ventrículo esquerdo. Dentre estes quatro padrões característicos, (1) e (2) são os mais comuns em gatos domésticos; e também há relatos de hipertrofia acometendo apenas os músculos papilares (FERASIN, 2009a). Em alguns casos mais raros, o ventrículo direito também pode ser acometido (FOX; LIU; MARON, 1995).

As alterações estruturais do ventrículo esquerdo e dos músculos papilares ou a movimentação sistólica anormal (anterior) da valva mitral podem impedir o 
fechamento normal da mesma (MCDONALD et al., 2006a; FERASIN, 2009a). A regurgitação mitral resultante exacerba o aumento do volume e da pressão atriais esquerdos, podendo ocasionar congestão e edema pulmonar (FOX et al., 1999; FERASIN, 2009b). Frequências cardíacas mais rápidas interferem ainda mais no enchimento ventricular esquerdo, podendo exacerbar a isquemia miocárdica e induzindo a congestão venosa por encurtamento do período de enchimento diastólico. A contratilidade, ou função sistólica, geralmente encontra-se normal nos afetados, porém, alguns gatos apresentam disfunção sistólica regional secundária ao infarto ou à isquemia miocárdica (KITTLESON; KIENLE, 1998; NELSON; COUTO, 2005).

Alguns gatos também apresentam obstrução dinâmica do fluxo de saída do ventrículo esquerdo (cardiomiopatia hipertrófica obstrutiva - $\mathrm{CMHO}$ ) durante a sístole, provocando maior gradiente de pressão sistólico entre o ventrículo e a via de saída (WARE, 2007; FERASIN, 2009b). Nesses gatos, pode-se evidenciar hipertrofia excessiva e assimétrica do septo interventricular basilar ao exame ecocardiográfico ou necroscópico (FOX et al., 1999; FUENTES, 2006; FERASIN, 2009a). De acordo com Trehiou-Sechi et al. (2012), em Persas, a forma mais comum da CMH é a hipertrofia miocárdica septal assimétrica, com aumento da espessura do septo interventricular em região de via de saída do ventrículo esquerdo (região septal basal).

$\mathrm{Na} \mathrm{CMHO}$, a obstrução do fluxo de saída durante a sístole aumenta o estresse de parede e a demanda miocárdica de oxigênio, promovendo o desenvolvimento de isquemia miocárdica. A regurgitação mitral é exacerbada por forças que tendem a deslocar o folheto anterior em direção ao septo interventricular durante a ejeção (movimento anterior sistólico da valva mitral; fenômeno de Venturi) (GUNDLER; TIDHOLM; HÄGGSTRÖM, 2008). Um sopro de ejeção é frequentemente audível nos gatos com obstrução do fluxo de saída. Acredita-se que cerca de $25 \%$ a um terço dos gatos com $\mathrm{CMH}$ apresentem a hipertrofia septal assimétrica (NELSON; COUTO, 2005; FERASIN, 2009b). Obstrução de via de saída de ventrículo direito também pode ser observada em gatos, mas nem sempre há associação com cardiomiopatia hipertrófica obstrutiva (CMHO) e geralmente esta obstrução é discreta. Algum grau de regurgitação tricúspide também é comum na CMH (WARE, 2007). 
Vários fatores podem contribuir para o desenvolvimento de isquemia miocárdica, como: densidade capilar miocárdica inadequada para o grau de hipertrofia; estreitamento das artérias coronarianas intramurais; diminuição da pressão de perfusão da artéria coronariana; e aumento de pressão de enchimento do ventrículo esquerdo (ETTINGER; FELDMAN, 2005; NELSON; COUTO, 2005). Inicialmente, a isquemia prejudica o relaxamento ventricular ativo, levando ao aumento de pressão de enchimento ventricular; e também está relacionada à maior predisposição ao desenvolvimento de arritmias letais e dor torácica. A disfunção e a isquemia são exacerbadas por aumentos na frequência cardíaca (FOX et al., 1999).

A congestão venosa e o edema pulmonar geralmente resultam do aumento na pressão atrial esquerda (ETTINGER; FELDMAN, 2005; ABBOTT; MCLEAN, 2006). De acordo com Linney et al. (2014), o diâmetro, o volume e a função do átrio esquerdo podem indicar a cronicidade e a gravidade da disfunção diastólica associada à $\mathrm{CMH}$; e gatos com $\mathrm{CMH}$ e insuficiência cardíaca apresentam função contrátil atrial reduzida. Em alguns gatos, além de congestão e edema pulmonar, pode haver desenvolvimento de efusão pleural, geralmente transudato modificado (mais comum) ou de aspecto quiloso, em consequência à insuficiência cardíaca. Acredita-se que as pressões de capilares e veias pulmonares aumentadas causem vasoconstrição pulmonar, aumentando a pressão arterial pulmonar e determinando a insuficiência cardíaca congestiva direita secundária (KITTLESON; KIENLE, 1998).

A etiologia da efusão pleural em gatos com insuficiência cardíaca congestiva esquerda é discutível (BATY, 2004; CÔTÉ et al., 2011). Os vasos da pleura visceral, que recebem sangue venoso da superfície pleural pulmonar, desembocam nas veias pulmonares em gatos. O aumento da pressão venosa pulmonar secundário à ICC poderia levar à formação de efusão pleural, pelo aumento da pressão hidrostática e transudação de plasma através das paredes desses vasos. No entanto, os cães também possuem drenagem da pleura visceral nas veias pulmonares e não desenvolvem efusão pleural secundária à ICC esquerda (CÔTÉ et al., 2011).

Em consequência à hipertrofia ventricular, há diminuição no volume diastólico final e, então, no volume ejetado a cada sístole. Desta forma, há diminuição do débito cardíaco com consequente ativação de mecanismos neuro-humorais compensatórios (SISSON, 2004; MCDONALD; KITTLESON; KASS, 2008). Ativação do eixo renina-angiotensina-aldosterona e do sistema nervoso simpático e concentrações plasmáticas elevadas de fator de necrose tumoral (TNF) podem 
ocorrer em gatos com CMH (SISSON, 2004; MCDONALD; KITTLESON; KASS, 2008). Elevações nas concentrações de troponina ocorrem em gatos com $\mathrm{CMH}$ moderada a importante, e valores muito aumentados estão associados com manifestações de ICC (HORI et al., 2008).

Pode haver a formação de trombo, principalmente no interior do átrio esquerdo dilatado ou em outras áreas do coração, e o deslocamento do mesmo para a circulação caracteriza o quadro de tromboembolismo arterial sistêmico (TEAS) (KITTLESON; KIENLE, 1998; FOX et al., 1999). O aumento moderado a importante do átrio esquerdo e a estase sanguínea secundária são fatores de risco para o desenvolvimento do TEAS (BATY, 2004; FUENTES, 2012; LINNEY et al., 2014).

A incidência do TEAS em gatos com $\mathrm{CMH}$ é de aproximadamente $12-17 \%$ (RUSH et al., 2002; CÔTÉ et al., 2011; HOGAN et al., 2013). Quanto maior o tamanho do átrio esquerdo, maior a estase sanguínea e maior a chance de desenvolvimento do trombo (FUENTES, 2012). Porém, há relatos de TEAS em animais com aumento moderado ou aumento discreto do átrio esquerdo (CÔTÉ et al., 2011).

Para que ocorra a formação do trombo, há necessidade da presença dos componentes da tríade de Virchow: estase sanguínea; estado de hipercoagulabilidade e lesão endotelial (RUSH et al., 2002; HOGAN et al., 2013). A lesão endotelial promove a exposição de colágeno e, consequentemente, a ativação dos mecanismos de hemostasia (FUENTES, 2012); esta lesão endotelial pode ser observada em quadros de cardiomiopatias felinas com aumento atrial evidente, onde o estiramento atrial promove lesões no endotélio (HOGAN et al., 2013). A estase sanguínea favorece a agregação plaquetária e a formação do trombo e, em gatos cardiopatas com aumento atrial evidente, a velocidade do fluxo sanguíneo encontrase reduzida no interior da cavidade (RUSH et al., 2002). Em gatos, alguns trabalhos demonstram que a espécie felina tem aumento da sensibilidade plaquetária, além de tendência à hiperagregação plaquetária; relata-se, também, que a espécie felina possui aumento de fatores de coagulação II, V, VII, VIII, IX, XII e fibrinogênio; e diminuição da atividade antitrombina (HOGAN et al., 2013).

Aproximadamente $90 \%$ dos casos de TEAS são secundários a cardiopatias e, em 12 a 17\% destes casos, são secundários à cardiomiopatia hipertrófica (já que esta é a cardiopatia mais comum na espécie) (RUSH et al., 2002; FUENTES, 2012). 


\subsection{MANIFESTAÇÕES CLÍNICAS}

A $\mathrm{CMH}$ é relatada mais frequentemente em gatos machos, mas também acomete fêmeas (FERASIN et al., 2003; GRANSTRÖM et al., 2011). No geral, é mais descrita em animais jovens e de meia idade, com uma média de 5,5 a 6,5 anos. A idade do diagnóstico, no entanto, já foi relatada em filhotes menores de 12 meses e em idosos com mais de 16 anos, tanto em animais assintomáticos quanto sintomáticos (RUSH et al., 2002; CHETBOUL et al., 2006a; FUENTES, 2006; CÔTÉ et al., 2011). Embora incomum, animais de raças geneticamente predispostas podem ser diagnosticados com $\mathrm{CMH}$ com três meses de idade (normalmente gatos homozigotos dominantes da raça Ragdoll) (MEURS et al., 2007; GODIKSEN et al., 2011).

Aproximadamente $33 \%$ a $55 \%$ dos gatos diagnosticados com $\mathrm{CMH}$ são assintomáticos, sem alterações relatadas no histórico clínico (RUSH et al., 2002; CÔTÉ et al., 2011). Muitas vezes, a doença é descoberta após detecção de sopro ou de ritmo de galope, durante a auscultação, numa avaliação de rotina (NELSON; COUTO, 2005) ou devido à detecção de cardiomegalia em avaliação radiográfica não direcionada ao sistema cardiovascular, sendo um achado incidental (CÔTÉ et al., 2011). Gatos com alterações discretas podem permanecer assintomáticos por anos (CHETBOUL et al., 2006a; FUENTES, 2006).

As principais manifestações clínicas observadas incluem alterações respiratórias decorrentes do edema pulmonar, como taquipneia, ofegação, cansaço fácil e dispneia. Dispneia ocorre em $32-46 \%$ dos gatos diagnosticados com $\mathrm{CMH}$ (ATKINS et al., 1992; RUSH et al., 2002; RIESEN et al., 2008). A tosse muitas vezes é confundida com êmese e raramente ocorre em decorrência de cardiomiopatias, já que os gatos possuem poucos receptores de tosse em região bronquioalveolar, não havendo estímulo de tosse mesmo em cardiomegalias importantes (BATY, 2004; WARE, 2007).

Alterações agudas podem ser observadas em gatos sedentários, já que as modificações patológicas ocorrem gradualmente e passam despercebidas nestes animais. Dentre as manifestações agudas, pode haver desenvolvimento de tromboembolismo arterial sistêmico (TEAS) em alguns gatos, episódios de síncope, descompensação respiratória e, ocasionalmente, morte súbita (FOX et al., 1999; 
CÔTÉ et al., 2011). Letargia e anorexia podem ser as únicas evidências da afecção em alguns gatos (BATY, 2004; RIESEN et al., 2008). Estresse decorrente de procedimentos cirúrgicos, anestesias, fluidoterapias e doenças sistêmicas podem desencadear ICC em gatos com $\mathrm{CMH}$ aparentemente compensados. Os eventos estressantes mais relatados são fluidoterapia (28\%), anestesia/cirurgia (25\%) e uso de corticoides (21\%), além de doenças sistêmicas (RUSH et al., 2002).

Conforme já explicado anteriormente, a disfunção diastólica incita o desenvolvimento da insuficiência cardíaca congestiva, visto que as pressões de preenchimento ventricular estão aumentadas, o que se transmite às pressões do átrio esquerdo e veias pulmonares (LINNEY et al., 2014). Se a pressão das veias pulmonares ultrapassar aproximadamente $25 \mathrm{mmHg}$, edema pulmonar cardiogênico e/ou efusão pleural podem ocorrer, decorrentes de insuficiência cardíaca congestiva esquerda (ETTINGER; FELDMAN, 2005; ABBOTT; MCLEAN, 2006; CÔTÉ et al., 2011). A efusão pleural geralmente é classificada como transudato modificado ou de aspecto quiloso.

Geralmente, um gato acometido pela $\mathrm{CMH}$ só é levado ao veterinário quando a doença está em sua fase mais avançada, com sintomatologia respiratória decorrente do edema pulmonar e/ou efusão pleural, incluindo taquipneia e aparecimento súbito de dispneia (ATKINS et al., 1992; FUENTES, 2006).

Em estudo retrospectivo com 260 gatos com $\mathrm{CMH}, 46 \%$ apresentavam dispneia decorrente de edema pulmonar e metade destes pacientes com edema pulmonar também apresentavam efusão pleural associada (RUSH et al., 2002; CÔTÉ et al., 2011).

De acordo com Atkins et al. (1992), a presença de arritmias cardíacas ocorre em cerca de 25 a $40 \%$ dos casos diagnosticados com cardiomiopatia hipertrófica, podendo causar manifestações clínicas associadas como cansaço, dispneia, présíncope, síncope ou morte súbita. 


\subsection{DIAGNÓSTICO}

\subsubsection{Exame físico}

A ocorrência de sopro sistólico é a alteração de exame físico mais comum nos gatos com $\mathrm{CMH}$, presente em 44-72\% dos animais (RUSH et al., 2002; FERASIN et al., 2003; CÔTÉ et al., 2011). O sopro pode ocorrer tanto por regurgitação mitral quanto por obstrução da via de saída de ventrículo esquerdo; apesar de comum, alguns gatos não apresentam sopro, mesmo com hipertrofia ventricular importante (FERASIN, 2009b; PAYNE et al., 2010; WAGNER et al., 2010). Segundo Paige et al. (2009) e Wagner et al. (2010), nem todo gato com sopro apresenta cardiomiopatia e a ausência de sopro não descarta a $\mathrm{CMH}$, pois $69 \%$ dos gatos com $\mathrm{CMH}$ e assintomáticos não apresentavam sopro no estudo realizado por esses grupos de pesquisa.

A intensidade do sopro decorrente de obstrução de via de saída de ventrículo esquerdo varia de acordo com o grau de obstrução. O sopro pode ser discreto ou inaudível em gatos relaxados, principalmente após terapia com betabloqueadores; e pode tornar-se mais forte à medida que ocorre piora da obstrução dinâmica pelo aumento do estímulo simpático (NELSON; COUTO, 2005; WAGNER et al., 2010).

A presença de sopro não é diagnóstico de $\mathrm{CMH}$ em gatos, apresentando uma baixa sensibilidade (31\%) e especificidade (87\%), além de poder ocorrer em outras cardiomiopatias (CÔTÉ et al., 2004; PAIGE et al., 2009; PAYNE et al., 2010; WAGNER et al., 2010). Porém, no estudo de Paige et al. (2009), 31-62\% dos gatos com sopro apresentavam diferentes graus de hipertrofia ventricular e a presença de sopro de grau maior ou igual a três apresentou moderadas especificidade $(70 \%)$ e sensibilidade (61\%) para $\mathrm{CMH}$.

O ritmo de galope é a segunda alteração mais comum no exame físico desses animais com $\mathrm{CMH}$, sendo presente em aproximadamente $33 \%$ dos acometidos, seguido pela taquicardia (26\%) (FERASIN et al., 2003; CÔTÉ et al., 2004). Arritmias cardíacas são relativamente comuns na CMH (ATKINS et al., 1992; CÔTÉ et al., 2011). O som diastólico de galope é caracterizado pela evidenciação da quarta 
bulha (S4) e é principalmente observado quando a insuficiência cardíaca é evidente ou eminente (WARE, 2007; WAGNER et al., 2010).

O pulso femoral geralmente é forte, exceto nos casos de TEAS em porções distais da aorta. Essa variável pode ser pouco perceptível em animais obesos (CÔTÉ et al., 2011).

Gatos com insuficiência cardíaca congestiva podem apresentar taquipneia, dispneia e ortopneia quando em edema pulmonar ou com efusão pleural. Cerca de $36 \%$ dos gatos diagnosticados com $\mathrm{CMH}$ apresentam dispneia no momento do diagnóstico (FERASIN et al., 2003). Aumento de murmúrio vesicular, crepitação e, algumas vezes, cianose, geralmente acompanham os casos de edema pulmonar; a presença de efusão pleural dificulta a auscultação de sons pulmonares, principalmente em áreas ventrais (WARE, 2007).

Em animais sem manifestações de ICC, os achados do exame físico podem ser normais (ATKINS et al., 1992; PAYNE et al., 2010).

\subsubsection{Exame eletrocardiográfico}

Alterações eletrocardiográficas são comuns em animais com $\mathrm{CMH}$ e incluem: alterações indicativas de aumentos atrial e ventricular, taquiarritmias ventriculares ou supraventriculares (menos comuns) e desvio de eixo para a esquerda (TILLEY; GOODWIN, 1995). Fibrilação atrial pode ser observada em alguns gatos; bloqueios fasciculares também podem ser observados, bem como alterações na condução atrioventricular, com bloqueio atrioventricular completo (WARE, 2007).

O eletrocardiograma (ECG) ainda é considerado um método pouco sensível em casos de cardiomiopatia hipertrófica, apesar de 30 a $70 \%$ de gatos diagnosticados com tal afecção apresentarem alguma alteração neste exame (FERASIN et al., 2003; CÔTÉ; JAEGER, 2008). É utilizado para avaliar o ritmo e a condução cardíaca (HARVEY et al., 2005; CÔTÉ; JAEGER, 2008), sendo importante para pacientes com arritmias ou episódios de fraqueza ou síncope (KITTLESON, 2009b). As alterações, quando observadas, são inespecíficas e o exame, ainda que providencie informações, não é capaz de classificar ou confirmar a existência de doenças cardíacas em gatos domésticos (CÔTÉ et al., 2011). 
Em humanos, o ECG é um teste de triagem para detecção de hipertrofia ventricular, sendo um exame rápido e facilmente disponível (RYAN et al., 1995; CASELLI et al., 2009; KILLIAN et al., 2010; BOLIN; LAM, 2013). É utilizado como primeira ferramenta para diagnóstico de condições associadas à morte súbita (PELTO; OWENS; DREZNER, 2013). Alterações eletrocardiográficas na CMH são bastante variáveis e muitas vezes inespecíficas, mas comumente observadas em humanos carreadores de mutação antes mesmo da hipertrofia ventricular (RYAN et al., 1995; KONNO et al., 2005; LAKDAWALA et al., 2011; MATTOS et al., 2013). O ECG, em humanos, pode ser um sensível indicador da doença e uma ferramenta útil para a pesquisa da afecção em indivíduos de famílias acometidas (NAMDAR et al., 2012; NG et al., 2012).

O diagnóstico eletrocardiográfico de hipertrofia ventricular em humanos é baseado no aumento da voltagem dos complexos QRS em diferentes derivações (critério de voltagens) (MURPHY et al., 1985; KONNO et al., 2005; BACHAROVA, 2009). No entanto, estudos revelam baixa sensibilidade do eletrocardiograma e baixa correlação entre a amplitude do QRS e o grau de hipertrofia (BENDER et al., 2012; ROWIN et al., 2012). Porém, a presença de alterações eletrocardiográficas que sugerem hipertrofia ventricular em humanos pode ser considerada um marcador prognóstico e de gravidade, permitindo estratificação de risco (BACHAROVA, 2009).

$\mathrm{Em}$ gatos, poucos estudos foram realizados quanto à sensibilidade e à especificidade do ECG na deteç̧ão de hipertrofia ventricular. Num estudo em felinos com cardiomiopatia dilatada, $\mathrm{CMH}$ ou hipertireoidismo, o ECG indicou incorretamente aumento ventricular em gatos com hipertireoidismo e não detectou, de forma consistente, a presença de sobrecarga em pacientes com $\mathrm{CMH}$. Além disso, o ECG foi um pobre indicador de sobrecarga atrial nos gatos (MOISE et al., 1986). Em outro estudo, ao comparar o ECG com avaliação ecocardiográfica, observou-se que gatos com aumento do átrio esquerdo apresentavam onda $\mathrm{P} e$ intervalo PR com maior duração, com baixa sensibilidade mas alta especificidade (SCHÖBER et al., 2007). 


\subsubsection{Exame radiográfico}

A radiografia torácica é um exame importante por documentar a presença de insuficiência cardíaca congestiva, efusão pleural, edema pulmonar e outras condições não relacionadas ao músculo cardíaco (WARE, 2007; CÔTÉ et al., 2011). Seus resultados variam dependendo da hipertrofia observada, do grau de disfunção miocárdica, da presença de aumento das cavidades cardíacas e da gravidade da congestão circulatória (NELSON; COUTO, 2005; SCHÖBER et al., 2007).

Características radiográficas de $\mathrm{CMH}$ avançada incluem aumento de átrio esquerdo e aumento ventricular esquerdo de grau variável. A aparência clássica de coração em Valentine Shape na projeção ventrodorsal nem sempre está presente, mas é comum nos gatos com CMH com aumento atrial (ETTINGER; FELDMAN, 2005; SCHÖBER et al., 2007). Efusão pericárdica em quantidade moderada pode acentuar a cardiomegalia em alguns gatos. Em casos de $\mathrm{CMH}$ de grau discreto, a silhueta cardíaca praticamente não se altera na avaliação radiográfica (FUENTES, 2006; SCHÖBER et al., 2007).

Vasos pulmonares tortuosos e calibrosos indicam aumento de pressão em átrio e vascularização pulmonar. Nos casos onde há desenvolvimento de edema pulmonar, visibilizam-se áreas focais ou difusas de infiltrado intersticial ou alveolar, não necessariamente em região dorsal e hilar (como ocorre em cães). Efusão pleural também pode ser visibilizada radiograficamente em alguns casos (NELSON; COUTO, 2005; WARE, 2007). Segundo Côté et al. (2011), o edema pulmonar é mais comum que a efusão pleural em gatos com ICC causada pela $\mathrm{CMH}$ (ocorrendo em $22-66 \%$ e $7-34 \%$, respectivamente).

\subsubsection{Exame ecocardiográfico}

O ecocardiograma é o melhor meio diagnóstico não invasivo para a diferenciação de $\mathrm{CMH}$ de outras cardiomiopatias (CHETBOUL et al., 2006a; SIMPSON et al., 2007). A ecocardiografia bidimensional permite observação de áreas de hipertrofia na parede ventricular, septo interventricular ou músculos 
papilares e pode auxiliar na caracterização de anormalidades funcionais sistólicas ou diastólicas (CHETBOUL et al., 2006b; GUNDLER; TIDHOLM; HÄGGSTRÖM, 2008). A hipertrofia geralmente é simétrica, mas pode haver distribuição assimétrica apenas na parede ventricular, no septo ou no músculo papilar (CHETBOUL et al., 2006a; BRIZARD et al., 2009; FERASIN, 2009b).

A ecocardiografia é de grande importância para estabelecer o diagnóstico, porém, apesar das vantagens, esta técnica também apresenta limitações (KITTLESON; KIENLE, 1998; FERASIN, 2009b). A identificação dos quatro componentes básicos desta afecção (hipertrofia, disfunção diastólica, regurgitação mitral e obstrução de via de saída) e a correta interpretação das informações permite abordagens diagnóstica, prognóstica e terapêutica mais adequadas (GRAZIANO; ACQUATELLA, 2007).

A ecocardiografia em modo $M$ permite mensuração de estruturas, auxiliando na detecção de hipertrofia (BONAGURA, 1983; CHETBOUL et al., 2006a; FERASIN, 2009b). Segundo Ware (2007), o limite superior da espessura da parede ventricular esquerda e do septo interventricular na diástole é considerado entre 0,5 a 0,55 cm. Porém, de acordo com Gundler, Tidholm e Häggström (2008) e Wagner et al. (2010), alguns autores só consideram hipertrofia em gatos quando a espessura da parede ventricular esquerda e/ou do septo interventricular ultrapassa 0,6 cm (Figura 3).

Figura 3 - Imagem ecocardiográfica em modo M (corte transversal à altura dos músculos papilares em janela paraesternal direita) demonstrando hipertrofia miocárdica concêntrica simétrica de grau importante

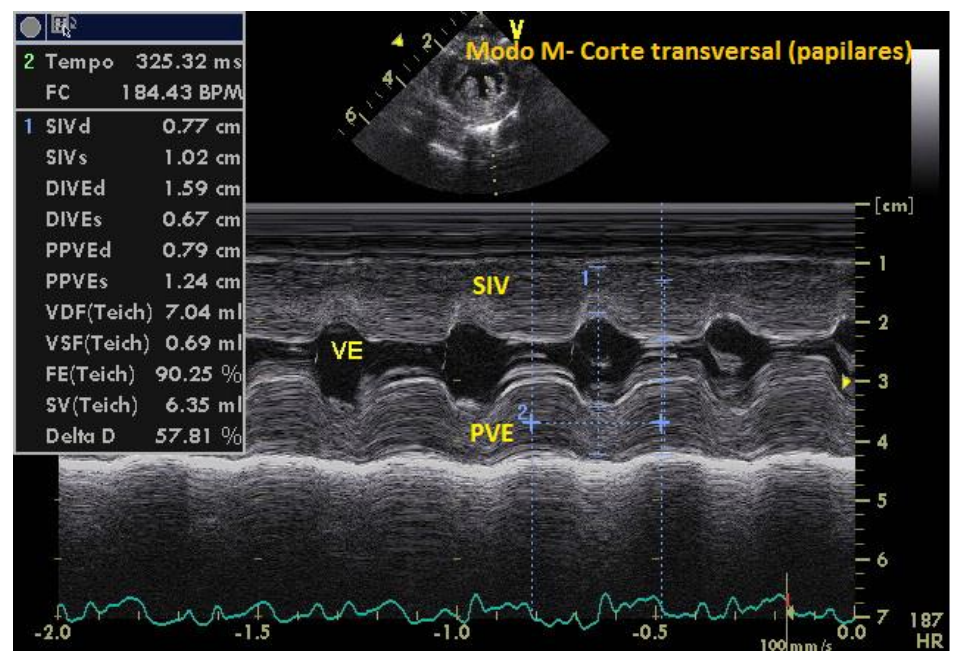

Legenda: PVE: parede livre de ventrículo esquerdo; SIV: septo interventricular; VE: ventrículo esquerdo.

Fonte: Serviço de Cardiologia do VCM/HOVET-USP. Responsável: Profa. Dra. Maria Helena Matiko Akao Larsson. 
O diagnóstico pode ser questionável em gatos com hipertrofia discreta ou focal; além disso, falso aumento na espessura da parede ventricular esquerda e do septo interventricular (pseudo-hipertrofia) pode ocorrer em casos de desidratação e taquicardia (WARE, 2007; GUNDLER; TIDHOLM; HÄGGSTRÖM, 2008).

Gatos com $\mathrm{CMH}$ de grau importante podem apresentar espessura de parede e septo de ventrículo esquerdo de $0,8 \mathrm{~cm}$ ou mais, mas o grau de hipertrofia não é necessariamente correlacionado com a intensidade das manifestações clínicas (FERASIN, 2009b). Hipertrofia de músculos papilares e obstrução sistólica de via de saída de ventrículo esquerdo podem ser observadas em alguns gatos. De acordo com Trehiou-Sechi et al. (2012), em Persas, a forma mais comum da $\mathrm{CMH}$ é a hipertrofia miocárdica septal assimétrica, com aumento da espessura do septo interventricular em região de via de saída do ventrículo esquerdo (região septal basal) (Figura 4). Quando há hipertrofia assimétrica, a mensuração das espessuras deve ser realizada no momento da diástole, utilizando o modo bidimensional ao ecocardiograma (BOON, 2011; CÔTÉ et al., 2011). Aumento de ecogenicidade de músculos papilares e de áreas subendocárdicas podem ser indicativos de isquemia e fibrose miocárdica (GUNDLER; TIDHOLM; HÄGGSTRÖM, 2008; BOON, 2011).

Figura 4 - Imagem ecocardiográfica em modo bidimensional (corte longitudinal de via de saída do ventrículo esquerdo em janela paraesternal direita) demonstrando hipertrofia miocárdica septal assimétrica (em região septal basal)

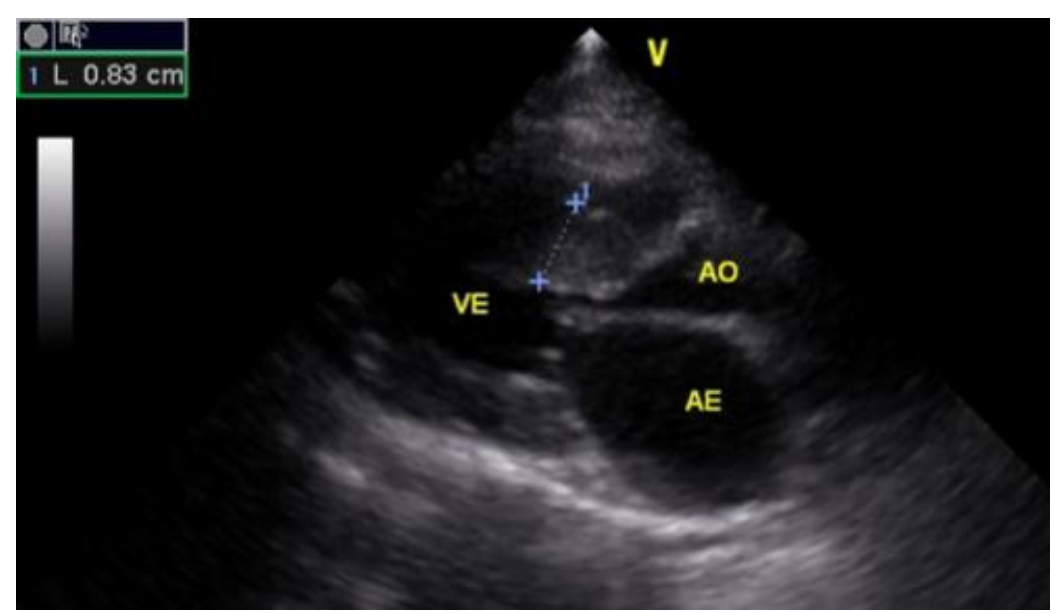

Legenda: AE: átrio esquerdo; AO: artéria aorta; SIV: septo interventricular; VE: ventrículo esquerdo. Fonte: Serviço de Cardiologia do VCM/HOVET-USP. Responsável: Profa. Dra. Maria Helena Matiko Akao Larsson. 
A fração de encurtamento (FS) do ventrículo esquerdo geralmente apresentase normal a aumentada, mas alguns gatos apresentam dilatação ventricular discreta a moderada e redução na contratilidade (BOON, 2011; CÔTÉ et al., 2011). Aumento ventricular direito, efusão pleural e efusão pericárdica podem ser observados em alguns casos (NELSON; COUTO, 2005).

Avaliação da função diastólica por meio da modalidade Doppler, como avaliação de fluxo mitral, fluxo em veias pulmonares e TRIV, geralmente é utilizada (SOUSA, 2007; WARE, 2007; NAGUEH et al., 2009). Porém, as velocidades espectrais do Doppler são determinadas não apenas pelas propriedades diastólicas intrínsecas do miocárdio, mas também por condições de carga, frequência cardíaca, função ventricular sistólica, intervalo de condução atrioventricular, restrição pericárdica, e outras variáveis hemodinâmicas (FOX et al., 1999; SCHÖBER, 2003).

Alterações no fluxo mitral decorrente de $\mathrm{CMH}$ incluem redução na velocidade máxima de enchimento ventricular rápido (onda $\mathrm{E}$ ), aumento no tempo de desaceleração da onda $E$, aumento na velocidade máxima de enchimento ventricular lento (onda A- contração atrial), redução na relação E/A (Figura 5) e aumento no TRIV (Figura 6). O pico da onda A é maior que o da onda $E$ em alguns casos. Estas modificações no fluxo mitral são consistentes com retardo no relaxamento miocárdico. Fluxo mitral pseudonormal pode ocorrer frente à função diastólica anormal, pois quando a rigidez ventricular causa aumento de pressão no átrio esquerdo, também há aumento na velocidade de enchimento rápido. O padrão pseudonormal é uma transição entre alteração de relaxamento ventricular e padrão restritivo (SOUSA, 2007; WARE, 2007; NAGUEH et al., 2009). Fluxo venoso pulmonar anormal pode auxiliar na diferenciação entre padrão pseudonormal e fluxo mitral normal (Figura 7). O padrão restritivo é caracterizado por diminuição no TRIV, onda $E$ mitral alta e onda A mitral baixa (SOUSA, 2007; NAGUEH et al., 2009). Nos gatos, muitas vezes o fluxo mitral apresenta uma fusão das ondas $E$ e $A$, em decorrência da alta frequência cardíaca, dificultando sua avaliação (DISATIAN; BRIGHT; BOON, 2008). Além disso, a proximidade entre estas duas ondas exige a necessidade do uso do registro eletrocardiográfico simultâneo e sobreposto à imagem Doppler, para diferenciação precisa (DISATIAN; BRIGHT; BOON, 2008; BOON, 2011). 
Figura 5 - Imagem ecocardiográfica de Doppler pulsado do fluxo transmitral demonstrando padrão de disfunção diastólica, caracterizado por alteração no relaxamento ventricular

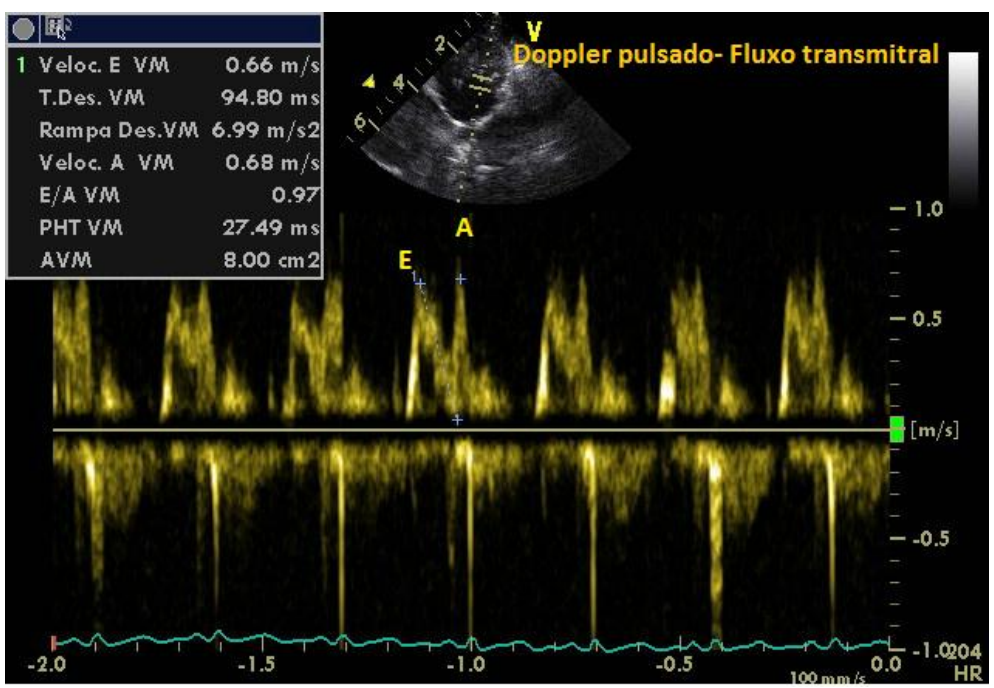

Legenda: A: velocidade máxima de enchimento ventricular lento (onda A); E: velocidade máxima de enchimento ventricular rápido (onda $\mathrm{E}$ ).

Fonte: $\quad$ Serviço de Cardiologia do VCM/HOVET-USP. Responsável: Profa. Dra. Maria Helena Matiko Akao Larsson.

Figura 6 - Imagem ecocardiográfica de Doppler pulsado demonstrando tempo de relaxamento isovolumétrico aumentado, comumente observado na disfunção diastólica

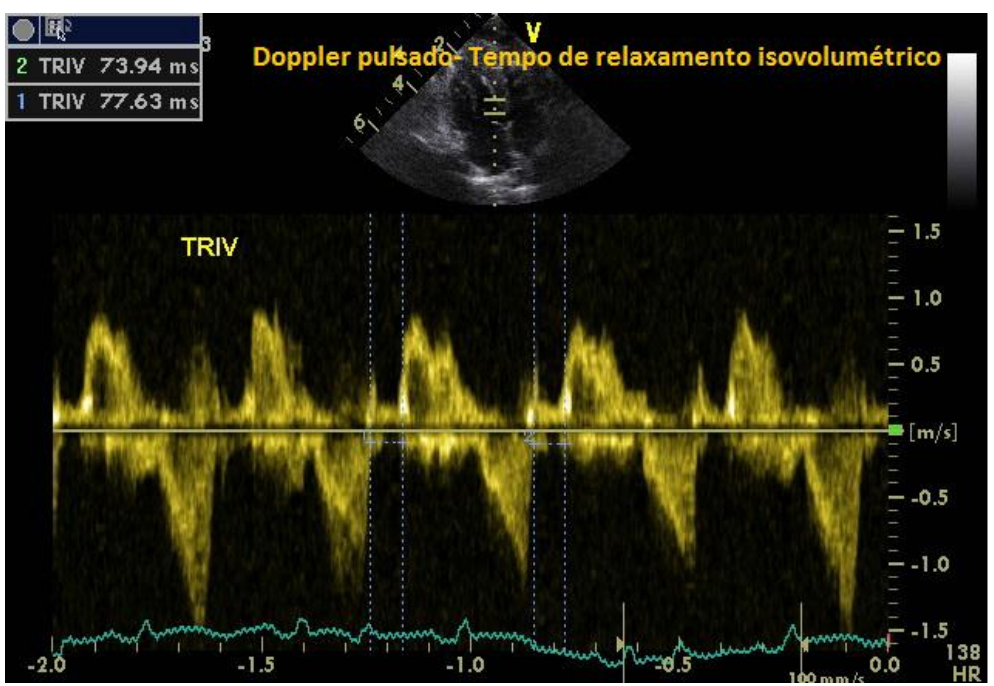

Legenda: TRIV: tempo de relaxamento isovolumétrico.

Fonte: Serviço de Cardiologia do VCM/HOVET-USP. Responsável: Profa. Dra. Maria Helena Matiko Akao Larsson. 
Figura 7 - Avaliação da função diastólica por meio de Doppler pulsado do fluxo transmitral, fluxo venoso pulmonar e Doppler tecidual pulsado. Formas para diferenciação entre padrão de alteração de relaxamento do ventrículo esquerdo, padrão pseudonormal e padrão restritivo de disfunção diastólica

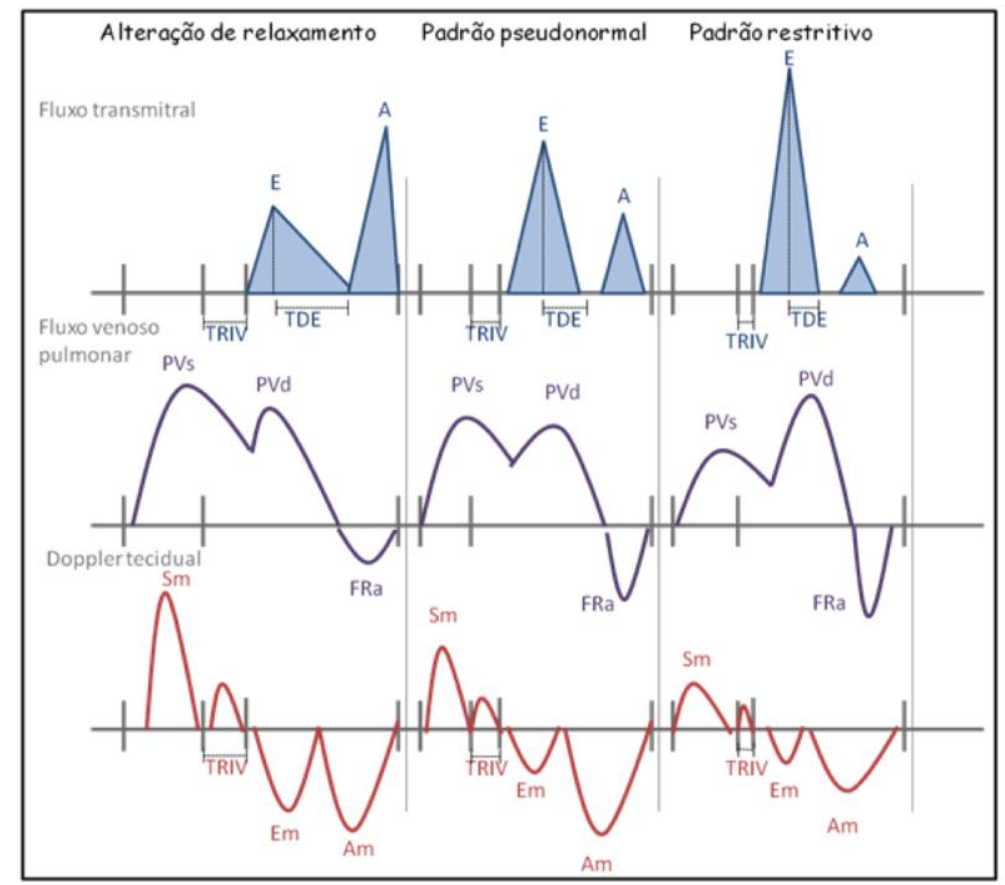

Legenda: A: enchimento ventricular lento (onda A); Am: enchimento ventricular lento (onda $A m$ ) avaliado pelo Doppler tecidual; E: enchimento ventricular rápido (onda E); Em: enchimento ventricular rápido avaliado pelo Doppler tecidual (onda Em); FRa: fluxo retrógrado atrial; PVd: fluxo venoso pulmonar diastólico; PVs: fluxo venoso pulmonar sistólico; Sm: onda sistólica avaliada pelo Doppler tecidual; TDE: tempo de desaceleração da onda E; TRIV: tempo de relaxamento isovolumétrico.

Fonte: (PELLEGRINO, A., 2014).

Com a obstrução dinâmica da via de saída do ventrículo esquerdo, o movimento anterior sistólico mitral (MAS) ou o fechamento parcial da valva aórtica podem ser visibilizados na ecocardiografia modo M (FOX et al., 1999). $\mathrm{Na}$ modalidade Doppler, pode-se detectar insuficiência valvar mitral e aumento na velocidade do fluxo de saída do ventrículo esquerdo (Figura 8) (NELSON; COUTO, 2005; WARE, 2007). 
Figura 8 - Imagem ecocardiográfica de Doppler colorido demonstrando insuficiência valvar mitral e obstrução de via de saída do ventrículo esquerdo

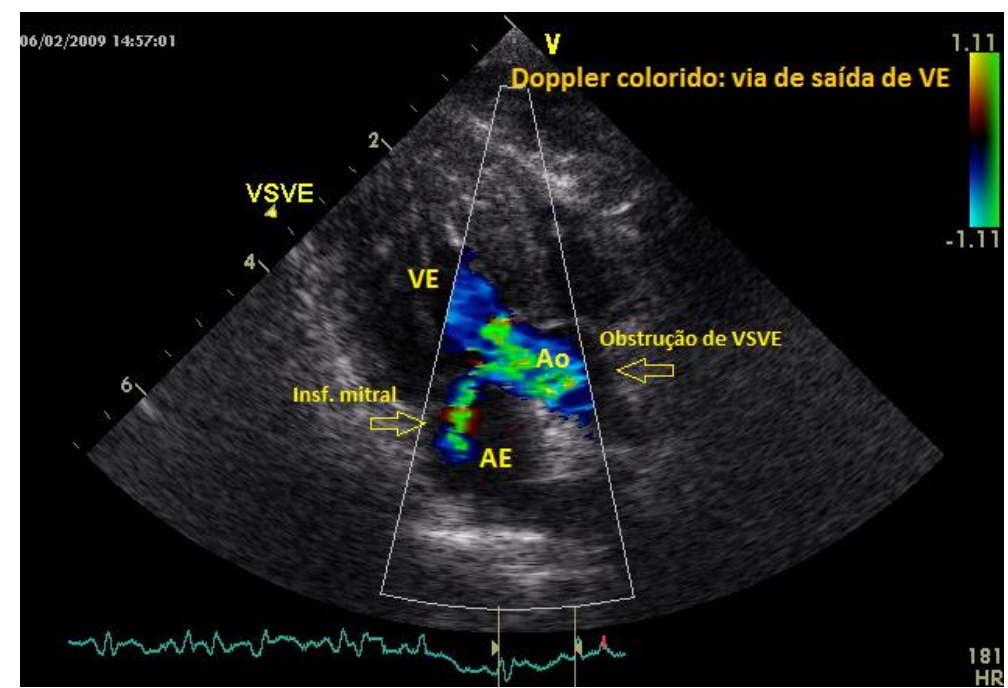

Legenda: AE: átrio esquerdo; Ao: aorta; Insf.: insuficiência; VE: ventrículo esquerdo; VSVE: via de saída do ventrículo esquerdo.

Fonte: $\quad$ Serviço de Cardiologia do VCM/HOVET-USP. Responsável: Profa. Dra. Maria Helena Matiko Akao Larsson.

A obstrução da via de saída do ventrículo esquerdo é devida ao movimento anterior sistólico da valva mitral (MAS) na maioria dos pacientes humanos (>95\%). Nos outros $5 \%$, a obstrução geralmente é medioventricular, com padrão definido por meio do Doppler contínuo (GRAZIANO; ACQUATELLA, 2007).

A velocidade máxima do fluxo é detectada na região do MAS; e o Doppler contínuo permite mostrar o padrão de fluxo típico da CMH obstrutiva (GRAZIANO; ACQUATELLA, 2007; BOON, 2011). Uma elevação da velocidade inicial é seguida de um aumento progressivo até a mesotelessístole, aumento este que pode coincidir com o começo do contato mitral com o septo. O padrão em forma de "adaga" é o mais frequente, mas não é o único, já que alguns apresentam padrões simétricos similares aos da estenose aórtica valvar fixa (GUNDLER; TIDHOLM; HÄGGSTRÖM, 2008; CÔTÉ et al., 2011). Cerca de 4 a 10\% dos pacientes apresentam obstrução medioventricular, com padrão de fluxo da via de saída de ventrículo esquerdo ao Doppler contínuo muito perfilado e menos agudo que o padrão clássico; e este padrão pode indicar maior risco de síncope e morte súbita em humanos (GRAZIANO; ACQUATELLA, 2007).

O aumento atrial varia de discreto a importante (Figura 9), e a parede atrial também pode apresentar-se espessada (SCHÖBER et al., 2007; LINNEY et al., 
2014). Segundo Linney et al. (2014), gatos com CMH apresentam maior diâmetro e volume do átrio esquerdo e menor função atrial em consequência à disfunção diastólica, sendo estas alterações mais evidentes e de maior intensidade nos gatos com CMH e ICC quando comparados aos assintomáticos, permitindo estratificação de risco. Formação de contraste espontâneo (smoke ou autocontraste) ocorre em alguns gatos com átrio esquerdo bastante aumentado (RUSH et al., 2002). Isto é resultado da estase sanguínea, o que predispõe à agregação celular e à formação de trombos. Pode haver visibilização de trombos no interior do átrio, principalmente na aurícula esquerda (RUSH et al., 2002; HOGAN et al., 2013).

Figura 9 - Imagem ecocardiográfica em modo bidimensional (corte transversal à altura dos grandes vasos em janela paraesternal direita), demonstrando aumento atrial esquerdo de grau importante

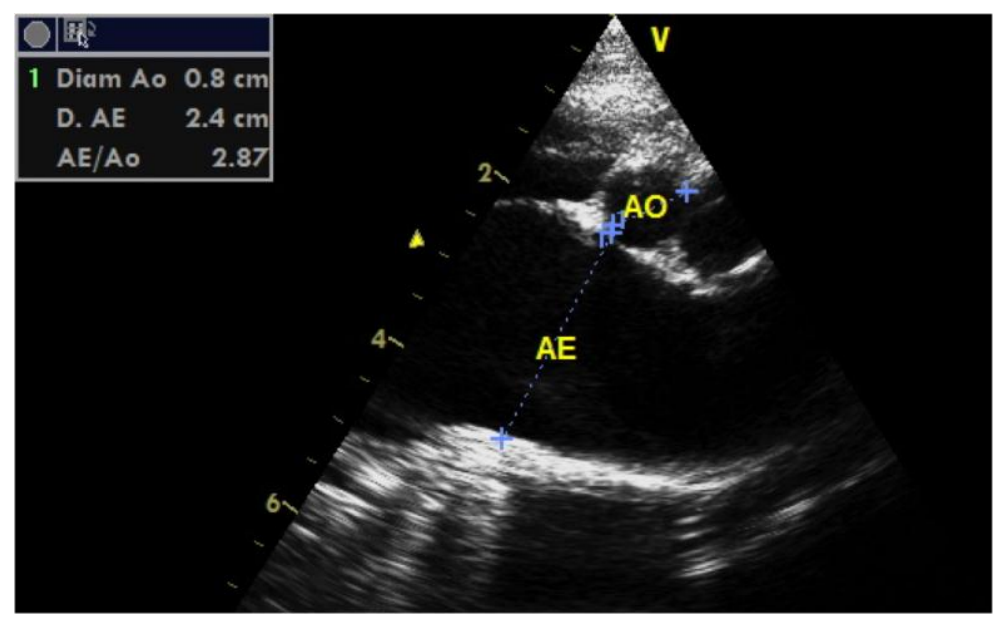

Legenda: AE: átrio esquerdo; $\mathrm{AO}$ : artéria aorta.

Fonte: Serviço de Cardiologia do VCM/HOVET-USP. Responsável: Profa. Dra. Maria Helena Matiko Akao Larsson

A função sistólica encontra-se normal a aumentada (estado hiperdinâmico) na maioria dos gatos com $\mathrm{CMH}$, mas podem existir áreas focais ou regionais com a contratilidade reduzida, o que exige uma avaliação ecocardiográfica mais minuciosa (SAMPEDRANO et al., 2006; FERASIN, 2009b). Em estágios finais da $\mathrm{CMH}$, onde se observam alterações consistentes com patofisiologia restritiva ou características que se assemelham à CMD ou à CMR, o ventrículo pode se apresentar dilatado e hipocinético e a disfunção sistólica torna-se evidente (SCHÖBER; FUENTES; BONAGURA, 2003; BOON, 2011). Aumento ventricular direito, efusão pleural e 
efusão pericárdica também podem ser observados em alguns casos (FERASIN, 2009b; BOON, 2011).

\subsubsection{Exame ecocardiográfico tecidual}

A modalidade Doppler tecidual compõe um conjunto de novas técnicas, baseadas no fenômeno "Doppler", que permite a avaliação da velocidade miocárdica (KOFFAS et al., 2003; MCDONALD et al., 2006b; SIMPSON et al., 2007). Trata-se de modalidade que complementa a avaliação convencional, permitindo a análise dos sinais provenientes do miocárdio, quantificando e avaliando sua movimentação, por meio do cálculo instantâneo de sua velocidade, em qualquer ponto específico do músculo cardíaco (FIRSTENBERG at al., 2001, NAGUEH at al., 2001; RUAN et al., 2006). É um dos métodos não invasivo mais sensível e específico para a avaliação de disfunções sistólicas ou diastólicas, sem apresentar influências de pré ou póscarga (OKI et al., 2000; MCDONALD et al., 2007); e é capaz de revelar alterações nas velocidades miocárdicas em cardiopatas (OYAMA, 2004; TESHIMA, 2005; WESS; SARKAR; HARTMANN, 2010; GANDJBAKHCH et al., 2012).

O Doppler tecidual é preferível à ecocardiografia convencional para avaliação de disfunção diastólica em algumas fases da CMH em gatos (GAVAGHAN et al., 1999; KOFFAS et al., 2003). Não é uma modalidade necessária para o diagnóstico de $\mathrm{CMH}$, mas pode auxiliar com informações adicionais em pacientes com suspeita de $\mathrm{CMH}$, em raças predispostas geneticamente, ou como ferramenta para avaliar a progressão (OKI et al., 2000; MCDONALD et al., 2007). Alguns estudos com uso de ecocardiografia na modalidade Doppler tecidual demonstraram que gatos com $\mathrm{CMH}$ apresentam diminuição das velocidades miocárdicas sistólicas e diastólicas, diminuição nos gradientes de velocidade, perda de uniformidade do movimento miocárdico (KOFFAS et al., 2006) e prolongamento do TRIV quando comparados com gatos normais (KOFFAS et al., 2008). Segundo Chetboul et al. (2006b), o Doppler tecidual é capaz de identificar disfunção ventricular longitudinal, nos gatos com $\mathrm{CMH}$, por diminuição na velocidade de $\mathrm{Em}$, aumento na velocidade de $\mathrm{Am}$ e presença de contrações pós-sistólicas. 
Gavaghan et al. (1999) mostraram que os índices de função diastólica em gatos com $\mathrm{CMH}$ e muitos com cardiomiopatia restritiva (CMR) diferem dos de gatos normais, sendo similares aos relatados em humanos com $\mathrm{CMH}$ e CMR.

Segundo Sampedrano et al. (2006), a disfunção diastólica observada em gatos com $\mathrm{CMH}$ e em gatos com hipertensão arterial não pode ser diferenciada por meio do Doppler tecidual. Porém, o mesmo foi capaz de detectar anormalidades sistólicas e diastólicas nos segmentos de parede ventricular esquerda antes do desenvolvimento de hipertrofia, em ambos os grupos.

Segundo Simpson et al. (2008), gatos com hipertrofia causada pela $\mathrm{CMH}$ apresentaram menores valores de Em em diversas regiões do miocárdio; e gatos com hipertrofia secundária ao hipertireoidismo apresentaram aumento nas velocidades de Sm, auxiliando na diferenciação entre as duas afecções.

Estudos recentes demonstraram que a velocidade miocárdica diastólica precoce $(E m)$ no anel mitral (Doppler tecidual), é menor em Maine Coons homozigotos para a mutação em relação aos heterozigotos; e nestes em relação aos normais. Porém, no estudo de Sampedrano et al. (2009), o genótipo heterozigoto não esteve sempre associado à hipertrofia miocárdica ou a alterações diastólicas importantes; e os gatos sem a mutação também desenvolveram hipertrofia, sugerindo outras causas genéticas envolvidas.

Uma diminuição significativa na relação $\mathrm{Em} / \mathrm{Am}$ do segmento basal do septo interventricular foi observada em gatos Maine Coons heterozigotos para a mutação e sem hipertrofia, quando comparados com gatos normais sem hipertrofia, o que confirma a associação do genótipo heterozigoto com alterações regionais na função diastólica (SAMPEDRANO et al., 2009). Segundo o estudo de McDonald et al. (2007), que avaliou parâmetros de Doppler tecidual em gatos da raça Maine Coon normais ou portadores de mutação com ou sem hipertrofia ventricular, os valores de velocidade de Em (região do anel mitral) sofrem redução de acordo com presença ou ausência de hipertrofia. Porém, o Doppler tecidual, isoladamente, não foi capaz de identificar os gatos geneticamente afetados.

A análise miocárdica pelo método do strain é nova e ainda pouco aplicada em gatos. Porém, segundo Wess, Sarkar e Hartmann (2010), é um método confiável, com boa repetibilidade, permitindo a detecção precoce de disfunção sistólica em determinadas fases da $\mathrm{CMH}$ felina. Em estudo realizado com gatos normais e gatos em diferentes estágios da $\mathrm{CMH}$, apesar da ecocardiografia convencional demonstrar 
estado normal ou aumentado de contratilidade (com base nas frações de ejeção e encurtamento), o strain foi significativamente menor em todos os animais com hipertrofia, quando comparados com os normais, demonstrando que a deformidade sistólica já se encontra alterada mesmo em fases iniciais da $\mathrm{CMH}$. Além disso, verificou-se correlação negativa entre valores de strain e espessura de septo e parede ventricular.

\subsubsection{Exames laboratoriais}

Testes laboratoriais, incluindo perfil hematológico, bioquímico (avaliação hepática, renal e dosagem de eletrólitos), exame de urina e dosagem de hormônio tireoidiano (T4 total), também são realizados para afastar possíveis diagnósticos diferenciais e monitorar efeitos colaterais de medicamentos utilizados nos tratamentos (CONNOLLY, 2008; CÔTÉ et al., 2011).

Discreto aumento de enzimas hepáticas (como alanina aminotransferase ou aspartato aminotransferase) ocorrem em aproximadamente $70 \%$ dos gatos com $\mathrm{CMH}$, segundo o estudo de Rush et al. (2002). O mesmo estudo não demonstrou diferenças nos valores de ureia e creatinina séricas entre gatos com $\mathrm{CMH}$ assintomáticos, em ICC ou com TEAS antes do início do tratamento.

Gatos com azotemia devem ser avaliados antes da introdução da terapia para ICC (RUSH et al., 2002). Porém, antes de classificar o paciente como doente renal, há necessidade de realização de exame de urina (avaliação da densidade e sedimentos urinários) e exclusão de causas pré-renais de azotemia (como a própria ICC, hipotensão, desidratação ou uso de medicamentos) (CÔTÉ et al., 2011).

O hemograma completo é importante para avaliar presença de anemia, já que gatos anêmicos apresentam piora na sobrecarga ventricular (alteração em précarga), o que contribui com a insuficiência cardíaca e com o aparecimento de arritmias em gatos com CMH importante e disfunção diastólica (CONNOLLY et al., 2008; CÔTÉ et al., 2011).

A dosagem do hormônio tireoidiano T4 total é fundamental em pacientes de meia idade a idosos que apresentam evidência de hipertrofia miocárdica concêntrica ao ecocardiograma, já que o hipertireoidismo é uma causa secundária de hipertrofia 
ventricular e faz parte do diagnóstico diferencial (FERASIN, 2009a; CÔTÉ et al., 2011).

Os biomarcadores cardíacos também podem ser incluídos na avaliação das cardiomiopatias, auxiliando no diagnóstico. Biomarcadores são substâncias encontradas no sangue e que são capazes de indicar lesões e/ou necrose de miócitos (marcadores de lesão), além da avaliação da função cardíaca (marcadores de função). Tais substâncias facilitam a classificação da doença cardíaca e especificam a fase em que esta se encontra, sendo um método pouco invasivo (CONNOLLY et al., 2008; LANGHORN ${ }^{1}$ et al., 2014).

Dentre os marcadores de função cardíaca, encontram-se o peptídeo natriurético atrial (ANP) e o peptídeo natriurético cerebral (NT-pro BNP). Os peptídeos natriuréticos são neuro-hormônios produzidos nas câmaras cardíacas e liberados na circulação em resposta ao estiramento ou sobrecarga miocárdica (CONNOLLY et al., 2008). A dosagem de NT-pro BNP é um teste sensível e acurado para a detecção de insuficiência cardíaca em gatos com cardiomiopatias (FOX et al., 2011); e pode ser utilizado para auxiliar na diferenciação de dispneia por causa cardíaca ou por causas respiratórias (CÔTÉ et al., 2011; FOX et al., 2011). Apesar de ser útil no diagnóstico de cardiomiopatia em pacientes assintomáticos, a dosagem de NT-pro-BNP também pode gerar resultados falsos-positivo e falsosnegativo (CONNOLLY et al., 2008).

De acordo com Fox et al. (2011), ao avaliar 140 gatos normais ao ecocardiograma e 113 gatos com CMH assintomática, o NT-pro-BNP foi maior nos animais com $\mathrm{CMH}$ em relação aos normais; e os valores de NT-pro-BNP foram maiores nos animais com a forma obstrutiva da afeção. Além disso, observou-se correlação positiva entre valores de NT-pro-BNP, espessura miocárdica e tamanho atrial esquerdo, permitindo a utilização do teste para inferir sobre a gravidade da afecção.

Dentre os biomarcadores cardíacos caracterizados como marcadores de lesão, encontram-se as troponinas cardíacas e as endotelinas (CONNOLLY et al., 2003; CONNOLLY et al., 2008; CÔTÉ et al., 2011). As troponinas são proteínas componentes do aparelho contrátil das células do músculo cardíaco e aumentam em

\footnotetext{
${ }^{1}$ LANGHORN, R. et al. Cardiac troponin I and T as prognostic markers in cats with hypertrophic cardiomyopathy. 2014 (a ser publicado no Journal of Veterinary Internal Medicine).
} 
situações de lesão miocárdica (marcador de isquemia e fibrose) (CÔTÉ et al., 2011). As endotelinas são peptídeos com potente capacidade vasoconstritora, são produzidas no endotélio dos vasos sanguíneos e são consideradas biomarcadores de lesão cardíaca de valor moderado em cães e gatos (CONNOLLY, 2008).

\subsubsection{Testes genéticos}

A CMH apresenta componente familial já estabelecido em animais das raças Maine Coon e Ragdoll (KITTLESON et al., 1999; MEURS et al., 2005; MEURS et al., 2007). Nestas duas raças, a CMH apresenta padrão de herança autossômica dominante (MEURS et al., 2005; MEURS et al., 2007; BORGEAT et al., 2014). Desta forma, ao avaliar o pedigree dessas famílias, espera-se encontrar tanto machos quanto fêmeas acometidos (já que não se trata de uma herança ligada a cromossomos sexuais); e os indivíduos fenotipicamente afetados podem ser tanto heterizogotos (apenas uma cópia da mutação) ou homozigotos (duas cópias da mutação) (KEREN; SYRRIS; MCKENNA, 2008; KIMURA, 2008; GODIKSEN et al., 2011; LONGERI et al., 2013).

Nos casos de herança autossômica recessiva, animais heterozigotos não apresentariam a afecção, mas poderiam passar a mutação aos seus descendentes. Para que ocorresse a manifestação fenotípica, haveria necessidade da presença das duas cópias da mutação (indivíduos homozigotos) (KEREN; SYRRIS; MCKENNA, 2008; KIMURA, 2008). Ao avaliar o pedigree de gatos afetados por doença de herança autossômica recessiva, machos e fêmeas seriam igualmente acometidos; e a afecção pode não se manifestar em algumas gerações. No cruzamento entre indivíduos heterozigotos, esperar-se-ia encontrar 25\% de animais fenotipicamente acometidos (CÔTÉ et al., 2011).

Já nas doenças com herança genética ligada ao cromossomo $X$ sexual, geralmente de caráter recessivo, machos com a mutação sempre seriam acometidos; e fêmeas poderiam ser portadoras da mutação (heterozigotas), acometidas (homozigotas) ou normais (KEREN; SYRRIS; MCKENNA, 2008; KIMURA, 2008). Na análise do pedigree da família, os machos seriam mais acometidos que as fêmeas (CÔTÉ et al., 2011). 
Além dos tipos de herança genética possíveis, deve-se avaliar o grau da penetrância genética da mutação (KEREN; SYRRIS; MCKENNA, 2008; KIMURA, 2008; MARSIGLIA, 2013). A penetrância determina o quanto a presença da mutação pode acometer o indivíduo. Assim, quando a penetrância de determinada mutação é incompleta ou variável (como ocorre na $\mathrm{CMH}$ ), nem todos os indivíduos acometidos irão manifestar a doença e, nos que manifestam, a afeção pode se apresentar com diferentes graus de gravidade (GODIKSEN et al., 2011; BORGEAT et al., 2014). O mecanismo de penetrância genética não é completamente conhecido, inclusive na medicina humana, mas existem fatores ambientais e genéticos envolvidos (KEREN; SYRRIS; MCKENNA, 2008; KIMURA, 2008; CÔTÉ et al., 2011; MARSIGLIA et al., 2014).

Duas mutações no gene da proteína C miosina ligante (MYBPC3) foram identificadas como causa da $\mathrm{CMH}$ familial nas raças Maine Coon e Ragdoll (GODIKSEN et al., 2011). Cada raça apresenta uma mutação exclusiva neste gene, que não é observada em outras raças de gatos avaliadas, conforme já mencionado anteriormente (KITTLESON et al., 1999; MEURS et al., 2005; MEURS et al., 2007). As mutações resultam em troca de um aminoácido conservado, alterando a conformação proteica da proteína C miosina ligante (MYBPC3). A penetrância destas mutações é incompleta e, portanto, alguns gatos positivos podem carrear a mutação sem desenvolver o fenótipo de hipertrofia ventricular (GODIKSEN et al., 2011). Por outro lado, alguns gatos das raças Maine Coon e Ragdoll apresentam $\mathrm{CMH}$ e são negativos para estas mutações, ou seja, existem outras mutações que causam a $\mathrm{CMH}$ familial nessas raças (MEURS et al., 2005; MEURS et al., 2007; FRIES; HEANEY; MEURS, 2008).

O diagnóstico ante-mortem da cardiomiopatia hipertrófica é baseado no ecocardiograma (CHETBOUL et al., 2006a; SIMPSON et al., 2007), que é o padrão ouro na detecção de hipertrofia ventricular (FERASIN, 2009b). Os programas de mapeamento da $\mathrm{CMH}$ por meio do ecocardiograma podem classificar os gatos como: livres da afeção (normais quanto à $\mathrm{CMH}$ ); suspeitos (grey zone); ou acometidos pela $\mathrm{CMH}$. Como a $\mathrm{CMH}$ ocorre principalmente em animais adultos e a faixa etária de acometimento é muito variável, inclusive numa mesma raça, há necessidade de reavaliações anuais preferencialmente até os 10 anos de idade para maior acurácia de resultado negativo (CÔTÉ et al., 2011; CHETBOUL et al., 2012).

Gatos de raças predispostas com exame ecocardiográfico normal, sem sopro 
ou ritmo de galope à auscultação, sem arritmias ao eletrocardiograma, podem ser considerados livres da CMH no momento da avaliação (FERASIN, 2009b), mas recomenda-se avaliação cardiológica anual (CÔTÉ et al., 2011).

Gatos que apresentam algumas alterações cardíacas, incluindo presença de sopro apesar de ecocardiograma normal, ou apresentando alterações ecocardiográficas que não descartam a $\mathrm{CMH}$, são considerados suspeitos para a afecção e devem ser momentaneamente retirados dos programas de cruzamentos. Nestes animais, recomenda-se reavaliação ecocardiográfica a cada seis meses até que se obtenha uma conclusão de seu diagnóstico (FUENTES, 2006; CÔTÉ et al., 2011).

Sabendo-se do caráter genético da $\mathrm{CMH}$, gatos acometidos devem ser retirados dos programas de reprodução e seus irmãos e filhos devem ser incluídos na avaliação ecocardiográfica de pesquisa da afecção (CÔTÉ et al., 2011; GODIKSEN et al., 2011).

Para a realização do teste genético de pesquisa das mutações relacionadas à $\mathrm{CMH}$, há necessidade de obtenção de amostras de DNA, que podem ser obtidas por sangue total (armazenado em tubo contendo EDTA) ou por material proveniente da mucosa oral (uso de swab) (MEURS et al., 2005; MARSIGLIA et al., 2014). O DNA extraído é, então, submetido a reações de sequenciamento (padrão ouro) para a identificação das mutações já conhecidas na espécie felina (MEURS et al., 2005; MEURS et al., 2007). O teste genético pode demonstrar resultado negativo (o gato não apresenta a mutação na região avaliada), heterozigoto ou homozigoto (GODIKSEN et al., 2011). A presença de um resultado negativo não exclui a chance do animal apresentar $\mathrm{CMH}$, pois existem outras mutações envolvidas que podem desencadear a afeção e que ainda não estão identificadas (MEURS et al., 2005; FRIES; HEANEY; MEURS, 2008; MARSIGLIA et al., 2014).

Segundo Fries, Heaney e Meurs (2008), aproximadamente 35\% das amostras de Maine Coons submetidas à análise genética são positivas para a mutação (com apenas $9 \%$ de homozigotos); enquanto que cerca de $28 \%$ das amostras de Ragdolls são positivas (com apenas $8 \%$ de homozigotos). Estes resultados demonstram 0 quão prevalente são as mutações nestas raças e o quanto é necessária a modificação nos programas de cruzamentos.

Para a organização dos programas de cruzamentos, os animais homozigotos (que apresentam maior risco de desenvolver formas mais agressivas da $\mathrm{CMH}$, 
principalmente o Ragdoll) devem ser retirados da reprodução (GODIKSEN et al., 2011; LONGERI et al., 2013; BORGEAT et al., 2014). Em relação aos heterozigotos, uma avaliação mais detalhada pode ser realizada antes da exclusão destes animais do plantel reprodutivo (GODIKSEN et al., 2011). Gatos heterozigotos que apresentam características raciais desejadas e marcantes e que não apresentam o fenótipo da $\mathrm{CMH}$ na idade reprodutiva poderiam ser submetidos a cruzamento com um indivíduo negativo para a mutação. A ausência da doença no momento da idade reprodutiva pode sugerir que, caso o indivíduo heterozigoto venha a apresentar a $\mathrm{CMH}$, a mesma seja branda. Este tipo de reprodução deve ser evitada e apenas utilizada em situações excepcionais. Caso o mesmo animal venha a desenvolver $\mathrm{CMH}$ à medida que avança sua idade, deve ser retirado da reprodução (CÔTÉ et al., 2011; GODIKSEN et al., 2011).

\subsubsection{Diagnóstico diferencial}

A cardiomiopatia hipertrófica é caracterizada por hipertrofia miocárdica concêntrica primária, ou seja, na ausência de causas secundárias de hipertrofia ventricular (CHETBOUL et al., 2006a; MCDONALD et al., 2007; CÔTÉ et al., 2011).

Hipertensão arterial sistêmica e hipertireoidismo são as principais causas de hipertrofia miocárdica felina secundária, sendo que ambas devem ser excluídas para que se possa fazer o diagnóstico de CMH idiopática (NUNEZ et al., 2004; SAMPEDRANO et al., 2006; SIMPSON et al., 2008). Outras causas secundárias de hipertrofia ventricular, embora menos frequentes, incluem a estenose aórtica e a acromegalia (MCDONALD et al., 2006a; CÔTÉ et al., 2011). A nefropatia também deve ser considerada durante o diagnóstico de $\mathrm{CMH}$, já que pacientes com doença renal podem desenvolver hipertensão e podem se apresentar desidratados, levando à hipertrofia ventricular secundária (NUNEZ et al., 2004; CÔTÉ et al, 2011).

A hipovolemia e/ou a desidratação moderada a grave diminui o tamanho da câmara ventricular esquerda, gerando o aparente espessamento da parede do ventrículo, fenômeno nominado de "pseudo-hipertrofia" (CAMPBELL; KITTLESON, 2007), que também deve fazer parte do diagnóstico diferencial de $\mathrm{CMH}$. 
Outras causas de hipertrofia miocárdica devem ser excluídas antes do diagnóstico de $\mathrm{CMH}$ (OKI et al., 2000), como doenças miocárdicas infiltrativas, ou alterações na ecogenicidade e presença de irregularidades na parede decorrentes de outras cardiomiopatias.

\subsection{PROGNÓSTICO}

O prognóstico de gatos com $\mathrm{CMH}$ é variável e é influenciado por fatores como resposta à terapia, ocorrência ou não de eventos tromboembólicos, progressão da doença e desenvolvimento de arritmias (FOX, 2003; PAYNE et al., 2013; SCHÖBER et al., 2013). Gatos machos, jovens e de raças puras (principalmente Ragdoll) tendem a apresentar alterações mais graves e de evolução clínica mais rápida (PAYNE et al., 2010; BORGEAT et al., 2014).

Gatos clinicamente normais, com hipertrofia ventricular discreta a moderada e aumento de átrio esquerdo, geralmente vivem bem por anos (PAYNE et al., 2010). Porém, hipertrofia ventricular importante, aumento atrial marcante, pacientes idosos, fibrilação atrial, efusão pleural e TEAS estão associados com pior prognóstico (BATY, 2004; PAYNE et al., 2013). Gatos com TEAS geralmente apresentam sobrevida inferior a seis meses. Alguns vivem bem por certo tempo, quando há controle dos sinais congestivos e quando não há infarto em órgãos vitais, porém a recorrência de TEAS é comum (WARE, 2007).

Num estudo com 260 gatos com $\mathrm{CMH}$, o tempo médio de sobrevida foi de 1129 dias em gatos assintomáticos, de 563 dias em gatos com ICC e de 184 dias em gatos com TEAS (RUSH et al., 2002). Em outro estudo com 74 gatos com $\mathrm{CMH}$, a média de sobrevida foi de 1830 dias em assintomáticos, de 92 dias em animais com ICC e de 61 dias em gatos com TEAS (CÔTÉ et al., 2011). Segundo Payne et al. (2010), a média de sobrevida de gatos com $\mathrm{CMH}$ foi de 1276 dias; e animais jovens, gatos assintomáticos, átrio esquerdo de dimensão normal, e presença de movimento anterior sistólico da valva mitral estiveram correlacionados com melhor prognóstico e melhor tempo de sobrevida.

Segundo Côté et al. (2011), aproximadamente metade dos gatos com ICC e todos os gatos com TEAS não apresentam sobrevida maior que seis meses. $O$ 
prognóstico é bom em gatos com hipertrofia miocárdica discreta; com CMH estável (sem progressão da hipertrofia); em animais sem aumento do átrio esquerdo; ou naqueles com mínima evolução no grau de hipertrofia em 12 a 16 meses. Quando ocorre aumento atrial significativo, a média para o surgimento de ICC varia de meses a dois anos. Quando a ICC se desenvolve, os gatos tendem a sobreviver por mais algumas semanas até 18 meses, mas a maioria não ultrapassa oito meses. Outros pontos como presença de fator desencadeante da ICC (agente estressor), colaboração do proprietário e do próprio paciente, velocidade de evolução da cardiomiopatia também influenciam no prognóstico.

De acordo com Linney et al. (2014), o diâmetro, o volume e a função do átrio esquerdo também funcionam como índice prognóstico e podem indicar a cronicidade e a gravidade da disfunção diastólica associada à $\mathrm{CMH}$. Segundo Payne et al. (2013), o prognóstico é pior nos gatos com $\mathrm{CMH}$ que apresentam algumas alterações ecocardiográficas como: função atrial reduzida; hipertrofia miocárdica importante; disfunção sistólica (com áreas de hipocinesia e diminuição da fração de encurtamento); e padrão restritivo de disfunção diastólica.

Em contraste aos estudos humanos, o movimento anterior sistólico da valva mitral (MAS) está associado à melhora na sobrevida em diferentes estudos com felinos (FOX; LIU; MARON, 1995; RUSH et al., 2002; PAYNE et al., 2010). Segundo Payne et al. (2010), o MAS esteve associado ao estado assintomático e não influenciou no tempo de sobrevida em gatos assintomáticos ou em gatos com insuficiência cardíaca congestiva.

\subsection{JUSTIFICATIVA}

Apesar da ocorrência familial da $\mathrm{CMH}$, indicativa de etiologia geneticamente determinada, também ser relatada em outras raças predispostas como o Persa, British Shorthair, American Shorthair e Sphynx, nenhuma mutação relevante relacionada à cardiomiopatia familial foi identificada nestes animais (BRIZARD et al., 2009; GRANSTRÖM et al., 2011; SILVERMAN; STERN; MEURS, 2012). Nestas raças acometidas e predispostas à $\mathrm{CMH}$, há aumento no interesse em mapear geneticamente os animais antes de realizar programas de cruzamentos, na tentativa 
de reduzir a ocorrência da afecção na população felina. Porém, a ausência de testes genéticos específicos para a maioria das raças faz com que tanto o diagnóstico como o mapeamento da cardiopatia sejam realizados principalmente por meio do exame ecocardiográfico. Além disso, muitos animais permanecem assintomáticos por anos e, quando apresentam manifestações clínicas, o diagnóstico já é tardio e o prognóstico de reservado a ruim.

Apesar da $\mathrm{CMH}$ ser uma afecção bastante comum em gatos, poucos estudos estimam a prevalência desta cardiopatia em algumas raças predispostas e em gatos sem definição racial. Em Persa, raça bastante comum e amplamente difundida no Brasil, a CMH apresenta alta incidência e envolvimento familial. Segundo a literatura, cerca de três a $15 \%$ de todos os gatos acometidos pela $\mathrm{CMH}$ são da raça Persa, apresentando a maior incidência dentre as raças puras estudadas (RUSH et al., 2002). Desta forma, informações sobre a prevalência da $\mathrm{CMH}$ no Persa apresenta relevância clínica e o mapeamento genético se faz fundamental para o diagnóstico precoce e para o conhecimento da fisiopatologia da afecção, justificando a importância do presente trabalho.

O mapeamento genético pode fornecer informações valiosas sobre a presença de mutações ou polimorfismos em alguns dos principais genes envolvidos na doença, permitindo compreender melhor seus aspectos fisiopatogênicos e fornecendo ferramentas para o controle e erradicação dessa doença nos gatis de gatos da raça Persa. Ainda, a descoberta da mutação causal da $\mathrm{CMH}$ no Persa pode trazer informações relevantes sobre patologia e genética comparada, uma vez que a mesma doença apresenta elevada incidência em seres humanos, fornecendo um novo modelo animal para o estudo e terapêutica da cardiomiopatia hipertrófica familial. 


\section{OBJETIVOS}

Realização do sequenciamento genético de dois dos principais genes potencialmente envolvidos na patogênese da cardiomiopatia hipertrófica felina: o exon 27 do gene da proteína C miosina ligante (MYBPC3) e o exon 5 do gene da alfa-actina cardíaca (ACTC1); e sua correlação com a presença da afecção em gatos da raça Persa. Objetiva-se correlacionar a afecção com as principais mutações genéticas envolvidas, com o intuito de tentar estabelecer a etiologia da $\mathrm{CMH}$ familial na referida raça.

Além disso, objetiva-se, secundariamente, avaliar a prevalência da cardiomiopatia hipertrófica na referida raça e investigar a influência de possíveis fatores de risco (sexo, peso, idade ou particularidades raciais e genéticas, como a presença da mutação relacionada à doença renal policística autossômica dominante) e a ocorrência da cardiomiopatia. 


\section{HIPÓTESE}

A hipótese do presente trabalho é que gatos da raça Persa com cardiomiopatia hipertrófica apresentam uma mutação comum em gene que codifica proteínas do sarcômero, não encontrada em gatos da mesma raça sem a afecção.

Uma vez encontrada correlação estatisticamente significante entre gatos com cardiomiopatia hipertrófica e a presença da mutação investigada, testes genéticos específicos para a raça Persa podem ser elaborados, favorecendo o mapeamento genético da $\mathrm{CMH}$ e auxiliando no diagnóstico precoce da afecção. 


\section{MATERIAL E MÉTODOS}

\subsection{LOCAL}

O presente estudo foi realizado no Serviço de Cardiologia do Departamento de Clínica Médica (VCM) do Hospital Veterinário (HOVET) da Faculdade de Medicina Veterinária e Zootecnia da Universidade de São Paulo (FMVZ-USP), no Laboratório de Patologia Morfológica e Molecular do Departamento de Patologia (VPT) da FMVZ-USP, no Setor de Sequenciamento de DNA do Centro de Pesquisas sob o Genoma Humano e Células-tronco do Instituto de Biociências da Universidade de São Paulo (IB-USP) e em gatis particulares de criadores de gatos da raça Persa.

\subsection{ANIMAIS E GRUPOS EXPERIMENTAIS}

Após aprovação da Comissão de Bioética (projeto $n^{\circ}$ 2533/2012), foram encaminhados para o projeto de pesquisa e previamente incluídos nos grupos experimentais, 100 gatos da raça Persa, machos e fêmeas, de faixa etária entre cinco e 168 meses $(52,459 \pm$ 40,54 meses) e peso corpóreo entre 2,0 e 7,95 $\mathrm{Kg}$ $(3,96 \pm 1,34 \mathrm{Kg})$.

Previamente à inclusão nos grupos experimentais, os animais foram avaliados por meio de anamnese, exame físico e exames laboratoriais, como: hemograma, dosagem de ureia e creatinina séricas, avaliação de atividade das enzimas hepáticas, dosagem de proteína total e albumina séricas, dosagem de eletrólitos séricos (sódio, potássio, cálcio total e fósforo) e dosagem de hormônio tireoidiano T4 total. Foram realizados, também, exame eletrocardiográfico e mensuração da pressão arterial de acordo com metodologias já estabelecidas, respectivamente, por Tilley (1992) e Brown et al. (2007). Todos os exames complementares realizados estão descritos e detalhados a seguir.

Foram excluídos do estudo animais que apresentaram outras alterações que pudessem causar hipertrofia miocárdica secundária, como gatos com hipertensão 
arterial sistêmica, nefropatia e/ou hipertireoidismo, além de animais que apresentavam infecções evidentes, alterações hepáticas ou renais primárias ou qualquer outra enfermidade que pudesse interferir no sistema cardiovascular.

Após interpretação ecocardiográfica e avaliação dos critérios de exclusão, foram eliminados do estudo 16 gatos cujos exames realizados estavam com dados incompletos ou com resultados inadequados para inclusão, um gato com alterações ecocardiográficas compatíveis com cardiomiopatia associada à presença de banda moderadora e um felino com suspeita de cardiomiopatia arritmogênica do ventrículo direito. Desta forma, foram aceitos, de acordo com os critérios de inclusão, 82 animais, que foram classificados, quanto à cardiomiopatia hipertrófica $(\mathrm{CMH})$, em:

- animais normais $(n=54)$ : valores diastólicos de septo interventricular (SIVd) e/ou de parede livre de ventrículo esquerdo (PVEd) menores que 0,5 cm;

- animais suspeitos para $\mathrm{CMH}(\mathrm{n}=6)$ : valores diastólicos de SIVd e/ou de PVEd maiores ou iguais a 0,5 e menores que $0,6 \mathrm{~cm}$;

- animais com CMH ( $n=22)$ : valores diastólicos de SIVd e/ou de PVEd maiores ou iguais a $0,6 \mathrm{~cm}$.

Os animais suspeitos para a $\mathrm{CMH}$ foram excluídos da avaliação genética e, dentre os animais normais, foram selecionados apenas os gatos com idade superior a sete anos. Como o objetivo do trabalho era avaliar as possíveis mutações relacionadas à cardiomiopatia hipertrófica e esta afecção é genotipicamente e fenotipicamente heterogênea e com penetrância incompleta, optou-se pela escolha dos animais normais de maior faixa etária (diminuindo o risco da seleção de animais aparentemente normais, portadores de mutações, mas ainda sem manifestação fenotípica).

Desta forma, os grupos experimentais ficaram definidos como:

- Grupo normal $(n=20)$;

- Grupo com CMH (n=22).

\subsection{ANAMNESE E EXAME FÍSICO}

Todos os animais avaliados foram submetidos à anamnese completa e ao exame físico previamente à inclusão no projeto. Após a identificação do paciente, 
indagou-se sobre seu estado geral e atitude e pesquisou-se sobre presença de manifestações cardiorrespiratórias como: taquipneia, dispneia, cansaço fácil, intolerância a exercícios, cianose, pré-síncope, síncope, convulsão, edema, ascite e tosse. Também foram analisados os antecedentes mórbidos e familiares, epidemiologia para dirofilariose e necessidade de uso de medicações para cardiopatia e/ou para outra comorbidade. Fez-se o questionamento para avaliação dos sistemas digestório, neurológico, osteoarticular, geniturinário e dermatológico. Além disso, questionou-se sobre antecedentes familiares em relação à presença de cardiomiopatia hipertrófica e/ou de doença renal policística (PKD) no gatil de origem do animal.

Ao exame físico, realizou-se a avaliação do padrão e da frequência respiratória por meio de inspeção direta. Realizou-se a inspeção das mucosas ocular e oral, quanto à coloração e ao brilho, e avaliou-se o tempo de preenchimento capilar. O grau de hidratação foi avaliado subjetivamente, por meio de observação do grau de elasticidade cutânea e brilho de mucosas. Realizou-se a palpação dos linfonodos periféricos (quanto ao tamanho, temperatura, consistência e mobilidade), palpação abdominal (pesquisa de organomegalias ou presença de massas intracavitárias), palpação de tireoide e palpação do pulso arterial femoral (quanto à frequência, ritmo e intensidade). Procedeu-se a auscultação cardíaca e pulmonar para definição do ritmo cardíaco, da frequência cardíaca e da classificação das bulhas cardíacas quanto à fonese, ao ritmo e à presença ou não de sopro.

\subsection{MENSURAÇÃO DA PRESSÃO ARTERIAL}

A determinação da pressão arterial sistólica (PAS) foi realizada por método não invasivo por meio do dispositivo de Doppler vascular (marca MedMega®, modelo DV610). Foram realizadas, no mínimo, cinco determinações, considerandose a média dos valores obtidos. Neste procedimento, os animais foram posicionados em decúbito lateral direito, mensurando-se a circunferência do membro torácico direito ou esquerdo do animal, e colocando-se um manguito (com largura correspondente a 30-40\% da circunferência do mesmo) ao nível do terço médio do rádio-ulna. $\mathrm{O}$ transdutor foi posicionado entre os coxins do carpo e metacarpo, sobre 
a região da artéria medial, iniciando-se a insuflação do manguito até a interrupção do pulso. A pressão arterial sistólica foi caracterizada no momento do retorno da percepção do pulso (ao desinflar o manguito), de acordo com a metodologia já estabelecida (BROWN; HENIK; FINCO, 2000; BROWN et al., 2007; WARE, 2007). Consideraram-se normais os valores de pressão arterial sistólica de até $150 \mathrm{mmHg}$ (BROWN et al., 2007).

\subsection{EXAME ELETROCARDIOGRÁFICO}

O exame eletrocardiográfico foi realizado no eletrocardiógrafo ECAFIX® modelo ECG 6 com os animais posicionados em decúbito lateral direito, registrandose as derivações bipolares I, II e III e as unipolares aumentadas aVR, aVL e aVF, bem como as pré-cordiais CV5RL (rV2), CV6LL (V2), CV6LU (V4) e V10 em velocidade de registro de $25 \mathrm{~mm} / \mathrm{s}$ e calibração de $1 \mathrm{mV}$ igual a $1 \mathrm{~cm}$. Posteriormente, a derivação bipolar II foi registrada em velocidade de $50 \mathrm{~mm} / \mathrm{s}$.

Os parâmetros eletrocardiográficos foram avaliados de acordo com Tilley (1992), Harvey et al. (2005) e Côté et al. (2011), e as variáveis analisadas foram: frequência cardíaca; ritmo cardíaco; eixo cardíaco elétrico; largura e amplitude da onda P; intervalo PR; largura do complexo QRS; amplitude de onda R; intervalo QT; polaridade e altura da onda T; avaliação do segmento ST quanto ao nivelamento e à morfologia; amplitude das ondas $\mathrm{R}$ e $\mathrm{S}$ e polaridade das ondas $\mathrm{T}$ nas derivações pré-cordiais CV5RL (rV2), CV6LL (V2) e CV6LU (V4); polaridade dos complexos QRS e das ondas T na derivação pré-cordial V10.

\subsection{EXAMES LABORATORIAIS}

Amostras de sangue foram obtidas por meio de punção da veia jugular e, imediatamente, acondicionadas em tubos a vácuo contendo anticoagulante EDTA (para a realização do hemograma completo) e acondicionadas em tubos a vácuo com coagulante e centrifugadas a 5000 rpm por 5 minutos para a obtenção do soro 
e posterior realização de exames de bioquímica sérica (dosagem de ureia e creatinina séricas, avaliação de atividade das enzimas hepáticas, dosagem de proteína total e albumina séricas, dosagem de eletrólitos e dosagem de hormônio tireoidiano T4 total).

$\mathrm{Na}$ avaliação do hemograma completo, as contagens totais de hemácias e leucócitos, bem como a dosagem de hemoglobina, foram realizadas em contador hematológico automático de uso veterinário da marca $A B X$ - modelo $A B C$ vet. $O$ volume globular foi determinado pela técnica do micro-hematócrito em centrífuga. $A$ contagem diferencial de leucócitos foi realizada por microscopia óptica em esfregaços de sangue "in natura”, corados pela técnica de Rosenfeld.

Para a realização do perfil bioquímico completo, foi utilizado analisador bioquímico automático da marca Labtest e modelo Labmax 240. O perfil hepático incluiu dosagens séricas de fosfatase alcalina (FA), aspartato aminotransferase (AST), alanino aminotransferase (ALT), gamaglutamiltransferase (GGT), proteína total e albumina. O perfil renal foi avaliado pela realização de dosagem sérica de ureia e creatinina. Determinou-se, também, a dosagem sérica de sódio, potássio, cálcio total e fósforo. A determinação do hormônio tireoidiano T4 total foi realizada no Instituto de Diagnóstico e Especialidades Provet, por meio da técnica de radioimunoensaio, em equipamento da marca ABBOT ANSR.

A avaliação da presença da mutação relacionada à doença renal policística autossômica dominante (PKD) foi realizada no Departamento de Patologia, por meio de reação de polimerase em cadeia (no exon 29 do gene PKD1 felino).

\subsection{EXAME ECOCARDIOGRÁFICO}

O exame ecocardiográfico foi realizado no ecocardiógrafo portátil modelo Vivid-I (General Electric Co.- GE) provido de software para realização dos modos de imagem: Doppler tecidual pulsado e colorido, strain, strain rate, tissue tracking, transdutor setorial matricial 1,5 a $4 \mathrm{MHz}$ e transdutor setorial de 3 a $8 \mathrm{MHz}$. Os animais, livres de sedação e/ou tranquilização, foram posicionados em decúbito lateral esquerdo com o transdutor (setorial de 3 a $8 \mathrm{MHz}$ ) sobre o tórax, para a obtenção das imagens através da janela paraesternal direita e paraesternal 
esquerda cranial e caudal. Quando necessário e autorizado pelo proprietário, realizou-se a tricotomia da região torácica em toda sua extensão, entre o bordo esternal e a articulação costocondral. Uma camada de gel foi aplicada entre o transdutor e a parede torácica do animal, com a finalidade de diminuir a interferência do ar que se interpõe entre os mesmos.

O exame ecocardiográfico foi realizado conforme recomendações da Echocardiography Committee of the Specialty of Cardiology - American College of Veterinary Internal Medicine (THOMAS et al., 1993) e American Society of Echocardiography (ASE) (BOON, 2011) quanto ao posicionamento, janelas e cortes, bem como à determinação de medidas e valores nos diferentes modos (bidimensional, modo M, e Doppler pulsado, contínuo e colorido) (OYAMA, 2004; BOON, 2011; CHETBOUL et al., 2012). Durante todo o exame ecocardiográfico, fezse o monitoramento eletrocardiográfico simultâneo (em derivação bipolar DII) para facilitar a identificação das fases do ciclo cardíaco e para auxiliar na obtenção das medidas ecocardiográficas.

Foram realizadas, no mínimo, três determinações de cada parâmetro ecocardiográfico avaliado nas diferentes fases do ciclo cardíaco, considerando-se a média dos valores obtidos, minimizando-se, desta forma, as interferências causadas pela respiração, pela movimentação do coração dentro do tórax e pelas mudanças no enchimento cardíaco (BOON, 2011; CHETBOUL et al., 2012).

As imagens para a mensuração do ventrículo esquerdo (VE) foram adquiridas por meio da janela paraesternal direita, corte transversal (ou eixo curto), na altura da inserção das cordoalhas tendíneas em músculos papilares (CHETBOUL et al., 2012). Para a mensuração das estruturas, utilizou-se o método do modo $M$, a partir do corte transversal. Foram avaliados, segundo Boon (2011), os seguintes parâmetros em modo M do ventrículo esquerdo:

- frequência cardíaca (FC);

- espessura do septo interventricular no final da diástole (SIVd);

-espessura da parede livre do ventrículo esquerdo no final da diástole (PVEd);

- diâmetro diastólico final da cavidade do ventrículo esquerdo (DVEd);

- diâmetro sistólico final da cavidade do ventrículo esquerdo (DVEs);

- espessura do septo interventricular no final da sístole (SIVs);

- espessura da parede livre do ventrículo esquerdo no final da sístole (PVEs);

- relação septo-parede na diástole (SIVd/PVEd); 
- fração de encurtamento (FS);

- fração de ejeção (método de Teichholz) (Fej).

De acordo com Sampedrano et al. (2009) e Chetboul et al. (2012), a presença de hipertrofia miocárdica foi definida quando a espessura diastólica do septo interventricular (SIVd) e/ou da parede livre de ventrículo esquerdo (PVEd) era superior a 0,6 cm. Os animais com espessuras diastólicas menores que 0,5 cm foram considerados normais; e os gatos com valores de espessuras diastólicas entre 0,5 e $0,6 \mathrm{~cm}$ foram considerados normais, porém suspeitos para a $\mathrm{CMH}$. A hipertrofia concêntrica foi considerada simétrica quando a relação SIVd/PVEd estava entre 0,7 e 1,3 (SAMPEDRANO et al., 2009; CHETBOUL et al, 2012).

Considerou-se hipertrofia miocárdica assimétrica quando a relação SIVd/PVEd se encontrava menor ou igual a 0,7 ou maior que 1,3 , de acordo com Sampedrano et al. (2009). Na presença de hipertrofia miocárdica assimétrica, fez-se a mensuração da área de hipertrofia segmentar por meio do modo bidimensional (mensurando-se a área de maior espessura, na fase da diástole). De acordo com Chetboul et al. (2012), a mensuração da região basal do septo interventricular (em região de via de saída do ventrículo esquerdo; SIVAo) foi realizada em todos os animais por meio do modo bidimensional.

Realizou-se, também, a avaliação em modo $\mathrm{M}$ na janela paraesternal direita, corte transversal (ou eixo curto), na altura do anel mitral, com o objetivo de investigar a presença de movimento anterior sistólico (MAS) do folheto anterior da valva mitral.

As mensurações do diâmetro da raiz da aorta $(A o)$ e do diâmetro do átrio esquerdo $(A E)$, bem como da relação átrio esquerdo/aorta $(A E / A o)$, foram realizadas pelo modo bidimensional (ABBOTT; MCLEAN, 2006; CHETBOUL et al., 2012; LINNEY et al., 2014). Para tanto, utilizou-se a janela paraesternal direita, corte transversal (ou eixo curto), em região de base cardíaca. O diâmetro interno da aorta foi medido ao longo da comissura entre as válvulas não coronariana e coronariana direita, no momento seguinte ao fechamento da valva aórtica; e o átrio esquerdo, no mesmo quadro, também em seu diâmetro interno, traçando-se uma linha paralela à comissura entre as válvulas não coronariana e coronariana esquerda. Considerou-se aumento de átrio esquerdo quando a relação $\mathrm{AE} / \mathrm{Ao}$ (pelo modo bidimensional, eixo curto) foi superior a 1,5, de acordo com Wess, Sarkar e Hartmann (2010). 
A modalidade Doppler (pulsado, contínuo e colorido) foi utilizada para avaliação dos fluxos transvalvares e para pesquisa de fluxos regurgitantes (insuficiências valvares) ou fluxos de obstrução (estenoses ou obstrução de via de saída). Os parâmetros avaliados pelo Doppler pulsado foram:

- fluxo aórtico (janela paraesternal esquerda caudal, corte apical 5 câmaras): mensuração da velocidade máxima (em $\mathrm{m} / \mathrm{s}$ ) e do gradiente de pressão (em $\mathrm{mmHg}$ ) do fluxo sanguíneo através do aparelho valvar aórtico (volume de amostra posicionado junto aos folhetos aórticos na face voltada para a artéria aorta);

- fluxo pulmonar (janela paraesternal esquerda cranial, corte longitudinal da via de saída do ventrículo direito): mensuração da velocidade máxima (em $\mathrm{m} / \mathrm{s}$ ) e do gradiente de pressão (em $\mathrm{mmHg}$ ) do fluxo sanguíneo através do aparelho valvar pulmonar (volume de amostra posicionado junto aos folhetos pulmonares na face voltada para a artéria pulmonar);

- fluxo mitral (janela paraesternal esquerda caudal, corte apical 4 câmaras): mensuração da velocidade máxima $(\mathrm{em} \mathrm{m} / \mathrm{s})$ da onda de enchimento ventricular rápido (ou onda $E$ ) e da onda de enchimento ventricular lento/ contração atrial (ou onda $A$ ), bem como determinação da relação $E / A$ e do tempo de desaceleração da onda $E$ (em ms) (volume de amostra posicionado junto aos folhetos da valva mitral, no interior do ventrículo esquerdo);

- tempo de relaxamento isovolumétrico (TRIV) (janela paraesternal esquerda caudal, corte apical 5 câmaras): mensuração do intervalo de tempo (em ms) entre o final do fluxo sistólico na via de saída do ventrículo esquerdo (fluxo aórtico) e o início do fluxo diastólico mitral (onda E) (volume de amostra posicionado entre a via de saída do ventrículo esquerdo e o aparelho valvar mitral, no interior do ventrículo esquerdo).

As alterações no fluxo mitral decorrentes de alteração no relaxamento ventricular (comumente observadas na $\mathrm{CMH}$ ) consideradas foram: redução na velocidade máxima de enchimento ventricular rápido (onda $\mathrm{E}$ ), aumento no tempo de desaceleração da onda $E$, aumento na velocidade máxima de enchimento ventricular lento (onda A- contração atrial), redução na relação E/A e aumento no TRIV (NAGUEH et al., 2009; BOON, 2011; CHETBOUL et al., 2012). As alterações no fluxo mitral decorrentes de alteração na distensibilidade ventricular (padrão restritivo, também observado em fases de disfunção diastólica importante na $\mathrm{CMH}$ ) consideradas foram: aumento na velocidade máxima de enchimento ventricular 
rápido (onda $E$ ), diminuição no tempo de desaceleração da onda $E$, diminuição na velocidade máxima de enchimento ventricular lento (onda A- contração atrial), relação E/A superior a dois e diminuição no TRIV (NAGUEH et al., 2009).

$\mathrm{Na}$ presença de fluxos valvares regurgitantes, a insuficiência valvar foi classificada, qualitativamente, em grau discreto, moderado ou importante, de acordo com a área ocupada pela regurgitação (avaliação com Doppler colorido e Doppler pulsado). Utilizou-se o Doppler contínuo para avaliação de fluxos de alta velocidade (fluxos regurgitantes ou fluxos de obstrução), permitindo a obtenção de sua respectiva velocidade máxima (em $\mathrm{m} / \mathrm{s}$ ) e de seu gradiente de pressão $(\mathrm{em} \mathrm{mmHg}$ ). A velocidade e o gradiente sub-aórtico foram avaliados por meio do Doppler contínuo e a obstrução da via de saída de ventrículo esquerdo foi considerada presente quando o gradiente sub-aórtico era superior a $30 \mathrm{mmHg}$.

De acordo com a classificação realizada por Wess, Sarkar e Hartmann (2010), os gatos com $\mathrm{CMH}$ do presente projeto foram subclassificados, quanto ao grau da hipertrofia, em: $\mathrm{CMH}$ discreta (hipertrofia concêntrica focal ou generalizada com espessura diastólica de SIVd e/ou PVEd entre 0,60 e 0,65 cm e relação AE/Ao menor que 1,5); $\mathrm{CMH}$ moderada (hipertrofia concêntrica focal ou generalizada com espessura diastólica de SIVd e/ou PVEd entre 0,65 e $0,70 \mathrm{~cm}$ e relação AE/Ao menor que 1,8; ou hipertrofia concêntrica focal ou generalizada com espessura diastólica de SIVd e/ou PVEd entre 0,60 e 0,65 cm e relação AE/Ao entre 1,5 e 1,8); e $\mathrm{CMH}$ importante (hipertrofia concêntrica focal ou generalizada com espessura diastólica de SIVd e/ou PVEd maior que $0,70 \mathrm{~cm}$; ou hipertrofia concêntrica focal ou generalizada com espessura diastólica de SIVd e/ou PVEd maior que 0,60 cm e relação $A E / A o$ maior que 1,8$)$.

\subsection{AVALIAÇÃO GENÉTICA}

\subsubsection{Regiões genômicas avaliadas}

Dois genes potencialmente envolvidos na patogênese da cardiomiopatia hipertrófica felina foram analisados no presente projeto: o gene da proteína C 
miosina ligante (MYBPC3) e o gene da alfa-actina cardíaca (ACTC1). Para tanto, foram analisados dois exons referentes a estes dois genes do sarcômero descritos na cardiomiopatia hipertrófica:

- gene da proteína C miosina ligante (MYBPC3) (exon 27);

- gene da alfa-actina cardíaca (ACTC1) (exon 5).

\subsubsection{Extração do DNA}

Para a obtenção de amostra e extração do DNA genômico dos felinos controles ou portadores da cardiomiopatia hipertrófica, foram utilizados tubos especiais para coleta de sangue e conservação do DNA genômico (PAXGene Blood DNA Tube, QIAGEN) (MEURS et al., 2007; MEURS et al., 2009). Foram obtidos 5 $\mathrm{mL}$ de sangue total de cada animal e conservados nestes tubos, que preservam 0 material genético por até 14 dias em temperatura ambiente, facilitando, assim, a coleta do material biológico nos criatórios de gatos da raça Persa. Após a coleta, o material foi enviado ao Laboratório de Patologia Morfológica e Molecular do Departamento de Patologia (VPT), para a extração do DNA por colunas de afinidade (PAXGene Blood DNA Kit, QIAGEN).

A extração de DNA, a partir das amostras de sangue colhidas em EDTA, foi realizada segundo recomendações de kit de sílica comercial (Illustra blood genomicPrep Mini Spin Kit - GE Healthcare, EUA). A avaliação da qualidade e quantidade do DNA extraído foi realizada por meio da análise da integridade e pureza das amostras pelo aparelho NanoDrop (NanoDrop Technologies, EUA).

\subsubsection{Genotipagem e reação de polimerase em cadeia (PCR)}

A reação de polimerase em cadeia (PCR) foi realizada para o exon 5 do gene ACTC1 e para o exon 27 do gene MYBPC3 felino (MEURS et al., 2009). Para tanto foram utilizados os primers conforme o quadro 1. 
Quadro 1 - Primers da reação de PCR dos genes felinos ACTC1 (exon 5) e MYBPC3 (exon 27) - São Paulo - 2014

\begin{tabular}{l|c|c|c|}
\hline Gene & Exon & \multicolumn{1}{c|}{ Forward } & Reverse \\
\hline ACTC1 & 5 & CAC GGG TCT TCT GTG TCC & ACC ACC ACC TAG TCC TGG AA \\
\hline MYBPC3 & 27 & GTT CCG GCT GGT CTC TCT C & CTA AGG TCA GGG GAG GAA GC \\
\hline Legenda: & ACTC1: gene da alfa actina cardíaca; MYBPC3: gene da proteína C miosina ligante; \\
& forward: sequência forward do primer; reverse: sequência reverse do primer; A: adenina; \\
& T: timina ; C: citosina; G: guanina. \\
Fonte: & (MEURS et al., 2009).
\end{tabular}

Aproximadamente $100 \mathrm{ng}$ de DNA foram utilizados por reação de PCR. As condições da reação de PCR foram as seguintes: 1 pmol de cada primer forward e reverse; 1,25 mM de desoxinucleotídeos (dNTP); 1,75 mM de cloreto de magnésio (MgCl2) e 0,375 U da enzima Taq polimerase (Life Technologies, EUA) em $20 \mu \mathrm{L}$ de reação. A solução foi inicialmente incubada à $94^{\circ} \mathrm{C}$ por 3 minutos para a desnaturação, posteriormente submetida a 40 ciclos de $94^{\circ} \mathrm{C}$ por 1 minuto, $58^{\circ} \mathrm{C}$ por 1 minuto e $72^{\circ} \mathrm{C}$ por 1 minuto; e a uma extensão final de $72^{\circ} \mathrm{C}$ por 5 minutos. $\mathrm{A}$ reação foi analisada em gel de agarose a $2 \%$ e fotografada para documentação usando o sistema Image Master VDS (Pharmacia Biotech). Todas as amostras de DNA foram sequenciadas. As bandas correspondentes aos produtos amplificados foram purificadas, utilizando-se um kit comercial segundo instruções do fabricante (QIAquick PCR Purification Kit, QIAgen, Hilden, Alemanha). Após a purificação, o DNA foi quantificado visualmente por meio de comparação das bandas obtidas com um padrão de peso molecular (Low Mass DNA Ladder, Invitrogen, EUA) em gel de agarose $2 \%$.

\subsubsection{Sequenciamento genético}

A reação de sequenciamento foi realizada no Setor de Sequenciamento de DNA do Centro de Pesquisas sob o Genoma Humano e Células-tronco do Instituto de Biociências da Universidade de São Paulo (IB-USP). Para tanto, utilizaram-se $4 \mu \mathrm{L}$ de BigDye 3 (BigDye Terminator v3.1 Cycle Sequencing Kit, Applied Biosystems, EUA), $4 \mu \mathrm{L}$ de tampão $5 \mathrm{X}, 0,5 \mu \mathrm{L}$ de cada oligonucleotídeo iniciador, $10 \mu \mathrm{M}$ em reações separadas, 40ng do DNA alvo e água ultrapura livre de DNAse e 
RNAse para uma reação final de $20 \mu \mathrm{L}$. O equipamento utilizado foi um sequenciador automático capilar (ABIPrism 3730 DNA Analyser, Applied Biosystems, EUA) segundo o protocolo do Centro de Estudos do Genoma Humano.

Os cromatogramas gerados para cada uma das sequências forward e reverse de cada amostra foram avaliados com relação à sua qualidade no aplicativo Phred online (http://asparagin.cenargen.embrapa.br/phph/1). Eles, ainda, foram analisados e editados manualmente com o programa Chromas Lite v. 2.1.1. (http://technelysium.com.au/?page_id=13) com a finalidade de observar e corrigir possíveis erros de interpretação e discrepâncias entre cada uma das fitas sequenciadas. A sequência final de cada amostra foi obtida com o aplicativo Capcontig do programa computacional BioEdit v.5.0.9 (www.mbio.ncsu.edu/bioedit/bioedit.html) e submetida à pesquisa de homologia com outras sequências depositadas no GenBank, por meio do programa Blast 2.2.29 (http://www.ncbi.nlm.nih.gov/blast/).

\subsubsection{Interpretação dos resultados genéticos}

As sequências de nucleotídeos foram avaliadas e as modificações no sequenciamento foram comparadas entre animais acometidos pela $\mathrm{CMH}$ e animais controles. De acordo com a metodologia descrita por Meurs et al. (2009), as modificações nos pares de bases foram consideradas como causa de $\mathrm{CMH}$ de acordo com o seguinte critério:

- quando presente em alguns gatos acometidos e ausente nos gatos normais ou em sequências genéticas previamente publicadas;

- quando promove mudança em aminoácido conservado na espécie;

- quando promove mudança em aminoácido para outro de diferente polaridade, estrutura ou de diferente padrão ácido-base. 


\subsection{ANÁLISE ESTATÍSTICA}

Os resultados finais foram submetidos ao teste de Shapiro-Wilks para testar se os parâmetros apresentavam distribuição normal (Gaussiana), com o objetivo de se optar pelo uso do método paramétrico ou não paramétrico.

Média, desvio padrão, valor mínimo, valor máximo e a mediana foram calculados em todas as variáveis com distribuição normal. Para comparar as médias das variáveis contínuas (medidas avaliadas e suas derivadas, bem como frequência cardíaca, peso e idade) utilizou-se o p-valor do teste T-Student e/ou Mann-Whitney (quando se compararam dois grupos); e utilizou-se o p-valor da ANOVA e/ou Kruskal-Wallis (quando se compararam três ou mais grupos).

De acordo com Siegel e Castellan (1988), sugere-se utilizar o teste de MannWhitney e Kruskal-Wallis no lugar dos respectivos testes T e ANOVA sempre que algum dos testes de normalidade de Shapiro-Wilks forem rejeitados em, pelo menos, um grupo ou quando existirem poucos dados (NETER et al., 1996).

Para as variáveis categóricas (grupos, gêneros, animais inteiros ou castrados) utilizaram-se tabelas de frequência e o teste Qui-Quadrado de Pearson e/ou o teste exato de Fisher (VIEIRA, 1998) para verificar a associação destas variáveis com os grupos estudados. Optou-se pelo teste de Fisher quando a aproximação do teste de Pearson foi fraca.

As determinações da sensibilidade, especificidade, acurácia, valor preditivo positivo, valor preditivo negativo, razão de probabilidade positiva e razão de probabilidade negativa foram realizadas de acordo com Siegel e Castellan (1988) e Neter et al. (1996).

O nível de significância aplicado nos testes foi de 5\%, sempre considerando hipóteses alternativas bicaudais. 


\section{RESULTADOS}

\subsection{ANIMAIS E GRUPOS EXPERIMENTAIS}

Dos 100 gatos da raça Persa inicialmente avaliados (faixa etária entre cinco e 168 meses, com média de 52,459 \pm 40,54 meses; e peso corpóreo entre 2,0 e 7,95 $\mathrm{Kg}$, com média de 3,96 $\pm 1,34 \mathrm{Kg}$ ), 18 gatos foram excluídos de acordo com os critérios de exclusão e inclusão, seis gatos foram suspeitos para a $\mathrm{CMH}$ (e também excluídos da análise), 54 gatos eram fenotipicamente normais quanto à $\mathrm{CMH}$ e 22 eram acometidos pela $\mathrm{CMH}$. Desta forma, a prevalência da $\mathrm{CMH}$ observada no presente estudo foi de $22 \%$.

Como o objetivo do trabalho era avaliar as possíveis mutações relacionadas à cardiomiopatia hipertrófica e esta afecção é genotipicamente e fenotipicamente heterogênea e com penetrância incompleta, optou-se pela escolha dos animais normais de faixa etária mais avançada (diminuindo o risco da seleção de animais aparentemente normais, portadores de mutações mas ainda sem manifestação fenotípica). Desta forma, as análises foram realizadas em 20 gatos normais e em 22 gatos com $\mathrm{CMH}$ (totalizado 42 animais).

Dos 42 gatos da raça Persa avaliados, 23 eram machos $(54,76 \%)$ e 19 eram fêmeas $(45,24 \%)$. De todos os gatos machos, 12 eram inteiros $(52,17 \%)$ e 11 eram orquiectomizados $(47,83 \%)$. Dentre as fêmeas, apenas seis eram inteiras $(31,58 \%)$ e 13 eram castradas $(68,42 \%)$.

Quanto ao peso corpóreo, a variação encontrada nos animais estudados foi de 2,15 a 7,95 Kg $(4,42 \pm 1,21 \mathrm{Kg})$. O peso médio dos machos foi de 4,69 $\pm 1,43 \mathrm{Kg}$ $(2,15$ a $7,95 \mathrm{Kg})$, sendo obtido valor médio de $3,41 \pm 1,18 \mathrm{Kg}$ em machos inteiros e de $5,07 \pm 1,31 \mathrm{Kg}$ em machos castrados. Nas fêmeas, o peso corpóreo variou entre 2,9 e 5,95 Kg $(4,08 \pm 1,02 \mathrm{Kg})$, sendo a média obtida de 3,50 \pm 0,01 $\mathrm{Kg}$ nas fêmeas inteiras e de 4,16 \pm 1,07 nas castradas. Apesar do peso corpóreo dos animais castrados ser maior que dos inteiros; e dos gatos machos, maior que das fêmeas; não foram observadas diferenças estatísticas. 
A faixa etária dos animais do presente projeto variou de 24 a 168 meses $(93,14 \pm 35,60$ meses). A média de idade dos machos foi de 94,69 $\pm 41,29$ meses e das fêmeas, 91,26 \pm 38,27 meses, não havendo diferenças estatísticas entre ambos.

Dentre os 42 gatos, 40 eram procedentes de gatis do Brasil $(95,24 \%)$, um da Alemanha (2,38\%) e um da França (2,38\%). Todos os animais residiam em cidades do Estado de São Paulo, a saber: São Paulo-capital e São Bernardo do Campo.

No grupo controle (gatos normais quanto à $\mathrm{CMH} ; \mathrm{n}=20$ ), $45 \%$ dos animais eram machos e 55\%, fêmeas. O peso corpóreo variou de 2,9 a 7,95 $\mathrm{Kg}(4,62 \pm 1,38$ $\mathrm{Kg}$ ) e idade entre 67 e 156 meses (106,4 \pm 25,32 meses). Destes animais, 80\% eram castrados e $20 \%$, inteiros. Já no grupo acometido pela $\mathrm{CMH}(n=22), 63,64 \%$ dos gatos eram machos e apenas 36,36\%, fêmeas. O peso corpóreo variou de 2,15 a $6,15 \mathrm{Kg}(4,25 \pm 1,07 \mathrm{Kg})$ e a idade entre 24 e 168 meses (81,09 \pm 44,96 meses). Desses gatos, 36,36\% eram castrados e 63,64\%, inteiros. Os valores (média, desvio padrão, mínimo e máximo) de peso corpóreo e idade e a distribuição sexual (porcentagem de machos e fêmeas) nos diferentes grupos estão descritos na tabela 1. Foram observadas diferenças estatísticas em relação à idade dos animais, com predomínio de animais mais velhos no grupo normal $(P=0,0365)$ (Gráfico 1). Além disso, a proporção de gatos inteiros foi significativamente superior no grupo com $\mathrm{CMH}(\mathrm{P}=0,005)$ (Gráfico 2). Apesar do aparente predomínio de machos nos animais com $\mathrm{CMH}$, não foram observadas diferenças estatísticas quanto à distribuição sexual nos diferentes grupos (Gráfico 3).

Tabela 1 - Distribuição dos animais (fenotipicamente normais e acometidos pela $\mathrm{CMH}$ ), segundo peso corpóreo, idade e sexo - São Paulo - 2014

\begin{tabular}{lcccc}
\hline Classificação & Peso $(\mathrm{Kg})$ & Idade (meses) & Machos (\%) & Fêmeas (\%) \\
\hline Normais & $4,62 \pm 1,38$ & $106,40 \pm 25,32^{\mathrm{a}}$ & $45,00 \%$ & $55,00 \%$ \\
$(\mathrm{n}=20)$ & $(2,9-7,95)$ & $(67-156)$ & $(\mathrm{n}=09)$ & $(\mathrm{n}=11)$ \\
CMH & $4,25 \pm 1,07$ & $81,09 \pm 44,96^{\mathrm{b}}$ & $63,64 \%$ & $36,36 \%$ \\
$(\mathrm{n}=22)$ & $(2,15-6,15)$ & $(24-168)$ & $(\mathrm{n}=14)$ & $(\mathrm{n}=08)$ \\
\hline
\end{tabular}

Nota: $\mathrm{CMH}$ : cardiomiopatia hipertrófica; $\mathrm{n}$ : número de animais; ${ }^{\mathrm{a}, \mathrm{b}}$ : indicadores de diferenças estatísticas.

Fonte: Faculdade de Medicina Veterinária e Zootecnia da Universidade de São Paulo 
Gráfico 1 -Distribuição etária (em meses) dos gatos da raça Persa nos diferentes grupos experimentais $\left(\mathrm{CMH}\right.$ : cardiomiopatia hipertrófica; ${ }^{\mathrm{a}, \mathrm{b}}$ : indicadores de diferenças estatísticas) - São Paulo - 2014

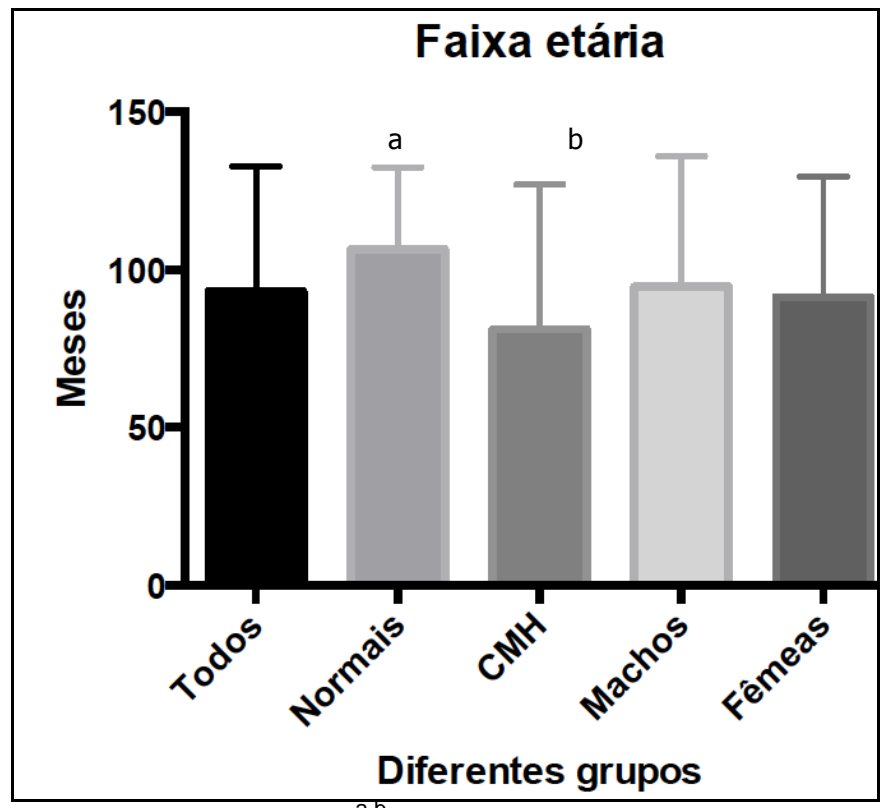

Legenda: $\mathrm{CMH}$ : cardiomiopatia hipertrófica; ${ }^{a, b}$ : indicadores de diferenças estatísticas).

Fonte: $\quad$ Faculdade de Medicina Veterinária e Zootecnia da Universidade de São Paulo.

Gráfico 2 - Proporção de animais castrados e inteiros nos gatos da raça Persa nos diferentes grupos experimentais - São Paulo - 2014

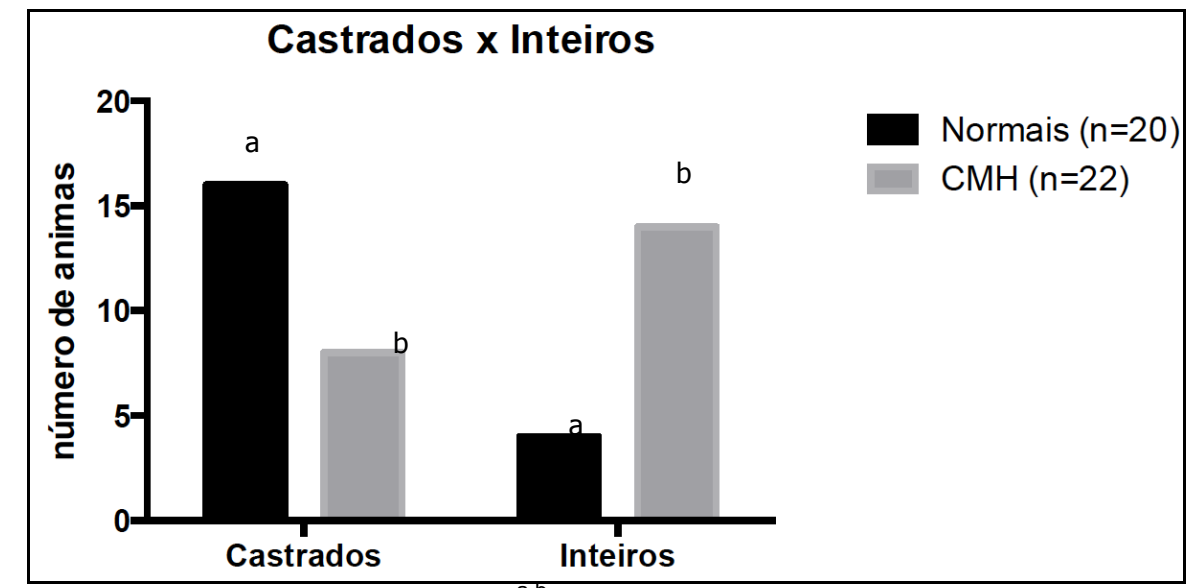

Legenda: $\mathrm{CMH}$ : cardiomiopatia hipertrófica; ${ }^{\text {a,b }}$ : indicadores de diferenças estatísticas.

Fonte: $\quad$ Faculdade de Medicina Veterinária e Zootecnia da Universidade de São Paulo. 
Gráfico 3 -Distribuição sexual dos gatos da raça Persa nos diferentes grupos experimentais - São Paulo - 2014

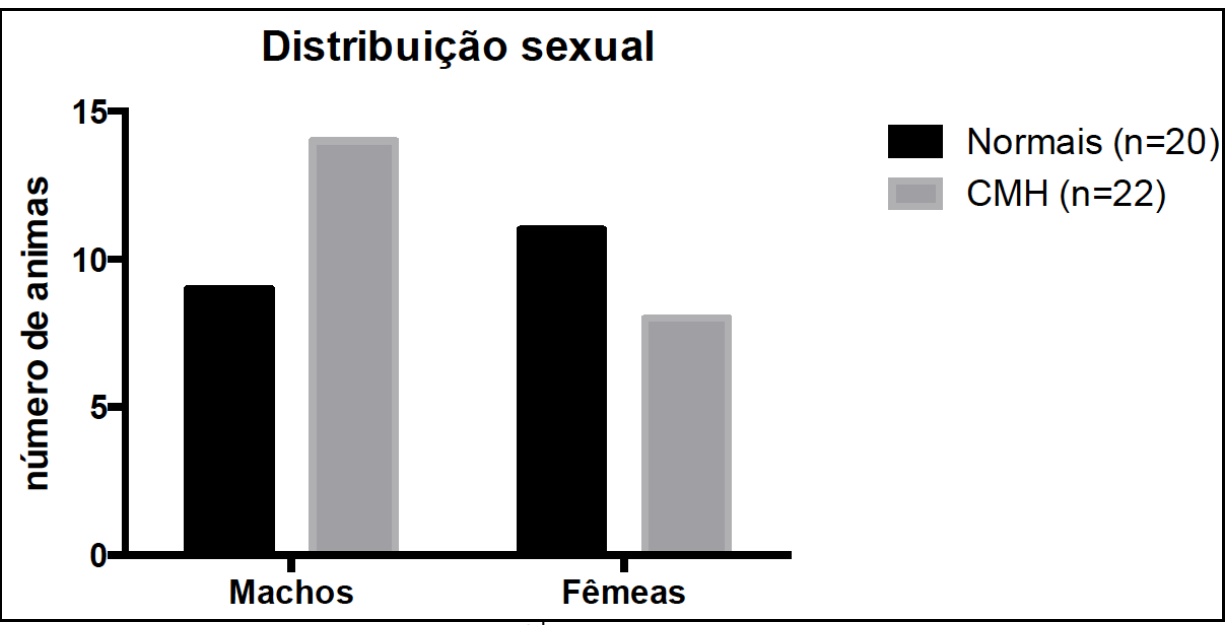

Legenda: $\mathrm{CMH}$ : cardiomiopatia hipertrófica; ${ }^{\mathrm{a}, \mathrm{b}}$ : indicadores de diferenças estatísticas.

Fonte: $\quad$ Faculdade de Medicina Veterinária e Zootecnia da Universidade de São Paulo.

\subsection{ANAMNESE E EXAME FÍSICO}

À anamnese, constatou-se que $83,34 \%$ da população estudada $(n=42)$ era assintomática quanto ao sistema cardiorrespiratório. Dentre os animais normais, apenas um (2,38\% do total avaliado) apresentava dispneia inspiratória devido a complicações e sequelas de complexo respiratório felino. As demais manifestações cardiorrespiratórias foram observadas apenas nos animais acometidos pela $\mathrm{CMH}, \mathrm{a}$ saber: um animal com tosse relacionada ao diagnóstico de bronquite $(2,38 \%)$; um com cansaço (2,38\%); um com dispneia (2,38\%); dois com cansaço e dispneia $(4,76 \%)$; um com cansaço, dispneia e pré-síncope $(2,38 \%)$; e outro com cansaço, dispneia e convulsão (2,38\%).

Ao avaliar apenas o grupo dos animais com $\mathrm{CMH}, 68,19 \%$ dos gatos eram assintomáticos quanto ao sistema cardiorrespiratório; e 31,81\% apresentavam manifestações clínicas. Já no grupo dos animais normais, apenas $5 \%$ apresentavam manifestações relacionadas ao sistema cardiorrespiratório; e 95\% eram assintomáticos.

De todos os animais estudados, nenhum apresentava epidemiologia relacionada à ocorrência de dirofilariose e nenhum gato havia recebido qualquer tipo de preventivo quanto à afecção. 
Quanto aos demais sistemas, foram referidos à anamnese: perda de peso (7,14\%); inapetência e perda de peso (2,38\%); poliúria, polidipsia, êmese e perda de peso $(4,76 \%)$; e êmese $(7,14 \%)$.

Dentre os antecedentes mórbidos descritos pelos proprietários, os mais relatados foram alterações dermatológicas $(7,14 \%)$ e complexo respiratório felino (7,14\%). Quanto aos antecedentes familiares, $28,56 \%$ dos animais apresentavam histórico de doença renal policística (PKD) na família e 19,04\% possuíam familiares com cardiomiopatia hipertrófica.

No momento da realização do projeto, cinco gatos com cardiomiopatia hipertrófica já estavam sendo medicados com atenolol (22,72\% dos animais com $\mathrm{CMH} ; 11,90 \%$ do total). Nenhum outro gato apresentava diagnóstico prévio de cardiopatia, sendo, portanto, o diagnóstico realizado durante o trabalho atual.

Ao exame físico, todos os animais apresentaram bom estado geral, hidratação adequada, normosfigmia e tempo de preenchimento capilar de um segundo. À avaliação do padrão respiratório por meio de inspeção direta, 85,72\% apresentaram-se eupneicos e apenas $14,28 \%$ estavam dispneicos $(11,90 \%$ com dispneia inspiratória e $2,38 \%$ com dispneia mista). Os linfonodos submandibulares encontraram-se aumentados em apenas um gato (2,38\%). À palpação abdominal, observou-se linfonodomegalia em um gato $(2,38 \%)$ e nefromegalia em outros dois $(4,76 \%)$. À avaliação das mucosas por meio de inspeção direta, um animal apresentou mucosas congestas $(2,38 \%)$ e outro mucosa hipocorada $(2,38 \%)$. À palpação de tireoides, cinco animais apresentaram tireoides palpáveis $(11,90 \%)$. Outras alterações observadas ao exame físico foram: presença de dermatopatia, gengivite, obesidade e escore corporal baixo.

À auscultação, 15 animais não apresentaram sopro (35,70\%), dos quais oito eram normais $(19,04 \%)$ e sete possuíam CMH (16,66\%). Por outro lado, 27 gatos manifestavam sopro à auscultação $(64,28 \%)$, sendo 11 (26,19\%) com sopro de grau II/VI, $13(30,95 \%)$ de grau III/VI e três $(7,14 \%)$ de grau IV/VI.

Ao avaliar apenas os animais normais, oito gatos não apresentaram sopro (40\%), seis apresentaram sopro de grau II/VI (30\%), e seis de grau III/VI (30\%). Já em relação aos gatos com $\mathrm{CMH}$, sete não apresentaram sopro $(31,82 \%)$, cinco apresentaram sopro grau II/VI (22,73\%), sete de grau III/VI $(31,82 \%)$ e três de grau IV/VI (13,63\%). 
Quanto à fonese das bulhas, 37 animais (88,10\%) apresentaram bulhas normofonéticas, três apresentaram hipofonese (7,14\%) e dois apresentaram hiperfonese de bulhas (4,76\%). Quanto ao ritmo, apenas três gatos apresentavam ritmo de galope $(7,14 \%)$ e todos os demais ritmo cardíaco regular $(92,86 \%)$. O desdobramento de bulhas foi observado em um animal (2,38\%).

Quanto à auscultação de campos pulmonares, três gatos apresentaram aumento de ruído inspiratório (7,14\%) e apenas um animal com $\mathrm{CMH}$ apresentou crepitação em campos pulmonares craniais e caudais $(2,38 \%)$.

\subsection{EXAME ELETROCARDIOGRÁFICO}

Ao exame eletrocardiográfico, o ritmo mais frequente foi o ritmo sinusal normal, seguido da taquicardia sinusal (Apêndice $A$; Tabela 2). Não foram observadas arritmias supraventriculares em nenhum grupo estudado. Apenas um gato com $\mathrm{CMH}$ apresentou arritmia ventricular, com complexos ventriculares prematuros (VPCs) isolados e polimórficos (2,38\%). Dentre os distúrbios de condução e bloqueios, observou-se presença de bloqueio de ramo direito (BRD) completo e incompleto, de bloqueio de fascículo anterior esquerdo (BFAE) e bloqueio atrioventricular de primeiro grau (Tabela 2). Demais parâmetros como: eixo cardíaco elétrico, polaridade de onda T nas diferentes derivações e segmento ST, estão descritos na tabela 2.

Os resultados obtidos quanto à frequência cardíaca, largura e amplitude da onda $\mathrm{P}$, intervalo PR, largura do complexo QRS, amplitude de onda $R$, intervalo QT e amplitude das ondas R e S nas derivações pré-cordiais CV5RL (rV2), CV6LL (V2) e CV6LU (V4) estão descritos na tabela 3 (Apêndices A e B). Dentre os parâmetros avaliados, a largura e a amplitude da onda $\mathrm{P}$ (em derivação DII) foram estatisticamente maiores nos animais com $\mathrm{CMH}(\mathrm{P}=0,0127$ e $\mathrm{P}=0,0002$, respectivamente) (Gráficos 4 e 5). A onda $R$ (em derivação DIl e em pré-cordial CV6LL) também foi estatisticamente maior nos animais com $\mathrm{CMH}$ quando comparados com os gatos normais ( $\mathrm{P}=0,049$ e $\mathrm{P}=0,0252$, respectivamente) (Gráfico $5)$. 
Tabela 2 - Parâmetros eletrocardiográficos nos diferentes grupos avaliados - São Paulo - 2014

\begin{tabular}{|c|c|c|c|}
\hline Parâmetros & Todos $(n=42)$ & Normais $(n=20)$ & $\mathrm{CMH}(\mathrm{n}=22)$ \\
\hline \multicolumn{4}{|l|}{ Ritmo } \\
\hline RSN & $85,71 \%(n=36)$ & $95 \%(n=19)$ & $77,28 \%(n=17)$ \\
\hline TS & $14,29 \%(n=6)$ & $5 \%(n=1)$ & $22,72 \%(n=5)$ \\
\hline \multicolumn{4}{|l|}{ Bloqueio: } \\
\hline Ausente & $66,68 \%(n=28)$ & $60 \%(n=12)$ & $72,73 \%(n=16)$ \\
\hline BRD incompleto & $14,28 \%(n=6)$ & $20 \%(n=4)$ & $9,10 \%(n=2)$ \\
\hline BFAE & $11,90 \%(n=5)$ & $10 \%(n=2)$ & $13,63 \%(n=3)$ \\
\hline BRD & $4,76 \%(n=2)$ & $5 \%(n=1)$ & $4,54 \%(n=1)$ \\
\hline BRD incompleto + BAV $1^{\circ}$ & $2,38 \%(n=1)$ & $5 \%(n=1)$ & $0(n=0)$ \\
\hline \multicolumn{4}{|l|}{ Eixo elétrico } \\
\hline Normal & $61,92 \%(n=26)$ & $55 \%(n=11)$ & $68,19 \%(n=15)$ \\
\hline Desvio à D & $21,42 \%(n=9)$ & $30 \%(n=6)$ & $13,63 \%(n=3)$ \\
\hline Desvio à E & $16,66 \%(n=7)$ & $15 \%(n=3)$ & $18,18 \%(n=4)$ \\
\hline \multicolumn{4}{|l|}{ Segmento ST } \\
\hline Normal & $97,62 \%(n=41)$ & $100 \%(n=20)$ & $95,46 \%(n=21)$ \\
\hline Supradesnível & $2,38 \%(n=1)$ & $0(n=0)$ & $4,54 \%(n=1)$ \\
\hline Infradesnível & $0(n=0)$ & $0(n=0)$ & $0(n=0)$ \\
\hline \multicolumn{4}{|l|}{ Onda T DII } \\
\hline Positiva & $92,86 \%(n=39)$ & $90 \%(n=18)$ & $95,46 \%(n=21)$ \\
\hline Negativa & $7,14 \%(n=3)$ & $10 \%(n=2)$ & $4,54 \%(n=1)$ \\
\hline \multicolumn{4}{|l|}{ Onda T CV5RL } \\
\hline Positiva & $76,20 \%(n=32)$ & $85 \%(n=17)$ & $68,19 \%(n=15)$ \\
\hline Negativa & $0(n=0)$ & $0(n=0)$ & $0(n=0)$ \\
\hline Não avaliado & $23,80 \%(n=10)$ & $15 \%(n=3)$ & $31,81 \%(n=7)$ \\
\hline \multicolumn{4}{|l|}{ Onda T CV6LL } \\
\hline Positiva & $69,06 \%(n=29)$ & $80 \%(n=16)$ & $59,09 \%(n=13)$ \\
\hline Negativa & $4,76 \%(n=2)$ & $0(n=0)$ & $9,10 \%(n=2)$ \\
\hline Não avaliado & $26,18 \%(n=11)$ & $20 \%(n=4)$ & $31,81 \%(n=7)$ \\
\hline \multicolumn{4}{|l|}{ Onda T CV6LU } \\
\hline Positiva & $52,40 \%(n=22)$ & $65 \%(n=13)$ & $40,92 \%(n=9)$ \\
\hline Negativa & $9,52 \%(n=4)$ & $5 \%(n=1)$ & $13,63 \%(n=3)$ \\
\hline Não avaliado & $38,08 \%(n=16)$ & $30 \%(n=6)$ & $45,45 \%(n=10)$ \\
\hline \multicolumn{4}{|l|}{ QRS V10 } \\
\hline Positivo & $14,28 \%(n=6)$ & $15 \%(n=3)$ & $13,63 \%(n=3)$ \\
\hline Negativo & $35,70 \%(n=15)$ & $35 \%(n=7)$ & $36,37 \%(n=8)$ \\
\hline Não avaliado & $49,98 \%(n=21)$ & $50 \%(n=10)$ & $50,00 \%(n=11)$ \\
\hline \multicolumn{4}{|l|}{ Onda T V10 } \\
\hline Positiva & $26,18 \%(n=11)$ & $25 \%(n=5)$ & $27,28 \%(n=6)$ \\
\hline Negativa & $21,42 \%(n=9)$ & $20 \%(n=4)$ & $22,72 \%(n=5)$ \\
\hline Não avaliado & $52,40 \%(n=22)$ & $55 \%(n=11)$ & $50,00 \%(n=11)$ \\
\hline
\end{tabular}

Nota: RSN: ritmo sinusal normal; TS: taquicardia sinusal; BRD: bloqueio de ramo direito; BFAE: bloqueio de fascículo anterior esquerdo; BAV: bloqueio atrioventricular; D: direita; E: esquerda; $\mathrm{n}$ : número de animais.

Fonte: Faculdade de Medicina Veterinária e Zootecnia da Universidade de São Paulo 
Tabela 3 - $\quad$ Média e desvio padrão de parâmetros eletrocardiográficos de gatos da raça Persa São Paulo - 2014

\begin{tabular}{lccc}
\hline Parâmetros & Todos $(\mathbf{n}=\mathbf{4 2})$ & Normais $(\mathbf{n}=\mathbf{2 0})$ & CMH $(\mathbf{n}=\mathbf{2 2})$ \\
\hline FC (bpm) & $205,22 \pm 29,00$ & $200,50 \pm 21,55$ & $209,52 \pm 35,79$ \\
P (s) & $0,036 \pm 0,009$ & $0,032 \pm 0,007^{\mathrm{a}}$ & $0,039 \pm 0,009^{\mathrm{b}}$ \\
P (mV) & $0,158 \pm 0,052$ & $0,128 \pm 0,043^{\mathrm{a}}$ & $0,186 \pm 0,044^{\mathrm{b}}$ \\
PR $(\mathbf{s})$ & $0,077 \pm 0,009$ & $0,078 \pm 0,008$ & $0,076 \pm 0,010$ \\
QRS $(\mathbf{s})$ & $0,030 \pm 0,009$ & $0,029 \pm 0,009$ & $0,031 \pm 0,010$ \\
R (mV) & $0,275 \pm 0,235$ & $0,193 \pm 0,168^{\mathrm{a}}$ & $0,350 \pm 0,296^{\mathrm{b}}$ \\
QT (s) & $0,140 \pm 0,018$ & $0,139 \pm 0,020$ & $0,141 \pm 0,018$ \\
R CV5RL (mV) & $0,226 \pm 0,131$ & $0,179 \pm 0,115$ & $0,270 \pm 0,147$ \\
S CV5RL (mV) & $0,233 \pm 0,234$ & $0,179 \pm 0,156$ & $0,283 \pm 0,283$ \\
R CV6LL (mV) & $0,324 \pm 0,240$ & $0,206 \pm 0,118^{\mathrm{a}}$ & $0,433 \pm 0,352^{\mathrm{b}}$ \\
S CV6LL (mV) & $0,089 \pm 0,081$ & $0,081 \pm 0,075$ & $0,097 \pm 0,088$ \\
R CV6LU (mV) & $0,274 \pm 0,247$ & $0,182 \pm 0,103$ & $0,358 \pm 0,378$ \\
S CV6LU (mV) & $0,061 \pm 0,060$ & $0,050 \pm 0,050$ & $0,071 \pm 0,066$ \\
\hline
\end{tabular}

Nota: $\overline{\mathrm{CMH}}$ : cardiomiopatia hipertrófica; FC: frequência cardíaca; $\mathrm{P}(\mathrm{s})$ : largura de onda $\mathrm{P} ; \mathrm{P}(\mathrm{mV})$ : amplitude de onda P; PR (s): intervalo PR; QRS (s): largura do complexo QRS; R (mV): amplitude da onda R; QT (s): intervalo QT; R CV5RL (mV): amplitude da onda R em CV5RL; S CV5RL (mV): amplitude da onda S em CV5RL; R CV6LL (mV): amplitude da onda R em CV6LL; S CV6LL (mV): amplitude da onda S em CV6LL; R CV6LU (mV): amplitude da onda R em CV6LU; S CV6LU (mV): amplitude da onda S em C6LU; (s): segundos; (mV): milivolts; ${ }^{a, b}$ : indicadores de diferenças estatísticas.

Fonte: Faculdade de Medicina Veterinária e Zootecnia da Universidade de São Paulo

Gráfico 4 -Largura da onda P (em segundos; na derivação DII) do eletrocardiograma em gatos da raça Persa nos diferentes grupos experimentais - São Paulo - 2014

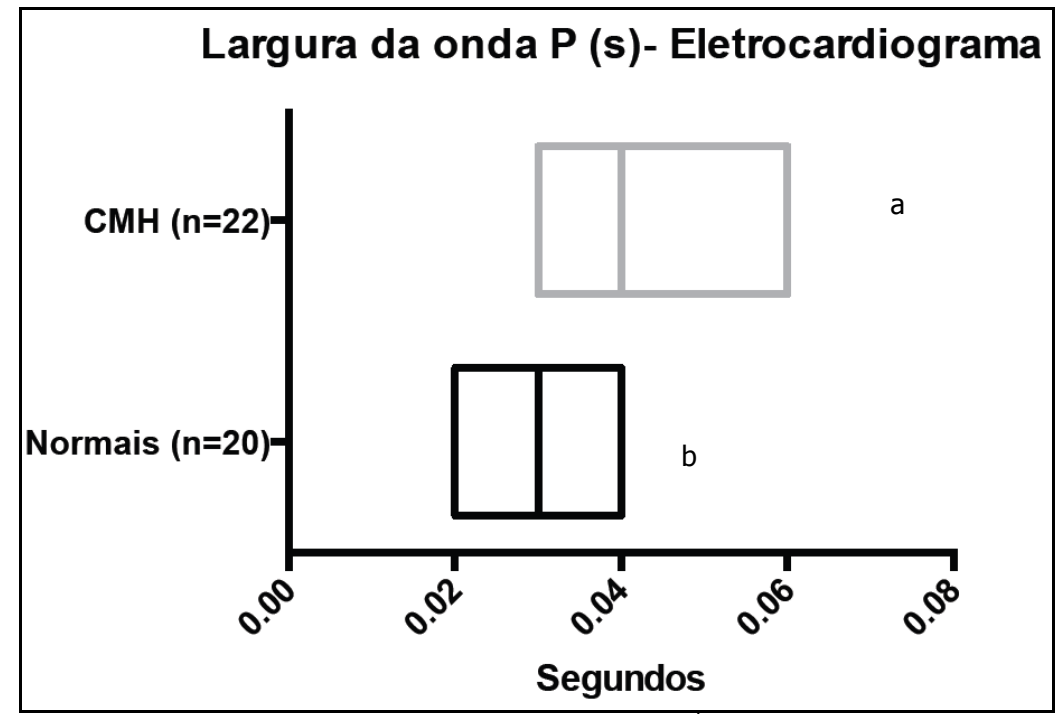

Legenda: $\mathrm{CMH}$ : cardiomiopatia hipertrófica; (s): segundos; ${ }^{a, b}$ : indicadores de diferenças estatísticas. Fonte: $\quad$ Faculdade de Medicina Veterinária e Zootecnia da Universidade de São Paulo. 
Gráfico 5 - Amplitude da onda P (na derivação DII) e da onda R (em derivação DII e em precordial CV6LL) no eletrocardiograma de gatos da raça Persa nos diferentes grupos experimentais - São Paulo - 2014

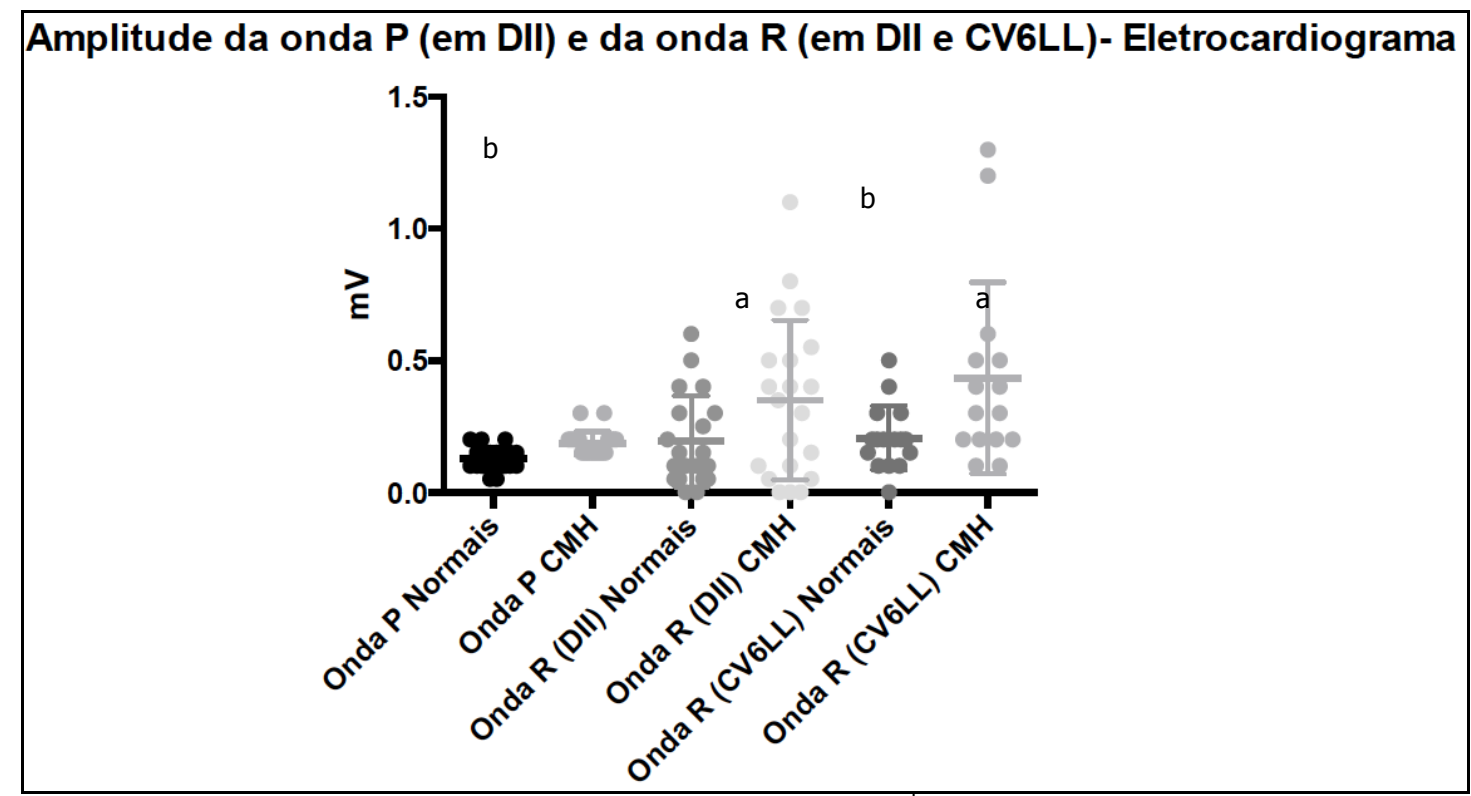

Legenda: $\mathrm{CMH}$ : cardiomiopatia hipertrófica; $(\mathrm{mV})$ : milivolts; ${ }^{\text {a,b }}$ : indicadores de diferenças estatísticas. Fonte: $\quad$ Faculdade de Medicina Veterinária e Zootecnia da Universidade de São Paulo.

De todos os animais avaliados, apenas dois (4,76\%) apresentaram distúrbio de repolarização ventricular (ambos com $\mathrm{CMH}$ ). Os parâmetros eletrocardiográficos foram sugestivos de sobrecarga de átrio esquerdo (largura de onda $\mathrm{P}$ superior a $0,04 \mathrm{~s})$ em apenas quatro gatos com $\mathrm{CMH}(9,52 \%$ do total); de sobrecarga ventricular esquerda (complexo QRS com largura superior a 0,04 s; amplitude da onda $\mathrm{R}$ superior a 0,9 mV em derivação DII; e/ou amplitude de onda $\mathrm{R}$ superior a 1,0 $\mathrm{mV}$ em derivações pré-cordiais CV6LL e/ou CV6LU) em quatro gatos com $\mathrm{CMH}$ $(9,52 \%$ do total); e de sobrecarga ventricular direita (e/ou bloqueio de ramo direito completo ou incompleto) em nove indivíduos $(21,42 \%$ do total; sendo seis normais e três com $\mathrm{CMH}$ ).

Dentre os animais com parâmetros eletrocardiográficos sugestivos de sobrecarga atrial esquerda $(n=4)$, apenas dois gatos com $\mathrm{CMH}$ realmente apresentavam aumento de átrio esquerdo ao ecocardiograma. Por outro lado, dentre os gatos com aumento atrial esquerdo detectado ao ecocardiograma $(n=8)$, apenas dois apresentaram alterações eletrocardiográficas sugestivas de sobrecarga atrial esquerda. Desta forma, a sensibilidade do ECG em detectar aumento de AE foi de $25,0 \%$ e a especificidade foi de $94,21 \%$, com acurácia de $81,39 \%$, valor preditivo positivo (VPP) de 50,0\% e valor preditivo negativo (VPN) de $84,61 \%$. A razão de 
probabilidade positiva (RPP) foi de 4,37 e a razão de probabilidade negativa (RPN) foi de 0,79 .

Dentre os animais com parâmetros eletrocardiográficos sugestivos de sobrecarga ventricular esquerda $(n=4)$, quatro realmente apresentavam aumento da espessura do septo interventricular e/ou da parede livre do VE ao ecocardiograma (quadro condizente com $\mathrm{CMH}$ ). Por outro lado, de todos os gatos com $\mathrm{CMH}$ detectada ao ecocardiograma $(n=22)$, apenas quatro apresentaram alterações eletrocardiográficas sugestivas de sobrecarga ventricular esquerda. Desta forma, a sensibilidade do ECG em detectar sobrecarga ventricular esquerda foi de $18,19 \%$ e a especificidade foi de 100\%, com acurácia de 57,14\% (VPP de 100\% e VPN de $52,63 \%)$.

\subsection{MENSURAÇÃO DA PRESSÃO ARTERIAL}

Quanto aos valores de pressão arterial sistólica, a média obtida dentre todos os animais foi de $142,93 \pm 17,93 \mathrm{mmHg}$ (mínimo de 108 e máximo de $180 \mathrm{mmHg}$ ). Oito animais apresentaram valores de pressão arterial sistólica superiores ao limite de normalidade de $150 \mathrm{mmHg}$ (cinco gatos normais e três com $\mathrm{CMH}$ ). Destes, quatro apresentaram aumento discreto, com valores entre 160 e 166 mmHg (dois animais com $\mathrm{CMH}$ e um normal); dois apresentaram aumento moderado (um normal e um com $\mathrm{CMH}$ ); e dois apresentaram aumento importante, com valores de 180 $\mathrm{mmHg}$ (todos normais). Os animais com aumento de pressão arterial sistólica apresentaram-se bastante agitados durante a mensuração, podendo justificar esta elevação (secundária ao estresse). Além disso, nenhum animal com aumento de pressão arterial sistólica apresentou outras alterações sistêmicas que pudessem sugerir um quadro de hipertensão arterial crônico.

Nos indivíduos normais, a média da pressão arterial sistólica foi de 143,75 \pm $19,11 \mathrm{mmHg}$, com valor mínimo de $118 \mathrm{mmHg}$ e máximo de 180 mmHg (Apêndice C). Nos pacientes com $\mathrm{CMH}$, a média da pressão arterial sistólica foi de 142,60 \pm 16,86 mmHg, com valor mínimo de 108 mmHg e máximo de 176 mmHg (Apêndice C). Não foram observadas diferenças estatísticas nos valores de pressão arterial sistólica entre animais normais e acometidos pela $\mathrm{CMH}$. O único gato com $\mathrm{CMH}$ e 
aumento moderado da pressão arterial $(176 \mathrm{mmHg})$ não foi excluído da avaliação por apresentar-se extremamente agitado durante a realização do exame e por possuir histórico de pressão arterial sistólica normal em outras avaliações prévias ao estudo.

\subsection{EXAMES LABORATORIAIS}

Não foram observadas alterações significativas nos exames hematológicos e bioquímicos realizados. Valores de hormônio tireoidiano T4 total revelaram-se dentro da normalidade nos animais, excluindo-se a possibilidade de hipertireoidismo.

O eritrograma mostrou-se normal em todos os animais avaliados. No leucograma, observou-se discreta leucocitose em cinco animais. Destes, nenhum apresentava desvios à esquerda, neutrófilos tóxicos ou qualquer outro indicativo de infecção. Eosinofilia discreta foi observada num gato; quatro indivíduos apresentaram discreta leucopenia; e os valores de plaquetas revelaram-se dentro da normalidade em todos os gatos analisados.

À avaliação bioquímica, todos os animais apresentaram valores de creatinina sérica dentro do limite de normalidade, com exceção de um gato com $\mathrm{CMH}$ que apresentou discreto aumento de ureia e creatinina séricas $(63,28 \mathrm{mg} / \mathrm{dL}$ e 1,92 $\mathrm{mg} / \mathrm{dL}$, respectivamente). Porém, este mesmo animal apresentava-se hidratado e com densidade urinária normal, diminuindo a possibilidade de nefropatia. Além disso, cinco animais obtiveram valores de ureia isoladamente aumentados. À avaliação das enzimas hepáticas, todos os valores de proteína total, albumina sérica, fosfatase alcalina (FA), aspartato aminotransferase (AST) e gamaglutamiltransferase (GGT) encontraram-se dentro do limite de normalidade para a espécie estudada. Apenas quatro animais (três com $\mathrm{CMH}$ e um normal) apresentaram discreto aumento na alanino aminotransferase (ALT), isoladamente. Todos os valores de eletrólitos (cálcio total, fósforo, sódio e potássio) estavam normais nos pacientes avaliados. 


\subsection{EXAME ECOCARDIOGRÁFICO}

Após seleção dos grupos experimentais, 20 animais $(47,61 \%)$ foram considerados normais quanto à cardiomiopatia hipertrófica (valores de SIVd e/ou PVEd menores que 0,5 cm), e 22 gatos (52,39\%) apresentavam alterações ecocardiográficas condizentes com a $\mathrm{CMH}$ (valores de SIVd e/ou PVEd maiores ou iguais a 0,6 cm) (Gráfico 6).

Gráfico 6 -Espessuras diastólicas do septo interventricular e da parede livre do ventrículo esquerdo ao ecocardiograma de gatos da raça Persa nos diferentes grupos experimentais - São Paulo - 2014

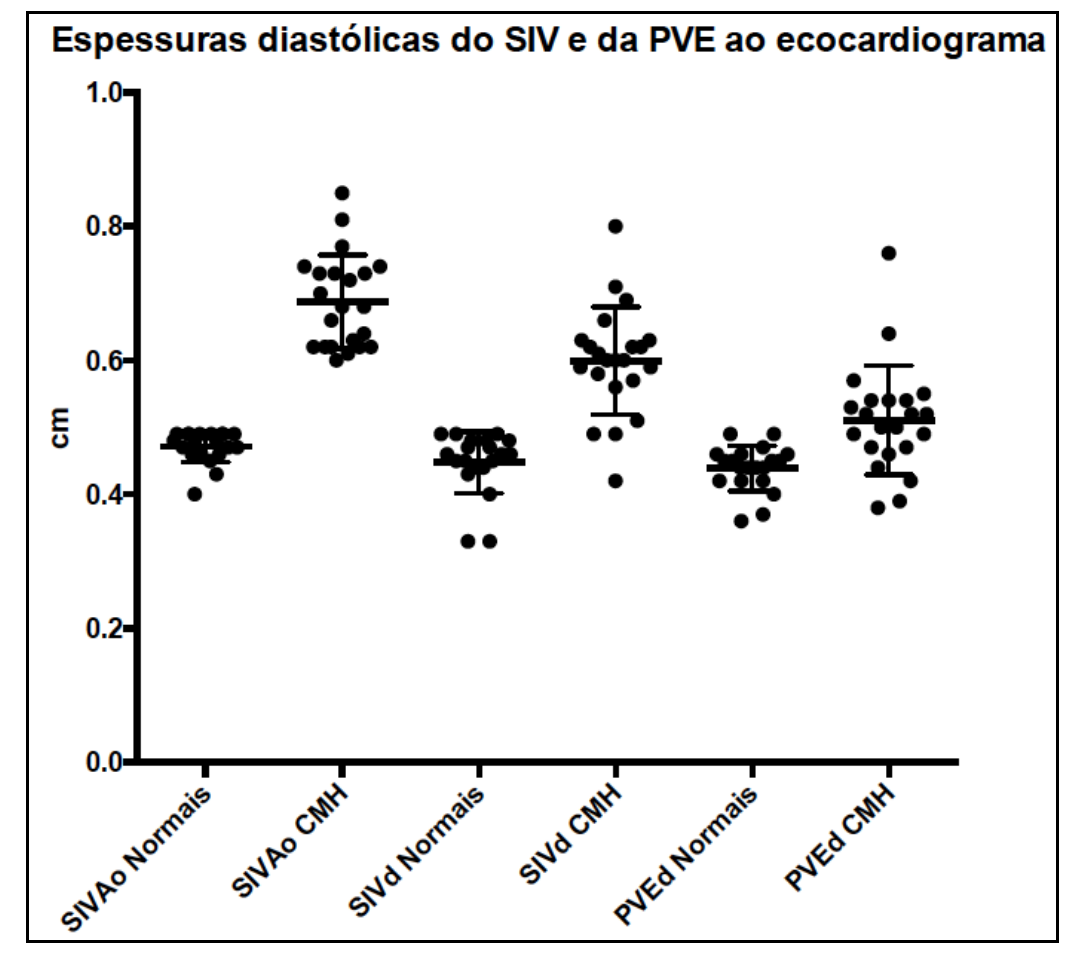

Legenda: $\mathrm{CMH}$ : cardiomiopatia hipertrófica; SIVao: espessura diastólica do septo interventricular em região basal de via de saída do ventrículo esquerdo; SIVd: espessura diastólica do septo interventricular; PVEd: espessura diastólica da parede livre do ventrículo esquerdo.

Fonte: $\quad$ Faculdade de Medicina Veterinária e Zootecnia da Universidade de São Paulo.

Os valores de ecocardiografia convencional obtidos nos diferentes grupos estão descritos na tabela 4 (Apêndices D e E). 
Tabela 4 - Média e desvio padrão de parâmetros de ecocardiografia convencional de gatos da raça Persa - São Paulo - 2014

\begin{tabular}{lccc}
\hline Parâmetros & Todos (n=42) & Normais $\mathbf{( n = 2 0 )}$ & CMH (n=22) \\
\hline FC (bpm) & $201,71 \pm 29,636$ & $206,80 \pm 24,762$ & $197,09 \pm 34,068$ \\
SIVAo (cm) & $0,584 \pm 0,047$ & $0,472 \pm 0,023^{\mathrm{a}}$ & $0,687 \pm 0,069^{\mathrm{b}}$ \\
SIVd (cm) & $0,529 \pm 0,062$ & $0,448 \pm 0,045^{\mathrm{a}}$ & $0,600 \pm 0,078^{\mathrm{b}}$ \\
PVEd (cm) & $0,476 \pm 0,057$ & $0,439 \pm 0,033^{\mathrm{a}}$ & $0,511 \pm 0,079^{\mathrm{b}}$ \\
SIVd/PVEd & $1,103 \pm 0,083$ & $1,019 \pm 0,067^{\mathrm{a}}$ & $1,180 \pm 0,098^{\mathrm{b}}$ \\
DVEd (cm) & $1,378 \pm 0,176$ & $1,437 \pm 0,163$ & $1,325 \pm 0,188$ \\
DVEs (cm) & $0,616 \pm 0,149$ & $0,624 \pm 0,139$ & $0,610 \pm 0,159$ \\
FS (\%) & $55,49 \pm 0,070$ & $56,65 \pm 0,063$ & $54,44 \pm 0,078$ \\
Fej & $0,882 \pm 0,057$ & $0,891 \pm 0,046$ & $0,874 \pm 0,067$ \\
Ao (cm) & $0,914 \pm 0,105$ & $0,922 \pm 0,109$ & $0,908 \pm 0,102$ \\
AE (cm) & $1,232 \pm 0,227$ & $1,142 \pm 0,139^{\mathrm{a}}$ & $1,315 \pm 0,308^{\mathrm{b}}$ \\
AE/Ao & $1,356 \pm 0,240$ & $1,244 \pm 0,097^{\mathrm{a}}$ & $1,459 \pm 0,370^{\mathrm{b}}$ \\
Fl. Ao- Vmáx & $1,224 \pm 0,520$ & $0,982 \pm 0,200^{\mathrm{a}}$ & $1,445 \pm 0,812^{\mathrm{b}}$ \\
FI. Ao- grad & $7,670 \pm 8,682$ & $4,018 \pm 1,814^{\mathrm{a}}$ & $10,990 \pm 14,927^{\mathrm{b}}$ \\
FI. Pulm- Vmáx & $0,984 \pm 0,192$ & $1,004 \pm 0,161$ & $0,966 \pm 0,222$ \\
FI. Pulm- grad & $4,035 \pm 1,636$ & $4,148 \pm 1,281$ & $3,933 \pm 1,960$ \\
Onda E (m/s) & $0,774 \pm 0,260$ & $0,770 \pm 0,223$ & $0,779 \pm 0,295$ \\
TDE (ms) & $61,48 \pm 17,194$ & $58,88 \pm 16,857$ & $63,86 \pm 17,501$ \\
Onda A (m/s) & $0,584 \pm 0,145$ & $0,584 \pm 0,151$ & $0,604 \pm 0,141$ \\
E/A & $1,205 \pm 0,481$ & $1,177 \pm 0,410$ & $1,231 \pm 0,547$ \\
TRIV (ms) & $45,660 \pm 6,543$ & $45,10 \pm 3,713$ & $46,17 \pm 9,117$ \\
\hline
\end{tabular}

Nota: CMH: cardiomiopatia hipertrófica; FC (bpm): frequência cardíaca em batimentos por minuto; SIVAo $(\mathrm{cm})$ : espessura diastólica do septo interventricular em região de via de saída do ventrículo esquerdo em centímetros; SIVd $(\mathrm{cm})$ : espessura diastólica do septo interventricular em centímetros; PVEd $(\mathrm{cm})$ : espessura diastólica da parede livre do ventrículo esquerdo em centímetros; DVEd $(\mathrm{cm})$ : diâmetro diastólico da cavidade do ventrículo esquerdo em centímetros; DVEs $(\mathrm{cm})$ : diâmetro sistólico da cavidade do ventrículo esquerdo em centímetros; FS (\%): fração de encurtamento; Fej: fração de ejeção; Ao $(\mathrm{cm})$ : diâmetro da raiz da aorta, em centímetro, no corte transversal em modo bidimensional; $A E(\mathrm{~cm})$ : diâmetro do átrio esquerdo, em centímetro, no corte transversal em modo bidimensional; $A E / A o$ : relação átrio esquerdo-aorta; $\mathrm{FI}$. Ao: fluxo aórtico; Vmáx $(\mathrm{m} / \mathrm{s})$ : velocidade máxima em metros por segundo; grad $(\mathrm{mmHg})$ : gradiente de pressão em milímetros de mercúrio; Fl. Pulm: fluxo na artéria pulmonar; TDE (ms): tempo de desaceleração de onda $E$, em milissegundos; E/A: relação $E / A$; TRIV (ms): tempo de relaxamento isovolumétrico, em milissegundos; $n$ : número de animais.; ${ }^{\mathrm{a}, \mathrm{b}}$ : indicadores de diferenças estatísticas.

Fonte: Faculdade de Medicina Veterinária e Zootecnia da Universidade de São Paulo

Nenhum animal apresentou aumento de diâmetro diastólico final da cavidade do ventrículo esquerdo (DVEd) e de diâmetro sistólico final da cavidade do ventrículo esquerdo (DVEs). A fração de encurtamento (FS) e a fração de ejeção (Fej) estavam aumentadas em 13 animais (30,95\%), dos quais, seis com $\mathrm{CMH}$ e sete ecocardiograficamente normais. Nenhum paciente apresentou diminuição nas frações de encurtamento e/ou de ejeção.

À avaliação das dimensões da raiz da aorta e do diâmetro do átrio esquerdo por meio do método bidimensional (corte transversal), oito animais com $\mathrm{CMH}$ apresentaram relação $A E / A o$ maior que 1,5 , indicativa de aumento atrial $(19,04 \%$ do total; $36,36 \%$ dentre os gatos com $\mathrm{CMH}$ ). Destes animais com aumento atrial, o átrio 
esquerdo estava discretamente aumentado em quatro gatos, moderadamente aumentado em um e com aumento importante em outros três.

Quanto à avaliação morfológica e subjetiva dos aparelhos valvares, todas as valvas (mitral, tricúspide, aórtica e pulmonar) encontravam-se anatomicamente normais. Em sete animais com $\mathrm{CMH}$, observou-se o movimento anterior sistólico da valva mitral (MAS) (16,67\% do total; 31,81\% dentre os gatos com $\mathrm{CMH})$.

$\mathrm{Na}$ avaliação dos fluxos transvalvares por meio do Doppler pulsado, nenhum indivíduo apresentou alterações na velocidade máxima do fluxo da artéria pulmonar, nem em seu gradiente de pressão. Quanto ao fluxo aórtico, três animais com $\mathrm{CMH}$ $(7,14 \%$ do total; $13,63 \%$ dentre os gatos com $\mathrm{CMH})$ apresentaram aumento na velocidade máxima e no gradiente de pressão da artéria aorta. Todos estes gatos com aumento no fluxo aórtico pelo Doppler pulsado também apresentaram movimento anterior sistólico da valva mitral.

$\mathrm{Na}$ avaliação do fluxo transmitral por meio de Doppler pulsado, houve fusão das ondas $E$ e A, impedindo correta avaliação, em 12 animais (28,57\%). Inversão de ondas $E$ e $A$ (ou seja, relação E/A menor que um) esteve presente em 12 animais (28,57\%), a saber: sete acometidos pela $\mathrm{CMH}$ e cinco normais. Fluxo transmitral de padrão restritivo (alteração na distensibilidade ventricular), com relação E/A maior que dois, foi observado em apenas um gato com $\mathrm{CMH}$ (2,38\%). Nos demais animais (40,48\%), a relação E/A revelou-se dentro da normalidade (relação E/A maior que um e menor que dois), não permitindo, isoladamente, diferenciação entre o padrão normal e o padrão pseudonormal.

O tempo de desaceleração da onda mitral E (TDE) apresentou-se aumentado (maior que $79 \mathrm{~ms}$ ) em oito animais (19,04\%), sendo seis acometidos pela $\mathrm{CMH}$ e dois animais normais. O TDE estava diminuído (menor que 53 ms) em 14 animais $(33,34 \%)$, sendo oito acometidos pela $\mathrm{CMH}$ e seis normais.

O tempo de relaxamento isovolumétrico (TRIV) estava aumentado (maior que $54 \mathrm{~ms}$ ) em quatro animais $(9,52 \%)$, podendo caracterizar alteração no relaxamento ventricular. Destes, todos eram acometidos pela $\mathrm{CMH}$. O TRIV estava reduzido (menor que $38 \mathrm{~ms}$ ) em quatro animais (9,52\%), todos com $\mathrm{CMH}$.

À avaliação dos fluxos transvalvares por meio do Doppler colorido, observouse insuficiência valvar mitral em 28 animais (66,67\%), insuficiência valvar tricúspide de grau discreto em 11 animais (26,19\%) e turbulência sistólica em via de saída do ventrículo esquerdo em três pacientes com $\mathrm{CMH}(7,14 \%$ do total). Não foram 
observadas insuficiências das valvas aórtica e/ou pulmonar; e a insuficiência tricúspide não apresentava repercussão hemodinâmica em átrio e/ou em ventrículo direito. Quanto ao grau da regurgitação mitral, 26 pacientes apresentaram insuficiência discreta $(61,90 \%$ do total), sendo nove normais e 17 com $\mathrm{CMH}$. E dois gatos com $\mathrm{CMH}$ apresentaram insuficiência mitral de grau moderado $(4,76 \%$ do total). Dos três animais com $\mathrm{CMH}$ e com turbulência sistólica em via de saída do ventrículo esquerdo, dois apresentavam obstrução de via de saída de grau discreto e um, de grau moderado.

Ao avaliar apenas os indivíduos acometidos pela $\mathrm{CMH}(\mathrm{n}=22)$, a presença de hipertrofia miocárdica septal em região de via de saída do ventrículo esquerdo (SIVAo) ocorreu em 20 animais (90,90\%) e, em quatro gatos, observou-se hipertrofia miocárdica concêntrica (18,18\%; dois destes gatos também apresentavam hipertrofia miocárdica septal mais evidente em região basal de via de saída do ventrículo esquerdo). De acordo com a classificação utilizada por Wess, Sarkar e Hartmann (2010) descrita anteriormente, em 10 gatos acometidos a $\mathrm{CMH}$ foi considerada de grau discreto (45,45\%); de grau moderado em outros nove gatos (40,90\%); e de grau importante em três gatos (13,65\%).

Sete gatos com $\mathrm{CMH}$ apresentavam movimento anterior sistólico da valva mitral (MAS) $(31,81 \%)$ e, destes, três mostraram turbulência sistólica em via de saída de ventrículo esquerdo (13,63\%), sendo dois com aumento discreto e um com aumento moderado no gradiente de pressão aórtico. Dezenove apresentavam insuficiência valvar mitral (86,36\%) e nove, insuficiência valvar tricúspide $(40,90 \%)$. Dos oito animais com aumento atrial esquerdo (36,36\%), quatro apresentavam aumento discreto (18,19\%), um moderado (4,54\%) e três, importante (13,63\%).

O diâmetro do átrio esquerdo (em modo bidimensional) foi significativamente maior nos acometidos pela $\mathrm{CMH}$ em relação aos normais $(P=0,030)$ (Gráfico 7). Observaram-se, também, diferenças estatísticas na relação AE/Ao, que foi maior nos acometidos pela $\mathrm{CMH}$ em relação aos normais $(P=0,0178)$ (Gráfico 7); e na velocidade e gradiente de pressão do fluxo aórtico, que foi maior nos acometidos pela $\mathrm{CMH}$ em relação aos normais $(\mathrm{P}=0,0201$ e $\mathrm{P}=0,049$, respectivamente) (Gráfico 8). Nos demais parâmetros de ecocardiografia convencional, não foram observadas alterações significativas nos diferentes grupos avaliados. 
Gráfico 7 -Diâmetro do átrio esquerdo ao ecocardiograma de gatos da raça Persa nos diferentes grupos experimentais - São Paulo - 2014

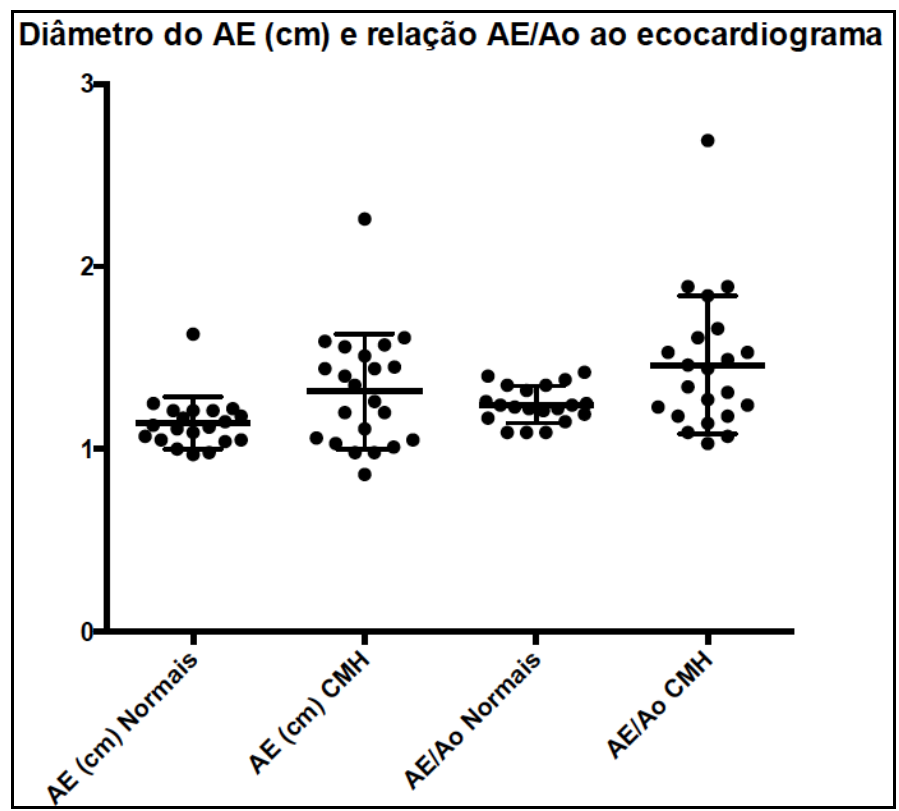

Legenda: $\mathrm{CMH}$ : cardiomiopatia hipertrófica; $\mathrm{AE}$ : diâmetro do átrio esquerdo em centímetros; $\mathrm{AE} / \mathrm{Ao}$ : relação átrio esquerdo aorta.

Fonte: $\quad$ Faculdade de Medicina Veterinária e Zootecnia da Universidade de São Paulo.

Gráfico 8 - Gradiente de pressão $(\mathrm{mmHg})$ do fluxo aórtico ao ecocardiograma de gatos da raça Persa nos diferentes grupos experimentais - São Paulo - 2014

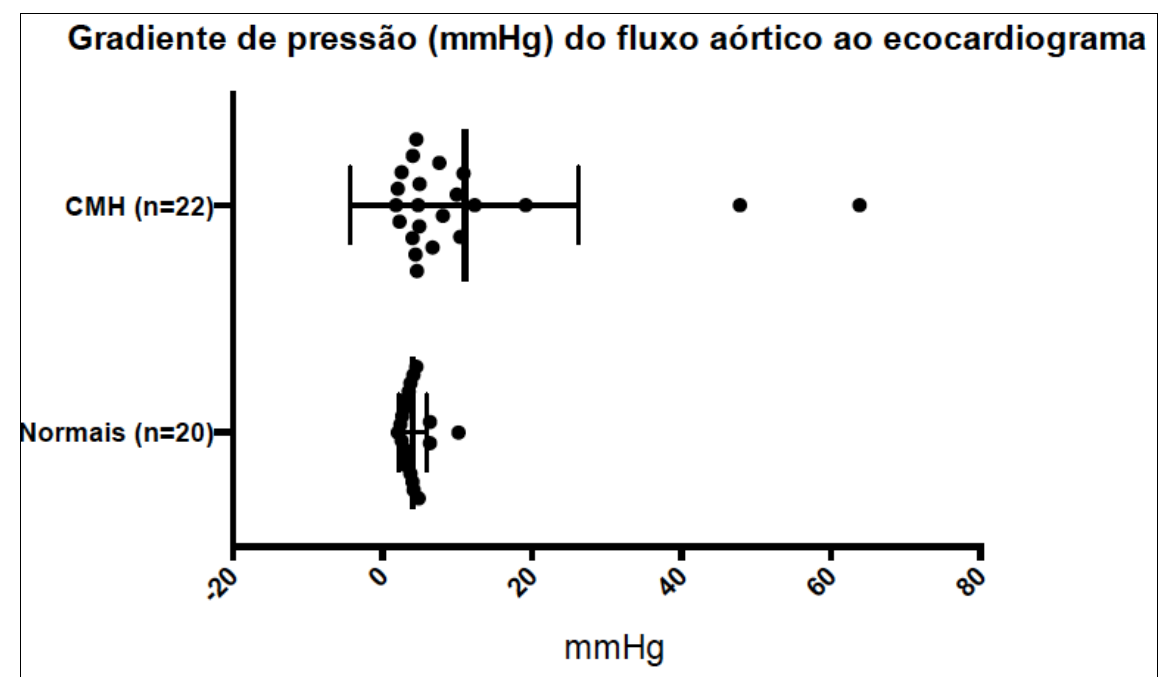

Legenda: $\quad \mathrm{CMH}$ : cardiomiopatia hipertrófica; Grad Ao: gradiente de pressão do fluxo aórtico; $\mathrm{mmHg}$ : milímetros de mercúrio.

Fonte: $\quad$ Faculdade de Medicina Veterinária e Zootecnia da Universidade de São Paulo.

Ao correlacionar a presença de insuficiências valvares e/ou obstrução de via de saída do ventrículo esquerdo e a detecção de sopro ao exame físico, pode-se observar que: 30 gatos apresentaram fluxos turbulentos (insuficiências e/ou 
obstrução de via de saída) ao ecocardiograma; e 27 gatos apresentaram sopro à auscultação cardíaca. Destes animais com fluxos turbulentos $(n=30), 20$ apresentaram sopro e 10 não apresentaram sopro à auscultação cardíaca. Por outro lado, dos 27 animais com sopro à auscultação, 20 gatos revelaram fluxos turbulentos e sete gatos não apresentavam fluxos turbulentos ao ecocardiograma. Desta forma, a sensibilidade da auscultação de sopro para detecção de anormalidades ao ecocardiograma foi de $66,67 \%$ e a especificidade foi de $46,15 \%$, com acurácia de $60,46 \%$ (VPP de $74,07 \%$ e VPN de $37,50 \%$ ).

\subsection{AVALIAÇÃO GENÉTICA}

\subsubsection{Análise do sequenciamento de DNA do exon 5 do gene ACTC1 felino}

A extração e o sequenciamento do DNA do exon 5 do gene ACTC1 felino foram realizados nas 20 amostras dos animais sem $\mathrm{CMH}$ (grupo normal) e nas amostras dos 22 animais com $\mathrm{CMH}$ (grupo com $\mathrm{CMH}$ ). A figura abaixo demonstra os produtos de PCR purificados em gel de agarose $2 \%$ para a realização do sequenciamento (Figura 10).

Figura 10 -Eletroforese em gel de agarose $2 \%$ dos produtos de PCR purificados do exon 5 do gene ACTC1 felino

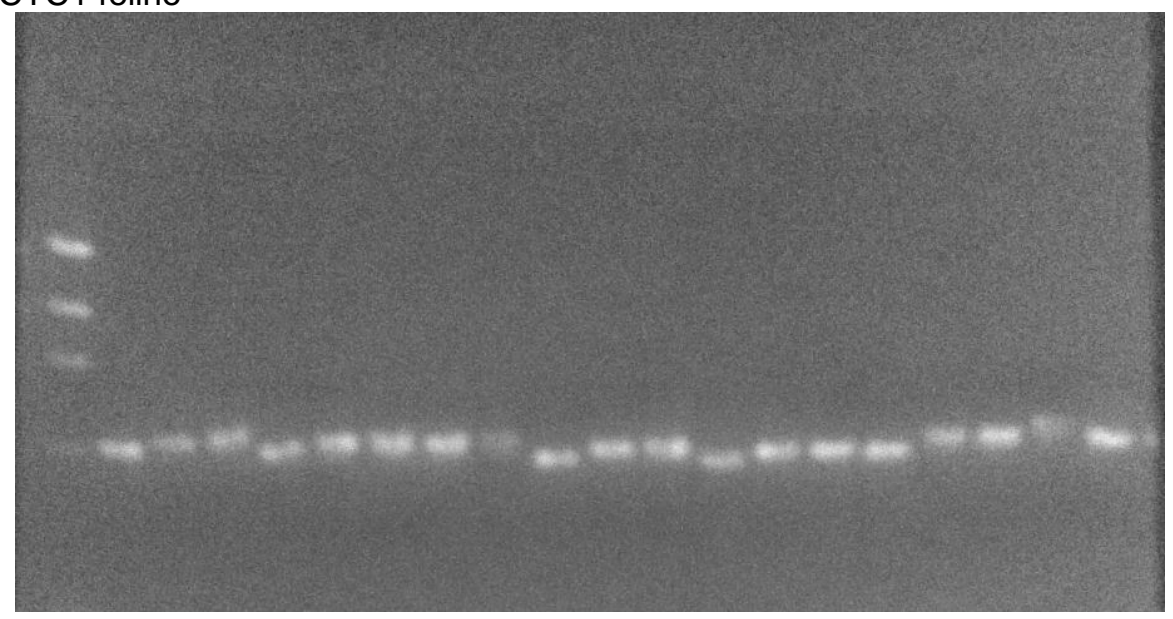

Legenda: Demonstração das bandas formadas por meio de eletroforese em gel de agarose $2 \%$ dos produtos de PCR purificados do exon 5 do gene ACTC1 felino.

Fonte: Departamento de Patologia da FMVZ-USP. Responsável: Prof. Dr. Bruno Cogliati. 
Os resultados obtidos pelo sequenciamento das amostras foram comparados com a sequência do RNA mensageiro do gene ACTC1 felino depositada no GenBank (GenBank \# XM_003987297.2; Ensembl:ENSFCAG00000014067) (Figura 11) e com a sequência consenso obtida dos animais normais do estudo.

Figura 11- Sequência do RNA mensageiro do gene ACTC1 felino depositada no GenBank

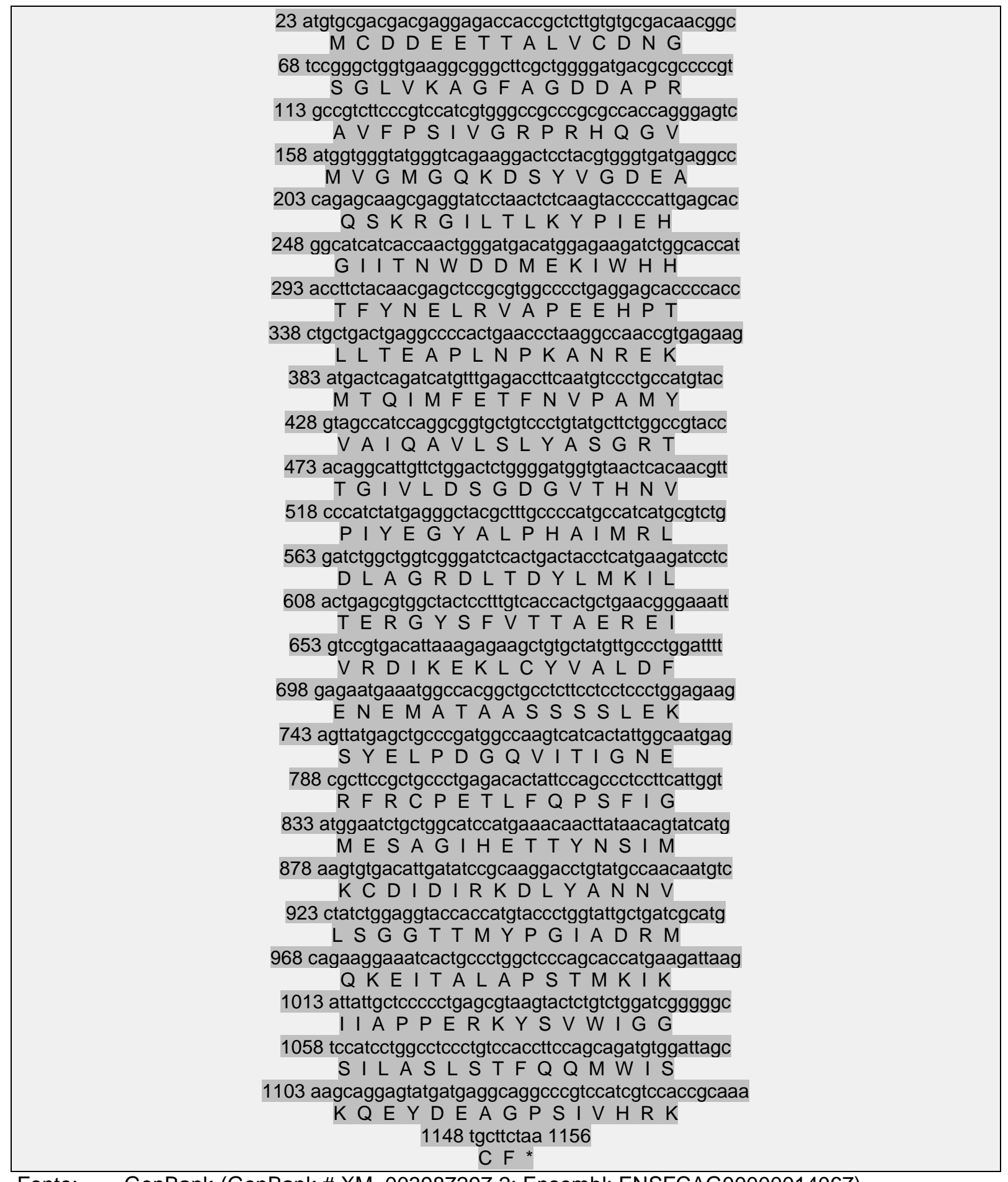

Fonte: GenBank (GenBank \# XM_003987297.2; Ensembl: ENSFCAG00000014067). 
Apenas um polimorfismo de nucleotídeo único (SNP) foi identificado no exon 5 do gene ACTC1 felino, na posição 890 de seu RNA mensageiro, correspondente a uma troca de citosina (C) para adenina (A) (Figura 12). Este SNP foi observado, em heterozigose, em três animais do grupo normal e em seis animais do grupo com $\mathrm{CMH}$ (Tabelas 5 e 6), não havendo diferenças estatísticas em relação à ocorrência desta mutação nos diferentes grupos. Os demais animais apresentaram citosina em homozigose (CC) nesta posição. Comparando-se com a sequência proteica putativa gerada pelo programa ORF Finder (http://www.ncbi.nlm.nih.gov/gorf/orfig.cgi) (Figura 13), não se observou troca de aminoácido na sequência, sendo esta, portanto, uma mutação silenciosa.

As frequências alélica e genotípica estão representadas nas tabelas 5 e 6 . Não foram observadas diferenças estatísticas em relação a estas frequências alélicas e genotípicas (SNP na posição 890 do RNA mensageiro do exon 5 do gene ACTC1 felino) entre o grupo normal e o grupo com $\mathrm{CMH}$.

Apesar da presença da mutação (troca de citosina por adenina) em alguns animais, não foi observada a troca de aminoácido na sequência proteica (mutação silenciosa); e a mutação não ocorreu exclusivamente nos animais com $\mathrm{CMH}$.

Tabela 5 - Frequência alélica relacionada ao SNP na posição 890 do RNA mensageiro do exon 5 do gene ACTC1 felino - São Paulo - 2014

\begin{tabular}{lcccc}
\hline Genótipos & \multicolumn{2}{c}{ Normais $(\mathbf{n = 2 0})$} & \multicolumn{2}{c}{ CMH (n=22) } \\
\hline & $\mathbf{N}$ & $\%$ & $\mathbf{N}$ & $\%$ \\
\hline Alelo C & $37 / 40$ & $92,50 \%$ & $38 / 44$ & $86,36 \%$ \\
Alelo A & $3 / 40$ & $7,50 \%$ & $6 / 44$ & $13,64 \%$ \\
\hline
\end{tabular}

Nota: SNP: polimorfismo de nucleotídeo único; $\mathrm{CMH}$ : cardiomiopatia hipertrófica; alelo $\mathrm{A}$ : adenina; alelo $\mathrm{C}$ : citosina; N: número; \%: porcentagem.

Fonte: Faculdade de Medicina Veterinária e Zootecnia da Universidade de São Paulo.

Tabela 6 - Frequência genotípica relacionada ao SNP na posição 890 do RNA mensageiro do exon 5 do gene ACTC1 felino - São Paulo - 2014

\begin{tabular}{lcccc}
\hline Genótipos & \multicolumn{2}{c}{ Normais $(\mathbf{n = 2 0})$} & \multicolumn{2}{c}{ CMH (n=22) } \\
\hline & $\mathbf{N}$ & $\%$ & $\mathbf{N}$ & $\%$ \\
\hline Genótipo CC & $17 / 20$ & $85,00 \%$ & $16 / 22$ & $72,73 \%$ \\
Genótipo CA & $3 / 20$ & $15,00 \%$ & $6 / 22$ & $27,27 \%$ \\
Genótipo AA & 0 & $0 \%$ & 0 & $0 \%$
\end{tabular}

Nota: SNP: polimorfismo de nucleotídeo único; $\mathrm{CMH}$ : cardiomiopatia hipertrófica; genótipo CC: citosina em homozigose; genótipo CA: troca de citosina por adenina em heterozigose; genótipo AA: adenina em homozigose; N: número; \%: porcentagem.

Fonte: Faculdade de Medicina Veterinária e Zootecnia da Universidade de São Paulo. 
Figura 12 - Eletroferograma do sequenciamento do exon 5 do gene ACTC1 felino demonstrando uma alteração em heterozigose na posição 890 do RNA mensageiro

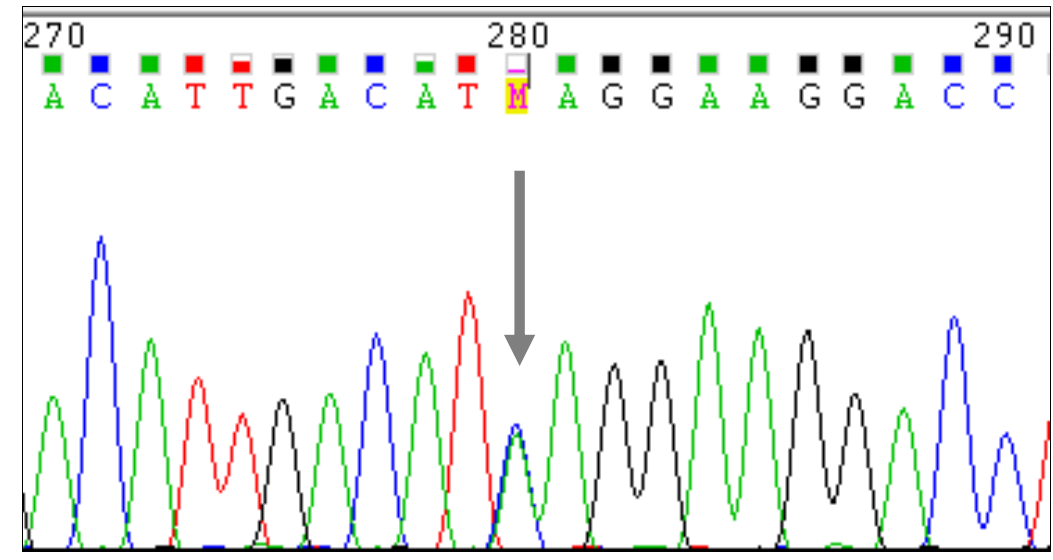

Legenda: Seta cinza indicando alteração em heterozigose na posição 890 do RNA mensageiro.

Fonte: Departamento de Patologia da FMVZ-USP. Responsável: Prof. Dr. Bruno Cogliati.

Figura 13 - Sequência obtida pelo programa ORF Finder considerando o polimorfismo de nucleotídeo único (troca de $\mathrm{C}$ por $\mathrm{A}$ ) na posição 890 do exon 5 do gene ACTC1 felino

\begin{tabular}{|cc|}
\hline & 14 atggctwgygtctcctttgcagggatggagtctgccggcatccac \\
M A X V S F A G M E S A G I H & 59 gaaaccacctacwacagcatcatgaagtgcgacattgacataagg \\
E T T Y X S I M K C D I D I R \\
104 aaggacctgtatgccaacaacgtcctctccgggggcaccaccatg \\
K D L Y A N N V L S G G T T M \\
14 atggctwgygtctcctttgcagggatggagtctgccggcatccac \\
M A X V S F A G M E S A G I H \\
59 gaaaccacctacwacagcatcatgaagtgcgacattgacatcagg \\
E T T Y X S I M K C D I D I R \\
104 aaggacctgtatgccaacaacgtcctctccgggggcaccaccatg \\
K D L Y A N N V L S G G T T M
\end{tabular}

Três polimorfismos de nucleotídeo único (SNP) foram identificados no intron 5-6 (SNP-1, SNP-2 e SNP-3, respectivamente). No primeiro SNP encontrado (SNP1) no intron 5-6 (Figura 14), 15 animais normais e 15 animais com $\mathrm{CMH}$ apresentaram timina ( $\mathrm{T}$ ) em homozigose nessa posição (TT), três animais normais e seis animais com $\mathrm{CMH}$ apresentaram $\mathrm{C}$ e $\mathrm{T}$ nessa posição (CT), e dois animais normais e um animal com $\mathrm{CMH}$ revelou citosina em homozigose nessa posição (CC). As frequências alélicas e genotípicas estão expostas nas tabelas 7 e 8 , 
respectivamente, e não foram observadas diferenças estatísticas quanto à sua ocorrência nos grupos avaliados.

Tabela 7 - Frequência alélica relacionada ao SNP-1 no intron 5-6 do gene ACTC1 felino - São Paulo $-2014$

\begin{tabular}{lcccc}
\hline Genótipos & \multicolumn{2}{c}{ Normais $(\mathbf{n = 2 0})$} & \multicolumn{2}{c}{ CMH (n=22) } \\
\hline & $\mathbf{N}$ & $\%$ & $\mathbf{N}$ & $\%$ \\
\hline Alelo C & $7 / 40$ & $17,50 \%$ & $8 / 44$ & $18,18 \%$ \\
Alelo T & $33 / 40$ & $82,50 \%$ & $36 / 44$ & $81,82 \%$ \\
\hline
\end{tabular}

Nota: SNP-1: primeiro polimorfismo de nucleotídeo único encontrado no intron $5-6 ; \mathrm{CMH}$ : cardiomiopatia hipertrófica; alelo C: citosina; alelo T: timina; N: número; \%: porcentagem. Fonte: Faculdade de Medicina Veterinária e Zootecnia da Universidade de São Paulo.

Tabela 8 - Frequência genotípica relacionada ao SNP-1 no intron 5-6 do gene ACTC1 felino - São Paulo - 2014

\begin{tabular}{lcccc}
\hline Genótipos & \multicolumn{2}{c}{ Normais $(\mathbf{n = 2 0})$} & \multicolumn{2}{c}{ CMH (n=22) } \\
\hline & $\mathbf{N}$ & $\%$ & $\mathbf{N}$ & $\%$ \\
\hline Genótipo TT & $15 / 20$ & $75,00 \%$ & $15 / 22$ & $68,19 \%$ \\
Genótipo CT & $3 / 20$ & $15,00 \%$ & $6 / 22$ & $27,27 \%$ \\
Genótipo CC & $2 / 20$ & $10,00 \%$ & $1 / 22$ & $4,54 \%$ \\
\hline
\end{tabular}

Nota: SNP-1: primeiro polimorfismo de nucleotídeo único encontrado no intron 5-6; $\mathrm{CMH}$ : cardiomiopatia hipertrófica; genótipo CC: citosina em homozigose; genótipo CT: citosina e timina em heterozigose; genótipo TT: timina em homozigose; N: número; \%: porcentagem.

Fonte: Faculdade de Medicina Veterinária e Zootecnia da Universidade de São Paulo.

Figura 14 - Eletroferograma do sequenciamento do intron 5-6 do gene ACTC1 felino, demonstrando presença de polimorfismo de nucleotídeo único (SNP-1)

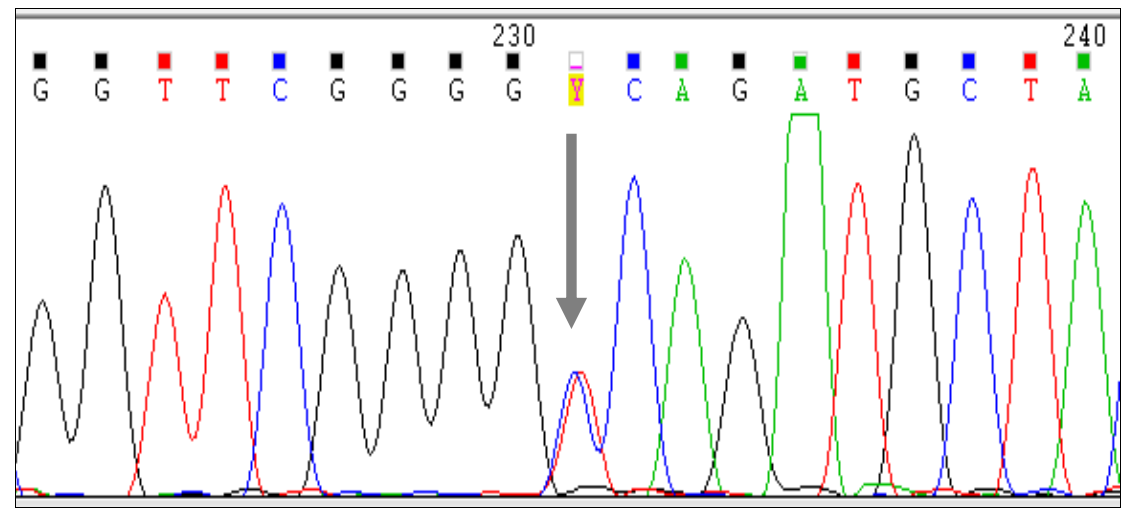

Legenda: Seta cinza indicando a presença de polimorfismo de nucleotídeo único (SNP-1). Fonte: Departamento de Patologia da FMVZ-USP. Responsável: Prof. Dr. Bruno Cogliati.

No segundo SNP encontrado no intron 5-6 (SNP-2) (Figura 15), 18 animais normais e 18 animais com $\mathrm{CMH}$ apresentaram citosina em homozigose nessa 
posição (CC), um animal normal e quatro animais com $\mathrm{CMH}$ apresentaram $\mathrm{T}$ e $\mathrm{C}$ nessa posição (TC), apenas um animal normal revelou timina em homozigose nessa posição (TT). As frequências alélicas e genotípicas estão expostas na tabelas 9 e 10, respectivamente, e não foram observadas diferenças estatísticas quanto à sua ocorrência nos grupos avaliados.

Tabela 9 - Frequência alélica relacionada ao SNP-2 no intron 5-6 do gene ACTC1 felino - São Paulo $-2014$

\begin{tabular}{lcccc}
\hline Genótipos & \multicolumn{2}{c}{ Normais $(\mathbf{n = 2 0 )}$} & \multicolumn{2}{c}{$\mathbf{C M H}(\mathbf{n = 2 2})$} \\
\hline & $\mathbf{N}$ & $\%$ & $\mathbf{N}$ & $\%$ \\
\hline Alelo C & $37 / 40$ & $92,50 \%$ & $43 / 44$ & $97,73 \%$ \\
Alelo T & $3 / 40$ & $7,50 \%$ & $1 / 44$ & $2,27 \%$ \\
\hline
\end{tabular}

Nota: SNP-2: segundo polimorfismo de nucleotídeo único encontrado no intron 5-6; $\mathrm{CMH}$ : cardiomiopatia hipertrófica; alelo C: citosina; alelo T: timina; N: número; \%: porcentagem. Fonte: Faculdade de Medicina Veterinária e Zootecnia da Universidade de São Paulo.

Tabela 10 - Frequência genotípica relacionada ao SNP-2 no intron 5-6 do gene ACTC1 felino - São Paulo - 2014

\begin{tabular}{lcccc}
\hline Genótipos & \multicolumn{2}{c}{ Normais $(\mathbf{n}=\mathbf{2 0})$} & \multicolumn{2}{c}{ CMH (n=22) } \\
\hline & $\mathbf{N}$ & $\%$ & $\mathbf{N}$ & $\%$ \\
\hline Genótipo CC & $18 / 20$ & $90,00 \%$ & $18 / 22$ & $81,82 \%$ \\
Genótipo TC & $1 / 20$ & $5,00 \%$ & $4 / 22$ & $18,18 \%$ \\
Genótipo TT & $1 / 20$ & $5,00 \%$ & 0 & $0 \%$ \\
\hline
\end{tabular}

Nota: SNP-2: segundo polimorfismo de nucleotídeo único encontrado no intron 5-6; $\mathrm{CMH}$ : cardiomiopatia hipertrófica; genótipo CC: citosina em homozigose; genótipo TC: timina e citosina em heterozigose; genótipo TT: timina em homozigose; N: número; \%: porcentagem.

Fonte: Faculdade de Medicina Veterinária e Zootecnia da Universidade de São Paulo. 
Figura 15 - Eletroferograma do sequenciamento do intron 5-6 do gene ACTC1 felino, demonstrando presença de polimorfismo de nucleotídeo único (SNP-2)

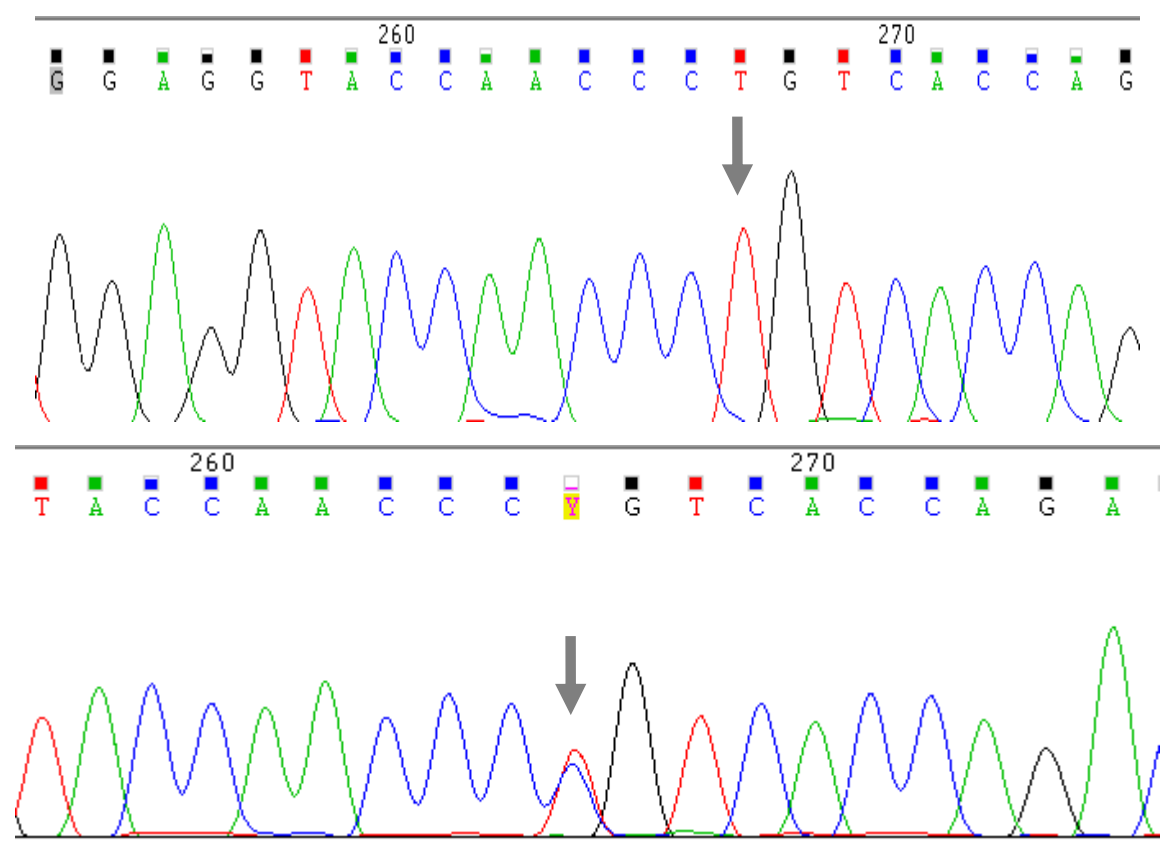

Legenda: Setas cinzas indicando presença de polimorfismo de nucleotídeo único (SNP-2).

Fonte: Departamento de Patologia da FMVZ-USP. Responsável: Prof. Dr. Bruno Cogliati.

No último SNP identificado no intron 5-6 do gene ACTC1 felino (SNP-3) (Figura 16), 19 animais normais e 21 animais com $\mathrm{CMH}$ apresentaram guanina em homozigose nessa posição (GG), apenas um animal do grupo normal e um do grupo $\mathrm{CMH}$ apresentaram mutação pontual $\mathrm{A}>\mathrm{G}(\mathrm{GA})$. As frequências alélica e genotípica estão expostas nas tabelas 11 e 12, respectivamente, e não foram observadas diferenças estatísticas quanto à sua ocorrência nos grupos avaliados.

Tabela 11 -Frequência alélica relacionada ao SNP-3 no intron 5-6 do gene ACTC1 felino - São Paulo $-2014$

\begin{tabular}{lcccc}
\hline Genótipos & \multicolumn{2}{c}{ Normais $(\mathbf{n = 2 0})$} & \multicolumn{2}{c}{ CMH (n=22) } \\
\hline & $\mathbf{N}$ & $\%$ & $\mathbf{N}$ & $\%$ \\
\hline Alelo G & $39 / 40$ & $97,50 \%$ & $43 / 44$ & $97,73 \%$ \\
Alelo A & $1 / 40$ & $2,50 \%$ & $1 / 44$ & $2,27 \%$ \\
\hline
\end{tabular}

Nota: SNP-3: terceiro polimorfismo de nucleotídeo único encontrado no intron 5-6; $\mathrm{CMH}$ : cardiomiopatia hipertrófica; alelo G: guanina; alelo A: adenina; N: número; \%: porcentagem. Fonte: Faculdade de Medicina Veterinária e Zootecnia da Universidade de São Paulo. 
Tabela 12 -Frequência genotípica relacionada ao SNP-3 no intron 5-6 do gene ACTC1 felino - São Paulo - 2014

\begin{tabular}{lcccc}
\hline Genótipos & \multicolumn{2}{c}{ Normais ( $\mathbf{n = 2 0}$} & \multicolumn{2}{c}{ CMH (n=22) } \\
\hline & $\mathbf{N}$ & $\%$ & $\mathbf{N}$ & $\%$ \\
\hline Genótipo GG & $19 / 20$ & $95,00 \%$ & $21 / 22$ & $95,46 \%$ \\
Genótipo GA & $1 / 20$ & $5,00 \%$ & $1 / 22$ & $4,54 \%$
\end{tabular}

Nota: SNP-3: terceiro polimorfismo de nucleotídeo único encontrado no intron 5-6; $\mathrm{CMH}$ : cardiomiopatia hipertrófica; genótipo GG: guanina em homozigose; genótipo GA: troca de guanina por adenina em heterozigose; genótipo AA: adenina em homozigose; N: número; \%: porcentagem.

Fonte: Faculdade de Medicina Veterinária e Zootecnia da Universidade de São Paulo.

Figura 16 - Eletroferograma do sequenciamento do intron 5-6 do gene ACTC1 felino, demonstrando presença de polimorfismo de nucleotídeo único (SNP-3), com alteração em heterozigose

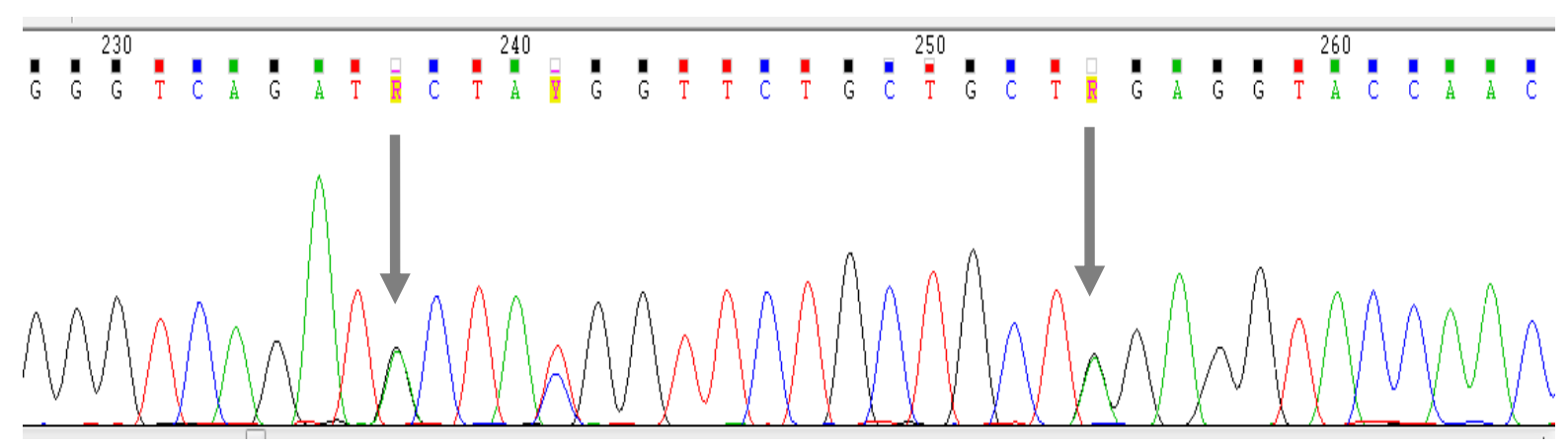

Legenda: Setas cinzas indicando presença de polimorfismo de nucleotídeo único (SNP-3), com alteração em heterozigose.

Fonte: Departamento de Patologia da FMVZ-USP. Responsável: Prof. Dr. Bruno Cogliati.

Com base nos resultados obtidos com o sequenciamento do exon 5 do gene ACTC1 felino, apesar das mutações e polimorfismos observados, não foi possível correlacionar a ocorrência da cardiomiopatia hipertrófica com mutações neste referido exon.

\subsubsection{Análise do sequenciamento de DNA do exon 27 do gene MYBPC3 felino}

A extração e o sequenciamento do DNA do exon 27 do gene MYBPC3 felino foram realizados nas 20 amostras dos animais sem $\mathrm{CMH}$ (grupo normal) e nos 22 animais com $\mathrm{CMH}$ (grupo com $\mathrm{CMH}$ ). Os resultados obtidos pelo sequenciamento das amostras foram comparados com a sequência do RNA mensageiro do gene MYBPC3 felino depositada no GenBank (GenBank \# XM_006937282.1; Ensembl: 
ENSFCAG00000002530) e com a sequência consenso obtida dos animais normais do estudo.

Não foram observados polimorfismos de nucleotídeo único (SNP), nem adições ou deleções nas sequências obtidas para o exon 27 do gene MYBPC3 felino.

Desta forma, a hipertrofia miocárdica encontrada nos gatos da raça Persa avaliados no presente estudo também não pode ser atribuída a alterações no exon 27 do gene da proteína C miosina ligante (MYBPC3 felino).

\subsection{ESTUDO POPULACIONAL DOS GATOS DA RAÇA PERSA $(n=100)$}

Inicialmente, foram encaminhados para o projeto de pesquisa e previamente incluídos nos grupos experimentais, 100 gatos da raça Persa, machos e fêmeas, de faixa etária entre cinco e 168 meses $(52,459 \pm 40,54$ meses $)$ e peso corpóreo entre 2,0 e $7,95 \mathrm{Kg}(3,96 \pm 1,34 \mathrm{Kg})$.

Destes 100 animais, 16 gatos foram excluídos da avaliação por possuírem alterações citadas nos critérios de exclusão (a saber: nefropatia; hipertensão arterial sistêmica; quadros infecciosos e/ou inflamatórios; amostras laboratoriais insuficientes para realização de todos os exames necessários; animais que não permitiram a realização de todos os exames complementares necessários para o projeto). Após avaliação ecocardiográfica, 22 gatos apresentaram alterações sugestivas de cardiomiopatia hipertrófica, um gato apresentou alterações sugestivas de cardiomiopatia arritmogênica do ventrículo direito (CMAVD) e outro gato, alterações ecocardiográficas relacionadas à presença de banda moderadora no ventrículo esquerdo. Desta forma, a prevalência das cardiomiopatias observadas nos gatos da raça Persa da população estudada foi de: $22 \%$ para $\mathrm{CMH}, 1 \%$ para CMAVD e $1 \%$ para outras cardiomiopatias.

Após avaliação de critérios de inclusão e exclusão, foram aceitos para 0 estudo 82 animais (54 gatos ecocardiograficamente normais; seis gatos suspeitos para $\mathrm{CMH}$; e 22 gatos com alterações condizentes com $\mathrm{CMH}$ ).

Destes 82 gatos, 34 eram machos (41,46\%) e 48 fêmeas (58,54\%). De todos os machos, 23 eram inteiros $(67,64 \%)$ e 11 orquiectomizados $(32,36 \%)$. Dentre as 
fêmeas, apenas 13 eram castradas $(27,08 \%)$ e a maioria inteira $(72,92 \%)$. O peso

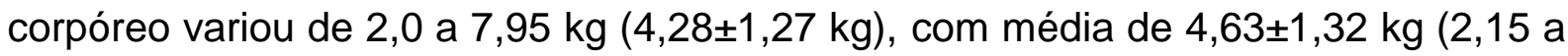
$7,95 \mathrm{~kg})$ nos machos e 3,79 $\pm 1,02 \mathrm{~kg}(2,0$ a 5,95 kg) nas fêmeas, sem diferenças estatísticas entre ambos. A faixa etária variou de 10 a 168 meses $(62,66 \pm 43,00$

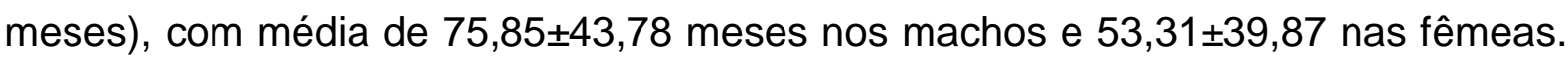
A idade dos machos foi estatisticamente superior à das fêmeas $(P=0,019)$.

Em relação à presença ou ausência da cardiomiopatia hipertrófica, os valores (média, desvio padrão, mínimo e máximo) de peso corpóreo e idade e a distribuição sexual (porcentagem de machos e fêmeas) entre os animais normais, suspeitos ou com $\mathrm{CMH}$ estão descritos na tabela 13. Foram observadas diferenças estatísticas em relação à idade e à distribuição sexual nos diferentes grupos, com faixa etária significativamente maior nos animais com $\mathrm{CMH}(\mathrm{P}=0,017)$ e predomínio de machos nos animais com $\mathrm{CMH}(\mathrm{P}=0,019)$.

Tabela 13 - Distribuição dos animais segundo peso corpóreo, idade e sexo ( $n=82)$ - São Paulo 2014

\begin{tabular}{lcccc}
\hline Classificação & Peso $\mathbf{~ K g ) ~}$ & Idade (meses) & Machos (\%) & Fêmeas (\%) \\
\hline Normais & $4,45 \pm 1,45$ & $58,79 \pm 41,11^{\mathrm{b}}$ & $31,48 \% \%^{\mathrm{a}}$ & $68,5 \%^{\mathrm{a}}$ \\
( $\mathrm{n}=\mathbf{5 4})$ & $(2,0-7,95)$ & $(11-156)$ & $(\mathrm{n}=17)$ & $(\mathrm{n}=37)$ \\
Suspeitos & $3,50 \pm 0,16$ & $29,83 \pm 13,37^{\mathrm{a}}$ & $50,00 \%$ & $50,00 \%$ \\
$(\mathrm{n}=\mathbf{0 6})$ & $(3,3-3,7)$ & $(10-52)$ & $(\mathrm{n}=03)$ & $(\mathrm{n}=03)$ \\
CMH & $4,25 \pm 1,07$ & $81,09 \pm 44,96^{\mathrm{c}}$ & $63,64 \% \%^{\mathrm{b}}$ & $36,36 \%{ }^{\mathrm{b}}$ \\
$(\mathbf{n}=\mathbf{2 2})$ & $(2,15-6,15)$ & $(24-168)$ & $(\mathrm{n}=14)$ & $(\mathrm{n}=08)$ \\
\hline
\end{tabular}

Nota: $\mathrm{CMH}=$ cardiomiopatia hipertrófica; $\mathrm{n}=$ número de animais; ${ }^{\mathrm{a}, \mathrm{b}, \mathrm{c}}$ indicadores de diferenças estatísticas.

Fonte: Faculdade de Medicina Veterinária e Zootecnia da Universidade de São Paulo.

Os parâmetros ecocardiográficos obtidos nos 82 animais estão descritos na tabela 14. Foram observadas diferenças estatísticas no diâmetro do átrio esquerdo, na relação $A E / A o$ e na velocidade máxima e gradiente de pressão do fluxo aórtico, com valores maiores nos animais com $\mathrm{CMH}(\mathrm{P}<0,0001 ; \mathrm{P}=0,0003 ; \mathrm{P}=0,0003$ e $P=0,0024$, respectivamente). 
Tabela 14 - Média e desvio padrão de parâmetros ecocardiográficos em gatos da raça Persa (n=82) - São Paulo - 2014

\begin{tabular}{lcccc}
\hline Parâmetros & $\begin{array}{c}\text { Todos } \\
(\mathbf{n}=\mathbf{8 2})\end{array}$ & $\begin{array}{c}\text { Normais } \\
(\mathbf{n}=\mathbf{5 4})\end{array}$ & $\begin{array}{c}\text { Suspeitos } \\
(\mathbf{n = 0 6})\end{array}$ & $\begin{array}{c}\text { CMH } \\
(\mathbf{n}=\mathbf{2 2})\end{array}$ \\
\hline FC (bpm) & $191,68 \pm 31,61$ & $191,78 \pm 29,60$ & $171,00 \pm 31,26$ & $197,09 \pm 34,07$ \\
SIVAo (cm) & $0,52 \pm 0,12$ & $0,45 \pm 0,04^{\mathrm{a}}$ & $0,49 \pm 0,06^{\mathrm{b}}$ & $0,69 \pm 0,07^{\mathrm{c}}$ \\
SIVd (cm) & $0,48 \pm 0,09$ & $0,43 \pm 0,04^{\mathrm{a}}$ & $0,50 \pm 0,05^{\mathrm{b}}$ & $0,60 \pm 0,07^{\mathrm{c}}$ \\
PVEd (cm) & $0,44 \pm 0,07$ & $0,42 \pm 0,04^{\mathrm{a}}$ & $0,44 \pm 0,04^{\mathrm{b}}$ & $0,51 \pm 0,08^{\mathrm{c}}$ \\
SIVd/PVEd & $1,08 \pm 0,11$ & $1,04 \pm 0,08^{\mathrm{a}}$ & $1,14 \pm 0,12^{\mathrm{b}}$ & $1,18 \pm 0,09^{\mathrm{c}}$ \\
DVEd (cm) & $1,38 \pm 0,18$ & $1,41 \pm 0,17$ & $1,41 \pm 0,24$ & $1,32 \pm 0,19$ \\
DVEs (cm) & $0,64 \pm 0,15$ & $0,65 \pm 0,14$ & $0,68 \pm 0,19$ & $0,61 \pm 0,16$ \\
FS (\%) & $54,15 \pm 0,06$ & $54,00 \pm 0,06$ & $52,30 \pm 0,06$ & $54,44 \pm 0,07$ \\
Fej & $0,87 \pm 0,05$ & $0,87 \pm 0,04$ & $0,86 \pm 0,05$ & $0,87 \pm 0,06$ \\
Ao (cm) & $0,88 \pm 0,11$ & $0,88 \pm 0,11$ & $0,84 \pm 0,10$ & $0,90 \pm 0,10$ \\
AE (cm) & $1,14 \pm 0,23$ & $1,08 \pm 0,16^{\mathrm{a}}$ & $0,99 \pm 0,14^{\mathrm{a}}$ & $1,31 \pm 0,30^{\mathrm{b}}$ \\
AE/Ao & $1,29 \pm 0,24$ & $1,24 \pm 0,11^{\mathrm{a}}$ & $1,18 \pm 0,11^{\mathrm{a}}$ & $1,46 \pm 0,37^{\mathrm{b}}$ \\
FI. Ao- Vmáx & $1,07 \pm 0,52$ & $0,94 \pm 0,25^{\mathrm{a}}$ & $0,92 \pm 0,14^{\mathrm{a}}$ & $1,44 \pm 0,81^{\mathrm{b}}$ \\
FI. Ao- grad & $5,68 \pm 8,56$ & $3,76 \pm 2,16^{\mathrm{a}}$ & $3,47 \pm 1,00^{\mathrm{a}}$ & $10,99 \pm 14,92^{\mathrm{b}}$ \\
FI. Pulm- Vmáx & $0,94 \pm 0,20$ & $0,93 \pm 0,19$ & $0,89 \pm 0,15$ & $0,97 \pm 0,22$ \\
FI. Pulm- grad & $3,66 \pm 1,57$ & $3,60 \pm 1,41$ & $3,26 \pm 1,02$ & $3,93 \pm 1,96$ \\
Onda E (m/s) & $0,75 \pm 0,21$ & $0,75 \pm 0,18$ & $0,66 \pm 0,07$ & $0,78 \pm 0,29$ \\
TDE (ms) & $61,17 \pm 15,48$ & $59,51 \pm 14,22$ & $66,17 \pm 15,98$ & $63,86 \pm 17,50$ \\
Onda A (m/s) & $0,56 \pm 0,14$ & $0,54 \pm 0,14$ & $0,53 \pm 0,09$ & $0,60 \pm 0,14$ \\
E/A & $1,31 \pm 0,38$ & $1,36 \pm 0,31$ & $1,26 \pm 0,13$ & $1,23 \pm 0,54$ \\
TRIV (ms) & $46,65 \pm 6,75$ & $46,50 \pm 5,48$ & $49,67 \pm 6,16$ & $46,17 \pm 9,11$ \\
\hline No:FC (bpm)
\end{tabular}

Nota: FC $(\mathrm{bpm})=$ frequência cardíaca em batimentos por minuto; SIVAo $(\mathrm{cm})=$ espessura diastólica do septo interventricular em região de via de saída do ventrículo esquerdo em centímetros; SIVd (cm) = espessura diastólica do septo interventricular em centímetros; PVEd $(\mathrm{cm})=$ espessura diastólica da parede livre do ventrículo esquerdo em centímetros; DVEd $(\mathrm{cm})=$ diâmetro diastólico da cavidade do ventrículo esquerdo em centímetros; DVEs $(\mathrm{cm})=$ diâmetro sistólico da cavidade do ventrículo esquerdo em centímetros; FS $(\%)=$ fração de encurtamento; Fej = fração de ejeção; $A o(\mathrm{~cm})=$ diâmetro da raiz da aorta, em centímetro, no corte transversal em modo bidimensional; $A E(\mathrm{~cm})=$ diâmetro do átrio esquerdo, em centímetro, no corte transversal em modo bidimensional; $A E / A O=$ relação átrio esquerdo-aorta; $\mathrm{Fl}$. Ao = fluxo aórtico; Vmáx $(\mathrm{m} / \mathrm{s})=$ velocidade máxima em metros por segundo; grad $(\mathrm{mmHg})=$ gradiente de pressão em milímetros de mercúrio; FI. Pulm = fluxo na artéria pulmonar; TDE $(\mathrm{ms})=$ tempo de desaceleração de onda $E$, em milissegundos; $E / A=$ relação $E / A$; $\operatorname{TRIV}(\mathrm{ms})=$ tempo de relaxamento isovolumétrico, em milissegundos; $\mathrm{CMH}=$ cardiomiopatia hipertrófica; $\mathrm{n}=$ número de animais; ${ }^{\mathrm{a}, \mathrm{b}, \mathrm{c}}$ indicadores de diferenças estatísticas.

Fonte: Faculdade de Medicina Veterinária e Zootecnia da Universidade de São Paulo

Conforme já descrito anteriormente, a hipertrofia miocárdica septal em região basal do septo interventricular (região de via de saída do ventrículo esquerdo; hipertrofia assimétrica) foi a mais prevalente nos gatos Persas avaliados (90,9\% dos casos); sendo a hipertrofia miocárdica concêntrica simétrica menos comum nesta população $(9,1 \%)$.

Ao exame eletrocardiográfico, o ritmo mais frequente foi o ritmo sinusal normal $(83,34 \%)$, seguido da taquicardia sinusal $(9,52 \%)$ e arritmia sinusal $(7,14 \%)$. Dentre os distúrbios de condução e bloqueios, observou-se presença de bloqueio de ramo direito (BRD) completo e incompleto, de bloqueio de fascículo anterior esquerdo (BFAE) e bloqueio atrioventricular de primeiro grau, não havendo 
diferenças estatísticas em relação à sua ocorrência nos grupos avaliados. Demais parâmetros como: frequência cardíaca, largura e amplitude da onda $P$, intervalo $P R$, largura do complexo QRS, amplitude de onda R, intervalo QT e amplitude das ondas R e S nas derivações precordiais CV5RL (rV2), CV6LL (V2) e CV6LU (V4), estão descritos na tabela 15.

Tabela 15 - Média e desvio padrão de parâmetros eletrocardiográficos em gatos da raça Persa $(\mathrm{n}=82)$ - São Paulo - 2014

\begin{tabular}{lcccc}
\hline Parâmetros & Todos $(\mathbf{n}=\mathbf{8 2})$ & Normais $(\mathbf{n}=\mathbf{5 4})$ & Suspeitos $(\mathbf{n}=\mathbf{6})$ & CMH $(\mathbf{n}=\mathbf{2 2})$ \\
\hline FC (bpm) & $194,20 \pm 32,01$ & $190,19 \pm 29,78^{\mathrm{a}}$ & $176,67 \pm 9,42^{\mathrm{b}}$ & $209,52 \pm 35,78^{\mathrm{a}}$ \\
P (s) & $0,04 \pm 0,01$ & $0,03 \pm 0,01$ & $0,04 \pm 0,01$ & $0,04 \pm 0,01$ \\
P (mV) & $0,15 \pm 0,05$ & $0,13 \pm 0,04^{\mathrm{a}}$ & $0,16 \pm 0,03^{\mathrm{a}}$ & $0,19 \pm 0,04^{\mathrm{b}}$ \\
PR (s) & $0,08 \pm 0,01$ & $0,08 \pm 0,01$ & $0,07 \pm 0,01$ & $0,08 \pm 0,01$ \\
QRS (s) & $0,03 \pm 0,01$ & $0,03 \pm 0,01$ & $0,03 \pm 0,00$ & $0,03 \pm 0,01$ \\
R (mV) & $0,27 \pm 0,21$ & $0,22 \pm 0,15^{\mathrm{a}}$ & $0,36 \pm 0,18^{\mathrm{a}}$ & $0,35 \pm 0,29^{\mathrm{b}}$ \\
QT $(\mathbf{s})$ & $0,15 \pm 0,02$ & $0,15 \pm 0,02$ & $0,16 \pm 0,01$ & $0,14 \pm 0,02$ \\
R CV5RL & $0,23 \pm 0,15$ & $0,21 \pm 0,12$ & $0,30 \pm 0,26$ & $0,27 \pm 0,15$ \\
S CV5RL & $0,21 \pm 0,19$ & $0,18 \pm 0,13$ & $0,28 \pm 0,14$ & $0,28 \pm 0,28$ \\
R CV6LL & $0,28 \pm 0,25$ & $0,22 \pm 0,14^{\mathrm{a}}$ & $0,38 \pm 0,36^{\mathrm{a}}$ & $0,43 \pm 0,35^{\mathrm{b}}$ \\
S CV6LL & $0,12 \pm 0,12$ & $0,12 \pm 0,12$ & $0,16 \pm 0,12$ & $0,10 \pm 0,08$ \\
R CV6LU & $0,23 \pm 0,23$ & $0,18 \pm 0,1^{\mathrm{a}}$ & $0,30 \pm 0,2^{\mathrm{a}}$ & $0,36 \pm 0,37^{\mathrm{b}}$ \\
S CV6LU & $0,06 \pm 0,07$ & $0,06 \pm 0,07$ & $0,05 \pm 0,04$ & $0,07 \pm 0,06$ \\
\hline
\end{tabular}

Nota: $F C=$ frequência cardíaca; $P(\mathrm{~s})=$ largura de onda P; $\mathrm{P}(\mathrm{mV})=$ amplitude de onda P; PR $(\mathrm{s})=$ intervalo PR; QRS (s) = largura do complexo QRS; R (mV) = amplitude da onda R; QT (s) = intervalo QT; R CV5RL= amplitude da onda R em CV5RL em mV; S CV5RL= amplitude da onda S em CV5RL em mV; R CV6LL= amplitude da onda R em CV6LL em mV; S CV6LL= amplitude da onda $S$ em CV6LL em mV; R CV6LU= amplitude da onda R em CV6LU em mV; S CV6LU= amplitude da onda S em C6LU em mV; $(\mathrm{s})=$ segundos; $(\mathrm{mV})$ = milivolts; $\mathrm{CMH}=$ cardiomiopatia hipertrófica; $\mathrm{n}=$ número de animais, ${ }^{a, b}$ indicadores de diferenças estatísticas.

Fonte: Faculdade de Medicina Veterinária e Zootecnia da Universidade de São Paulo

A amplitude da onda $\mathrm{P}$ em derivação $\mathrm{DIl}$ foi significativamente maior nos animais com $\mathrm{CMH}(\mathrm{P}<0,0001)$; e a amplitude da onda $\mathrm{R}$ em derivação DIl e em precordiais CV6LL e CV6LU foi significativamente maior nos animais com $\mathrm{CMH}$ ( $P=0,026, \quad P=0,0091$ e $P=0,037$, respectivamente). A frequência cardíaca foi estatisticamente inferior nos animais suspeitos $(P=0,02)$. Não foram observadas diferenças estatísticas nos demais parâmetros eletrocardiográficos avaliados.

Dentre os animais com parâmetros eletrocardiográficos sugestivos de sobrecarga atrial esquerda $(n=8)$, apenas dois gatos com $\mathrm{CMH}$ realmente apresentavam aumento de átrio esquerdo ao ecocardiograma. Por outro lado, dentre os gatos com aumento atrial esquerdo detectado ao ecocardiograma $(n=8)$, apenas dois apresentaram alterações eletrocardiográficas sugestivas de sobrecarga atrial esquerda. Desta forma, a sensibilidade do ECG em detectar aumento de AE em toda população estudada ( $n=82$ ) foi de $25,00 \%$ e a especificidade foi de $91,89 \%$, 
com acurácia de 85,36\%, valor preditivo positivo (VPP) de 25,00\% e valor preditivo negativo (VPN) de 91,89\%. A razão de probabilidade positiva (RPP) foi de 3,083 e a razão de probabilidade negativa (RPN) foi de 0,816. Não foi observada correlação positiva estatisticamente significativa entre a duração de onda $P$ do eletrocardiograma e a relação $\mathrm{AE} / \mathrm{Ao}$ do ecocardiograma.

Dentre os animais com parâmetros eletrocardiográficos sugestivos de sobrecarga ventricular esquerda $(n=8)$, cinco realmente apresentavam aumento da espessura do septo interventricular e/ou da parede livre do VE ao ecocardiograma (quadro condizente com hipertrofia). Por outro lado, de todos os gatos com $\mathrm{CMH}$ detectada ao ecocardiograma $(\mathrm{n}=22)$, apenas cinco apresentaram alterações eletrocardiográficas sugestivas de sobrecarga ventricular esquerda. Desta forma, a sensibilidade do ECG em detectar sobrecarga ventricular esquerda foi de $22,73 \%$ e a especificidade foi de 95,00\%, com acurácia de 89,02\% (VPP de 62,50\% e VPN de $91,89 \%$ ). A razão de probabilidade positiva (RPP) foi de 4,546 e a razão de probabilidade negativa (RPN) foi de 0,813.

Avaliando a população total $(n=82)$, ao correlacionar a presença de cardiomiopatia hipertrófica e a detecção de sopro ao exame físico, pode-se observar que: 22 gatos apresentavam $\mathrm{CMH}$ ao ecocardiograma e 34 gatos apresentaram sopro à auscultação cardíaca. Destes animais com $\mathrm{CMH}(\mathrm{n}=22), 15$ apresentaram sopro à auscultação. Por outro lado, dos 34 animais com sopro à auscultação, 15 apresentavam $\mathrm{CMH}$. Desta forma, a sensibilidade da auscultação de sopro para detecção de $\mathrm{CMH}$ foi de $68,18 \%$ e a especificidade foi de $68,34 \%$, com acurácia de $68,29 \%$ (VPP de 44,11\% e VPN de $85,41 \%$ ).

Nos grupo de gatos com $\mathrm{CMH}(\mathrm{n}=22)$, alguns animais avaliados eram pertencentes à mesma família. Pode-se observar esta influência familial em três subgrupos populacionais: subgrupo I (composto por um pai e três filhos acometidos); subgrupo II (composto por um pai e um filho acometido); subgrupo III (composto por quatro gatos procedentes de mesmo gatil, com parentesco de segundo grau entre eles).

Todos os animais da amostragem total de Persas $(n=82)$ foram, também, submetidos à avaliação genética da mutação relacionada à doença renal policística autossômica dominante por meio de reação de PCR (PKD- polycystic kidney disease; teste genético para a mutação no exon 29 do gene PKD1 felino), afeção comum em felinos da raça Persa. Apesar de nenhum animal avaliado apresentar 
alterações laboratoriais sugestivas de nefropatia (alterações em ureia, creatinina, eletrólitos e em exame de urina), nem alterações em exame clínico (anamnese e exame físico), e todos se encontrarem normotensos, nove gatos apresentaram teste genético positivo para a PKD (Quadro 2). Destes nove animais PKD positivos geneticamente, seis eram pertencentes ao grupo da $\mathrm{CMH}$ e três, do grupo normal. $\mathrm{A}$ proporção de gatos com PKD positivo no grupo da $\mathrm{CMH}$ foi estatisticamente maior que no grupo dos animais normais ( $P=0,0148$; Gráfico 9).

Quadro 2 - Gatos da raça Persa positivos para a mutação relacionada à doença renal policística autossômica dominante (PKD1) - São Paulo - 2014

\begin{tabular}{|c|c|c|c|c|c|c|c|c|}
\hline ID & Grupo & $\begin{array}{c}\text { SIVAo } \\
\text { (cm) }\end{array}$ & $\begin{array}{c}\text { SIVd } \\
\text { (cm) }\end{array}$ & $\begin{array}{c}\text { PVEd } \\
\text { (cm) }\end{array}$ & Sintomas DRC & $\begin{array}{c}\text { PAS } \\
\mathbf{m m H g}\end{array}$ & $\begin{array}{c}\text { Ureia } \\
\mathbf{m g} / \mathbf{d L}\end{array}$ & $\begin{array}{c}\text { Creatinina } \\
\mathbf{m g} / \mathbf{d L}\end{array}$ \\
\hline $\mathbf{8}$ & Normais & 0,49 & 0,49 & 0,49 & Assintomático & 132 & 74,9 & 1,33 \\
\hline $\mathbf{9}$ & Normais & 0,46 & 0,45 & 0,45 & Assintomático & 120 & 49,0 & 1,12 \\
\hline $\mathbf{1 7}$ & Normais & 0,40 & 0,40 & 0,42 & Assintomático & 142 & 53,1 & 1,25 \\
\hline $\mathbf{2 1}$ & CMH & 0,85 & 0,80 & 0,76 & Assintomático & 140 & 60,5 & 1,48 \\
\hline $\mathbf{2 2}$ & $\mathrm{CMH}$ & 0,62 & 0,51 & 0,42 & Assintomático & 144 & 30,1 & 0,88 \\
\hline $\mathbf{3 2}$ & $\mathrm{CMH}$ & 0,74 & 0,66 & 0,55 & Assintomático & 120 & 55,6 & 1,45 \\
\hline $\mathbf{3 4}$ & $\mathrm{CMH}$ & 0,81 & 0,71 & 0,47 & Assintomático & 158 & 42,6 & 1,04 \\
\hline $\mathbf{3 5}$ & $\mathrm{CMH}$ & 0,73 & 0,60 & 0,49 & Assintomático & 126 & 46,4 & 1,16 \\
\hline $\mathbf{3 8}$ & $\mathrm{CMH}$ & 0,73 & 0,61 & 0,52 & Assintomático & 140 & 54,8 & 1,44 \\
\hline
\end{tabular}

Legenda: ID = identificação; $\mathrm{CMH}=$ cardiomiopatia hipertrófica; SIVAo = espessura diastólica do septo interventricular na região de via de saída do ventrículo esquerdo; SIVd = espessura diastólica do septo interventricular; PVEd = espessura diastólica da parede livre do ventrículo esquerdo; $\mathrm{cm}=$ centímetros; Sintomas $\mathrm{DRC}=$ manifestações clínicas relacionadas à doença renal crônica; PAS $\mathrm{mmHg}=$ média da pressão arterial sistólica em milímetros de mercúrio; $\mathrm{mg} / \mathrm{dL}=$ miligramas por decilitro .

Fonte: $\quad$ Faculdade de Medicina Veterinária e Zootecnia da Universidade de São Paulo.

Gráfico 9 - Teste genético da doença renal policística (PKD1) em gatos da raça Persa nos diferentes grupos experimentais - São Paulo - 2014

Teste genético para doença renal policística (PKD)
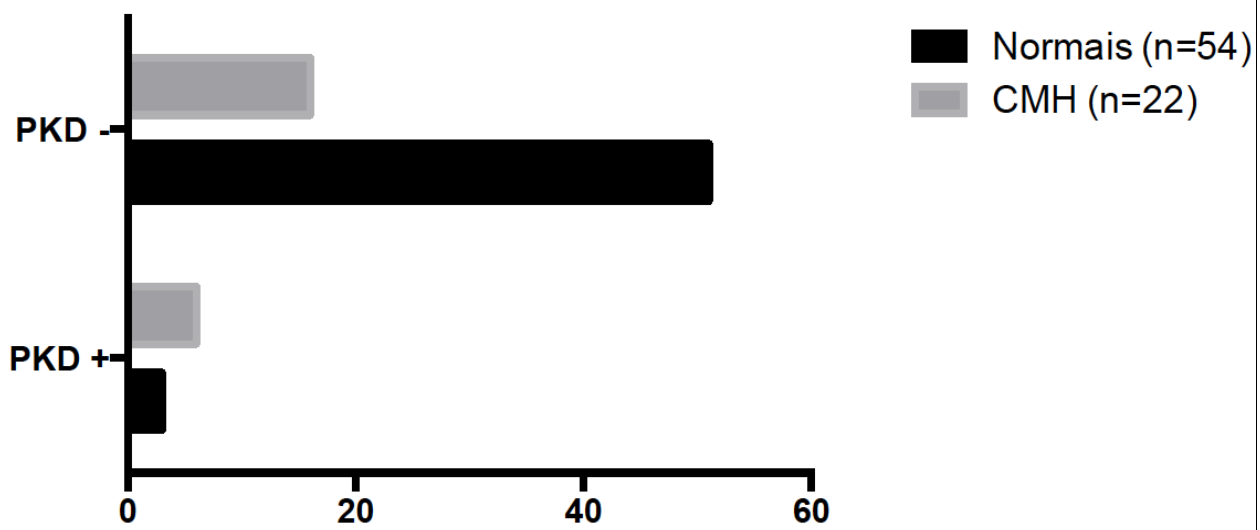

$\mathrm{CMH}(\mathrm{n}=22)$

Legenda: $\quad \mathrm{CMH}$ : cardiomiopatia hipertrófica; $\mathrm{PKD}+$ : positivo para a mutação no gene que causa a doença renal policística; PKD-: negativo para a mutação no gene que causa a doença renal policística.

Fonte: $\quad$ Faculdade de Medicina Veterinária e Zootecnia da Universidade de São Paulo. 
Considerando a população avaliada dividida em grupo PKD positivo $(n=9)$ e grupo PKD negativo ( $n=73)$, em relação aos parâmetros ecocardiográficos, não foram observadas diferenças em relação à função diastólica, ao aspecto e movimentação dos folhetos valvares, bem quanto aos fluxos transvalvares nos diferentes grupos. Porém, gatos da raça Persa PKD positivos apresentaram maior prevalência de hipertrofia miocárdica septal do que gatos negativos para esta mutação ( $P=0,0001)$. Não foram observadas diferenças estatísticas nos valores de pressão arterial sistólica e nos parâmetros eletrocardiográficos entre gatos com ou sem a mutação relacionada à PKD. 


\section{DISCUSSÃO}

\subsection{ESTUDO POPULACIONAL DOS GATOS DA RAÇA PERSA}

A população avaliada no presente estudo foi composta por gatos da raça Persa, machos ou fêmeas, de qualquer faixa etária, residentes no estado de São Paulo. Nos 100 gatos inicialmente avaliados, a prevalência da cardiomiopatia hipertrófica foi de $22 \%$, a de cardiomiopatia arritmogênica do ventrículo direito (CMAVD) de 1\% e de outras cardiomiopatias, 1\%. De acordo Kittleson et al. (1999), Chetboul et al. (2006a) e McDonald et al. (2007), a CMH é a principal cardiopatia causadora de mortalidade e morbidade nos felinos. Em humanos, estima-se que a prevalência seja de um a cada 500 indivíduos (FERNANDEZ, 1998; GRAZIANO; ACQUATELLA, 2007); em gatos, a prevalência descrita na literatura varia de 8,5\% (GRANSTRÖM et al., 2011) a 41,5\% (PAIGE et al., 2009; MARY et al., 2010), com diferenças de acordo com o padrão racial avaliado.

No presente trabalho, foram considerados suspeitos para a $\mathrm{CMH}$, seis animais (6\%). De acordo com dados da literatura, a $\mathrm{CMH}$ é uma doença miocárdica geneticamente e fenotipicamente heterogênea caracterizada por aumento na massa ventricular esquerda; o diagnóstico nem sempre é fácil e a intensidade e o padrão da hipertrofia ventricular é bastante variável nos animais acometidos, podendo existir animais com suspeita diagnóstica (grey zone) (CONNOLLY et al., 2003; BATY, 2004; WESS et al., 2010; CÔTÉ et al., 2011).

Considerando a população total investigada $(n=82)$ após critérios de exclusão, a faixa etária dos animais com $\mathrm{CMH}$ foi estatisticamente superior à dos demais animais suspeitos e normais. De acordo com Trehiou-Sechi et al. (2012), em Persas, a $\mathrm{CMH}$ é mais comumente diagnosticada em animais mais velhos, com média de idade no diagnóstico de 11 anos, padrão diferente do encontrado em outras raças como Maine Coon e Ragdoll (onde a afecção é mais precoce) (GODIKSEN et al., 2011; BORGEAT et al., 2014). No presente estudo, a média de idade dos animais com $\mathrm{CMH}$ foi de 6,7 anos, diferindo, em parte, da média relatada por Trehiou-Sechi et al. (2012). Porém, deve-se ressaltar que a maioria dos animais acometidos pela referida cardiomiopatia só obteve o diagnóstico após a realização do projeto, sendo 
o diagnóstico realizado antes do surgimento de manifestações clínicas ou de suspeita da afecção. De acordo com Longeri et al. (2013), a CMH apresenta componente hereditário em algumas raças, mas sua incidência aumenta conforme a idade dos animais, à semelhança do que foi obtido no presente estudo.

A distribuição de machos e fêmeas na população total estudada ( $n=82)$ foi homogênea. Porém, a proporção de machos entre os acometidos pela $\mathrm{CMH}$ foi significativamente maior (63,64\%). Segundo Chetboul et al. (2006a), Fuentes (2006) e Granström et al. (2011), a CMH é relatada mais frequentemente em gatos machos de meia idade, mas também pode ocorrer em fêmeas, em jovens ou idosos. Alguns estudos não referem diferenças na ocorrência da afecção entre machos e fêmeas, porém há relatos de que as manifestações podem ser precoces e mais evidentes nos indivíduos do sexo masculino (McDONALD et al., 2007; WARE, 2007; ABBOTT, 2010; PAYNE et al., 2010). No presente estudo, a média de idade dos machos foi estatisticamente superior à faixa etária das fêmeas; e os animais com $\mathrm{CMH}$ também eram estatisticamente de maior média de idade. Desta forma, não se pode correlacionar diretamente se a $\mathrm{CMH}$ foi realmente mais prevalente nos machos ou se ocorreu mais nos animais de maior faixa etária, ou em ambos os casos.

À avaliação ecocardiográfica convencional, 54 animais foram considerados normais quanto à $\mathrm{CMH}$, seis gatos foram considerados suspeitos e 22 indivíduos já apresentavam alterações ecocardiográficas condizentes com a $\mathrm{CMH}$. De acordo com Chetboul et al. (2006a) e Ferasin (2009b), a ecocardiografia em modo M e em modo bidimensional permite mensuração de estruturas, auxiliando na detecção de hipertrofia. Segundo Ware (2007), o limite superior da espessura da parede ventricular esquerda e do septo interventricular na diástole é considerado entre 0,5 a 0,55 cm. Porém, de acordo com Gundler, Tidholm e Häggström (2008) e Côté et al. (2011), alguns autores só consideram hipertrofia em gatos quando a espessura da parede ventricular esquerda e/ou do septo interventricular ultrapassa 0,6 cm. Desta forma, seguindo os dados de literatura e com a intenção de melhorar a especificidade da avaliação, considerou-se hipertrofia apenas nos animais com espessuras iguais ou superiores a $0,6 \mathrm{~cm}$; e consideraram-se normais apenas os com valores inferiores a $0,5 \mathrm{~cm}$.

À avaliação ecocardiográfica dos 82 animais, o diâmetro do átrio esquerdo $(A E)$ e a relação átrio esquerdo-aorta ( $A E / A o)$ foram maiores nos animais acometidos pela $\mathrm{CMH}$ em relação aos demais. Observaram-se diferenças na 
velocidade e no gradiente de pressão do fluxo aórtico, que foram maiores nos acometidos quando comparados aos animais normais. Dentre os animais com $\mathrm{CMH}$, a presença de hipertrofia miocárdica septal em região de via de saída do ventrículo esquerdo (SIVAo) ocorreu em 90,90\% dos casos. Segundo a literatura, o ecocardiograma é o melhor meio diagnóstico não invasivo para a diferenciação de $\mathrm{CMH}$ de outras cardiomiopatias e permite caracterizar anormalidades funcionais e estruturais (CHETBOUL et al., 2006a; CHETBOUL et al., 2006b; SIMPSON et al., 2007; GUNDLER; TIDHOLM; HÄGGSTRÖM, 2008). Em consequência da disfunção diastólica e dos fluxos regurgitantes, o átrio aumenta de tamanho, às vezes de forma acentuada, mas o volume ventricular esquerdo permanece normal ou diminuído (GUNDLER; TIDHOLM; HÄGGSTRÖM, 2008; SCHÖBER et al., 2007; LINNEY et al., 2014), justificando os resultados encontrados. De acordo com Trehiou-Sechi et al. (2012), em Persas, a forma mais comum da $\mathrm{CMH}$ é a hipertrofia miocárdica septal, compatível com o que foi encontrado no presente trabalho. A presença desta hipertrofia septal em região de via de saída do ventrículo esquerdo (região septal basal) também pode justificar o maior gradiente de pressão e a maior velocidade do fluxo aórtico nos animais acometidos, pois o septo interventricular hipertrofiado pode dificultar a passagem do sangue na via de saída ventricular esquerda, conforme já relatado por outros autores (BOON, 2011; CHETBOUL et al., 2012).

Ao exame eletrocardiográfico, o ritmo mais frequente foi o ritmo sinusal normal, seguido da taquicardia sinusal e arritmia sinusal. A arritmia sinusal foi observada apenas em alguns animais normais quanto à $\mathrm{CMH}$ e pode ser justificada pela presença de estenose de narina e outras alterações relacionadas à conformação braquicefálica dos Persas. De acordo com a literatura, alterações respiratórias podem levar à ativação do sistema nervoso autônomo parassimpático, que resulta em arritmia sinusal (ou arritmia respiratória), bradicardia ou parada sinusal (HARVEY et al., 2005; CÔTÉ; JAEGER, 2008). Não foram observadas diferenças quanto à ocorrência de ritmo sinusal ou taquicardia sinusal nos diferentes grupos. Apenas um animal, acometido pela $\mathrm{CMH}$, apresentou complexos ventriculares prematuros (VPCs) isolados e polimórficos durante a monitorização. Dentre os distúrbios de condução e bloqueios, observou-se presença de bloqueio de ramo direito (BRD) completo e incompleto, de bloqueio de fascículo anterior esquerdo (BFAE) e de bloqueio atrioventricular de primeiro grau. De acordo com Tilley e Goodwin (1995), alterações eletrocardiográficas são comuns em animais 
com $\mathrm{CMH}$ e incluem: alterações indicativas de aumento atrial e ventricular, taquiarritmias ventriculares ou supraventriculares e desvio de eixo para a esquerda. Fibrilação atrial pode ser observada em alguns gatos; e também pode haver desenvolvimento de bloqueios fasciculares e de alterações na condução atrioventricular, com bloqueio atrioventricular completo ou bradicardia sinusal (WARE, 2007). No presente estudo, a presença de bloqueios de ramo e/ou de fascículos não esteve sempre correlacionada com a presença de $\mathrm{CMH}$. Indivíduos normais e suspeitos também apresentaram esses distúrbios de condução do estímulo cardíaco.

De todos os animais avaliados, apenas dois gatos com $\mathrm{CMH}$ apresentaram distúrbio de repolarização ventricular, um com supradesnível de segmento ST de 0,2 $\mathrm{mV}$ e outro com alteração na amplitude da onda T. De acordo com Ware (2007), a hipertrofia ventricular pode deflagrar desenvolvimento de áreas de isquemia, fibrose e hipóxia tecidual, podendo justificar as alterações eletrocardiográficas condizentes com alteração na repolarização ventricular.

À avaliação eletrocardiográfica, os valores de amplitude de onda $R$ na derivação DII e nas precordiais CV6LL e CV6LU foram maiores nos animais acometidos pela CMH em relação aos demais. Segundo Tilley (1992) e Harvey et al. (2005), amplitude da onda $\mathrm{R}$ superior a 0,9 mV em derivação DII e superior a 1,0 mV em precordiais CV6LL e CV6LU em gatos são alterações eletrocardiográficas sugestivas de sobrecarga ventricular (seja concêntrica ou excêntrica). Apesar dos valores de amplitude de onda $R$ nestas diferentes derivações serem superiores nos gatos com $\mathrm{CMH}$ em relação aos demais, nem todos os gatos com $\mathrm{CMH}$ avaliados no trabalho atual apresentaram amplitudes acima do valor de referência para a espécie. De acordo com Bacharova (2009), Bender et al. (2012) e Rowin et al. (2012), o eletrocardiograma (ECG) apresenta baixa sensibilidade na detecção de sobrecargas e há baixa correlação entre a amplitude do QRS e o grau de hipertrofia em humanos. Porém, o ECG apresenta boa especificidade no diagnóstico hipertrofia ventricular no homem (LAKDAWALA et al., 2011).

Apesar do exame ecocardiográfico demonstrar diferença estatística em relação ao tamanho do átrio esquerdo (significativamente maior nos gatos com $\mathrm{CMH}$ ), não foram observadas diferenças eletrocardiográficas em relação à duração da onda $P$ (que poderia sugerir sobrecarga atrial esquerda) nos diferentes grupos. Resultados semelhantes já foram demonstrados em trabalhos citados na literatura, 
onde o eletrocardiograma foi um pobre indicador de sobrecarga atrial nos gatos (MOISE et al., 1986). No presente trabalho, observou-se amplitude da onda $P$ significativamente maior nos animais com $\mathrm{CMH}$ quando comparados com os demais. Porém, nenhum gato apresentou sobrecarga atrial direita ao ecocardiograma e nenhum animal apresentou alterações eletrocardiográficas que sugerissem aumento atrial direito (amplitude da onda $\mathrm{P}$ estava dentro da normalidade em todos os animais).

No presente trabalho, a sensibilidade do ECG em detectar aumento de AE foi de $25 \%$ e a especificidade foi de $91,89 \%$, com acurácia de $85,36 \%$. De acordo com Moise et al. (1986), o eletrocardiograma não é um exame sensível para detectar aumento de AE em gatos; e Schöber et al. (2007) encontraram resultados com baixa sensibilidade mas boa especificidade, à semelhança dos resultados deste trabalho. Além da baixa sensibilidade e da especificidade média a alta do ECG em detectar aumento de $A E$, não foi observada correlação entre a duração de onda $P$ do eletrocardiograma e a relação $\mathrm{AE} / \mathrm{Ao}$ do ecocardiograma, diferentemente de outros trabalhos citados na literatura veterinária (SCHÖBER et al., 2007) e humana (RYAN et al., 1995; NAMDAR et al., 2012), onde houve correlação positiva entre onda P e tamanho atrial esquerdo.

A razão de probabilidade (também interpretável como razão de verossimilhança) pode ser utilizada para determinar o valor de um teste diagnóstico e é expressa em chances (SIEGEL; CASTELLAN, 1988; NETER et al., 1996). Estas razões expressam quantas vezes mais provável (ou menos) se encontra um resultado de um teste em indivíduos acometidos comparado com os não acometidos. Quanto maior a razão de probabilidade positiva (RPP), melhor o teste (é mais provável do resultado ser verdadeiro positivo do que falso-positivo); e quanto menor a razão de probabilidade negativa (RPN), melhor o teste (é mais provável de ser um verdadeiro resultado negativo do que um falso-negativo) (SIEGEL; CASTELLAN, 1988; NETER et al., 1996). No presente trabalho, a RPP para avaliação de sobrecarga atrial esquerda pelo ECG foi de 3,08 e a RPN foi de 0,81 . Desta forma, a chance do ECG detectar sobrecarga de AE em indivíduos que realmente tenham aumento de $\mathrm{AE}$ é 3,08 vezes maior que a chance de detectar sobrecarga de $\mathrm{AE}$ em indivíduos que não apresentam o aumento. Por outro lado, a chance do ECG não detectar sobrecarga de $A E$ em indivíduos que apresentam 
aumento do $A E$ é 0,81 vezes a chance de não detectar sobrecarga de $A E$ em indivíduos que realmente não tenham esse aumento atrial.

No presente estudo, a sensibilidade do ECG em detectar sobrecarga ventricular esquerda foi de $22,73 \%$ e a especificidade foi de $95 \%$, com acurácia de 89,02\%. De acordo com Lakdawala et al. (2011), o ECG apresenta boa especificidade mas baixa sensibilidade em detectar aumentos ventriculares. Em humanos, o diagnóstico eletrocardiográfico de hipertrofia ventricular é baseado no aumento da voltagem dos complexos QRS em diferentes derivações (MURPHY et al., 1985; KONNO et al., 2005; BACHAROVA, 2009); e a combinação destes critérios pode aumentar a sensibilidade do método, permitindo seu uso como exame de triagem com maior segurança. Em gatos, poucos estudos foram realizados quanto à sensibilidade e especificidade do ECG na detecção de hipertrofia ventricular. MOISE et al. (1986) constataram que o ECG indicou incorretamente aumento ventricular em gatos com hipertireoidismo e não detectou consistentemente a presença de sobrecarga ventricular em pacientes com $\mathrm{CMH}$, mostrando a baixa sensibilidade do ECG para esta finalidade.

A RPP para avaliação de sobrecarga ventricular esquerda pelo ECG foi de 4,54 e a RPN foi de 0,81. Desta forma, a chance do ECG detectar sobrecarga ventricular esquerda em indivíduos que realmente tenham hipertrofia é 4,54 vezes maior que a chance de detectar sobrecarga ventricular esquerda em indivíduos sem aumento. Por outro lado, a chance do ECG não detectar sobrecarga ventricular esquerda em indivíduos com hipertrofia é 0,81 vezes a chance de não detectar sobrecarga ventricular esquerda em indivíduos sem aumento.

Apesar do exame eletrocardiográfico não permitir diagnóstico preciso de hipertrofia de VE neste estudo, a presença de alterações eletrocardiográficas sugestivas de sobrecarga ventricular foram bastante consistentes com $\mathrm{CMH}$ (especificidade de 95\%). A ausência de alterações no ECG não exclui a $\mathrm{CMH}$, mas a presença dessas alterações aumenta bastante a suspeita de $\mathrm{CMH}$ nesses animais. O mesmo não é válido para sobrecargas atriais (sensibilidade e especificidade insuficientes para um bom diagnóstico). Segundo Bacharova (2009), Bender et al. (2012) e Rowin et al. 2012, apesar da baixa sensibilidade do ECG em detectar sobrecarga do VE, a presença de alterações eletrocardiográficas que sugerem hipertrofia ventricular pode ser considerada um marcador prognóstico e de gravidade, permitindo estratificação de risco desses pacientes. De acordo com 
Killian et al. (2010) e Grossman et al. (2012), devido ao baixo valor preditivo positivo do ECG em detectar hipertrofia, pode haver necessidade de confirmação ecocardiográfica, principalmente, em indivíduos mais jovens. A habilidade do ECG em estimar a hipertrofia ventricular é baixa e os argumentos a favor de seu uso como ferramenta diagnóstica na $\mathrm{CMH}$ estão relacionados ao baixo custo e boa disponibilidade do método (BACHAROVA, 2009; ROWIN et al., 2012).

Segundo Rush et al. (2002), Ferasin et al. (2003) e Côté et al. (2011), a ocorrência de sopro sistólico, tanto por regurgitação mitral quanto por obstrução de via de saída de ventrículo esquerdo, é comum em gatos com $\mathrm{CMH}$, mas alguns animais não apresentam sopro, apesar da presença de hipertrofia ventricular importante. No presente estudo, 41,46\% dos animais apresentaram sopro em bordo esternal à auscultação de bulhas cardíacas, porém, nem todos os animais que manifestaram sopro tinham cardiomiopatia. A sensibilidade da auscultação de sopro para a detecção de $\mathrm{CMH}$ foi de $68,18 \%$ e a especificidade foi de $68,34 \%$, com acurácia de 68,29\%. Segundo Côté et al. (2004), Payne et al. (2010) e Wagner et al. (2010), a presença de sopro não é diagnóstico de $\mathrm{CMH}$ em gatos, apresentando uma baixa sensibilidade e especificidade, à semelhança dos resultados obtidos. No estudo de Paige et al. (2009), 31 a 62\% dos gatos com sopro apresentavam diferentes graus de hipertrofia ventricular; e a presença de sopro de maior grau apresentou maior especificidade e sensibilidade para a $\mathrm{CMH}$. No presente estudo, intensidade do sopro foi maior nos indivíduos acometidos pela CMH em comparação aos indivíduos normais, corroborando com as informações descritas na literatura.

Segundo Ferasin et al. (2003) e Ware (2007), som diastólico de galope (S4) também pode ser auscultado, principalmente quando a insuficiência cardíaca é evidente ou eminente. No presente estudo, apenas três animais apresentaram ritmo de galope e somente um destes animais apresentava $\mathrm{CMH}$. Portanto, não foi possível correlacionar os achados do ritmo de galope com os dados da literatura neste estudo.

No presente projeto, muitos dos animais do grupo com $\mathrm{CMH}$ eram pertencentes a um mesmo grupo familial. Pode-se obter, ao menos, três famílias distintas com indivíduos acometidos pela mesma cardiomiopatia (relação de parentesco, irmãos e primos). De acordo com Kittleson (2009a), Granström et al. (2011) e Longeri et al. (2013), a CMH apresenta herança genética em algumas famílias de gatos. Em algumas raças como o Persa, sabe-se do componente familial 
da $\mathrm{CMH}$, mas ainda não se conhece a forma de transmissão nem a mutação envolvida.

De acordo com Côté et al. (2011), nas afeções genéticas com padrão de herança autossômica dominante (padrão comumente observado na $\mathrm{CMH}$ das raças já estudadas geneticamente), espera-se encontrar tanto machos quanto fêmeas acometidos, e os indivíduos com a afecção podem ser heterozigotos ou homozigotos. No presente estudo, pode-se notar machos e fêmeas acometidos, famílias onde o pai e os filhos apresentavam $\mathrm{CMH}$, além de animais acometidos com parentesco de segundo grau e pertencentes a um mesmo gatil, o que condiz com os dados da literatura, mas não permite comprovação do tipo de herança genética envolvida.

Para a avaliação genética e pesquisa de possíveis alterações relacionadas à cardiomiopatia hipertrófica, dos 82 animais, foram selecionados os 20 gatos normais com maior faixa etária e os 22 animais com $\mathrm{CMH}$. De acordo com Ferasin et al. (2003) e Baty (2004), devido à penetrância incompleta, a prevalência da $\mathrm{CMH}$ aumenta significativamente de acordo com a faixa etária (FERASIN et al., 2003; CHETBOUL et al., 2012) e alguns animais, apesar de apresentarem mutação, desenvolvem a afecção mais tardiamente, principalmente gatos da raça Persa (TREHIOU-SECHI et al., 2012). Portanto, a escolha dos animais mais velhos foi baseada na literatura.

Avaliações e discussões mais detalhadas sobre os resultados encontrados serão descritas a seguir, considerando-se apenas os animais dos grupos experimentais $(n=42$ : sendo 20 normais e 22 com $C M H)$.

\subsection{ANÁLISE DOS GRUPOS EXPERIMENTAIS}

Nos 42 gatos Persas que participaram da etapa de avaliação genética, a distribuição de machos e fêmeas foi homogênea. Apesar do aparente predomínio de machos no grupo da $\mathrm{CMH}$, não foram observadas diferenças estatísticas entre os grupos (normais e com $\mathrm{CMH}$ ). Conforme citado anteriormente e de acordo com dados da literatura, há relatos de predisposição sexual na $\mathrm{CMH}$ (onde machos são mais acometidos), mas alguns trabalhos não mostram diferenças na prevalência 
entre machos e fêmeas, demonstrando apenas uma tendência à maior gravidade em machos (McDONALD et al., 2007; WARE, 2007; ABBOTT, 2010; PAYNE et al., 2010).

Observou-se diferença estatística na idade dos animais, com gatos de maior faixa etária no grupo normal. Esta diferença pode ser justificada pelo critério de escolha do grupo experimental, onde propositalmente optou-se pela seleção dos animais mais velhos, na tentativa de não selecionar "falsos normais", ou seja, animais com mutação e ainda sem alterações evidentes (já que a penetrância é incompleta e a idade de aparecimento de alterações clínicas ocorre mais tardiamente nos Persas) (FERASIN et al., 2003; BATY, 2004; CHETBOUL et al., 2012; TREHIOU-SECHI et al., 2012).

A proporção de animais inteiros no grupo com $\mathrm{CMH}$ foi superior à do grupo normal. De acordo com a literatura, não há relatos de influência hormonal (animais inteiros ou castrados) com a presença ou ausência da $\mathrm{CMH}$. Segundo Fuentes (2006) e Freeman et al. (2012), outras causas atribuídas à CMH incluem: maior sensibilidade ou maior produção de catecolaminas; resposta anormal de hipertrofia frente à isquemia, à fibrose ou a fatores tróficos; e influências relacionadas à taxa de crescimento e a fatores nutricionais. No presente estudo, como o grupo normal foi composto por animais mais velhos, a chance de selecionar gatos já submetidos à castração foi maior, podendo justificar este resultado encontrado.

Ao avaliar as manifestações clínicas do sistema cardiorrespiratório (relacionadas ou não à presença da cardiomiopatia hipertrófica), a maioria da população estudada era assintomática (83,34\%). Segundo Rush et al. (2002), Fuentes (2006) e Côté et al. (2011), gatos com CMH podem permanecer assintomáticos por anos; podem desenvolver insuficiência cardíaca congestiva, tromboembolismo arterial sistêmico ou morte súbita; ou podem não apresentar nenhuma evolução da cardiopatia, morrendo por causas não cardíacas (PAYNE et al., 2010; PAYNE et al., 2013). Considerando-se o grupo com $\mathrm{CMH}, 68,19 \%$ dos gatos avaliados eram assintomáticos. Segundo Atkins et al. (1992), Rush et al. (2002) e Riesen et al. (2008), as principais manifestações clínicas observadas incluem alterações respiratórias decorrentes de congestão/edema pulmonar ou efusão pleural, como taquipneia, ofegação, cansaço fácil, cianose e dispneia. Alguns gatos com cardiomiopatia podem apresentar pré-síncope, síncope e fraqueza (BATY, 2004). No presente estudo, as principais manifestações clínicas relatadas 
foram dispneia, cansaço e pré-síncope, porém nem sempre correlacionadas apenas com $\mathrm{CMH}$, já que muitos animais também apresentavam alterações decorrentes da síndrome do braquicefálico.

A população estudada, maioria assintomática, praticamente não apresentou alterações ao exame físico. Dentre as alterações observadas, apenas seis animais (14,28\%) estavam dispneicos à avaliação do padrão respiratório por meio de inspeção direta. Porém, destes dispneicos, cinco apresentavam dispneia inspiratória (correlacionada com estenose de narinas e alterações em vias respiratórias decorrentes de síndrome do braquicefálico); e apenas um animal apresentava padrão de dispneia mista (gato acometido por $\mathrm{CMH}$ de grau importante; com crepitação em campos pulmonares à auscultação). Segundo Kittleson e Kienle (1998) e Fox et al. (1999), a disfunção diastólica presente na CMH pode levar ao desenvolvimento da insuficiência cardíaca congestiva, visto que as pressões de preenchimento ventricular estão aumentadas, o que se transmite às pressões do átrio esquerdo e veias pulmonares (LINNEY et al., 2014). Desta forma, edema pulmonar cardiogênico e/ou efusão pleural podem ocorrer devido à insuficiência cardíaca congestiva esquerda (ABBOTT; MCLEAN, 2006; CÔTÉ et al., 2011), justificando a presença da dispneia no animal em questão, que se apresentava em possível quadro de edema pulmonar.

Ao avaliar os 42 animais, 64,28\% apresentaram sopro em bordo esternal à auscultação de bulhas cardíacas, sendo que a intensidade do sopro foi maior nos indivíduos acometidos pela CMH em comparação aos indivíduos normais. De acordo com Rush et al. (2002) e Ferasin et al. (2003), a ocorrência de sopro sistólico é justificada pela turbulência causada tanto na regurgitação mitral quanto na obstrução de via de saída de ventrículo esquerdo, e ocorre em $44-72 \%$ dos gatos com $\mathrm{CMH}$. No presente trabalho, correlacionando-se a detecção do sopro ao exame físico e a presença de fluxos turbulentos (de insuficiências ou obstruções), pode-se observar que a sensibilidade e a especificidade da auscultação de sopro como indicador de anormalidades ecocardiográficas são baixas em gatos. Conforme já mencionado anteriormente, de acordo com Paige et al. (2009), Payne et al. (2010) e Wagner et al. (2010), nem todo gato com sopro apresenta cardiopatia e nem todo gato com cardiomiopatia apresenta sopro, à semelhança dos resultados encontrados.

Ao exame eletrocardiográfico dos 42 animais, o ritmo mais frequente foi 0 ritmo sinusal normal, seguido da taquicardia sinusal, sem diferenças quanto à 
ocorrência nos diferentes grupos. Apenas um animal, acometido pela $\mathrm{CMH}$, apresentou complexos ventriculares prematuros (VPCs) isolados e polimórficos durante a monitorização. Os distúrbios de condução e bloqueios encontrados não apresentaram diferenças em relação à sua ocorrência nos grupos. De acordo com Tilley e Goodwin (1995), alterações eletrocardiográficas são comuns em animais com $\mathrm{CMH}$ e incluem: alterações indicativas de sobrecarga, taquiarritmias ventriculares ou supraventriculares, desvio de eixo para a esquerda, bloqueios fasciculares ou atrioventriculares (HARVEY et al., 2005; CÔTÉ; JAEGER, 2008).

Dois gatos com $\mathrm{CMH}$ apresentaram distúrbio de repolarização ventricular, o que pode ser justificado, conforme mencionado anteriormente, pelo desenvolvimento de áreas de isquemia, fibrose e hipóxia tecidual resultantes da hipertrofia miocárdica (TILLEY; GOODWIN, 1995; WARE, 2007).

Os valores de amplitude de onda $\mathrm{R}$ na derivação DIl e na precordial CV6LL foram maiores nos animais acometidos pela $\mathrm{CMH}$. Conforme citado anteriormente, aumento na amplitude da onda $R$ e/ou na duração do complexo QRS está relacionado a sobrecargas ventriculares (TILLEY, 1992; HARVEY et al., 2005; CÔTÉ; JAEGER, 2008). Apesar dos valores de amplitude de onda $R$ nestas diferentes derivações serem superiores nos gatos com $\mathrm{CMH}$ em relação aos demais, nem todos os gatos com $\mathrm{CMH}$ avaliados no trabalho atual apresentaram amplitudes acima do valor de referência para a espécie.

A duração e a amplitude da onda $\mathrm{P}$ foram maiores nos gatos com $\mathrm{CMH}$. $\mathrm{A}$ maior duração da onda $\mathrm{P}$ nos animais com $\mathrm{CMH}$ pode ser justificada pelo maior diâmetro do átrio esquerdo observado ecocardiograficamente nos mesmos. Já em relação à amplitude da onda $\mathrm{P}$, nenhum gato apresentou sobrecarga atrial direita ao ecocardiograma e nenhum animal apresentou alterações eletrocardiográficas que sugerissem aumento atrial direito (amplitude da onda $\mathrm{P}$ estava dentro da normalidade em todos os animais).

Considerando-se apenas os animais dos grupos experimentais $(n=42)$, a sensibilidade do eletrocardiograma em detectar aumento do átrio esquerdo foi de $25 \%$ e a especificidade $94,21 \%$, resultado consistente com os dados de literatura já citados, onde a sensibilidade do ECG para detecção de aumento atrial esquerdo é baixa (MOISE et al., 1986; SCHÖBER et al., 2007). Já em relação à detecção de sobrecarga de ventrículo esquerdo, a sensibilidade foi baixa (18,19\%) com especificidade de $100 \%$. Desta forma, todos os gatos com sobrecarga ventricular 
esquerda ao eletrocardiograma realmente apresentavam hipertrofia miocárdica, resultado consistente com os dados descritos na literatura humana (BACHAROVA, 2009; LAKDAWALA et al., 2011) e veterinária (MOISE et al., 1986), embora nenhum destes estudos tenha demonstrado $100 \%$ de especificidade. Esta especificidade de $100 \%$ pode ser justificada pelo baixo número de animais avaliados no trabalho atual.

A mensuração da pressão arterial sistólica foi utilizada como critério de exclusão e inclusão para os grupos experimentais, já que a hipertensão arterial sistêmica faz parte do diagnóstico diferencial de hipertrofia miocárdica. Apesar deste critério, oito animais apresentaram valores de pressão arterial sistólica superiores ao limite de normalidade de $150 \mathrm{mmHg}$ (cinco gatos normais e três com $\mathrm{CMH}$ ) e mesmo assim participaram do projeto. Destes animais, quatro apresentaram aumento discreto da pressão arterial sistólica, com valores entre 160 e 166 mmHg; dois apresentaram aumento moderado; e dois apresentaram aumento importante, com valores de $180 \mathrm{mmHg}$ (todos do grupo normal). Chetboul et al. (2012) consideraram, para inclusão de gatos no grupo de $\mathrm{CMH}$ de seu estudo, animais com valores de pressão arterial sistólica de até $160 \mathrm{mmHg}$; e valores maiores também foram obtidos em animais tensos e agitados durante a mensuração. Segundo Brown et al. (2007), pressão arterial sistólica de até $160 \mathrm{mmHg}$ apresenta baixo risco de lesão em órgãos-alvo (olhos, rins, sistema nervoso central e coração). Ainda segundo o consenso escrito por Brown et al. (2007), para que se possa fechar o diagnóstico de hipertensão arterial sistêmica, há necessidade de mais de uma mensuração (em momentos distintos), de correlação com doenças de base e lesão em órgãos-alvo, e de exclusão do estresse como causa de falso aumento de pressão (hipertensão secundária ao estresse no momento da mensuração). Todos animais com aumento de pressão arterial sistólica do presente estudo apresentaram-se bastante agitados durante a mensuração, podendo justificar esta elevação (secundária ao estresse). Além disso, nenhum animal com aumento de pressão arterial sistólica apresentou outras alterações sistêmicas que pudessem sugerir um quadro de hipertensão arterial crônico. O único gato com $\mathrm{CMH}$ e aumento moderado da pressão arterial (176 mmHg) não foi excluído da avaliação por apresentar-se extremamente agitado durante a realização do exame e por ter histórico de pressão arterial sistólica normal em outras avaliações prévias ao estudo (este paciente já apresentava diagnóstico de $\mathrm{CMH}$ há três anos). Os dois gatos normais com aumento importante da pressão arterial $(180 \mathrm{mmHg})$ continuaram na avaliação por não fazerem parte do grupo da 
$\mathrm{CMH}$ (apresentavam espessuras miocárdicas normais) e por também estarem muito agitados no momento da mensuração.

Hipertensão arterial sistêmica, nefropatia e hipertireoidismo são as principais causas de hipertrofia miocárdica secundária em felinos e devem ser excluídas para que se possa fazer o diagnóstico de CMH idiopática (NUNEZ et al., 2004; SAMPEDRANO et al., 2006; SIMPSOM et al., 2008). Nenhum animal avaliado apresentou alterações significativas nos exames hematológicos e bioquímicos. Os valores de hormônio tireoidiano T4 total encontraram-se dentro da normalidade, excluindo-se, assim, a possibilidade de hipertireoidismo. Nenhum animal apresentou infecções evidentes, alterações hepáticas ou renais primárias ou qualquer outra enfermidade que pudesse interferir no sistema cardiovascular. Outras causas secundárias de hipertrofia ventricular incluem a estenose aórtica e a acromegalia (MCDONALD et al., 2006a), e ambas também foram excluídas nos animais em questão.

Conforme citado anteriormente e de acordo com dados da literatura, considerou-se hipertrofia quando a espessura da parede ventricular esquerda e/ou do septo interventricular, avaliada ecocardiograficamente, ultrapassou 0,6 cm (GUNDLER; TIDHOLM; HÄGGSTRÖM, 2008). Apesar de alguns autores considerarem como limite superior de normalidade valores de 0,5 ou $0,55 \mathrm{~cm}$ (WARE, 2007; BOON, 2011), optou-se pelo valor de corte de 0,6 cm para evitar a escolha de animais com valores próximos à normalidade e para aumentar a especificidade do método na detecção de hipertrofia.

À avaliação ecocardiográfica dos 42 animais, o diâmetro do átrio esquerdo e a relação átrio esquerdo-aorta foram maiores nos animais acometidos pela $\mathrm{CMH}$ em relação aos demais. Observaram-se diferenças na velocidade e no gradiente de pressão do fluxo aórtico, que foram maiores nos acometidos quando comparados aos animais normais. Conforme já mencionado anteriormente, o ecocardiograma é o melhor meio para diagnóstico não invasivo de $\mathrm{CMH}$, permitindo caracterizar hipertrofia (simétrica ou assimétrica) e anormalidades funcionais ou estruturais (CHETBOUL et al., 2006a; CHETBOUL et al., 2006b; SIMPSON et al., 2007). Em consequência da disfunção diastólica e dos fluxos regurgitantes, o átrio aumenta de tamanho, às vezes de forma importante, devido à sobrecarga de pressão (GUNDLER; TIDHOLM; HÄGGSTRÖM, 2008; FERASIN, 2009a; LINNEY et al., 2014). Segundo Ware (2007) e Linney et al. (2014), o aumento atrial, decorrente da 
disfunção diastólica e de pressões de enchimento ventricular aumentadas, pode variar de discreto a importante, e a parede atrial também pode se apresentar espessada nos quadros de $\mathrm{CMH}$, justificando os resultados encontrados no presente estudo.

Conforme já discutido anteriormente, dentre os animais com $\mathrm{CMH}$, a presença de hipertrofia miocárdica septal em região basal de via de saída do ventrículo esquerdo (SIVAo) ocorreu em 90,90\% dos casos, o que está em concordância com os resultados já publicados quanto aos parâmetros ecocardiográficos na raça Persa (TREHIOU-SECHI et al., 2012) e pode justificar o maior gradiente de pressão e a maior velocidade do fluxo aórtico nos animais acometidos, já que o septo interventricular hipertrofiado pode dificultar a passagem do sangue na via de saída ventricular esquerda (BOON, 2011).

De acordo com a classificação utilizada por Wess, Sarkar e Hartmann (2010) em 10 gatos acometidos no presente estudo, a $\mathrm{CMH}$ foi considerada de grau discreto; em nove gatos, de grau moderado; e em três, de grau importante. Os gatos com $\mathrm{CMH}$ importante (cujo critério de gravidade utilizado envolve apenas o diâmetro do átrio esquerdo e o grau de espessura miocárdica) também apresentavam algumas alterações hemodinâmicas evidentes, como insuficiências valvares, movimento anterior sistólico da valva mitral, padrão restritivo de disfunção diastólica e obstrução de via de saída do ventrículo esquerdo. De acordo com Chetboul et al. (2006b) e Gundler, Tidholm e Häggström (2008), o ecocardiograma permite identificação e quantificação de áreas de hipertrofia na parede ventricular, no septo interventricular ou nos músculos papilares; mas apenas a correta interpretação das informações permite avaliação e estratificação de riscos (GRAZIANO; ACQUATELLA, 2007).

Quanto à avaliação dos aparelhos valvares, sete animais com $\mathrm{CMH}$ apresentaram movimento anterior sistólico da valva mitral (MAS). De acordo com Graziano e Acquatella (2007), a obstrução da via de saída do ventrículo esquerdo é devida ao movimento anterior sistólico da valva mitral na maioria dos pacientes humanos (>95\%). Com a obstrução dinâmica da via de saída do ventrículo esquerdo, o movimento anterior sistólico mitral ou o fechamento parcial da valva aórtica podem ser visibilizados e, na modalidade Doppler, pode-se detectar insuficiência valvar mitral e aumento na velocidade do fluxo de saída do ventrículo esquerdo (NELSON; COUTO, 2005; WARE, 2007; BOON, 2011). 
Turbulência sistólica em via de saída do ventrículo esquerdo com aumento na velocidade e no gradiente de pressão do fluxo aórtico (obstrução de via de saída do ventrículo esquerdo) foi observada em três gatos com $\mathrm{CMH}$, todos com movimento anterior sistólico da valva mitral. Segundo Ware (2007) e Ferasin (2009), gatos com obstrução dinâmica do fluxo de saída do ventrículo esquerdo (cardiomiopatia hipertrófica obstrutiva) durante a sístole, apresentam maior gradiente de pressão sistólico entre o ventrículo e a via de saída. Esta obstrução aumenta o estresse de parede e a demanda miocárdica de oxigênio, promovendo o desenvolvimento de isquemia miocárdica (GUNDLER; TIDHOLM; HÄGGSTRÖM, 2008).

Segundo Ware (2007) e Boon (2011), alterações no fluxo mitral decorrentes de $\mathrm{CMH}$ incluem redução na velocidade máxima de enchimento ventricular rápido (onda E), aumento no tempo de desaceleração da onda $E$, aumento na velocidade máxima de enchimento ventricular lento (onda A- contração atrial), redução na relação E/A e aumento no TRIV, conjunto de alterações que caracterizam disfunção de relaxamento ventricular. Porém, as avaliações no fluxo transmitral e no TRIV sofrem influências de pré-carga, pós-carga e frequência cardíaca, não sendo patognomônicas de disfunção diastólica (CHETBOUL et al., 2006a; BOON, 2011). No presente estudo, a inversão de ondas E e A (ou seja, relação E/A menor que um) esteve presente tanto em animais normais quanto em animais com $\mathrm{CMH}$. Fluxo transmitral com padrão restritivo de disfunção diastólica, caracterizando alteração na distensibilidade ventricular (relação E/A maior que dois; tempo de relaxamento isovolumétrico e de desaceleração da onda $E$ diminuídos) foi observada em apenas um gato com $\mathrm{CMH}$, indicando sobrecarga de pressão em átrio esquerdo. Nos demais animais, a relação $E / A$ apresentou-se dentro da normalidade, não permitindo, isoladamente, diferenciação entre o padrão normal e 0 padrão pseudonormal.

\subsection{ANÁLISE GENÉTICA}

Nos 42 gatos da raça Persa do presente estudo, foram avaliados dois exons referentes a dois genes comumente relatados por apresentarem mutações que causam $\mathrm{CMH}$ familial em humanos: o exon 27 do gene MYBPC3 e o exon 5 do gene 
ACTC1. De acordo com Meurs et al. (2009) e Marsiglia et al. (2014), os principais genes que codificam proteínas do sarcômero e que estão relacionados às mutações envolvidas na $\mathrm{CMH}$ familial humana são: gene da cadeia pesada da beta-miosina (MYH7), gene da proteína C miosina ligante (MYBPC3), gene da troponina cardíaca T (TNNT2), gene da troponina I (TNNI3), gene da alfa-tropomiosina (TPM1), gene regulador da cadeia leve de miosina (MYL2), gene essencial da cadeia leve de miosina (MYL3) e gene da alfa-actina cardíaca (ACTC1), sendo que este grau de heterogeneidade genética também é observado em famílias de gatos.

Segundo Maron e Maron (2013) e Marsiglia (2013), aproximadamente $70 \%$ das mutações relacionadas à $\mathrm{CMH}$ humana familial estão localizadas nos genes da cadeia pesada da beta-miosina (MYH7) e da proteína C miosina ligante (MYBPC3). Mais de 240 mutações no gene MYBPC3 já foram descritas em humanos com $\mathrm{CMH}$; e mutações neste gene são responsáveis por aproximadamente $30 \%$ de todos os casos de $\mathrm{CMH}$ familial descritos no homem (FRIES; HEANEY; MEURS, 2008; GODISKEN et al., 2011), sugerindo que este gene é importante na patogênese da afecção (BORGEAT et al., 2014). Mutações em diferentes regiões deste mesmo gene também já foram associadas com a CMH familial em Ragdolls e Maine Coons, demonstrando a importância deste gene também nos felinos (BORGEAT et al., 2014). Desta forma, no presente trabalho, optou-se pela escolha do gene MYBPC3 na investigação das possíveis mutações nos gatos da raça Persa (em região diferente da relatada no Maine Coon e no Ragdoll).

De acordo com os resultados de Meurs et al. (2009), onde investigaram-se mutações nos oito principais genes envolvidos na patogênese da $\mathrm{CMH}$ em diferentes raças de gatos (excetuando-se o Persa), foram observados três polimorfismos de nucleotídeos únicos (SNP) no exon 5 do gene ACTC1 felino (em 16 animais) e um SNP no exon 27 do gene MYBPC3 (em 10 animais). Segundo Longeri et al. (2013), que avaliaram mutações relacionadas à $\mathrm{CMH}$ em diferentes raças de gatos, não foi possível identificar os polimorfismos A31P, A74T e R820W do gene MYBPC3 na raça Persa. Desta forma, baseando-se nestes trabalhos, optou-se pela escolha do exon 5 (do gene ACTC1) e do exon 27 (do gene MYBPC3), ainda não analisados em população de gatos da raça Persa. Apesar deste critério para seleção de genes avaliados, a escolha, ainda sim, pode ser considerada aleatória (visto que existem mais de 1400 mutações já descritas em 
humanos, segundo a literatura) (MCTAGGART, 2002; HÄGGSTRÖM, 2003; MARON; MARON, 2013).

Foi identificado um polimorfismo de nucleotídeo único (SNP) na posição 890 do exon 5 do gene ACTC1 e três SNP no intron 5-6 do mesmo gene. Nenhum polimorfismo, adição ou deleção foi observado em outras regiões avaliadas no gene ACTC1. Apesar dos SNP observados neste estudo, os mesmos não se enquadram nos critérios de mutação causal da $\mathrm{CMH}$ porque não provocam mudança em aminoácidos, não promovem alteração estrutural na proteína codificada e não ocorreram exclusivamente em animais com CMH. Segundo Meurs et al. (2009), Longeri et al. (2013) e Marsiglia et al. (2014), para que uma mutação esteja relacionada com a $\mathrm{CMH}$, a alteração no par de base deve resultar em mudança no aminoácido para outro de diferente polaridade, estrutura ou de diferente padrão ácido-base; e deve ocorrer exclusivamente nos indivíduos com $\mathrm{CMH}$, o que não ocorreu no presente estudo. Segundo Kittleson (2009) e Ho (2011), a patofisiologia da $\mathrm{CMH}$ relacionada às mutações em genes que codificam proteínas do sarcômero ainda é pouco conhecida e controversa. Acredita-se que a proteína anormal produzida pelo gene mutado resulte em sarcômeros com função e contratilidade reduzidas, o que faz com que os sarcômeros funcionais tenham que trabalhar para suportar uma carga maior, levando à substituição de sarcômeros alterados por sarcômeros adicionais, o que resulta em hipertrofia miocárdica e desarranjo de miócitos e miofibrilas (KITTLESON, 2009; HO, 2011). Porém, segundo Marsiglia (2013), apesar do grande número de genes já descritos em humanos com $\mathrm{CMH}$, os mecanismos moleculares que determinam a manifestação fenotípica ainda não foram elucidados.

Apesar da ausência de mutações significativas no presente trabalho, a identificação destes SNP pode ser útil para futuros estudos de $\mathrm{CMH}$ familial em diferentes raças de felinos. O estudo de Meurs et al. (2009), por exemplo, investigou a presença de mutações em algumas raças de gatos como Maine Coon, Norwergian Forest Cat, Sphynx, Siberiano e British Shorthair; permitiu identificação de 33 polimorfismos de nucleotídeos únicos (SPN) em sete destes genes, mas nenhuma mutação esteve relacionada à causa de $\mathrm{CMH}$ nestas raças. Apesar da ausência de resultados conclusivos, o estudo de Meurs et al. (2009), assim como o presente estudo, fornecem informações que auxiliam na elaboração de novas pesquisas. 
Em relação ao exon 27 do gene MYBPC3, não foram observados polimorfismos de nucleotídeo único (SNP), adição ou deleção nas regiões avaliadas no presente estudo. Desta forma, o exon 27 do gene MYBPC3 não está relacionado à $\mathrm{CMH}$ familial em gatos da raça Persa. Segundo o estudo de Meurs et al. (2009), 10 gatos de diferentes raças (que não o Persa) apresentaram um polimorfismo de nucleotídeo único no exon 27 do gene MYBPC3. Apesar da presença deste SNP, a mutação encontrada não promoveu modificação estrutural na proteína codificada e não esteve relacionada à causa da $\mathrm{CMH}$ nestes animais.

À semelhança dos resultados obtidos neste estudo, outros pesquisadores também não observaram mutações no gene MYBPC3 que justificassem a $\mathrm{CMH}$ em outras raças que não no Maine Coon e no Ragdoll (MEURS et al., 2009; KITTLESON, 2009a; LONGERI et al., 2013; BORGEAT et al., 2014). De acordo com estudo de Longeri et al. (2013), que avaliou a frequência das mutações A31P, R820W e do polimorfismo A74T (no gene MYBPC3) em 1855 gatos de 28 diferentes raças, as mutações A31P e R820W ocorreram exclusivamente em gatos das raças Maine Coon e Ragdoll, respectivamente. Nas demais raças avaliadas, não foi identificada mutação relacionada à $\mathrm{CMH}$, mas a afecção foi prevalente nas raças puras e sua incidência aumentou conforme a idade dos animais. O polimorfismo A74P encontrado em alguns animais não esteve relacionado ao fenótipo $\mathrm{CMH}$ e não pareceu estar correlacionado com a CMH familial.

A ausência de mutações significativas nestas regiões analisadas no presente trabalho não descarta a possibilidade destes genes estarem envolvidos na etiopatogenia da $\mathrm{CMH}$, já que é possível a existência de outras mutações em regiões deste gene que não foram avaliadas (regiões promotoras ou regiões não traduzidas). De acordo com Vera et al. (2010) e Marsiglia (2013), porém, a maioria das mutações causadoras de $\mathrm{CMH}$ familial em humanos é localizada nestas regiões de exons.

Os gatos da raça Persa avaliados neste estudo, ainda assim, apresentavam alta prevalência de $\mathrm{CMH}$. Dentre as possibilidades para a etiologia genética familial nestes gatos, pode-se citar a existência de mutação em algum outro gene já descrito na $\mathrm{CMH}$ familial em humanos; a presença de mutação em gene ainda não relatado como causador de $\mathrm{CMH}$; ou a presença de $\mathrm{CMH}$ de etiologia ainda não conhecida. De acordo com Ingles et al. (2001) e Ho et al. (2011), a forma de transmissão mais comum da $\mathrm{CMH}$ humana é a autossômica dominante, mas em poucos casos, a $\mathrm{CMH}$ 
está relacionada a mutações do genoma mitocondrial (DE et al., 2011). Além disso, aproximadamente dois terços dos indivíduos apresentam histórico familiar e o restante apresenta mutações esporádicas nem sempre conhecidas (MARON; MARON, 2013; SISAKIAN, 2014).

Apesar da presença de alguns polimorfismos de nucleotídeo único, a mutação causal da $\mathrm{CMH}$ em gatos da raça Persa não foi elucidada. Mutações nestes dois exons de genes cardíacos não parecem ser a causa da cardiomiopatia na referida raça. Avaliações de genes cardíacos adicionais são necessárias para a identificação da causa molecular desta cardiopatia em animais da raça Persa. Outros estudos já publicados sobre a herança genética da $\mathrm{CMH}$ em diferentes raças de felinos também não evidenciaram novas mutações envolvidas na patogênese da afecção (MEURS et al., 2009; WESS et al., 2010; LONGERI et al., 2013). Até o presente momento, nenhum estudo genético da $\mathrm{CMH}$ com população exclusivamente composta por gatos da raça Persa foi publicado, demonstrando, ainda assim, a importância dos resultados obtidos.

\subsection{DOENÇA RENAL POLICÍSTICA E HIPERTROFIA VENTRICULAR}

Embora não fizesse parte do objetivo primário do presente projeto, a população total $(n=82)$ foi, também, submetida à avaliação genética da mutação relacionada à doença renal policística autossômica dominante (PKD), por ser uma afecção comum nos gatis da raça Persa. A PKD felina é caracterizada pela presença de múltiplos cistos localizados em parênquima renal e, ocasionalmente, hepático e pancreático, sendo uma importante causa de doença renal crônica terminal (NORTHINGTON; JULIANA, 1977; BILLER et al., 1996; EATON et al., 1997; PEDERSEN et al., 2003). É a doença genética mais prevalente em gatos, acometendo principalmente animais da raça Persa ou correlacionados (BILLER; CHEW; DIBARTOLA, 1990; BILLER et al., 1996; BONAZZI et al., 2009; LEE et al., 2010b; SCALOL et al., 2014). Da mesma forma, em humanos, constitui-se na doença renal monogênica mais comum, acometendo um em cada 400-1000 indivíduos, com curso clínico muito semelhante à doença em gatos (BILLER et al., 
1996; EATON et al., 1997; PEDERSEN et al., 2003; CADNAPAPHORNCHAl et al., 2008).

No presente estudo, a pesquisa da doença renal policística autossômica dominante foi realizada por teste genético, por meio de reação de PCR, com pesquisa da mutação no exon 29 do gene PKD1 felino. Segundo a literatura, uma mutação pontual (troca de C por A) no exon 29 do gene PKD-1 é a causa da doença renal policística nos gatos (HELPS et al., 2007; LEE et al., 2010b), sendo que o teste genético para a pesquisa desta mutação (por meio de técnica de reação de PCR) permite fechar o diagnóstico da afecção (HELPS et al., 2007; SCALOL et al., 2014). O ultrassom abdominal permite a identificação dos cistos e, segundo Bonazzi et al. (2009), apresenta sensibilidade de $96,2 \%$ e especificidade de $91 \%$ para 0 diagnóstico da PKD em gatos. Desta forma, para o diagnóstico correto, o ideal é a realização do ultrassom associado ao teste genético (BONAZZI et al., 2007; BONAZZI et al., 2009).

Para a seleção dos animais do presente estudo, nenhum gato incluído nos grupos experimentais apresentou alterações laboratoriais sugestivas de nefropatia e/ou de hipertensão arterial, já que ambas as afecções fazem parte do diagnóstico diferencial de hipertrofia ventricular secundária. Da mesma forma, nenhum gato apresentou alterações em exame clínico (anamnese e exame físico) que sugerisse doença renal. Apesar da adoção destes critérios e lembrando que o ultrassom abdominal não foi incluído nos exames de triagem, nove gatos apresentaram teste genético positivo para a doença renal policística autossômica dominante, correspondendo a uma prevalência de $10,97 \%$ na população estudada. Segundo a literatura, a prevalência da doença renal policística em gatos da raça Persa varia de 24,2\% a 46\% (BARRS et al., 2001; CANNON et al., 2001; BARTHEZ; RIVIER; BEGON, 2003; LEE et al., 2010a; SCALOL et al., 2014); e a PKD pode, também, acometer gatos de outras raças, embora menos comumente (BARTHEZ; RIVIER; BEGON, 2003; SCALOL et al., 2014).

Destes nove animais PKD positivos geneticamente, seis eram pertencentes ao grupo da $\mathrm{CMH}$ e três, do grupo normal. A proporção de gatos PKD positivos no grupo da $\mathrm{CMH}$ foi estatisticamente maior que no grupo dos animais normais. Da mesma forma, avaliando inversamente, gatos da raça Persa com PKD apresentaram maior prevalência de hipertrofia miocárdica septal do que gatos negativos para esta mutação. Segundo a literatura, complicações cardiovasculares são as principais 
causas de morbidade e mortalidade em pacientes humanos com PKD (VIRZI et al., 2011; ECDER, 2013); e a prevalência destas alterações varia de 0 a 30\% (LUMIAHO et al., 2001). Há relatos de associação entre PKD e afecções cardíacas como hipertensão arterial sistêmica e consequente hipertrofia ventricular, disfunção diastólica, alteração morfológica valvar, prolapso valvar e desenvolvimento de aneurismas em humanos acometidos (LUMIAHO et al., 2001; ECDER, 2013). Em gatos, não há relatos quanto a possíveis anormalidades cardíacas em indivíduos com PKD.

Considerando a população estudada dividida em grupo PKD positivo $(n=9)$ e grupo PKD negativo $(n=73)$, não foram observadas diferenças estatísticas nos parâmetros eletrocardiográficos nem nos valores de pressão arterial. Em relação aos parâmetros ecocardiográficos, não foram observadas diferenças em relação à função diastólica, ao aspecto e movimentação dos folhetos valvares, bem quanto aos fluxos transvalvares nos diferentes grupos, o que difere dos resultados observados em humanos, onde indivíduos com PKD são mais predispostos a alterações valvares (LUMIAHO et al., 2001; VIRZI et al., 2011; ECDER, 2013).

No presente estudo, a proporção de hipertrofia miocárdica foi estatisticamente maior nos animais PKD positivos (ou a proporção de animais PKD positivos foi maior no grupo com $\mathrm{CMH}$ ), apesar de todos os pacientes apresentarem pressão arterial sistêmica normal. De acordo com a literatura, ativação do sistema renina angiotensina aldosterona (SRAA), tanto em consequência da expansão dos cistos quanto devido à isquemia local (alterações na vascularização renal), está relacionada ao desenvolvimento de hipertensão arterial sistêmica e hipertrofia de ventrículo esquerdo nos pacientes humanos PKD positivos (ECDER et al., 1999; PHILLIPS et al., 2007; SCHRIER, 2009). A hipertensão arterial acomete 50 a 70\% dos humanos PKD positivos, ocorre antes de haver piora na função renal, e pode causar hipertrofia ventricular secundária, levando a complicações cardiovasculares (CHAPMAN et al., 1997; ECDER, 2013). Na maioria dos casos, a hipertrofia é secundária a quadros de hipertensão arterial sistêmica, mas há relatos de hipertrofia ventricular em pacientes normotensos e com função renal normal, indicando uma disfunção diastólica precoce e de etiologia pouco elucidada (CHAPMAN et al., 1997; BARDAJl et al., 1998; ECDER et al., 2003), o que pode estar relacionado aos resultados obtidos no presente estudo (já que nenhum gato com hipertrofia e teste genético positivo para PKD apresentou hipertensão). 
Segundo o estudo de Chapman et al. (1997), a hipertrofia do ventrículo esquerdo foi observada em $23 \%$ dos pacientes PKD positivos e normotensos. Estes pacientes, avaliados por mais sete anos, não desenvolveram hipertensão arterial sistêmica. Algumas pesquisas sugerem que a hipertrofia presente em pacientes com PKD normotensos pode ser explicada por fatores modificadores genéticos, como mutações no gene que codifica a enzima conversora de angiotensina, por exemplo (CHAPMAN et al., 1997; ECDER et al., 2003; WANIC-KOSSOWSKA et al., 2014). Outros estudos sugerem ativação precoce do sistema renina angiotensina aldosterona como possível causa da hipertrofia miocárdica (SAGGAR-MALIK et al., 1994); e até mesmo a presença de resistência à insulina, presente em alguns humanos com PKD, como desencadeador desta hipertrofia (LUMIAHO et al., 2003).

Humanos PKD positivos, normotensos e com função renal normal podem apresentar disfunção endotelial, alterações na velocidade do fluxo coronariano, disfunção diastólica biventricular e espessamento da camada íntima-média da carótida, indicando alterações cardiovasculares em fases precoces (MARTINEZ-VEA et al., 2000; MARTINEZ-VEA et al., 2004; ECDER, 2013). Porém, em gatos, não há estudos avaliando alterações cardiovasculares na PKD.

Poucos estudos avaliaram a ocorrência de hipertensão arterial sistêmica e a presença de alterações nos determinantes hormonais que regulam a pressão arterial em gatos acometidos pela doença renal policística (PEDERSEN et al., 2003). Porém, nenhum estudo correlacionou presença de hipertrofia ventricular, alterações valvares ou anormalidades sistólicas e diastólicas com a PKD felina. Segundo Pederson et al. (2003), gatos com PKD apresentam maiores valores de pressão arterial e alguns animais apresentam maiores valores da razão aldosterona-renina em relação a gatos normais.

Em Persas, a cardiomiopatia hipertrófica $(\mathrm{CMH})$, principal cardiopatia felina caracterizada por hipertrofia ventricular primária, também é uma afecção prevalente na raça e possui componente genético familial. Desta forma, não foi possível concluir, neste estudo, se a hipertrofia ventricular está associada à nefropatia causada pela PKD (embora ainda sem alterações em ureia, creatinina, densidade urinária e pressão arterial); ou se há ocorrência concomitante de $\mathrm{CMH}$ nestes animais.

Desta forma, gatos da raça Persa com PKD apresentam maior prevalência de hipertrofia miocárdica septal. Há necessidade de mais estudos para avaliar a relação 
causal (PKD e hipertrofia) ou associação genética de PKD e $\mathrm{CMH}$, com maior número de indivíduos. Em ambos casos, faz-se importante a realização de exames eletro e ecocardiográficos em felinos diagnosticados com doença policística; bem como é importante a avaliação de presença de mutação para doença renal policística nos Persas com diagnóstico de $\mathrm{CMH}$ (como possível diagnóstico diferencial). Estes resultados são bastante interessantes e inéditos na literatura, já que não há estudos avaliando as possíveis alterações cardíacas associadas à doença policística em Persas.

\subsection{LIMITAÇÕES}

As principais limitações do presente estudo referem-se ao baixo número de mutações genéticas investigadas. Sabe-se que existem mais de 1400 mutações descritas em mais de 11 genes relacionados à cardiomiopatia hipertrófica familial em humanos. Em gatos, há descrições de estudos genéticos em, pelo menos, oito diferentes genes relacionados à $\mathrm{CMH}$ felina. Porém, devido à dificuldade técnica e financeira, houve necessidade de avaliação de apenas duas regiões.

A ideia original do projeto era avaliar oitos genes relacionados à cardiomiopatia hipertrófica em felinos, por sequenciamento em larga escala (por metodologia de sequenciamento lon Torrent). Após a coleta de sangue e extração de DNA dos animais controles ou afetados pela doença, iniciou-se a padronização dos primers referentes a estes genes. No entanto, o primeiro problema enfrentado foi a ausência da sequência completa dos genes felinos no GenBank; ou seja, estes genes ainda não tinham sido sequenciados inteiramente até o momento da realização deste projeto. Assim, foi possível a construção de conjuntos de primers apenas nas extremidades dos genes, baseando-se na sequência descrita em humanos, quando necessário. Porém, esta estratégia necessita que ocorra a amplificação de fragmentos muito grandes de DNA que, muitas vezes, não é possível devido à fragmentação do template de DNA e/ou a outros problemas. De qualquer maneira, optou-se por utilizar a metodologia de amplificação conhecida como Touchdown e Nested PCR, utilizando uma enzima adequada para amplificação de longos trechos de DNA (long PCR). No entanto, devido ao tamanho 
de alguns genes e à qualidade do material extraído, esta metodologia também se mostrou inviável. Devido a estes problemas, optou-se por escolher os dois exons de genes relacionados à cardiomiopatia hipertrófica felina, utilizando sequências de primers já padronizadas e publicadas em artigos científicos. Assim, realizou-se a amplificação e análise mutacional convencional por sequenciamento em capilar.

A escolha dos dois exons avaliados foi fundamentada em estudos previamente publicados sobre $\mathrm{CMH}$ familial felina. Regiões genéticas já avaliadas anteriormente (em populações que continham gatos Persas) sem resultados positivos foram excluídas; e mutações sabidamente relacionadas a algumas raças (como Maine Coon e Ragdoll) não foram investigadas. Apesar desta precaução, a escolha dos dois genes avaliados ainda assim pode ser considerada ao acaso.

Além disso, outra limitação relacionada ao estudo foi o baixo número de animais avaliados geneticamente. Devido aos gastos financeiros necessários para avaliação genética individual (técnica de sequenciamento genético convencional), o número total de animais teve que ser pequeno.

Em relação aos resultados obtidos onde gatos PKD positivos apresentam maior prevalência de hipertrofia miocárdica, não foi possível estabelecer a relação de causa e efeito (doença renal policística causando hipertrofia), nem foi possível avaliar possíveis associações genéticas entre ambas as afeções (CMH e PKD). Apesar de todos os animais com hipertrofia miocárdica terem passado pelos critérios de inclusão e exclusão para entrarem no grupo com $\mathrm{CMH}$ (exclusão de causas secundárias de hipertrofia ventricular), alguns destes animais eram geneticamente positivos para esta mutação relacionada à doença policística. Em gatos, não há estudos avaliando alterações cardiovasculares na PKD. A limitação do presente trabalho envolve a não realização de exame ultrassonográfico como parte dos critérios de inclusão e exclusão. Não é possível compreender, neste estudo, se os gatos Persas com hipertrofia e PKD positivos realmente apresentam $\mathrm{CMH}$ familial; ou se a hipertrofia é secundária à nefropatia (embora em estágios iniciais, ainda sem alterações em função renal e pressão arterial). Portanto, há necessidade de mais estudos, com mais animais e com utilização de métodos para avaliação da possível ativação precoce do SRAA, por exemplo, para melhor compreensão dos resultados obtidos. 


\section{CONCLUSÃO}

No presente estudo, por meio da metodologia utilizada para a análise dos resultados, fundamentam-se as seguintes conclusões:

- a cardiomiopatia hipertrófica é prevalente em gatos da raça Persa e apresenta componente familial;

- a forma assimétrica da $\mathrm{CMH}$ (com hipertrofia miocárdica septal em região basal da via de saída do ventrículo esquerdo) é a forma mais comum em gatos da raça Persa;

- a $\mathrm{CMH}$ em gatos da raça Persa é mais observada em animais mais velhos e em machos;

- gatos da raça Persa com hipertrofia ventricular apresentam maiores valores de átrio esquerdo, relação átrio esquerdo/ aorta, velocidade e gradiente de pressão fluxo aórtico à ecocardiografia convencional;

- gatos da raça Persa com hipertrofia ventricular apresentam maiores valores de largura e amplitude da onda P (em derivação DII) e amplitude da onda $R$ (em derivação DIl e em precordiais CV6LL e CV6LU) ao eletrocardiograma;

- o exon 5 do gene da alfa-actina cardíaca (ACTC1 felino) não está relacionado à ocorrência da $\mathrm{CMH}$ em gatos da raça Persa;

- o exon 27 do gene da proteína C miosina ligante (MYBPC3) não está relacionado à ocorrência da $\mathrm{CMH}$ em gatos da raça Persa;

- gatos da raça Persa positivos para a mutação no exon 29 do gene PKD1 felino (doença renal policística autossômica dominante) apresentam maior prevalência de hipertrofia miocárdica.

Apesar da expectativa em relação à descoberta da mutação genética causadora de $\mathrm{CMH}$ em gatos da raça Persa, há necessidade de estudos mais extensos, com diferentes regiões e genes avaliados, e com maior número de indivíduos.

A associação entre presença da mutação no gene PKD1 e hipertrofia ventricular é um achado inédito, porém, ainda limitado, com necessidade de mais estudos para melhor compreensão. Ainda assim, os resultados obtidos tornam 
importante a realização de exames cardiológicos em felinos diagnosticados com doença policística; bem como da pesquisa da mutação PKD1 como diagnóstico diferencial de hipertrofia em Persas. 


\section{REFERÊNCIAS}

ABBOTT, J. A. Feline hypertrophic cardiomyopathy; an update. Veterinary Clinics of Small Animal Practice, v. 40, n. 4, p. 685-700, 2010.

ABBOTT, J. A.; MCLEAN, H. N. Two-dimensional echocardiographic assessment of the feline left atrium. Journal of Veterinary Internal Medicine, v. 20, p. 111-119, 2006.

ATKINS, C. E.; GALLO, A. M.; KURZMAN, I. D.; COWEN, P. Risk factors, clinical signs, and survival in cats with a clinical diagnosis of idiopathic hypertrophic cardiomyopathy: 74 cases (1985-1989). Journal of American Veterinary Medical Association, v. 201, n. 4, p. 613-618, 1992.

BACHAROVA, L. Electrocardiography- left ventricular mass discrepancies in left ventricular hypertrophy: electrocardiography imperfection or beyond perfection? Journal of Electrocardiography, v. 42, p. 593-96, 2009.

BARDAJI, A.; VEA, A. M.; GUTIERREZ, C.; RIDAO, C.; RICHART, C.; OLIVER, J. A. Left ventricular mass and diastolic function in normotensive Young adults with autosomal dominant polycystic kidney disease. American Journal of Kidney Diseases, v. 32, n. 6, p. 970-975, 1998.

BARRS, V. R.; GUNEW, M.; FOSTER, S. F.; BEATTY, J. A.; MALIK, R. Prevalence of autosomal dominant polycystic kidney disease in Persian cats and related-breeds in Sydney and Brisbane. Australian Veterinary Journal, v. 79, n. 4, p. 257-259, 2001.

BARTHEZ, P. Y.; RIVIER, P.; BEGON, D. Prevalence of polycystic kidney disease in Persian and Persian related cats in France. Journal of Feline Medicine and Surgery, v. 5, n. 6, p. 345-347, 2003.

BATY, C. J. Feline hypertrophic cardiomyopathy: an update. Veterinary Clinics of Small Animal Practice, v. 34, p. 1227-1234, 2004.

BENDER, S. R.; FRIEDMAN, D. J.; MARKOWITZ, S. M.; LERMAN, B. B; OKIN P. M. Electrocardiographic left ventricular hypertrophy predicts arrhythmia and mortality in patients with ischemic cardiomyopathy. Journal of Interventional Cardiac Electrophysiology, v. 34, p. 237-245, 2012. 
BILLER, D. S.; CHEW, D. J.; DIBARTOLA, S. P. Polycystic kidney disease in a family of Persian cats. Journal of American Veterinary Medical Association, v. 196, n. 8, p. 1288-1290, 1990.

BILLER, D. S.; DIBARTOLA, S. P.; EATON, K. A.; PFLUEGER, S.; WELLMAN, M. L.; RADIN, M.J. Inheritance of polycystic kidney disease in Persian cats. Journal of Heredity, v. 87, n. 1, p. 1-5, 1996.

BIOEDIT v.5.0.9. Disponível em: <http://www.mbio.ncsu.edu/bioedit/bioedit.html>. Acesso em: 27 junho 2014.

BLAST 2.2.29. Disponível em: <http://www.ncbi.nlm.nih.gov/blast/>. Acesso em: 27 junho 2014.

BOLIN, E.; LAM, W. A review of sensitivity, specificity, and likelihood ratios: evaluating the utility of the electrocardiogram as a screening tool in hypertrophic cardiomyopathy. Congenital Heart Diseases, v. 8, n. 5, p. 406-410, 2013.

BONAGURA, J. D. Feline cardiomyopathies. In: FUENTES, V. L; JOHNSON, L. R; DENNIS, S. BSAVA Manual of canine and feline cardiorrespiratory medicine. 2. ed. Gloucester: BSAVA, 2010. cap. 25, p. 220-236.

BONAGURA J. D. M-mode echocardiography: basic principles. Veterinary Clinics of North America, v. 13, n. 2, p. 299-319, 1983.

BONAZZI, M.; VOLTA, A.; GNUDI, G.; BOTTARELLI, E.; GAZZOLA, M.; BERTONI, G. Prevalence of the polycystic kidney disease and renal and urinary bladder ultrasonographic abnormalities in Persian and Exotic Shorthair cats in Italy. Journal of Feline Medicine and Surgery, v. 9, n. 5, p. 387-391, 2007.

BONAZZI, M.; VOLTA, A.; GNUDI, G.; COZZI, M. C.; STRILLACCI, M. G.; POLLI, M.; LONGERI, M.; MANFREDI, S.; BERTONI, G. Comparison between ultrasound and genetic testing for the early diagnosis of polycystic kidney disease in Persian and Exotic shorthair. Journal of Feline Medicine and Surgery, v. 11, n. 6, p. 430-434, 2009.

BOON J.A. Manual of veterinary echocardiography. 2. ed. West Sussex: WileyBlackwell, 2011. $610 \mathrm{p}$. 
BORGEAT, K.; CASAMIAN-SORROSAL, D.; FUENTES, V. L.; CONNOLLY, D. J. Association of the myosin binding protein C3 mutation (MYBPC3 R820W) with cardiac death in a survey of 236 Ragdoll cats. Journal of Veterinary Cardiology, v. 16, p. 73-80, 2014.

BRAUNWALD, E.; LAMBREW, C. T.; ROCKOFF, S. D.; ROSS, J.; MORROW, A. C. Idiopathic hypertrophic subaortic stenosis: a description of the disease based upon an analysis of 64 patients. Circulation, v. 30, n. 4, p. 3-119, 1964.

BRIZARD, D.; AMBERGER, C.; HARTNACK, S.; DOHERR, M.; LOMBARD, C. Phenotypes and echocardiographic characteristics of a European population of domestic shorthair cats with idiopathic hypertrophic cardiomyopathy. Schwiez Arch Tierheilkd, v. 151, n. 11, p. 529-538, 2009.

BROWN, S.; ATKINS, C.; BAGLEY, R.; CARR, A.; COWGILL, L.; DAVIDSON, M.; EGNER, B.; ELLIOTT, J.; HENIK, R.; LABATO, M.; LITTMAN, M.; POLZIN, D.; ROSS, L.; SNYDER, P.; STEPIEN, R. Guidelines for the identification, evaluation and management of systemic hypertension in dogs and cats. Journal of Veterinary Internal Medicine, v. 21, n. 3, p. 542-558, 2007.

BROWN, S. A.; HENIK, R. A.; FINCO, D. R. Diagnosis of systemic hypertension in dogs and cats. In: BONAGURA, J. D. Kirk's current veterinary therapy- Small animal practice. 13. ed. Philadelphia: W.B. Saunders, 2000. p. 835-838.

CADNAPAPHORNCHAI, M. A.; MCFANN, K.; STRAIN, J. D.; MASOUMI, A.; SCHRIER, R. W. Increased left ventricular mass in children with autosomal dominant polycystic kidney disease and borderline hypertension. Kidney International, v. 74, p. 1192-1196, 2008.

CAMPBELL, F. E.; KITTLESON, M. D. The effect of hydration status on the echocardiographic measurements of normal cats. Journal of Veterinary Internal Medicine, v. 21, n. 5, p. 1008-1015, 2007.

CANNON, M. J.; MACKAY, A. D.; BARR, F. J.; RUDORF, H.; BRADLEY, K. J.; GRUFFYDD-JONES, T. J. Prevalence of polycystic kidney disease in Persian cats in the United Kingdom. Veterinary Record, v. 149, n. 14, p. 409-411, 2001.

CAPEK, P.; VONDRASEK, J.; SKVOR, J.; BRDICKA, R. Hypertrophic cardiomyopathy: from mutation to functional analysis of defective protein. Croatian Medical Journal, v. 52, n. 3, p. 384-391, 2011. 
CASELLI, L.; GALANTI, G.; PADELETTI, L.; NIERI, M.; CECCHI, F.; CIPOLLINI, F.; BALDI, M.; PERROTTA, L.; VIGNINI, S.; MICHELUCCI, A. Diagnostic accuracy of extended-length electrocardiogram in differentiating between athlete's heart and hypertrophic cardiomyopathy. Journal of Electrocardiography, v. 42, p. 636-641, 2009.

CHAPMAN, A. B.; JOHSON, A. M.; RAINGUET, S.; HOSSACK, K.; GABOW, P.; SCHRIER, R. W. Left ventricular hypertrophy in autosomal dominant polycystic kidney disease. Journal of American Society of Nephrology, v. 8, p. 1292-1297, 1997.

CHETBOUL, V.; BLOT, S.; SAMPEDRANO, C. C.; THIBAUD, J. L.; GRANGER, N.; TISSIER, R.; BRUNEVAL, P.; GASCHEN, F.; GOUNI, V.; NICOLLE, A. P.; POUCHELON, J. L. Tissue Doppler imaging for detection of radial and longitudinal myocardial dysfunction in a family of cats affected by dystrophin-deficient hypertrophic muscular dystrophy. Journal of Veterinary Internal Medicine, v. 20, p. 640-647, 2006a.

CHETBOUL, V.; GOUNI, V.; SAMPEDRANO, C. C.; TISSIER, R.; SERRES, F.; POUCHELON, J. L. Assessment of regional systolic and diastolic myocardial functions using Tissue Doppler and Strain Imaging in dogs with dilated cardiomyopathy. Journal of Veterinary Internal Medicine, v. 21, p. 719-739, 2007.

CHETBOUL, V.; PETIT, A.; GOUNI, V.; TREHIOU-SECHI, E.; MISBACH, C.; BALOUKA, D.; SAMPEDRANO, C.; POUCHELON, J. L.; TISSIER, R.; ABITBOL, M. Prospective echocardiographic and tissue Doppler screening of a large Sphynx cat population: reference ranges, heart disease prevalence and genetic aspects.

Journal of Veterinary Cardiology, v. 14, n. 4, p. 497-509, 2012.

CHETBOUL, V.; SAMPEDRANO, C. C.; GOUNI, V.; NICOLLE, A. P.; POUCHELON, J. L. Two-dimensional color tissue Doppler imaging detects myocardial dysfunction before occurrence of hypertrophy in a young Maine Coon cat. Veterinary Radiology and Ultrasound, v. 47, n. 3, p. 295-300, 2006b.

CHROMAS LITE v. 2.1.1. Disponível em: <http://technelysium.com.au/page_id=13>. Acesso em: 27 junho 2014.

CONNOLLY, D. J.; CANNATA, J.; BOSWOOD, A.; ARCHER, J.; GROVES, E. A.; NEIGER, R. Cardiac troponin I in cats with hypertrophic cardiomyopathy. Journal of Feline Medicine and Surgery, v. 5, p. 209-216, 2003. 
CONNOLLY, D. J.; MAGALHAES, R. J.; SYME, H. M.; BOSWOOD, A.; FUENTES, V. L.; CHU, L.; METCALF, M. Circulating natriuretic peptides in cats with heart disease. Journal of Veterinary Internal Medicine, v. 22, n. 1, p. 90-105, 2008.

CÔTÉ, E.; JAEGER, R. Ventricular tachyarrhythmias in 106 cats: associated structural cardiac disorders. Journal of Veterinary Internal Medicine, v. 22, n. 6, p. 1444-1446, 2008.

CÔTÉ, E.; MANNING, A. M.; EMERSON, D.; LASTE, N. T.; MALAKOFF, R. L.; HASPSTER, N.K. Assessment of the prevalence of heart murmurs in overtly healthy cats. Journal of American Veterinary Medical Association, v. 225, n. 3, p. 384388, 2004.

CÔTÉ, E.; MCDONALD, K. A.; MEURS, K. M.; SLEEPER, M. M. Hypertrophic cardiomyopathy. In: CÔTÉ, E.; MCDONALD, K. A.; MEURS, K. M.; SLEEPER, M. M Feline Cardiology. Wiley Blackwell, 2011, p. $103-175$.

DE, S.; BOROWSKI, A. G.; WANG, H.; NYE, L.; XIN, B.; THOMAS, J. D.; TANG, W. $\mathrm{H}$. Subclinical echocardiographic abnormalities in phenotype-negative carriers of myosin-binding protein $\mathrm{C} 3$ gene mutation for hypertrophic cardiomyopathy. American Heart Journal, v. 162, n. 2, p. 262-267, 2011.

DISATIAN, S.; BRIGHT, J. M.; BOON, J. Association of age and heart rate with pulsed-wave Doppler measurements in healthy, nonsedated cats. Journal of Veterinary Internal Medicine, v. 22, p. 351-356, 2008.

EATON, K. A.; BILLER, D. S.; DIBARTOLA, S. P.; RADIN, M. J.; WELLMAN, M. L. Autosomal dominant polycystic kidney disease in Persian and Persian-cross cats. Veterinary Pathology, v. 34, n. 2, p. 117-126, 1997.

ECDER, T. Cardiovascular complications in autosomal dominant polycystic kidney disease. Current Hipertension Reviews, v. 9, n. 1, p. 2-11, 2013.

ECDER, T.; EDELSTEIN, C. L.; CHAPMAN, A. B.; JOHNSON, A. M.; TISON, L.; GILL, E. A.; BROSNAHAN, G. M.; SCHRIER, R. W. Reversal of left ventricular hypertrophy with angiotensin converting enzyme inhibition in hypertensive patients with autosomal dominant polycystic kidney disease. Nephrology Dialysis Transplantation, v. 14, p. 1113-1116, 1999.

ECDER, T.; MCFANN, K. K.; RAYNOLDS, M. V.; SCHRIER, R. W. No effect of angiotensin-converting enzyme gene polymorphism on disease progression and left 
ventricular hypertrophy in autosomal dominant polycystic kidney disease. American Journal of Nephrology, v. 23, p. 466-470, 2003.

ETTINGER, S. T.; FELDMAN, E. C. Textbook of veterinary internal medicine. 6.ed. St. Louis: Elsevier Saunders, 2005. v. 2, p. 912-1992.

FERASIN, L. Feline myocardial disease. Journal of Feline Medicine and Surgery, v. 11 , n. 1, p. 3-13, $2009 a$.

FERASIN, L. Feline myocardial disease- diagnosis, prognosis and clinical management. Journal of Feline Medicine and Surgery, v. 11, p. 183-194, 2009b.

FERASIN, L.; STURGESS, C. P.; CANNON, M. J.; CANEY, S. M.; GRUFFYDDJONES, T. J.; WOTTON, P. R. Feline idiopathic cardiomyopathy: a retrospective study of 106 cats (1994-2001). Journal of Feline Medicine and Surgery, v. 5, p. 151-159, 2003.

FERNANDEZ, E. A. Cardiomiopatia hipertrófica: estudo da sobrevida e de fatores prognósticos. 1998. 48f. Tese (Doutorado em Cardiologia) - Faculdade de Medicina, Universidade de São Paulo, São Paulo, 1998.

FIRSTENBERG, M. S.; GREENBERG, N. L.; MAIN, M. L.; DRINKO, J. K.; ODABASHIAN, J. A.; THOMAS, J. D.; GARCIA, M. J. Determinants of diastolic myocardial tissue Doppler velocities: influences of relaxation and preload. Journal of Applied Physiology, v. 90, n. 1, p. 299-307, 2001.

FOX, P. R. Feline cardiomyopathies. In: FOX, P. R.; SISSON, D.; MOISE, N. S. Textbook of canine and feline cardiology- principles and clinical practice. 2. ed. Philadelphia: W. B. Saunders, 1999. cap. 28, p. 621-677.

FOX, P. R. Prospective, double-blinded, multicenter evaluation of chronic therapies for feline diastolic heart failure: interin analysis. Journal of Veterinary Internal Medicine, v. 17, p. 372, 2003.

FOX, P. R.; LIU, S. K.; MARON, B. J. Echocardiographic assessment of spontaneously occurring feline hypertrophic cardiomyopathy: an animal modelo for human disease. Circulation, v. 92, n. 9, p. 2645-2651, 1995.

FOX, P. R.; RUSH, J. E.; REYNOLDS, C. A.; DEFRANCESCO, T. C.; KEEN, B. W.; ATKINS, C. E.; GORDON, S. G.; SCHÖBER, K. E.; BONAGURA, J. D.; STEPIEN, R. 
L.; KELLIHAN, H. B.; MACDONALD, K. A.; LEHMKUHL, L. B.; NGUYENBA, T. P.; SYDNEY, M. N.; LEFBOM, B. K.; HOGAN, D. F.; OYAMA, M. A. Multicenter evaluation of plasma N-terminal probrain natriuretic peptide (NT-pro BNP) as a biochemical screening test for asymptomatic (occult) cardiomyopathy in cats. Journal of Veterinary Internal Medicine, v. 25, n. 5, p. 1010-1016, 2011.

FREEMAN, L. M.; RUSH, J. E.; MEURS, K. M.; BULMER, B. J.; CUNNINGHAM, S. M. Body size and metabolic diferences in Maine Coon cats with and without hypertrophic cardiomyopathy. Journal of Feline Medicine and Surgery, v. 15, n. 2, p. $74-80,2012$.

FRIES, R.; HEANEY, A. M.; MEURS, K. M. Prevalence of the myosin-binding protein $C$ mutation in Maine Coon cats. Journal of Veterinary Internal Medicine, v. 22, p. 893-896, 2008.

FUENTES, V. L. Arterial thromboembolism: risks, realities and a rational first-line approach. Journal of Feline Medicine and Surgery, v. 14, n. 7, p. 459-470, 2012.

FUENTES, V. L. Cardiomyopathy- Establishing a diagnosis. In: AUGUST, J. F. Consultation in feline internal medicine. 5. ed. St. Louis: Elsevier Saunders, 2006. $771 \mathrm{p}$.

GANDJBAKHCH, E.; GACKOWSKI, A.; MONTCEL, S. T.; ISNARD, R.; HAMROUN, A.; RICHARD, P.; KOMAJDA, M.; CHARRON, P. Early identification of mutation carriers in familial hypertrophic cardiomyopathy by combined echocardiography and tissue Doppler imaging. European Heart Journal, v. 31, p. 1599-1607, 2010.

GARCIA-PAVIA, P.; VÁZQUEZ, M. E.; SEGOVIA, J.; SALAS, C.; AVELLANA, P.; GÓMEZ-BUENO, M.; VILCHES, C.; GALLARDO, M. E.; GARESSE, R.; MOLANO, J.; BORNSTEIN, B.; ALONSO-PULPON, L. Genetic basis of end-stage hypertrophic cardiomyopathy. European Journal of Heart Failure, v. 13, n. 11, p. 1193-1201, 2011.

GAVAGHAN, B. J.; KITTLESON, M. D.; FISHER, K. J.; KASS, P. H.; GAVAGHAN, M. A. Quantification of left ventricular diastolic wall motion by Doppler tissue imaging in healthy cats and cats with cardiomyopathy. American Journal of Veterinary Research, v. 60, p. 478-1486, 1999.

GODIKSEN, M. T.; GRANSTROM, S.; KOCH, J.; CHRISTIANSEN, M. Hypertrophic cardiomyopathy in young Maine Coon cats caused by the p.A31P cMyBP-C mutation- the clinical significance of having the mutation. Acta Veterinary Scandinavian, v. 9, p. 53-57, 2011. 
GOODWIN, J. F.; HOLLMAN, A.; CLELAND, W. P.; TEARE, D. Obstructive cardiomyopathy simulating aortic stenosis. British Heart Journal, v. 22, p. 403-414, 1960.

GRANSTRÖM, S.; GODIKSEN, M. T. N.; CHRISTIANSEN, M.; PIPPER, C. B.; WILLESEN, J. T.; KOCH, J. Prevalence of hypertrophic cardiomyopathy in a cohort of British Shorthair cats in Denmark. Journal of Veterinary Internal Medicine, v. 25, p. 866-871, 2011.

GRAZIANO, P.; ACQUATELLA, H. Ecocardiografia clínica na cardiomiopatia hipertrófica- importância do diagnóstico diferencial na tomada de decisões. In: SILVA, C. R. S. Ecocardiografia: princípios e aplicações clínicas. 1. ed. Rio de Janeiro: Revinter, 2007. p. 681-712.

GROSSMAN, A.; PROKUPETZ, A.; KOREN-MORAG, N.; GROSSMAN, E.; SHAMISS, A. Comparison of usefulness of Sokolow and Cornell criteria for left ventricular hypertrophy in subjects aged $<20$ years versus $>30$ years. American Journal of Cardiology, v. 110, p. 440-444, 2012.

GUNDLER, S.; TIDHOLM, A.; HÄGGSTRÖM, J. Prevalence of myocardial hypertrophy in a population of asymptomatic Swedish Maine coon cats. Acta Veterinaria Scandinavica, v. 50, n. 22, p. 1-6, 2008.

HÄGGSTRÖM, J. Hypertrophic cardiomyopathy in cats- it used to be simple. Journal of Feline Medicine and Surgery, v. 5, p. 139-141, 2003.

HARVEY, A. M.; FAENA, M.; DARKE, P. G.; FERASIN, L. Effect of body position on feline electrocardiographic recordings. Journal of Veterinary Internal Medicine, $v$. 19, n. 4, p. 533-536, 2005.

HELPS, C. R.; TASKER, S.; BARR, F. J.; WILLS, S. J.; GRUFFYDD-JONES, T. J. Detection of the single nucleotide polymorphism causing feline autosomal-dominant polycystic kidney disease in Persian from UK using a novel real-time PCR assay. Molecular and Cellular Probes, v. 21, n. 1, p. 31-34, 2007.

HO, C. Y. New paradigms in hypertrophic cardiomyopathy: insights from genetics. Progress in Pediatric Cardiology, v. 31, n. 2, p. 93-98, 2011.

HO, C. Y.; CARLSEN, C.; THUNE, J. J.; HAVNDRUP, O.; BUNDGAARD, H.; FARROHI, F.; RIVERO, J.; CIRINO, A. L.; ANDERSEN, P. S.; CHRISTIANSEN, M.; MARON, B. J.; ORAV, E. J.; KOBER, L. Echocardiography Strain imaging to assess 
early and late consequences of sarcomere mutations in hypertrophic cardiomyopathy. Circulation, v. 2, p. 314-321, 2009.

HO, C. Y.; SWEITZER, N. K.; MCDONOUGH, B.; MARON, B. J.; CASEY, S. A.; SEIDMAN, J. G.; SEIDMAN, C. E.; SOLOMON, S. D. Assessment of diastolic function with Doppler tissue imaging to predict genotype in preclinical hypertrophic cardiomyopathy. Circulation, v. 105, p. 2992-2997, 2002.

HOGAN, D.; FOX, P.; JACOB, K.; KEENE, B.; LASTE, N.; ROSENTHAL, S. Analysis of the feline arterial thromboembolism: clopidogrel vs aspirin trial (FAT CAT). In: ACVIM FORUM VETERINARY PROCEEDINGS, 177., 2013, Seattle.

Proceedings...Seatle: ACVIM, 2013. p.92.

HORI, Y.; YAMANO, S.; IWANAGA, K.; KANO, T.; TANABE, M.; UECHI, M.; KANAI, K.; NAKAO, R.; HOSHI, F.; HIGUCHI, S. Evaluation of plasma C-terminal atrial natriuretic peptide in healthy cats and cats with heart disease. Journal of Veterinary Internal Medicine, v. 22, p. 135-139, 2008.

INGLES, J.; ZODGEKAR, P. R.; YEATES, L.; MACCIOCCA, I.; SEMSARIAN, C.; FATKIN, D. Guidelines for genetic testing of inherited cardiac disorders. Heart and Lung Circulation, v. 20, n. 11, p. 681-687, 2011.

KATO, T. S.; IZAWA, H.; KOMAMURA, K.; NODA, A.; ASANO, H.; NAGATA, K.; HASHIMOTO, S.; ODA, N.; KAMIYA, C.; KANZAKI, H.; HASHIMURA, K.; UEDA, H. I.; MUROHARA, T.; KITAKAZE, M.; YOKOTA, M. Heterogeneity of regional systolic function detected by tissue Doppler imaging is linked to impaired global left ventricular relaxation in hypertrophic cardiomyopathy. Heart, v. 94, p. 1302-1306, 2007.

KEREN, A.; SYRRIS, P.; MCKENNA, W. J. Hypertrophic cardiomyopathy: the genetic determinants of clinical disease expression. Nature Clinical Practice Cardiovascular Medicine, v. 5, p. 158-186, 2008.

KILLIAN, L.; SIMPSON, J. M.; SAVIS, A.; RAWLINS, D.; SINHA, M. D. Electrocardiography is a poor screening test to detect left ventricular hypertrophy in children. Archives of Disease in Childhood, v. 95, p. 832-836, 2010.

KIMURA, A. Molecular etiology and pathogenesis of hereditary cardiomyopathy. Circulation, v. A, p. 38-48, 2008. 
KITTLESON, M. D. Feline hypertrophic cardiomyopathy: State of the art, part 1 and part 2. In: WORLD FELINE VETERINARY CONFERENCE, 1., 2011, Boston.

Proceedings...Boston: WFVC, 2011.

KITTLESON, M. D. The genetics of HCM- mutant cats. In: ACVIM FORUM VETERINARY PROCEEDINGS, 220., 2009, Canadian. Proceedings...Canadian: ACVIM, 2009a. p.120-121.

KITTLESON, M. D. Treatment of feline hypertrophic cardiomyopathy- lost dreams. In: ACVIM FORUM VETERINARY PROCEEDINGS, 219., 2009, Canadian.

Proceedings...Canadian: ACVIM, 2009b. p.117-119.

KITTLESON, M. D.; KIENLE, R. D. Small animal cardiovascular medicine. 1. ed. St. Louis: Mosby, 1998. 603 p.

KITTLESON, M. D.; MEURS, K.; MUNRO, M. Letter to the editor. Journal of Veterinary Internal Medicine, v. 24, p. 1242-1243, 2010.

KITTLESON, M. D.; MEURS, K. M.; MUNRO, M. J.; KITTLESON, J. A.; LIU, S. K.; PION, P. D.; TOWBIN, J. A. Familial hypertrophic cardiomyopathy in Maine Coon cats: an animal model of human disease. Circulation, v. 99, p. 3172-3180, 1999.

KOFFAS, H.; DUKES-MCEWAN, J.; CORCORAN, B. M.; MORAN, C. M.; FRENCH, A.; SBOROS, V.; ANDERSON, T.; SMITH, P.; SIMPSON, K.; MCDICKEN, W. N. Peak mean myocardial velocities and velocity gradients measured by color M-mode tissue Doppler imaging in healthy cats. Journal of Veterinary Internal Medicine, v. 17 , p. 510-524, 2003.

KOFFAS, H.; MCEWAN, J. D.; CORCORAN, B. M.; MORAN, C. M.; FRENCH, A.; SBOROST, V.; SIMPSON, K.; ANDERSON, T.; MCDICKEN, W. N. Colour M-mode tissue Doppler imaging in healthy cats and cats with hypertrophic cardiomyopathy. Journal of Small Animal Practice, v. 49, p. 330-338, 2008.

KOFFAS, H.; MCEWAN, J. D.; CORCORAN, B. M.; MORAN, C. M.; FRENCH, A.; SBOROST, V.; SIMPSON, K.; MCDICKEN, W. N. Pulsed tissue Doppler imaging in normal cats and cats with hypertrophic cardiomyopathy. Journal of Veterinary Internal Medicine, v. 20, p. 65-77, 2006.

KONNO, T.; SHIMIZU, M.; INO, H.; FUJINO, N.; HAYASHI, K.; UCHIYAMA, K.; KANEDA, T.; INOUE, M.; FUJITA, T.; MASUTA, E.; FUNADA, A.; MABUCHI, H. Differences in diagnostic value of four electrocardiographic voltage criteria for 
hypertrophic cardiomyopathy in a genotyped population. American Journal of Cardiology, v. 96, p. 1308-1312, 2005.

LAKDAWALA, N. K., THUNE, J. J.; MARON, B. J; CIRINO, A. L.; HAVNDRUP, O.; BUNDGAARD, H.; CHRISTIANSEN, M.; CARLSEN, C. M.; DORVAL, J.; KWONG, R. Y.; COLAN, S. D.; KOBER, L. V.; HO, C. Y. Electrocardiographic features of sarcomere mutation carriers with or without clinically overt hypertrophic cardiomyopathy. American Journal of Cardiology, v. 108, p. 1606-1613, 2011.

LEE, Y. J.; CHEN, H. Y.; HSU, W. L.; OU, C. M.; WONG, M. L. Diagnosis of feline polycystic kidney disease by a combination of ultrasonographic examination and PKD1 gene analysis. Veterinary Record, v. 167, n. 16, p. 614-618, 2010a.

LEE, Y. J.; CHEN, H. Y.; WONG, M. L.; HSU, W. L. Molecular detection of autosomal-dominant feline polycystic kidney disease by multiplex amplification refractory mutation system plymerase chain reaction. Journal of Veterinary Diagnostic Investigation, v. 22, n. 3, p. 424-428, $2010 \mathrm{~b}$.

LINNEY, C. J.; MCEWAN, J. D.; STEPHENSON, H. M.; ALVAREZ, J. L.; FONFARA, $S$. Left atrial size, atrial function and left ventricular diastolic function in cats with hypertrophic cardiomyopathy. Journal of Small Animal Practice, v. 55, p. 198-206, 2014.

LONGERI, M.; FERRARI, P.; KNAFELZ, P.; MEZZELANI, A.; MARABOTTI, A.; MILANESI, L.; PERTICA, G.; POLLI, M.; BRAMBILLA, P. G.; KITTLESON, M.; LYONS, L. A.; PORCIELLO, F. Myosin-binding protein C DNA variants in Domestic Cats (A31P, A74T, R820W) and their association with hypertrophic cardiomyopathy. Journal of Veterinary Internal Medicine, v. 27, n. 2, p. 275-285, 2013.

LUMIAHO, A.; IKÄHEIMO, R.; MIETTINEN, R.; NIEMITUKIA, L.; LAITINEN, T.; RANTALA, A.; LAMPAINEN, E.; LAAKSO, M.; HARTIKAINEN, J. Mitral valve prolapse and mitral regurgitation are common in patients with polycystic kidney disease type 1. American Journal of Kidney Disease, v. 38, n. 6, p. 1208-1216, 2001.

LUMIAHO, A.; PIHLAJAMÄKI, J.; HARTIKAINEN, J.; IKÄHEIMO, R.; MIETTINEN, R.; NIEMITUKIA, L.; LAMPAINEN, E.; LAAKSO, M. Insulin resistance is related to left ventricular hypertrophy in patients with polycystic kidney disease type 1. American Journal of Kidney Disease, v. 14, n. 6, p. 1219-1222, 2003.

MARIAN, A. J.; ROBERTS, R. Molecular genetics of hypertrophic cardiomyopathy. Annual Reviews of Medicine, v. 46, p. 213-222, 1995. 
MARIAN, A. J.; YU, T.; MANN, D. L.; GRAHAM, F. L.; ROBERTS, R. Expression of a mutation causing hypertrophic cardiomyopathy disrupts sarcomere assembly in adult feline cardiac myocytes. Circulation Research, v. 77, n. 1, p. 98-106, 1995.

MARON, B. J.; GARDIN, J. M.; FLACK, J. M.; GIDDING, S. S.; KUROSAKI, T. T.; BILD, D.E. Prevalence of hypertrophic cardiomyopathy in a general population of Young adults. Echocardiographic analysis of 4111 subjects in the CARDIA Study. Coronary Artery Risk Development in (Young) Adults. Circulation, v. 92, n. 4, p. 785789, 1995.

MARON, B. J.; MARON, M. S. Hypertrophic cardiomyopathy. Lancet, v. 381, p. 242255, 2013.

MARON, B. J.; OMMEN, S. R.; SEMSARIAN, C.; SPIRITO, P.; OLIVOTTO, I.; MARON, M. S. Hypertrophic cardiomyopathy: Present and future, with translation into contemporary cardiovascular medicine. Journal of American College of Cardiology, v. 64, n. 1, p. 83-99, 2014.

MARON, B. J.; TOWBIN, J. A.; THIENE, G.; ANTZELEVITCH, C.; CORRADO, D.; ARNETT, D.; MOSS, A. J.; SEIDMAN, C. E.; YOUNG, J. B. Contemporary definitions and classification of the cardiomyopathies: an American Heart Association Scientific Statement from the Council on Clinical Cardiology, Heart Failure and Transplantation Committee; Quality of Care and Outcomes Research and Functional Genomics and Translational Biology Interdisciplinary Working Groups; and Council on Epidemiology and Prevention. Circulation, v. 113, n. 14, p. 1807-1816, 2006.

\section{MARSIGLIA, J. D. C. Estudo genético de pacientes portadores de} cardiomiopatia hipertrófica. 2013. 98f. Tese (Doutorado em Cardiologia) Faculdade de Medicina, Universidade de São Paulo, São Paulo, 2013.

MARSIGLIA, J. D. C.; CREDIDIO, F. L.; OLIVEIRA, T. G. M.; REIS, R. F.; ANTUNES, M. O.; ARAUJO, A. Q.; PEDROSA, R. P.; FERREIRA, J. M. B. B.; MADY, C.; KRIEGER, J. E.; FERNANDEZ, E. A.; PEREIRA, A. C. Clinical predictors of a positive genetic test in hypertrophic cardiomyopathy in the Brazilian population.

Cardiovascular Disorders, v. 14, n. 36, 2014.

MARTIN, L.; VANDEWOUDE, S.; BOON, J.; BROWN, D. Left ventricular hypertrophy in a closed colony of Persian cats. Journal of Veterinary Internal Medicine, v. 8, p. 143, 1994.

MARTINEZ-VEA, A.; BARDAJI, A.; GUTIERREZ, C.; GARCIA, C.; PERALTA, C.; MARCAS, L.; OLIVER, J. A. Exercise blood pressure, cardiac structure, and diastolic 
function in Young normotensive patients with polycystic kidney disease: a prehypertensive state. American Journal of Kidney Disease, v. 44, n. 2, p. 216223, 2004.

MARTINEZ-VEA, A.; VALERO, F.A.; BARDAJI, A.; GUTIERREZ, C.; BROCH, M.; GARCIA, C.; RICHART, C.; OLIVER, J. A. Left ventricular hypertrophy in hypertensive patients with autosomal dominant polycystic kidney disease: influence of blood pressure and humoral and neuro-hormonal factors. American Journal of Nephrology, v. 20, p. 193-200, 2000.

MARY, J.; CHETBOUL, V.; SANPEDRANO, C. C.; ABITBOL, M.; GOUNI, V.; THEHIOU-SECHI, E.; TISSIER, R.; QUENEY, G.; POUCHELON, J. L.; THOMAS, A. Prevalence of the MYBPC3-A31P mutation in a large European feline population and association with hypertrophic cardiomyopathy in the Maine Coon breed. Journal of Veterinary Cardiology, v. 12, n. 3, p. 155-161, 2010.

MATTOS, B. P.; TORRES, M. A. R.; FREITAS, V. C.; SCOLARI, F. L.; LORETO M. $S$. Arritmias ventriculares e hipertrofia ventricular esquerda na cardiomiopatia hipertrófica. Arquivos Brasileiros de Cardiologia, v. 100, n. 5, p. 452-459, 2013.

MCDONALD, K. A.; KITTLESON, M. D.; KASS, P. H. Effect of spironolactone on diastolic function and left ventricular mass in Maine Coon cats with familial hypertrophic cardiomyopathy. Journal of Veterinary Internal Medicine, v. 22, p. 335-341, 2008.

MCDONALD, K. A.; KITTLESON, M. D.; KASS, P. H.; MEURS, K. M. Tissue Doppler imaging in Maine Coon cats with a mutation of myosin binding protein $\mathrm{C}$ with or without hypertrophy. Journal of Veterinary Internal Medicine, v. 21, p. 232-237, 2007.

MCDONALD, K. A.; KITTLESON, M. D.; LARSON, R. F.; KASS, P. H.; KLOSE, T.; WISNER, E. R. The effect of ramipril on left ventricular mass, myocardial fibrosis, diastolic function, and plasma neurohormones in Maine Coon cats with familial hypertrophic cardiomyopathy without heart failure. Journal of Veterinary Internal Medicine, v. 20, p. 1093-1105, 2006a.

MCDONALD, K. A.; KITTLESON, M. D.; NOLEN, T. G.; LARSON, R. F.; WISNER, E. $\mathrm{R}$. Tissue Doppler imaging and gradient echo cardiac magnetic resonance imaging in normal cats and cats with hypertrophic cardiomyopathy. Journal of Veterinary Internal Medicine, v. 20, p. 627-634, 2006b.

MCTAGGART, D. R. Tissue Doppler imaging in hypertrophic cardiomyopathy without left ventricular hypertrophy. Heart, Lung and Circulation, v. 11, p. 92-94, 2002. 
MEURS, K. M.; KITTLESON, M. D.; TOWBIN, J.; WARE, W. Familial systolic anterior motion of the mitral valve and/or hypertrophic cardiomyopathy inherited as an autosomal dominant trait in family of American Shorthair cats. Journal of Veterinary Internal Medicine, v. 11, n. 2, p. 138, 1997.

MEURS, K. M.; NORGARD, M. M.; EDERER, M. M.; HENDRIX, K. P.; KITTLESON, M. D. A substitution mutation in the myosin binding protein $\mathrm{C}$ gene in Ragdoll hypertrophic cardiomyopathy. Genomics, v. 90, p. 261-264, 2007.

MEURS, K. M.; NORGARD, M. M.; KUAN, M.; HÄGGSTRÖM, J.; KITTLESON, M. Analysis of 8 sarcomeric candidate genes for feline hypertrophic cardiomyopathy mutations in cats with hypertrophic cardiomyopathy. Journal of Veterinary Internal Medicine, v. 23, p. 840-843, 2009.

MEURS, K. M.; SANCHEZ, X.; DAVID, R. M.; BOWLES, N. E.; TOWBIN, J. A.; REISER, P. J.; KITTLESON, J. A.; MUNRO, M. J.; DRYBURGH, K.; MCDONALD, K. A.; KITTLESON, M. D. A cardiac myosin binding protein $\mathrm{C}$ mutation in the Maine Coon cat with familial hypertrophic cardiomyopathy. Human Molecular Genetics, v. 14, n. 23, p. 3587-3593, 2005.

MOISE, N. S.; DIETZE, A. E.; MEZZA, L. E.; STRICKLAND, D.; ERB, H. N.; EDWARDS, N. J. Echocardiography, electrocardiography, and radiography of cats with dilation cardiomyopathy, hypertrophic cardiomyopathy, and hyperthyroidism. American Journal of Veterinary Research, v. 47, n. 7, p. 1476-1486, 1986.

MURPHY, M. L.; THENABADU, N.; SOYSA, N.; MEADE, J.; DOHERTY, J. E.; BAKER, B. J. Sensitivity of electrocardiographic criteria for left ventricular hypertrophy according to type of cardiac disease. American Journal of Cardiology, v. 55 , p. 545-549, 1985.

NAGUEH, S. F.; APPLETON, C. C. P.; GILLEBERT, T. C.; MARINO, P. N.; OH, J. K.; SMISETH, O. A.; WAGGONER, A. D.; FLANCHKAMPF, F. A.; PELLIKKA, P. A.; EVANGELISTA, A. Recommendations for the evaluation of left ventricular diastolic function by echocardiography. Journal of the American Society of Echocardiography, v. 22, n. 2, p. 107-133, 2009.

NAGUEH, S. F.; BACHINSKI, L. L.; MEYER, D.; HILL, R.; ZOGHBI, W. A.; TAM, J. W.; QUINONES, M. A.; ROBERTS, R.; MARIAN, A. J. Tissue Doppler imaging consistently detects myocardial abnormalities in patients with hypertrophic cardiomyopathy and provides a novel means for early diagnosis before and independently of hypertrophy. Circulation, v. 104, p. 128-130, 2001. 
NAMDAR, M.; STEFFEL, J.; JETZER, S.; SCHIMED, C.; HÜRLIMANN, D.; CAMICI, G.G.; BAYRAK, F.; RICCIARDI, D.; RAO, J.; ASMUNDIS, C.; CHIERCHIA, G. B.; SAKOZY, A.; LÜSCHER, T. F.; JENNI, R.; DURU, F.; BRUGADA, P. Value of electrocardiogram in the differentiation of hypertensive heart disease, hypertrophic cardiomyopathy, aortic stenosis, amyloidosis, and Fabry disease. American Journal of Cardiology, v. 109, p. 587-593, 2012.

NELSON, R. W.; COUTO, C. G. Medicina interna de pequenos animais. 3. ed. Rio de Janeiro: Guanabara Koogan, 2005. 1084 p.

NETER, J.; KUTNER, M. H.; NACHTSHEIM, C. J.; WASSERMAN, W. Applied linear statistical models. 4. ed. U.S.A.: Times Mirror Higher Education Group, 1996. $1408 \mathrm{p}$.

NG, C.T.; ONG, H.Y.; CHEOK, C.; CHUA, T.S.J.; CHING, C.K. Prevalence of electrocardiographic abnormalities in an unselected young male multi-ethnic southEast Asian population undergoing pr-participation cardiovascular screening: results of the Singapore Armed Forces Electrocardiogram and Echocardiogram screening protocol. Europace, v. 14, p. 1018-1024, 2012.

NORTHINGTON, J. W.; JULIANA, M. M. Polycystic kidney disease in a cat. Journal of Small Animal Practice, v. 18, n. 10, p. 663-666, 1977.

NUNEZ, J.; ZAMORANO, J. L.; ISLA, L. P.; PALOMEQUE, C.; ALMERIA, C.; RODRIGO, J. L.; CORTEZA, J.; BANCHS, J.; MACAYA, C. Differences in regional systolic and diastolic function by Doppler tissue imaging in patients with hypertrophic cardiomyopathy and hypertrophy caused by hypertension. Journal of American Society of Echocardiography, v. 17, p. 717-722, 2004.

OKI, T.; MISHIRO, Y.; YAMADA, H.; ONOSE, Y.; MATSUOKA, M.; WAKATSUKI, T.; TABATA, T.; ITO, S. Detection of left ventricular regional relaxation abnormalities and asynchrony in patients with hypertrophic cardiomyopathy with hypertrophic cardiomyopathy with the use of tissue Doppler imaging. American Heart Journal, v. 139 , p. 487-502, 2000.

ORF Finder. Disponível em: <http://www.ncbi.nlm.nih.gov/gorf/orfig.cgi>. Acesso em: 27 junho 2014.

OYAMA, M. A. Advances in echocardiography. Veterinary Clinics of Small Animal Practice, v. 34, p. 1083-1104, 2004. 
PAIGE, C. F.; ABBOTT, J. A.; ELVINFER, F.; PYLE, R. L. Prevalence of cardiomyopathy in apparently healthy cats. Journal of American Veterinary Medical Association, v. 234, n. 11, p. 1398-1403, 2009.

PAYNE, J.; FUENTES, V. L.; BOSWOOD, A.; CONNOLLY, D.; KOFFAS, H.; BRODBELT, D. Population characteristics and survival in 127 referred cats with hypertrophic cardiomyopathy (1997 to 2005). Journal of Small Animal Practice, v. 51 , p. 540-547, 2010.

PAYNE, J. R.; BORGEAT, K.; CONNOLLY, D. J.; BOSWOOD, A.; DENNIS, S.; WAGNER, T.; MENAUT, P.; MAERZ, I.; EVANS, D.; SIMONS, V. E.; BRODBELT, D. C.; FUENTES, V. L. Prognostic indicators in cats with hypertrophic cardiomyopathy. Journal of Veterinary Internal Medicine, v. 27, p. 1427-1436, 2013.

PEDERSEN, K. M.; PEDERSEN, H. D.; HÄGGSTRÖM, J.; KOCH, J.; ERSBOLL, A. $\mathrm{K}$. Increased mean arterial pressure and aldosterone-to-renin ratio in Persian cats with polycystic kidney disease. Journal of Veterinary Internal Medicine, v. 17, n. 1, p. 21-27, 2003.

PELTO, H.; OWENS, D.; DREZNER, J. Electrocardiographic findings suggestive of cardiomyopathy: what to look for and what to do next. Current Sports Medicine Reports, v. 12, n. 2, p. 77-85, 2013.

PHRED Online. Disponível em: <http://asparagin.cenargen.embrapa.br/phph/1>. Acesso em: 27 junho 2014.

PHILLIPS, J. K.; HOPWOOD, D.; LOXLEY, R. A.; GHATORA, K.; COOMBES, J. D.; TAN, Y. S.; HARRISON, J. L.; MCKITRICK, D. J.; HOLOBOTVSKYY, V.; ARNOLDA, L. F.; RANGAN, G. K. Temporal relationship between renal cyst development, hypertension and cardiac hypertrophy in a new rat modelo $f$ autosoma recessive polycystic kidney disease. Kidney Blood Pressure Research, v. 30, p. 129-144, 2007.

RICHARDSON, P.; MCKENNA, W.; BRISTOW, M. Report of the 1995 World Health Organization/International Society and Federation of Cardiology Task Force on the Definition and Classification of Cardiomyopathies. Circulation, v. 93, p. 841-842, 1996.

RIESEN, S. C.; KOVACEVIV, A.; LOMBARD, C. W.; AMBERGER, C. Prevalence of heart disease in symptomatic cats: an overview from 1998 to 2005. European Journal of Companion Practice, v. 18, n. 1, p. 15-20, 2008. 
ROWIN, E. J.; MARON, B. J.; APPELBAUM, E.; LINK, M. S.; GIBSON, M.; LESSER, J. R.; HAAS, T. S.; UDELSON, J. E.; MANNING, W. J.; MARON, M. S. Significance of false negative electrocardiograms in preparticipation screening of athletes for hypertrophic cardiomyopathy. American Journal of Cardiology, v. 110, p. 10271032, 2012.

RUAN, Q.; RAO, L.; MIDDLETON, K. J.; KHOURY, D. S.; NAGHEH, S. F. Assessment of left ventricular diastolic function by early diastolic mitral annulus peak acceleration rate: experimental studies and clinical application. Journal of Applied Physiology. v. 110, p. 679-684, 2006.

RUSH, J. E.; FREEMAN, L. M.; FENOLLOSA, N. K.; BROWN, D. J. Population and survival characteristics of cats with hypertrophic cardiomyopathy: 260 cases (1990 1999). Journal of American Veterinary Medical Association, v. 220, p. 202 - 207, 2002.

RYAN, M. P.; CLELAND, J. G. F.; FRENCH, J. A.; JOSHI, J.; CHOUDHURY, L.; CHOJNOWSKA, L.; MICHALAK, E.; AL-MAHDAWI, S.; NIHOYANNOPOULOS, P.; OAKLEY, C. M. The standard electrocardiogram as a screening test for hypertrophic cardiomyopathy. American Journal of Cardiology, v. 76, p. 689-694, 1995.

SAGGAR-MALIK, A. K.; MISSOURIS, C. G.; GILL, J. S.; SINGER, D. R.; MARKANDU, N. D.; MACGREGOR, G. A. Left ventricular mass in normotensive subjects with autosomal dominant polycystic kidney disease. British Medical Journal, v. 309, p. 1617-1618, 1994.

SAMPEDRANO, C. C.; CHETBOUL, V.; GOUNI, V.; NICOLLE, A. P.; POUCHELON, J. L.; TISSIER, R. Systolic and diastolic myocardial dysfunction in cats with hypertrophic cardiomyopathy or systemic hypertension. Journal of Veterinary Internal Medicine, v. 20, p. 1106-1115, 2006.

SAMPEDRANO, C. C.; CHETBOUL, V.; MARY, J.; TISSIER, R.; ABITBOL, M.; SERRES, F.; GOUNI, V.; THOMAS, A.; POUCHELON, J. L. Prospective echocardiography and tissue Doppler imaging screening of a population of Maine Coon cats tested for the A31P mutation in the myosin-binding protein $\mathrm{C}$ gene: $\mathrm{a}$ specific analysis of the heterozygous status. Journal of Veterinary Internal Medicine, v. 23, p. 91-99, 2009.

SCALOL, M. C.; SILVA, T. F.; AQUINO, L. C.; CARNEIRO, F. T.; LIMA, M. G.; LEMOS, M. D.; PALUDO, G. R. Touchdown polymerase chain reaction detection of polycystic kidney disease and laboratory findings in diferente cat populations. Journal of Veterinary Diagnostic Investigation, v. 26, n. 4, p. 542-546, 2014. 
SCHRIER, R. W. Renal volume, renin-angiotensin-aldosterone system, hypertension, and left ventricular hypertrophy in patients with autosomal dominant polycystic kidney disease. Journal of American Society of Nephrology, v. 20, p. 1888-1893, 2009.

SCHÖBER, K. E.; FUENTES, V. L.; BONAGURA, J. D.. Comparison between invasive hemodynamic measurements and noninvasive assessment of left ventricular diastolic function by use of Doppler echocardiography in healthy anesthetized cats. American Journal of Veterinary Research, v. 64, n. 1, p. 93-103, 2003.

SCHÖBER, K. E.; MAERZ, I.; LUDEWIG, E.; STERN, J. A. Diagnostic accuracy of electrocardiography and thoracic radiography in the assessment of left atrial size in cats: comparison with transthoracic 2-dimensional echocardiography. Journal of Veterinary Internal Medicine, v. 21, n. 4, p. 09-718, 2007.

SCHÖBER, K. E.; ZIENTEK, J.; XIAOBAI, L.; FUENTES, V. L.; BONAGURA, J. D. Effect of treatment with atenolol on 5-year survival in cats with preclinical (asymptomatic) hypertrophic cardiomyopathy. Journal of Veterinary Cardiology, v. 15, n. 2, p. 93-104, 2013.

SEVERINO, S.; CASO, P.; CICALA, M.; GALDERISI, M.; SIMONE, L.; D’ANDREA, D.; D'ERRICO, A.; MININNI, N. Involvement of right ventricle in left ventricular hypertrophic cardiomyopathy: analysis by pulsed Doppler tissue imaging. European Journal of Echocardiography, v. 1, p. 281-288, 2000.

SIEGEL, S; CASTELLAN, N. J. Nonparametric statistics. 2. ed. New York: McGraw-Hill, 1988. 399 p.

SILVERMAN, S. J.; STERN, J. A.; MEURS, K. M. Hypertrophic cardiomyopathy in the Sphynx cat: a retrospective evaluation of clinical presentation and heritable etiology. Journal of Feline Medicine and Surgery, v. 14, n. 4, p. 246-249, 2012.

SIMPSON, K. E.; DEVINE, B. C.; GUNN-MOORE, D. A.; FRENCH, A. T.; DUKESMCEWAN, J.; KOFFAS, H.; MORAN, C. M.; CORCORAN, B. M. Assessment of the repeatability of feline echocardiography using conventional echocardiography and spectral pulse-wave Doppler tissue imaging techniques. Veterinary Radiology and Ultrasound, v. 48, n. 1, p. 58-68, 2007.

SIMPSON, K. E.; GUNN-MOORE, D. A.; SHAW, D. J.; FRENCH, A. T.; DUKESMCEWAN, J.; MORAN, C. M.; CORCORAN, B. M. Pulsed-wave Doppler tissue imaging velocities in normal geriatric cats and geriatric cats with primary or systemic diseases linked to specific cardiomyopathies in humans, and the influence of age and heart rate upon these velocities. Journal of Feline Medicine and Surgery, v. 8, p. 1-12, 2008. 
SISAKIAN, H. Cardiomiopathies: evolution of pathogenesis concepts and potential for new therapies. World Journal of Cardiology, v. 6, n. 6, p. 478-494, 2014.

SISSON, D. Neuroendocrine evaluation of cardiac disease. Veterinary Clinics of Small Animal Practice, v. 24, p. 1105-1260, 2004.

SOUSA, A. C. S. Avaliação da função diastólica de ventrículo esquerdo. In: SILVA, C. R. S. Ecocardiografia: princípios e aplicações clínicas. 1. ed. Rio de Janeiro: Revinter, 2007. p. 382-403.

TEARE, D. Asymmetrical hypertrophy of the heart in young adults. British Heart Journal, v. 20, n. 1, p. 1-8, 1958.

TESHIMA, K.; ASANO, K.; SASAKI, Y.; KATO, Y.; KUTARA, K.; EDAMURA, K.; HASEGAWA, A.; TANAKA, S. Assessment of left ventricular function using pulsed tissue Doppler imaging in healthy dogs and dogs with spontaneous mitral regurgitation. Journal of Medicine Science, v. 67, n. 12, p. 1207-1215, 2005.

THOMAS, W. P.; GABER, C. E.; JACOBS, G. J.; KAPLAN, P. M.; LOMBARD, C. W.; MOIISE, N. S.; MOSES, B. L. Recommendations for standards in transthoracic twodimensional echocardiography in the dog and cat. Journal of Veterinary Internal Medicine, v. 7, n. 4, p. 247-252, 1993.

TILLEY, L. P. Essentials of canine and feline electrocardiography. 3. ed. Philadelphia: Lea \& Febiger, 1992. 470 p.

TILLEY, L. P.; GOODWIN, J. K. Manual of canine and feline cardiology. 3. ed. Philadelphia: W.B. Saunders, 1995. 533 p.

TILLEY, L. P.; LIU, S. K.; GILBERTSON, S. R.; WAGNER, B. M.; LORD, P. F. Primary myocardial disease in the cat: a model for human cardiomyopathy.

American Pathology, v. 87, p. 493-513, 1977.

TREHIOU-SECHI, E.; TISSIER, R.; GOUNI, V.; MISBACH, C.; PETIT, A. M.; BALOUKA, D.; SAMPEDRANO, C. C.; CASTAIGNET, M.; POUCHELON, J. L.; CHETBOUL, V. Comparative echocardiographic and clinical features of hypertrophic cardiomyopathy in 5 breeds of cats: a retrospective analysis of 344 cases (20012011). Journal of Veterinary Internal Medicine, v. 26, n. 3, p. 532-541, 2012. 
VERA, R. T.; IGLESIAS, M. L.; PRIETO, H. M.; ORTIZ, M.; GARCIA, R. I.; CALLIZO, G. N.; NAVARRO, G. C.; ANDREO, R. J.; MARTINEZ, G. J. M.; LIADÓ, P. G.; LUENGOS, C. D.; MARQUÉS, T. J. The R820W mutation in the MyBPC3 gene, associated with hypertrophic cardiomyopathy in cats, causes hypertrophic cardiomyopathy and left ventricular non-compaction in humans. Internal Journal of Cardiology, v. 145, n. 2, p. 405-407, 2010.

VIEIRA, S. Introdução à bioestatística. Rio de Janeiro: Campus, 1998. 196 p.

VIRZI, G. M.; CORRADI, V.; PANAGIOTOU, A.; GASTALDON, F.; CRUZ, D. N.; CAL, M.; CLEMENTI, M.; RONCO, C. ADPKD: Prototype of cardiorrenal syndrome type 4. International Journal of Nephrology, v. 2011, p. 1-12, 2011.

WAGNER, T.; FUENTES, V. L.; PAYNE, J. R.; MCDERMOTT, N.; BRODBELT, D. Comparison of auscultatory and echocardiographic findings in healthy adult cats. Journal of Veterinary Cardiology, v. 12, n. 3, p. 171-182, 2010.

WANIC-KOSSOWSKA, M.; POSNIK, B.; KOBELSKI, M.; PAWLICZAK, E.; PAWLACZYK, K.; HOPPE, K.; SCHWERMER, K.; SIKORSKA, D. The polymorphism of the ACE gene affects left ventricular hypertrophy and causes disturbances in left ventricular systolic/diastolic function in patients with autosomal dominant polycystic kidney disease. The Scientific World Journal, v. 2014, p. 1-7, 2014.

WARE, W. Cardiovascular disease in small animal medicine. London: Manson Publishing Ltd., 2007. 396 p.

WESS, G.; SARKAR, R.; HARTMANN, K. Assessment of left ventricular function by Strain imaging echocardiography in various stages of feline hypertrophic cardiomyopathy. Journal of Veterinary Internal Medicine, v. 24, n. 6, p. 1375-1382, 2010.

WESS, G.; SCHINNER, C.; WEBER, K.; KÜCHENHOFF, H.; HARTMANN, K. Association of A31P and A74T polymorphisms in the myosin binding protein C3 gene and hypertrophic cardiomyopathy in Maine coon and other breed cats. Journal of Veterinary Internal Medicine, v. 24, p. 527-532, 2010.

WIGLE, E. D.; SASSON, Z.; HENDERSON, M. A.; RUDDY, T. D.; FULOP, J.; RAKOWSKI, H.; WILLIAMS, W. G. Hypertrophic cardiomyopathy: the importance of the site and the extent of hypertrophy- a review. Progress in Cardiovascular Diseases, v. 28, n. 1, p. 1-83, 1985. 
APÊNDICE A- Parâmetros eletrocardiográficos de gatos da raça Persa - São Paulo - 2014

(continua)

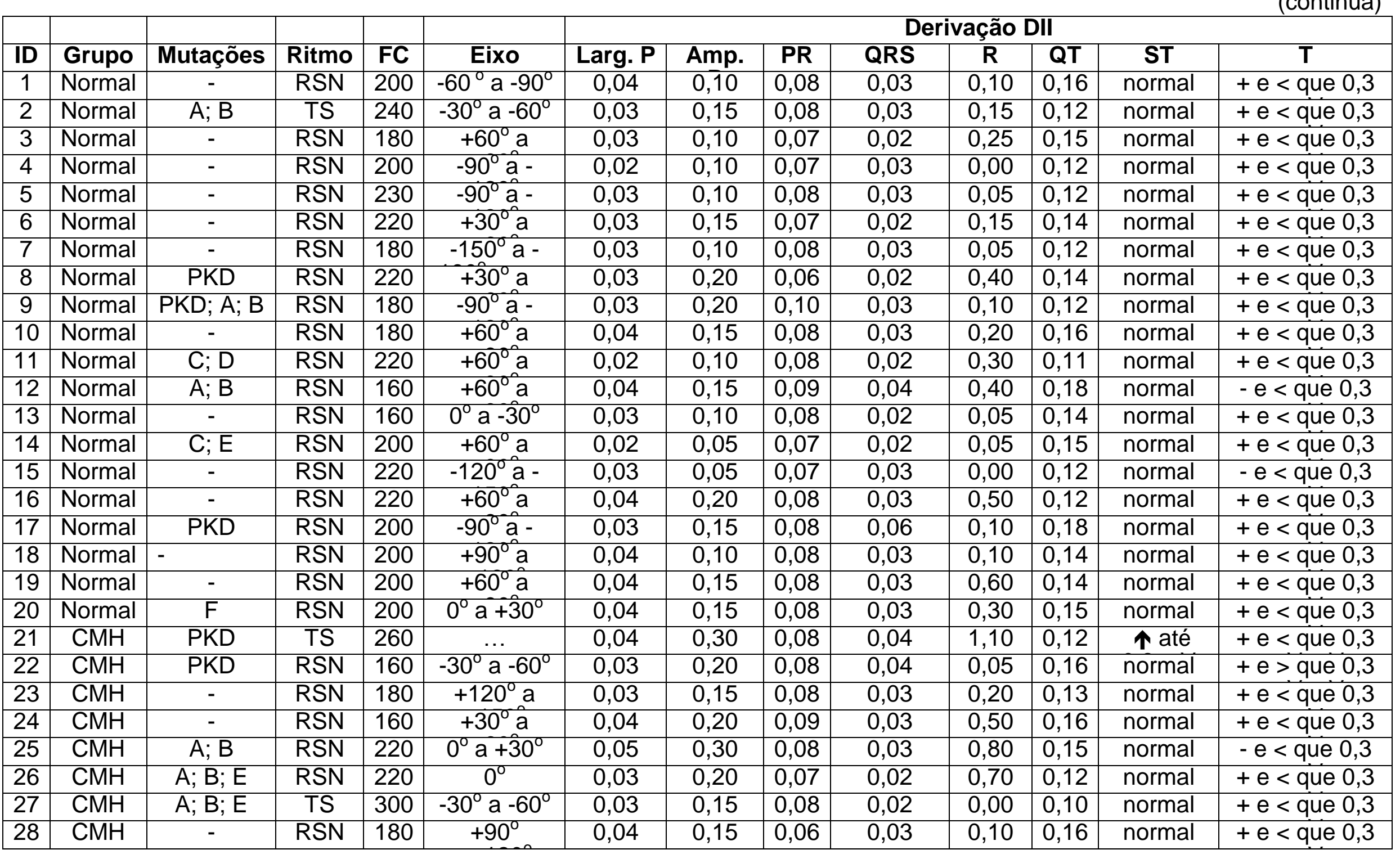


(conclusão)

\begin{tabular}{|c|c|c|c|c|c|c|c|c|c|c|c|c|c|}
\hline & & & & & & \multicolumn{8}{|c|}{ Derivação DII } \\
\hline 30 & $\mathrm{CMH}$ & - & TS & 240 & $+60^{\circ} \mathrm{a}$ & 0,05 & 0,20 & 0,06 & 0,03 & 0,40 & 0,15 & normal & $+e<$ que 0,3 \\
\hline 32 & $\mathrm{CMH}$ & PKD & $\mathrm{RSN}$ & 160 & $+60^{\circ} \mathrm{a}$ & 0,04 & 0,20 & 0,08 & 0,03 & 0,55 & 0,16 & normal & $+e<$ que 0,3 \\
\hline 33 & $\mathrm{CMH}$ & - & $\mathrm{RSN}$ & 220 & $+30^{\circ} \mathrm{a}$ & 0,03 & 0,15 & 0,08 & 0,05 & 0,40 & 0,14 & normal & $+e<$ que 0,3 \\
\hline 34 & $\mathrm{CMH}$ & PKD & RSN & 200 & $-90^{\circ} a-$ & 0,03 & 0,15 & 0,06 & 0,03 & 0,00 & 0,13 & normal & $+e<$ que 0,3 \\
\hline 37 & $\mathrm{CMH}$ & $\mathrm{F}$ & RSN & 220 & $-30^{\circ}$ a $-60^{\circ}$ & 0,03 & 0,15 & 0,08 & 0,02 & 0,05 & 0,12 & normal & $+e<$ que 0,3 \\
\hline 38 & $\mathrm{CMH}$ & PKD & $\mathrm{RSN}$ & 180 & $+60^{\circ} \mathrm{a}$ & 0,03 & 0,15 & 0,08 & 0,03 & 0,35 & 0,15 & normal & $+\mathrm{e}<$ que 0,3 \\
\hline 39 & $\mathrm{CMH}$ & - & RSN & 200 & $+60^{\circ} \mathrm{a}$ & 0,06 & 0,20 & 0,08 & 0,02 & 0,50 & 0,16 & normal & $+e<$ que 0,3 \\
\hline 40 & $\mathrm{CMH}$ & - & RSN & 210 & $+60^{\circ} \mathrm{a}$ & 0,03 & 0,18 & 0,07 & 0,03 & 0,35 & 0,14 & normal & $+e<$ que 0,3 \\
\hline 41 & $\mathrm{CMH}$ & - & RSN & 180 & $+90^{\circ} \mathrm{a}$ & 0,04 & 0,15 & 0,09 & 0,03 & 0,30 & 0,14 & normal & $+\mathrm{e}<$ que 0,3 \\
\hline 42 & $\mathrm{CMH}$ & $A ; B ; E$ & TS & 240 & $-90^{\circ} \mathrm{a}-$ & 0,04 & 0,15 & 0,06 & 0,06 & 0,10 & 0,14 & normal & $+e<$ que 0,3 \\
\hline
\end{tabular}

FC: frequência cardíaca (bpm); RSN: ritmo sinusal normal; TS: taquicardia sinusal; Larg. P: largura de onda P em segundos; Amp. P: amplitude de onda P em mV; PR: intervalo PR em segundos; QRS: largura do complexo QRS em segundos; R: amplitude da onda R em mV; QT: intervalo QT em segundos; ST: segmento ST; T: polaridade da onda T; (s): segundos; (mV): milivolts; ID: identificação; mutações A: troca de citosina por adenina em heterozigose na posição 890 do RNA mensageiro do gene ACTC1 felino; mutações B: heterozigose de citosina e timina no SNP-1 do intron 5-6 do gene ACTC1 felino; mutações C: homozigose de citosina no SNP-1 do intron 5-6 do gene ACTC1 felino; mutações D: homozigose de timina no SNP-2 do intron 5-6 do gene ACTC1 felino; mutações E: heterozigose de timina e citosina no SNP-2 do intron 5-6 do gene ACTC1 felino; mutações F: heterozigose de guanina e adenina no SNP-3 do intron 5-6 do gene ACTC1 felino; PDK: paciente positivo para a mutação no gene PKD1 da doença renal policística autossômica dominante; SNP: polimorfismos de nucleotídeo único. 
APÊNDICE B- Parâmetros eletrocardiográficos de gatos da raça Persa em derivações precordiais - São Paulo - 2014

\begin{tabular}{|c|c|c|c|c|c|c|c|c|c|c|c|c|c|c|}
\hline \multirow[b]{2}{*}{ ID } & \multirow[b]{2}{*}{ Grupo } & \multirow[b]{2}{*}{ Mutações } & \multirow[b]{2}{*}{ Bloqueios } & \multicolumn{3}{|c|}{ CV5RL } & \multicolumn{3}{|c|}{ CV6LL } & \multicolumn{3}{|c|}{ CV6LU } & \multicolumn{2}{|c|}{ V10 } \\
\hline & & & & $\mathbf{R}$ & $\mathbf{S}$ & $\mathbf{T}$ & $\mathbf{R}$ & $\mathbf{S}$ & $\mathbf{T}$ & $\mathbf{R}$ & S & $\mathbf{T}$ & QSR & $\mathbf{T}$ \\
\hline 1 & Normal & - & BFAE & 0,05 & 0,10 & + & 0,10 & 0,05 & + & 0,00 & 0,05 & + & $\ldots$ & $\ldots$ \\
\hline 2 & Normal & $A ; B$ & BFAE & 0,40 & 0,50 & + & 0,50 & 0,00 & + & 0,20 & 0,10 & + & - & - \\
\hline 3 & Normal & - & Ausente & 0,25 & 0,00 & + & 0,30 & 0,00 & + & 0,25 & 0,00 & + & - & + \\
\hline 4 & Normal & - & BRD i & 0,20 & 0,05 & + & 0,15 & 0,05 & + & 0,20 & 0,00 & + & + &.. \\
\hline 5 & Normal & - & BRD i & 0,10 & 0,10 & + & 0,10 & 0,10 & + & 0,05 & 0,10 & + & - & + \\
\hline 6 & Normal & - & Ausente & 0,15 & 0,10 & + & 0,20 & 0,05 & + & 0,30 & 0,10 & + & + & - \\
\hline 7 & Normal & - & BRD i & & & $\ldots$ & & & $\ldots$ & $\ldots$ & $\ldots$ & $\ldots$ & $\ldots$ & $\ldots$ \\
\hline 8 & Normal & PKD & Ausente & 0,30 & 0,10 & + & 0,40 & 0,10 & + & 0,40 & 0,00 & + & $\ldots$ & $\ldots$ \\
\hline 9 & Normal & PKD; A; B & BAV e BRD i & 0,10 & 0,20 & + & 0,20 & 0,00 & + & 0,20 & 0,00 & + & $\ldots$ & $\ldots$ \\
\hline 10 & Normal & - & Ausente & $\ldots$ & 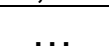 & $\ldots$ & $\ldots$ & $\ldots$ & $\ldots$ & $\ldots$ & $\ldots$ & $\ldots$ & $\ldots$ & $\ldots$ \\
\hline 11 & Normal & C; D & Ausente & 0,20 & 0,30 & + & & & $\ldots$ & .. & .. & $\ldots$ & $\ldots$ & $\ldots$ \\
\hline 12 & Normal & $A ; B$ & Ausente & 0,30 & 0,10 & + & 0,30 & 0,00 & + & & & $\ldots$ & - & - \\
\hline 13 & Normal & - & Ausente & 0,10 & 0,10 & + & 0,15 & 0,20 & + & 0,25 & 0,15 & + & $\ldots$ & $\ldots$ \\
\hline 14 & Normal & C; E & Ausente & & & $\ldots$ & & & $\ldots$ & $\ldots$ & $\ldots$ & $\ldots$ & $\ldots$ & $\ldots$ \\
\hline 15 & Normal & - & BRD i & 0,05 & 0,10 & + & 0,00 & 0,15 & + & & & $\ldots$ & $\ldots$ & $\ldots$ \\
\hline 16 & Normal & - & Ausente & 0,20 & 0,10 & + & 0,20 & 0,10 & + & 0,20 & 0,00 & - & - & + \\
\hline 17 & Normal & PKD & BRD & 0,40 & 0,60 & + & 0,20 & 0,10 & + & 0,15 & 0,00 & + & $\ldots$ & $\ldots$ \\
\hline 18 & Normal & - & Ausente & 0,10 & 0,10 & + & 0,10 & 0,25 & + & 0,05 & 0,10 & + & + & + \\
\hline 19 & Normal & - & Ausente & 0,15 & 0,20 & + & 0,20 & 0,00 & + & 0,20 & 0,05 & + & - & + \\
\hline 20 & Normal & $\mathrm{F}$ & Ausente & 0,00 & 0,30 & + & 0,20 & 0,15 & + & 0,10 & 0,05 & + & - & - \\
\hline 21 & $\mathrm{CMH}$ & PKD & Ausente & & & $\ldots$ & & & $\ldots$ & & & $\ldots$ & $\ldots$ & $\ldots$ \\
\hline 22 & $\mathrm{CMH}$ & PKD & BFAE & 0,30 & 0,40 & + & 0,60 & 0,10 & + & 0,60 & 0,10 & + & - & - \\
\hline 23 & $\mathrm{CMH}$ & - & Ausente & $\ldots$ & $\ldots$ & $\ldots$ & $\ldots$ & $\ldots$ & $\ldots$ & $\ldots$ & $\ldots$ & $\ldots$ & $\ldots$ & $\ldots$ \\
\hline 24 & $\mathrm{CMH}$ & - & Ausente & 0,20 & 0,10 & + & 0,20 & 0,00 & + & 0,15 & 0,15 & + & + & - \\
\hline 25 & $\mathrm{CMH}$ & $A ; B$ & Ausente & 0,50 & 1,20 & + & 1,30 & 0,00 & - & 1,50 & 0,00 & - & - & + \\
\hline 26 & $\mathrm{CMH}$ & $A ; B ; E$ & Ausente & 0,30 & 0,60 & + & 1,20 & 0,10 & + & $\ldots$ & $\ldots$ & $\ldots$ & $\ldots$ & $\ldots$ \\
\hline 27 & $\mathrm{CMH}$ & $\mathrm{A} ; \mathrm{B} ; \mathrm{E}$ & BFAE & 0,20 & 0,10 & + & 0,20 & 0,10 & + & 0,10 & 0,10 & + & - & + \\
\hline 28 & $\mathrm{CMH}$ & - & Ausente & 0,60 & 0,00 & + & 0,50 & 0,00 & + & 0,20 & 0,00 & + & - & - \\
\hline
\end{tabular}




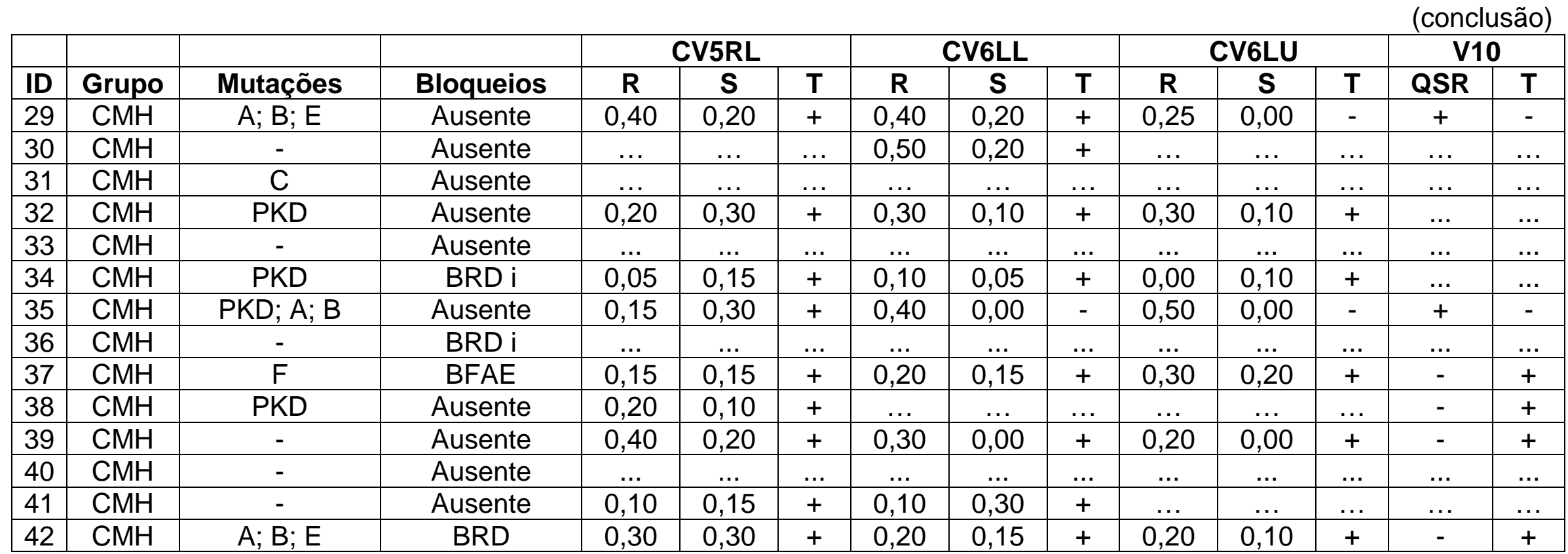

FC: frequência cardíaca (bpm); Ausente: ausência de bloqueios; BAV: bloqueio atrioventricular de primeiro grau; BFAE: bloqueio de fascículo anterior esquerdo; BRD i: bloqueio de ramo direito incompleto; BRD: bloqueio de ramo direito; R: amplitude da onda $\mathrm{R}$ em $\mathrm{mV}$; $\mathrm{S}$ : amplitude da onda S em mV; T: polaridade da onda T; QRS: polaridade do complexo QRS; (mV): milivolts; ID: identificação; mutações A: troca de citosina por adenina em heterozigose na posição 890 do RNA mensageiro do gene ACTC1 felino; mutações B: heterozigose de citosina e timina no SNP-1 do intron 5-6 do gene ACTC1 felino; mutações C: homozigose de citosina no SNP-1 do intron 5-6 do gene ACTC1 felino; mutações D: homozigose de timina no SNP-2 do intron 5-6 do gene ACTC1 felino; mutações E: heterozigose de timina e citosina no SNP-2 do intron 5-6 do gene ACTC1 felino; mutações F: heterozigose de guanina e adenina no SNP-3 do intron 5-6 do gene ACTC1 felino; PDK: paciente positivo para a mutação no gene PKD1 da doença renal policística autossômica dominante; SNP: polimorfismos de nucleotídeo único. 
APÊNDICE C- Pressão arterial sistólica de gatos da raça Persa - São Paulo - 2014

\begin{tabular}{|c|c|c|c|c|c|c|c|c|c|c|c|}
\hline & & & & & & & & & & & ntinue \\
\hline ID & Grupo & Mutações & Circ. & Manguito & Temperamento & PAS & PAS & PAS & PAS & PAS & PAS \\
\hline 1 & Normal & - & 9,0 & neonatal $3(3,5$ & tenso & 140 & 140 & 140 & 140 & 140 & 140 \\
\hline 2 & Normal & $A ; B$ & 6,0 & neonatal $2(2,5$ & tenso & 140 & 140 & 130 & 140 & 140 & 138 \\
\hline 3 & Normal & - & 4,5 & neonatal $2(2,5$ & tranquilo & 120 & 120 & 120 & 120 & 120 & 120 \\
\hline 5 & Normal & - & 6,0 & neonatal $2(2,5$ & tranquilo & 120 & 130 & 130 & 120 & 130 & 126 \\
\hline 6 & Normal & - & 6,5 & neonatal $2(2,5$ & agitado & 180 & 180 & & & & 180 \\
\hline 7 & Normal & - & 8,0 & neonatal $3(3,5$ & agitado & 160 & 160 & 160 & 140 & & 155 \\
\hline 10 & Normal & - & 6,5 & neonatal $2(2,5$ & tranquilo & 160 & 150 & 150 & 160 & 150 & 154 \\
\hline 11 & Normal & C; D & 7,5 & neonatal $3(3,5$ & agitado & 180 & 180 & 180 & & & 180 \\
\hline 12 & Normal & $A ; B$ & 6,5 & neonatal $2(2,5$ & tranquilo & 110 & 120 & 120 & 120 & 120 & 118 \\
\hline 13 & Normal & - & 6,7 & neonatal $2(2,5$ & tenso & 140 & 140 & 140 & 140 & 140 & 140 \\
\hline 14 & Normal & $\mathrm{C} ; \mathrm{E}$ & 6,6 & neonatal $2(2,5$ & tranquilo & 130 & 120 & 130 & 130 & 130 & 128 \\
\hline 15 & Normal & - & 6,5 & neonatal $2(2,5$ & agitado & 180 & 180 & 170 & 170 & 170 & 174 \\
\hline 20 & Normal & $\mathrm{F}$ & 4,6 & neonatal $2(2,5$ & tenso & 170 & 170 & 160 & 150 & 160 & 162 \\
\hline 21 & $\mathrm{CMH}$ & PKD & 7,1 & neonatal $3(3,5$ & tenso & 140 & 140 & 140 & & & 140 \\
\hline 22 & $\mathrm{CMH}$ & PKD & 6,0 & neonatal $2(2,5$ & tenso & 160 & 150 & 140 & 130 & 140 & 144 \\
\hline 23 & $\mathrm{CMH}$ & - & 6,5 & neonatal $2(2,5$ & agitado & 130 & 130 & 130 & 130 & 130 & 130 \\
\hline 24 & $\mathrm{CMH}$ & - & 6,5 & neonatal $2(2,5$ & tenso & 140 & 130 & 140 & 140 & 140 & 138 \\
\hline 25 & $\mathrm{CMH}$ & $A ; B$ & 6,5 & neonatal $2(2,5$ & tranquilo & 150 & 160 & 150 & 140 & 140 & 148 \\
\hline 26 & $\mathrm{CMH}$ & $A ; B ; E$ & 6,9 & neonatal $2(2,5$ & tranquilo & 190 & 180 & 170 & 170 & 170 & 176 \\
\hline 27 & $\mathrm{CMH}$ & $A ; B ; E$ & 7,5 & neonatal $3(3,5$ & tenso & 160 & 160 & 150 & 150 & 150 & 154 \\
\hline 28 & $\mathrm{CMH}$ & - & 6,3 & neonatal $3(3,5$ & agitado & 150 & 150 & 150 & & 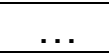 & 150 \\
\hline 29 & $\mathrm{CMH}$ & $A ; B ; E$ & 7,0 & neonatal $3(3,5$ & tranquilo & 120 & 120 & 120 & 120 & 120 & 120 \\
\hline
\end{tabular}




\begin{tabular}{|c|c|c|c|c|c|c|c|c|c|c|c|}
\hline & & & & & & & & & & & nclus \\
\hline ID & Grupo & Mutaçoes & Circ. & Manguito & Temperamento & PAS & PAS & PAS & PAS & PAS & PAS \\
\hline 30 & $\mathrm{CMH}$ & - & 5,0 & neonatal $2(2,5$ & agitado & 160 & 160 & 160 & 160 & 150 & 158 \\
\hline 31 & $\mathrm{CMH}$ & $\mathrm{C}$ & 5,6 & neonatal $2(2,5$ & agitado & 160 & & & & & 160 \\
\hline 32 & $\mathrm{CMH}$ & PKD & 7,5 & neonatal $3(3,5$ & tranquilo & 120 & 120 & 120 & 120 & 120 & 120 \\
\hline 33 & $\mathrm{CMH}$ & - & 7,6 & neonatal $3(3,5$ & tranquilo & 140 & 140 & 140 & 140 & 140 & 140 \\
\hline 34 & $\mathrm{CMH}$ & PKD & 6,0 & neonatal $2(2,5$ & tranquilo & 120 & 120 & 130 & 130 & 130 & 126 \\
\hline 35 & $\mathrm{CMH}$ & PKD; A; B & 6,5 & neonatal $2(2,5$ & tranquilo & 160 & 160 & 160 & 160 & 150 & 158 \\
\hline 36 & $\mathrm{CMH}$ & - & 7,5 & neonatal $2(2,5$ & agitado & 170 & 170 & 170 & 160 & 160 & 166 \\
\hline 37 & $\mathrm{CMH}$ & $\mathrm{F}$ & 6,5 & neonatal $2(2,5$ & tranquilo & 130 & 130 & 120 & 130 & 130 & 128 \\
\hline 38 & $\mathrm{CMH}$ & PKD & 7,5 & neonatal $3(3,5$ & tranquilo & 140 & 140 & 140 & 140 & 140 & 140 \\
\hline 39 & $\mathrm{CMH}$ & - & 6,2 & neonatal $2(2,5$ & tenso & 160 & 150 & 150 & 150 & 150 & 152 \\
\hline 40 & $\mathrm{CMH}$ & - & 6,4 & neonatal $2(2,5$ & tenso & 150 & 140 & & & & 145 \\
\hline 41 & $\mathrm{CMH}$ & - & 7,0 & neonatal $3(3,5$ & tranquilo & 110 & 110 & 100 & 110 & 110 & 108 \\
\hline 42 & $\mathrm{CMH}$ & $A ; B ; E$ & 8,4 & neonatal $3(3,5$ & agitado & 130 & 130 & 140 & 140 & 140 & 136 \\
\hline
\end{tabular}

Cir. membro: circunferência do membro em cm; Manguito: tipo e tamanho do manguito utilizado; Temperamento: temperamento do paciente durante a mensuração: PAS 1: primeira mensuração da pressão arterial sistólica; PAS 2: segunda mensuração da pressão arterial sistólica; PAS 3: terceira mensuração da pressão arterial sistólica; PAS 4: quarta mensuração da pressão arterial sistólica; PAS 5: quinta mensuração da pressão arterial sistólica; PAS média: média das mensurações da pressão arterial sistólica; ID: identificação; mutações A: troca de citosina por adenina em heterozigose na posição 890 do RNA mensageiro do gene ACTC1 felino; mutações B: heterozigose de citosina e timina no SNP-1 do intron 5-6 do gene ACTC1 felino; mutações C: homozigose de citosina no SNP-1 do intron 5-6 do gene ACTC1 felino; mutações D: homozigose de timina no SNP-2 do intron 5-6 do gene ACTC1 felino; mutações E: heterozigose de timina e citosina no SNP-2 do intron 5-6 do gene ACTC1 felino; mutações F: heterozigose de guanina e adenina no SNP-3 do intron 5-6 do gene ACTC1 felino; PDK: paciente positivo para a mutação no gene PKD1 da doença renal policística autossômica dominante; SNP: polimorfismos de nucleotídeo único. 
APÊNDICE D- Parâmetros ecocardiográficos de gatos da raça Persa - São Paulo - 2014

(continua)

\begin{tabular}{|c|c|c|c|c|c|c|c|c|c|c|c|c|c|}
\hline & & & Modo & & & Mod & $\mathrm{M}$ & & & & & Modo & B \\
\hline ID & Grupo & Mutações & SIVAo & SIVd & PVEd & SIVd/PVEd & DVEd & DVEs & FS & Fej & AO & $\mathbf{A E}$ & AE/Ao \\
\hline 1 & Normal & - & 0,48 & 0,44 & 0,46 & 0,96 & 1,66 & 0,83 & 50 & 0,84 & 0,96 & 1,05 & 1,09 \\
\hline 2 & Normal & $A ; B$ & 0,43 & 0,33 & 0,37 & 0,89 & 1,31 & 0,51 & 61 & 0,92 & 0,71 & 0,98 & 1,38 \\
\hline 3 & Normal & - & 0,46 & 0,48 & 0,44 & 1,09 & 1,44 & 0,65 & 54 & 0,88 & 1,08 & 1,18 & 1,09 \\
\hline 4 & Normal & - & 0,49 & 0,45 & 0,47 & 0,96 & 1,46 & 0,7 & 52 & 0,86 & 0,87 & 1,00 & 1,15 \\
\hline 5 & Normal & - & 0,49 & 0,49 & 0,45 & 1,09 & 1,31 & 0,64 & 51 & 0,85 & 1,00 & 1,25 & 1,25 \\
\hline 6 & Normal & - & 0,49 & 0,46 & 0,42 & 1,10 & 1,38 & 0,51 & 63 & 0,93 & 1,00 & 1,21 & 1,21 \\
\hline 7 & Normal & - & 0,49 & 0,48 & 0,44 & 1,09 & 1,59 & 0,77 & 52 & 0,86 & 0,93 & 1,11 & 1,19 \\
\hline 8 & Normal & PKD & 0,49 & 0,49 & 0,49 & 1,00 & 1,68 & 0,78 & 54 & 0,87 & 0,89 & 1,04 & 1,17 \\
\hline 9 & Normal & PKD; $A ; B$ & 0,46 & 0,45 & 0,45 & 1,00 & 1,53 & 0,81 & 47 & 0,82 & 0,84 & 1,13 & 1,35 \\
\hline 10 & Normal & - & 0,49 & 0,49 & 0,49 & 1,00 & 1,3 & 0,5 & 61 & 0,93 & 0,88 & 1,09 & 1,24 \\
\hline 11 & Normal & C; D & 0,46 & 0,46 & 0,45 & 1,02 & 1,67 & 0,58 & 65 & 0,94 & 1,15 & 1,63 & 1,42 \\
\hline 12 & Normal & $A ; B$ & 0,45 & 0,33 & 0,36 & 0,92 & 1,62 & 0,93 & 42 & 0,77 & 0,78 & 1,05 & 1,35 \\
\hline 13 & Normal & - & 0,47 & 0,47 & 0,40 & 1,18 & 1,59 & 0,7 & 56 & 0,89 & 0,94 & 1,15 & 1,22 \\
\hline 14 & Normal & $\mathrm{C} ; \mathrm{E}$ & 0,48 & 0,45 & 0,46 & 0,98 & 1,17 & 0,43 & 63 & 0,94 & 0,80 & 1,12 & 1,40 \\
\hline 15 & Normal & - & 0,49 & 0,48 & 0,45 & 1,07 & 1,29 & 0,53 & 59 & 0,91 & 0,88 & 1,07 & 1,22 \\
\hline 16 & Normal & - & 0,49 & 0,43 & 0,42 & 1,02 & 1,3 & 0,45 & 65 & 0,94 & 0,92 & 1,21 & 1,32 \\
\hline 17 & Normal & PKD & 0,40 & 0,40 & 0,42 & 0,95 & 1,13 & 0,5 & 55 & 0,89 & 0,98 & 1,22 & 1,24 \\
\hline 18 & Normal & - & 0,47 & 0,47 & 0,46 & 1,02 & 1,5 & 0,61 & 59 & 0,91 & 0,77 & 0,97 & 1,26 \\
\hline 19 & Normal & - & 0,47 & 0,46 & 0,44 & 1,05 & 1,47 & 0,5 & 65 & 0,95 & 0,98 & 1,21 & 1,23 \\
\hline 20 & Normal & $\mathrm{F}$ & 0,48 & 0,44 & 0,44 & 1,00 & 1,33 & 0,54 & 59 & 0,91 & 1,07 & 1,17 & 1,09 \\
\hline 21 & $\mathrm{CMH}$ & PKD & 0,85 & 0,80 & 0,76 & 1,05 & 1,30 & 0,60 & 57 & 0,90 & 1,00 & 1,61 & 1,61 \\
\hline 22 & $\mathrm{CMH}$ & PKD & 0,62 & 0,51 & 0,42 & 1,21 & 1,08 & 0,49 & 55 & 0,89 & 0,86 & 1,06 & 1,23 \\
\hline 23 & $\mathrm{CMH}$ & - & 0,62 & 0,58 & 0,46 & 1,26 & 1,30 & 0,66 & 49 & 0,84 & 0,95 & 0,98 & 1,03 \\
\hline 24 & $\mathrm{CMH}$ & - & 0,73 & 0,60 & 0,49 & 1,22 & 1,39 & 0,56 & 60 & 0,92 & 1,00 & 1,44 & 1,44 \\
\hline 25 & $\mathrm{CMH}$ & $A ; B$ & 0,66 & 0,69 & 0,64 & 1,08 & 1,46 & 0,91 & 38 & 0,72 & 0,84 & 2,26 & 2,69 \\
\hline 26 & $\mathrm{CMH}$ & $A ; B ; E$ & 0,62 & 0,57 & 0,54 & 1,06 & 1,29 & 0,47 & 63 & 0,94 & 0,94 & 1,40 & 1,49 \\
\hline 27 & $\mathrm{CMH}$ & $A ; B ; E$ & 0,68 & 0,63 & 0,54 & 1,17 & 1,47 & 0,72 & 51 & 0,85 & 0,83 & 1,57 & 1,89 \\
\hline 28 & $\mathrm{CMH}$ & - & 0,60 & 0,49 & 0,38 & 1,29 & 1,57 & 0,64 & 59 & 0,91 & 0,83 & 1,05 & 1,27 \\
\hline
\end{tabular}




\begin{tabular}{|c|c|c|c|c|c|c|c|c|c|c|c|c|c|}
\hline & & & Modo & \multicolumn{7}{|c|}{ Modo M } & \multicolumn{3}{|c|}{ Modo B } \\
\hline ID & Grupo & Mutações & SIVAo & SIVd & PVEd & SIVd/PVEd & DVEd & DVEs & FS & Fej & AO & $\mathrm{AE}$ & AE/Ao \\
\hline 29 & $\mathrm{CMH}$ & $A ; B ; E$ & 0,68 & 0,62 & 0,52 & 1,19 & 1,61 & 0,87 & 46 & 0,80 & 0,82 & 1,20 & 1,46 \\
\hline 30 & $\mathrm{CMH}$ & - & 0,63 & 0,42 & 0,39 & 1,08 & 1,48 & 0,67 & 55 & 0,88 & 0,94 & 1,11 & 1,18 \\
\hline 31 & $\mathrm{CMH}$ & $\mathrm{C}$ & 0,62 & 0,62 & 0,52 & 1,19 & 1,13 & 0,49 & 57 & 0,90 & 0,77 & 1,03 & 1,34 \\
\hline 32 & $\mathrm{CMH}$ & PKD & 0,74 & 0,66 & 0,55 & 1,20 & 1,51 & 0,52 & 66 & 0,95 & 0,95 & 1,45 & 1,53 \\
\hline 33 & $\mathrm{CMH}$ & - & 0,77 & 0,60 & 0,54 & 1,11 & 1,10 & 0,51 & 53 & 0,88 & 0,87 & 1,44 & 1,66 \\
\hline 34 & $\mathrm{CMH}$ & PKD & 0,81 & 0,71 & 0,47 & 1,51 & 1,42 & 0,93 & 35 & 0,68 & 0,84 & 1,59 & 1,89 \\
\hline 35 & $\mathrm{CMH}$ & PKD; $A ; B$ & 0,73 & 0,60 & 0,49 & 1,22 & 1,03 & 0,38 & 63 & 0,94 & 0,79 & 0,86 & 1,09 \\
\hline 36 & $\mathrm{CMH}$ & - & 0,61 & 0,49 & 0,44 & 1,11 & 1,36 & 0,68 & 50 & 0,85 & 0,86 & 0,98 & 1,14 \\
\hline 37 & $\mathrm{CMH}$ & $F$ & 0,72 & 0,59 & 0,53 & 1,11 & 1,10 & 0,51 & 53 & 0,88 & 1,14 & 1,35 & 1,18 \\
\hline 38 & $\mathrm{CMH}$ & PKD & 0,73 & 0,61 & 0,52 & 1,17 & 1,10 & 0,37 & 66 & 0,95 & 1,12 & 1,20 & 1,07 \\
\hline 39 & $\mathrm{CMH}$ & - & 0,62 & 0,59 & 0,50 & 1,18 & 1,12 & 0,44 & 60 & 0,92 & 0,99 & 1,51 & 1,53 \\
\hline 40 & $\mathrm{CMH}$ & - & 0,70 & 0,56 & 0,47 & 1,19 & 1,64 & 0,77 & 52 & 0,86 & 0,85 & 1,56 & 1,84 \\
\hline 41 & $\mathrm{CMH}$ & - & 0,64 & 0,63 & 0,57 & 1,11 & 1,20 & 0,49 & 59 & 0,91 & 0,77 & 1,01 & 1,31 \\
\hline 42 & $\mathrm{CMH}$ & $\mathrm{A} ; \mathrm{B} ; \mathrm{E}$ & 0,74 & 0,62 & 0,50 & 1,24 & 1,49 & 0,74 & 50 & 0,85 & 1,02 & 1,26 & 1,24 \\
\hline
\end{tabular}

FC: frequência cardíaca (bpm); SIVAo: espessura diastólica do septo interventricular em região de via de saída do ventrículo esquerdo (cm); SIVd: espessura diastólica do septo interventricular (cm); PVEd: espessura diastólica da parede livre do ventrículo esquerdo (cm); DVEd: diâmetro diastólico da cavidade do ventrículo esquerdo (cm); DVEs: diâmetro sistólico da cavidade do ventrículo esquerdo (cm); FS: fração de encurtamento (\%); Fej: fração de ejeção; Ao: diâmetro da raiz da aorta (cm); AE: diâmetro do átrio esquerdo (cm); AE/Ao: relação átrio esquerdo-aorta; Modo M: ecocardiografia em modo M; modo B: modo bidimensional; ID: identificação; mutações A: troca de citosina por adenina em heterozigose na posição 890 do RNA mensageiro do gene ACTC1 felino; mutações B: heterozigose de citosina e timina no SNP-1 do intron 5-6 do gene ACTC1 felino; mutações C: homozigose de citosina no SNP-1 do intron 5-6 do gene ACTC1 felino; mutações D: homozigose de timina no SNP-2 do intron 5-6 do gene ACTC1 felino; mutações E: heterozigose de timina e citosina no SNP-2 do intron 5-6 do gene ACTC1 felino; mutações F: heterozigose de guanina e adenina no SNP-3 do intron 5-6 do gene ACTC1 felino; PDK: paciente positivo para a mutação no gene PKD1 da doença renal policística autossômica dominante; SNP: polimorfismos de nucleotídeo único. 


\begin{tabular}{|c|c|c|c|c|c|c|c|c|c|c|c|c|c|c|c|}
\hline ID & Grupo & Mutações & Ao & Ao $G$ & Ap & Ap $G$ & $E$ & TDE & $\mathbf{A}$ & $E / A$ & TRIV & Mitral & Tricúspide & Aórtico & Pulmonar \\
\hline 1 & Normal & - & 1,02 & 4,19 & 0,92 & 3,41 & 0,65 & 66,00 & 0,75 & 0,87 & 44 & normal & normal & normal & normal \\
\hline 2 & Normal & $A ; B$ & 1,26 & 6,34 & 1,21 & 5,86 & 1,18 & 62,00 & $\mathrm{~F}$ & $\mathrm{~F}$ & 39 & escape & normal & normal & normal \\
\hline 3 & Normal & - & 1,10 & 4,84 & 1,02 & 4,50 & 0,60 & 74,00 & 0,56 & 1,07 & 44 & IM 1 & normal & normal & normal \\
\hline 4 & Normal & - & 0,81 & 2,64 & 0,73 & 2,12 & 0,78 & 18,00 & $\mathrm{~F}$ & $\mathrm{~F}$ & 46 & normal & normal & normal & normal \\
\hline 5 & Normal & - & 0,85 & 2,90 & 0,95 & 3,60 & 0,80 & 48,00 & $\mathrm{~F}$ & $\mathrm{~F}$ & 41 & IM 1 & normal & normal & normal \\
\hline 6 & Normal & - & 0,97 & 3,75 & 1,17 & 5,50 & 0,60 & 91,00 & 0,87 & 0,69 & 46 & normal & normal & normal & normal \\
\hline 7 & Normal & - & 0,86 & 2,96 & 0,90 & 3,21 & 0,65 & 51,00 & 0,39 & 1,67 & 47 & normal & normal & normal & normal \\
\hline 8 & Normal & PKD & 1,00 & 4,01 & 1,28 & 6,52 & 0,54 & 70,00 & 0,74 & 0,73 & 52 & escape & normal & normal & normal \\
\hline 9 & Normal & PKD; $\mathrm{A} ; \mathrm{B}$ & 0,72 & 2,05 & 0,82 & 2,72 & 0,63 & 39,00 & 0,44 & 1,43 & 44 & IM 1 & normal & normal & normal \\
\hline 10 & Normal & - & 1,02 & 4,13 & 1,14 & 5,17 & 0,84 & 48,00 & 0,46 & 1,83 & 44 & escape & IT 1 & normal & normal \\
\hline 11 & Normal & C; D & 1,60 & 10,19 & 1,04 & 4,33 & 1,40 & 58,00 & $\mathrm{~F}$ & $\mathrm{~F}$ & 41 & IM 1 & normal & normal & normal \\
\hline 12 & Normal & $A ; B$ & 0,78 & 2,41 & 0,92 & 3,39 & 0,58 & 86,00 & 0,47 & 1,23 & 49 & normal & normal & escape & normal \\
\hline 13 & Normal & - & 0,87 & 3,06 & 1,15 & 5,30 & 0,67 & 73,00 & 0,55 & 1,22 & 42 & escape & normal & normal & normal \\
\hline 14 & Normal & $\mathrm{C} ; \mathrm{E}$ & 1,06 & 4,53 & 1,02 & 4,13 & 0,54 & 65,00 & 0,68 & 0,79 & 52 & IM 1 & normal & normal & normal \\
\hline 15 & Normal & - & 0,93 & 3,51 & 1,09 & 4,75 & 0,89 & 54,00 & $\mathrm{~F}$ & $\mathrm{~F}$ & 51 & escape & normal & normal & normal \\
\hline 16 & Normal & - & 1,26 & 6,35 & 1,24 & 6,11 & 1,01 & 57,40 & $\mathrm{~F}$ & $\mathrm{~F}$ & 43 & IM 1 & normal & normal & normal \\
\hline 17 & Normal & PKD & 0,89 & 3,15 & 1,00 & 3,97 & 0,94 & 33,00 & $\mathrm{~F}$ & $\mathrm{~F}$ & 46 & IM 1 & normal & normal & normal \\
\hline 18 & Normal & - & 0,87 & 3,04 & 0,76 & 2,34 & 0,82 & 53,17 & $F$ & $\mathrm{~F}$ & 48 & IM 1 & normal & normal & normal \\
\hline 19 & Normal & - & 0,97 & 3,75 & 0,98 & 3,84 & 0,53 & 72,00 & 0,69 & 0,77 & 41 & escape & normal & normal & normal \\
\hline 20 & Normal & $\mathrm{F}$ & 0,80 & 2,56 & 0,74 & 2,19 & 0,75 & 59,00 & 0,41 & 1,83 & 42 & IM 1 & IT 1 & normal & normal \\
\hline 21 & $\mathrm{CMH}$ & PKD & 1,76 & 12,35 & 1,39 & 7,74 & 1,29 & 33,00 & 0,46 & 2,80 & 28 & IM 1 & normal & normal & normal \\
\hline 22 & $\mathrm{CMH}$ & PKD & 1,65 & 10,84 & 0,96 & 3,66 & 0,75 & 84,00 & 0,88 & 0,85 & 44 & IM 1 & IT 1 & normal & normal \\
\hline 23 & $\mathrm{CMH}$ & - & 0,76 & 2,30 & 0,88 & 3,13 & 0,71 & 75,00 & 0,65 & 1,09 & 52 & IM 1 & normal & normal & normal \\
\hline 24 & $\mathrm{CMH}$ & - & 0,72 & 2,05 & 0,81 & 2,64 & 0,52 & 78,00 & 0,63 & 0,83 & 49 & IM 1 & escape & normal & normal \\
\hline 25 & $\mathrm{CMH}$ & $A ; B$ & 3,99 & 63,83 & 0,85 & 2,90 & 1,65 & 41,00 & $\mathrm{~F}$ & $\mathrm{~F}$ & 30 & IM 1 & IT 1 & OVSVE & normal \\
\hline 26 & $\mathrm{CMH}$ & $\mathrm{A} ; \mathrm{B} ; \mathrm{E}$ & 1,01 & 4,05 & 0,93 & 3,48 & 0,75 & 74,00 & 0,58 & 1,29 & 52 & IM 1 & normal & normal & normal \\
\hline 27 & $\mathrm{CMH}$ & $\mathrm{A} ; \mathrm{B} ; \mathrm{E}$ & 3,46 & 47,82 & 1,33 & 7,08 & 0,94 & 59,00 & 0,73 & 1,29 & 33 & IM 2 & normal & OVSVE & normal \\
\hline 28 & $\mathrm{CMH}$ & - & 1,11 & 4,95 & 0,94 & 3,57 & 0,72 & 51,00 & 0,47 & 1,53 & 42 & IM 1 & IT 1 & normal & normal \\
\hline 29 & $\mathrm{CMH}$ & $A ; B ; E$ & 0,67 & 1,81 & 0,90 & 3,21 & 0,63 & 44,00 & 0,37 & 1,70 & 59 & IM 1 & IT 1 & normal & normal \\
\hline
\end{tabular}


(conclusão)

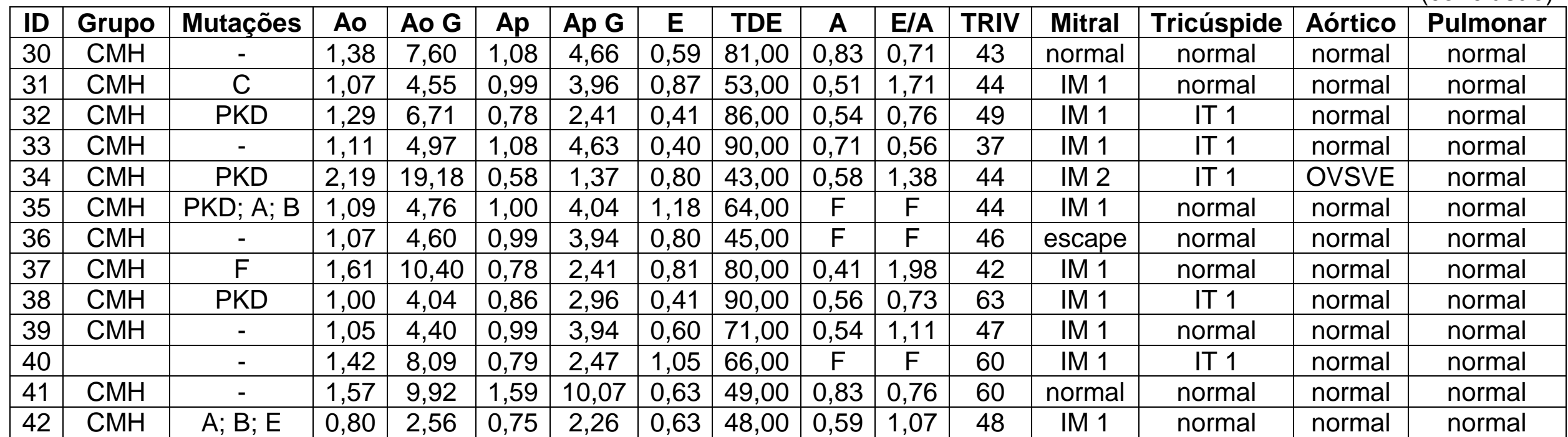

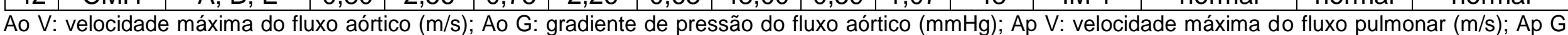

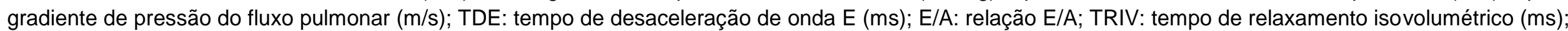

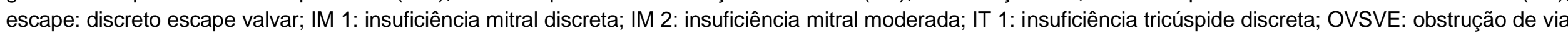

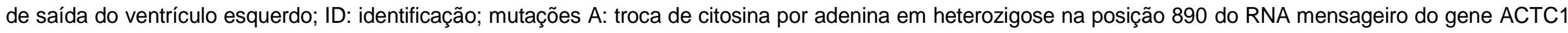

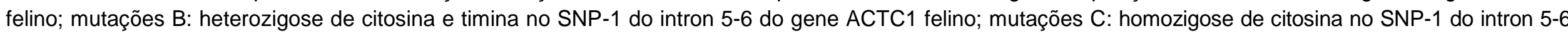

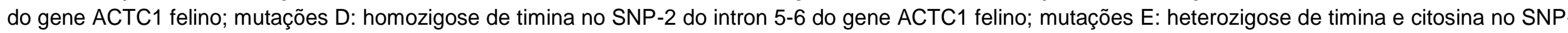

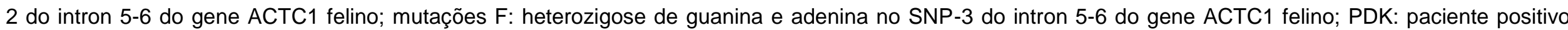
para a mutação no gene PKD1 da doença renal policística autossômica dominante; SNP: polimorfismos de nucleotídeo único. 